x'rokinglf
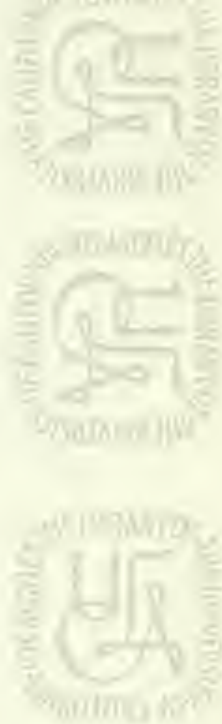

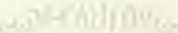

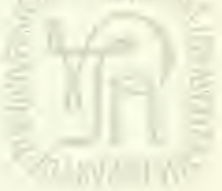

whing in litis
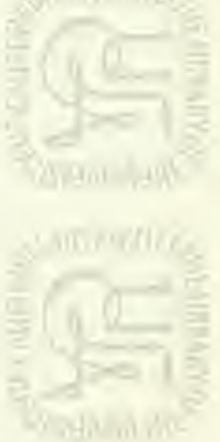

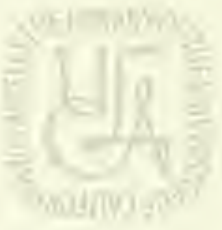

xh) II pirtry
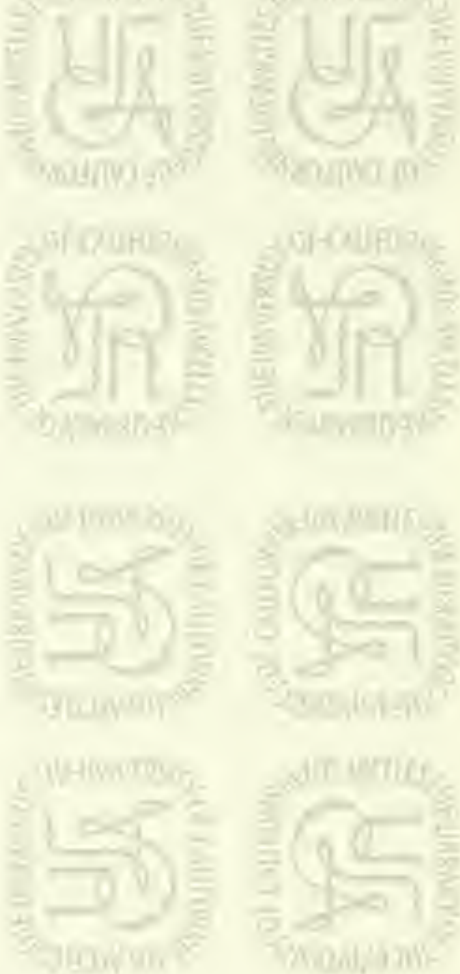

sir ithile

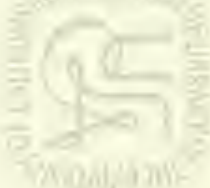

whillygyry
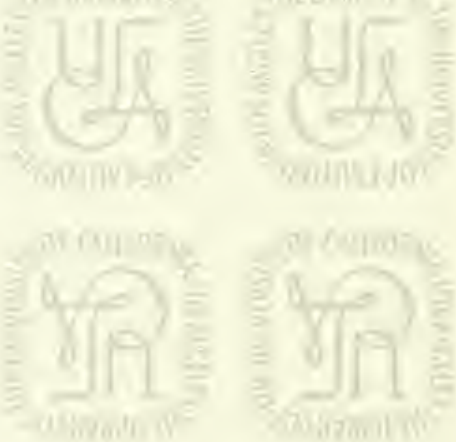

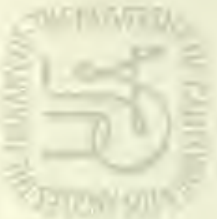

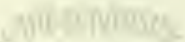
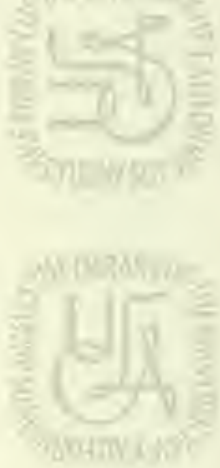

thiz rathon

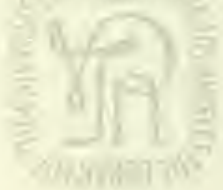

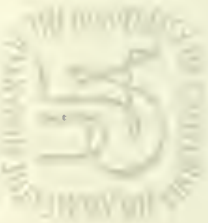




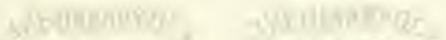

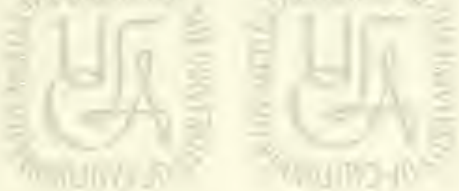

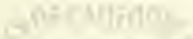

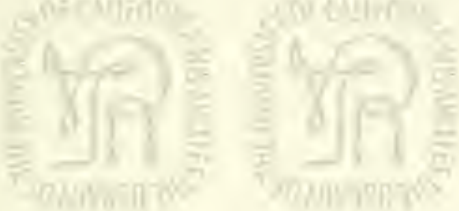

Din athing

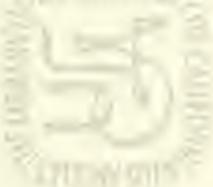

wil with wh
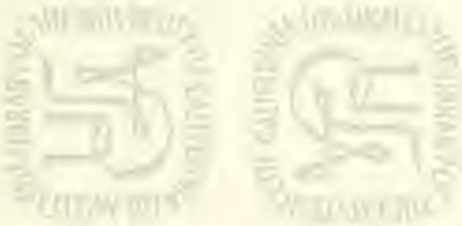

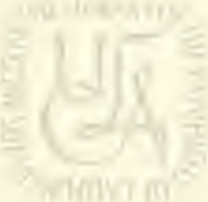

bit I ling

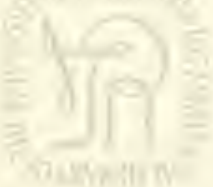

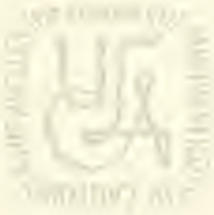

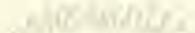

Whin an itic

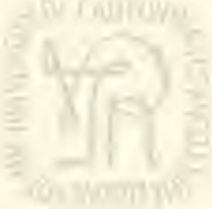

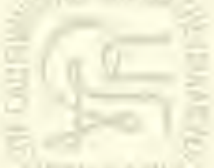

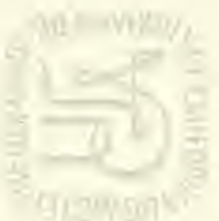

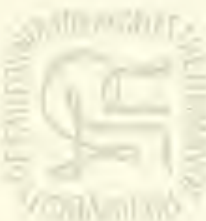
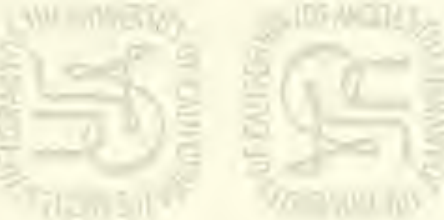

ath in whith ith

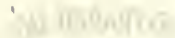
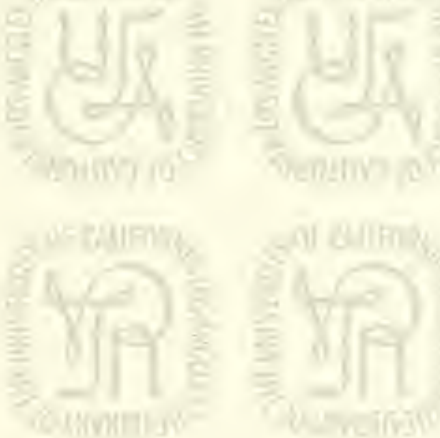

-oll Gilfing.
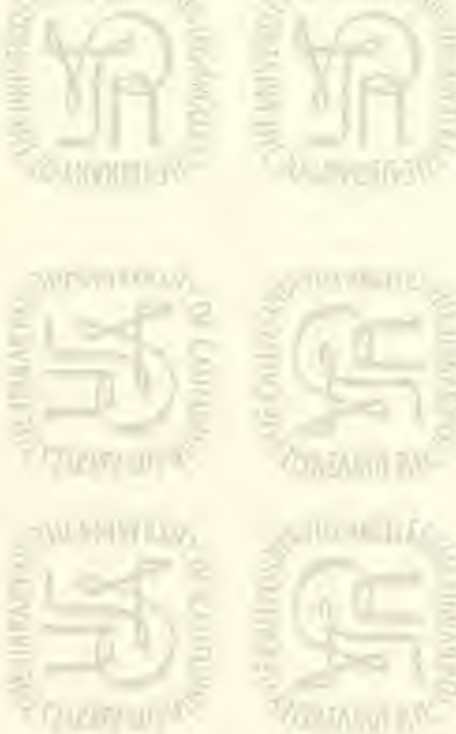

"Haunce Sajinam

Ealdomia' Eet, 2, 1907

-Tarents.

102 

ESSAYS IN PHILOSOPHY 


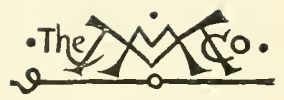




\title{
THE
}

\section{LIMITS OF EVOLUTION}

AND OTHER ESSAYS

\author{
ILLUSTRATING THE METAPHYSICAL THEORY \\ OF PERSONAL IDEALISM
}

BY

G. H. HOWISON, LL.D.

MILLS PROFESSOR OF PHILOSOPHY IN THE UNIVERSITY OF CALIFORNIA

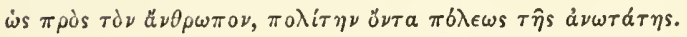

Marcus Aurelius: III, iI

On, to the bound of the waste,

On, to the City of God.

Matthew Arnold: Rugby Chapel

SECOND EDITION, REITSED AND ENLARGED

Norm Ģark

THE MACMILLAN COMPANY

LONDON: MACIIILLAN \& CO., LTD.

1904

All rights reseried 
Copyright, I901, 1904,

By THE MACMILLAN COMPANY.

Set up and electrotyped. Published April, rgor. Reprinted December, s904.

Yormoos Jisess

J. S. Cushing is Co, - Berwick \& Smith Co.

Norwood, Mass., U.S.A. 


\section{PREFACE}

THE thread connecting the following essays is already indicated on the title-page. They all illustrate, each from the field of its own subject, the metaphysical theory which I venture to call Personal Idealism. Partly, they show how this theory draws its arguments, as if unexpectedly, from the discussion now of this topic taken up for its own philosophical interest, and now of that; partly, they in turn reflect the light of the theory upon the discussion of the topic. To the running reader, the several papers, with titles so widely divergent, would hardly suggest any common trend of thought. They all have it, however; in fact, taken together, they may be said to present the mentioned philosophic theory in its bearings on all the chicf human concerns, - on knowledge, joy, and devotion; on Science, Art, and Religion. Still, in view of the great diversity of their subjects, one might easily fail of a clear and firm scizure of the thought that unites them, unless the clue were given by some words of introduction. 
Just what, then, does Personal Idealism as a philosophical theory mean? I can best reply, I suspect, by anticipating another question, which can hardly fail to be asked: Why should the word "personal" come into the title of the theory at all? Is not idealism the doctrine that mind is the only primary or absolute reality? -- and so is it not always the assertion that personality is the central source of things? Why, then, isn't the prefix superfluous? The answer is, that the actual history of philosophic thought, even after philosophy attains to the view that rational consciousness is the First Principle, exhibits a singular arrest of the movement toward putting complete personality at the centre of things. Historic idealism is, in fact, far from being personal; rather, it is well-nigh overwhelmingly impersonal.

Philosophy, it is often said, is the search after unity. As a statement of one philosophic aim, this is true enough; and certain it is that in this search after unity philosophy has almost always lost sight of its other interests, some of which are at least as great. The prevailing tendency in the history of thought, if we leave rigidly agnostic philosophers out of the account, has been to some form of monism; and idealistic philosophy, despite its diligent hostility to materialism, has usually been at one with its foe in absorption with the One-and-All. The only vital difference it introduces is to substitute for the one 
material Substance a single conscious Subject, or Universal Mind, through which, and in which, and for which, all things subsist-all things, including the so-called other minds. In the long history of idealistic thinking, even in the Western world from Plato to the present day, there is but one very eminent mind, the justly celebrated Leibnitz, who distinctly and systematically breaks with the monistic tradition. In recent times, particularly, through the infuence of Hcgel and his later school, idealistic thought, under the usurped name of Absolute Ideal. ism, has shared the field with its rival Evolutionism in advancing the doctrine of the One. The only important difference - no doubt a great one - is this: where evolutionism says the One Unknowable (if it refrains from saying Matter), this idealism says the One Mind, or the One Absolute Experience, allembracing, all-sustaining, all-determining.

To the ordinary mind of our Occidental world, alive with the spirit of Western civilisation, acting instinctively from the principle of individual responsibility, and of philosophy and its history as unexpert as Milton's Moloch was of wilcs, it would doubtless come as a surprise to learn that the main drift of philosophic thought in the Western world for the past century had been increasingly toward the Oriental view of things, and that amid Western civilisation individualism was not a philosophic matter-of-course. 
Yet such is the unmistakable fact. With this everyday Occidental's instinctive preference for personal initiative, responsibility, and credit, I confess myself in strong sympathy; and though from my acquaintance with the facts I cannot share in his surprise, I am glad of an opportunity to protest with him against this all-engulfing monism, fatal to our moral freedom even when taking on the plausible form of monistic idealism. Idealistic monism, though indeed a real philosophic advance as compared with other monism, is in the last resort irreconcilable with personality. By its unmitigated and immitigable determinism, with its one sole Real Agent, it directly annuls moral agency and personal freedom in all the conscious beings other than its so-called God. Accordingly, it leaves this professed God himself without genuine personality; for his consciousness is void of that recognition and reverence of the personal initiative of other minds which is at once the sign and the test of the true person.

The aim throughout the following papers, on the contrary, is to present, and in one way or another enforce, an idealistic system that shall be thoroughly personal in the sense just implied. Instead of any monism, these essays put forward a Pluralism: they advocate an eternal or metaphysical world of many minds, all alike possessing personal initiative, real self-direction, instead of an all-predestinating single 
Mind that alone has real free-agency. At the same time the aim is not at all to promote a certain other style of pluralism, which one might well enough call individualistic in the bad sense, whose dogmatic ideal is the dissolution of reality into a radically disjunct and wild "multiverse," - to borrow Professor James's expressive coinage, - instead of the universe of final harmony which is the ideal of our reason.

The pluralism here set forth is far removed from the anarchic individualism that seems to be advocated by such thinkers as, for instance, Professor Lutoslawski; ${ }^{1}$ nor is it to be confounded with that "pluralistic or individualistic philosophy" which Professor James himself, while brilliantly supporting it, defines ${ }^{2}$ by saying, "According to that philosophy, the truth is too great for any one actual mind, even though that mind be dubbed 'the Absolute,' to know the whole of it. . . There is no point of view absolutely public and universal." Rather, to the theory here set forth, the point of view of every actual mind, as that mind in its eternal wholeness is, is absolutely public and universal; and even in the mind's temporal aspect, the aspect of its struggle toward knowledge over the rugged road of experi-

1 IV. Lutoslawski: Veber die Grundvoraussetzungen und Consequenzen der individualistischen Weltanschaunng. Ifelsingfors, 1898 .

2 IV. James: Talks to Teachers on Psychology, etc., I'reface, page v. New York: Henry IIolt and Co., Igoo. 
ence, such a public and universal view must in every mind be potential. I confess, however, that I am almost ashamed to record, here and elsewhere in these pages, this dissent from Professor James, - a writer for whose genius I feel so warm an admiration, and with whom, on the great main matter, pluralism, I am in such hearty accord. Only, I cannot consent to put our common metaphysics at such risk and disadvantage, in comparison with monism, as a confessed and despairing ultimate irrationalism involves.

Something of the same tenor I might say, too, of my relation to the views of Mr. F. C. S. Schiller, the versatile author of that striking book, Riddles of the Sthinx. But in his case, it is chiefly his finite and pathological "God" that I am unwilling to admit as an implication of pluralism, much as I delight in the point and force of what he advances in support of our common view.

To put the theory of the present book in a clearer light, its chief points had best be summarised one by one. They may be stated as follows :

I. All existence is either (I) the existence of minds, or (2) the existence of the items and order of their experience; all the existences known as "matetial" consisting in certain of these experiences, with 
an order organised by the self-active forms of consciousness that in their unity constitute the substantial being of a mind, in distinction from its phenomenal life.

II. Accordingly, Time and Space, and all that both "contain," owe their entire existence to the essential correlation and coexistence of minds. This coexistence is not to be thought of as either their simultaneity or their contiguity. It is not at all spatial, nor temporal, but must be regarded as simply their logical implication of cach other in the selfdefining consciousness of each. And this recognition of each other as all alike self-determining, renders their coexistcnce a moral order.

III. These many minds, being in this mutual recognition of their moral reality the determining ground of all events and all mere "things," form the eternal (i.e. unconditionally real) world; and by a fitting metaphor, consecrated in the usage of ages, they may be said to constitute the "City of God." In this, all the members have the equality belonging to their common aim of fulfilling their one Rational Ideal; and God, the fulfilled Type of every mind, the living Bond of their union, reigns in it, not by the exercise of power, but solely by light; not by authority, but by reason; not by efficient, but 
by final causation, - that is, simply by being the impersonated Icleal of every mind.

IV. The members of this Eternal Republic have no origin but their purely logical one of reference to each other, including thus their primary reference to God. That is, in the literal sense of the word, they have no origin at all - no source in time whatever. There is nothing at all, prior to them, out of which their being arises; they are not "things" in the chain of efficient causation. They simply are, and together constitute the eternal order.

V. Still, they exist only in and through their mutually thought correlation, their eternal "City," and out of it would be non-existent. But through their thought-reciprocity with each other, God being included in the circle, they are the ground of all literally originated, all temporal and spatial existences.

VI. Hence, relatively to the natural world, they are free, in the sense of being in control of it: so far from being bound $b y$ it and its laws, they are the very source of all the law there is or can be in it. Relatively to God also, and to each other, all minds other than God are free, in the still higher sense that nothing but their own light and conviction determines their actions toward each other or toward God. 
This freedom belongs to every one of them in their total or eternal reality, be it burdened and obscured as it may in the world of their temporal experience; and its intrinsic tendency must be to fulfil itself in this external world also.

VII. This Pluralism held in union by reason, this World of Spirits, is thus the genuine Limoved One that moves all Things. ${ }^{1}$ Not the solitary God, but the whole World of Spirits including God, and united through recognition of him, is the real "Prime Mover" of which since the culmination of Greek philosophy we have heard so much. Its oneness is not that of a single inflexible Unit, leaving no room for freedom in the many, for a many that is really many, but is the oneness of uniting harmony, of spontaneous coöperation, in which every member, from inner initiative, from native contemplation of the same Ideal, joins in moving all things changeable toward the common goal.

VIII. This movement of things changeable toward the goal of a common Ideal is what we have in these days learned to call the process of Evolution. The World of Spirits, as the ground of it, can therefore neither be the product of evolution nor in any

${ }^{1}$ Aristotle's well-known definition of ( 
way subject to evolution; except that in the casc of minds other than God, who have their differentiation from him in a side of their being which is in one aspect contradictory of their Icleal, this sense-world of theirs is by its very nature, in its conjunction with their total nature, under the law of return toward the essential Ideal. In this world of sense, this essentially incomplete and tentative world of experience, evolution must therefore reign universally; but beyond this world of phenomena it cannot go. Every mind has an eternal reality that did not arise out of change, and that cannot by change pass away.

IX. These several conceptions, founded in the idea of the World of Spirits as a circuit of moral relationship, carry with them a profound change in our habitual notions of the creative office of God. Creation, so far as it can be an office of God toward other spirits, is not an event - not an act causative and effective in time. It is not an occurrence, dated at some instant in the life of God, after the lapse of æons of his solitary being. God has no being subject to time, such as we have; nor is the fundamental relation which minds bear to him a temporal relation. So far as it concerns minds, then, creation must simply mean the cternal fact that God is a complete moral agent, that his essence is just a perfect Conscience - the immutable recognition of the world 
of spirits as having each a reality as inexpugnable as his own, as sacred as his own, with rights to be revered; supremely, the right of self-direction from personal conviction. This immutable perfection of the moral recognition by God, let it be repeated, is the living Bond in the whole world of spirits. Did it not exist, did God not exist, there would be, there could be, no such world; there could be no other spirit at all. Real creation, then, means such an eternal depondence of other souls upon God that the non-existence of God would involve the non-existcnce of all souls, while his cxistence is the csscntial supplementing Reality that raises them to reality; without him, they would be but woid names and bare possibilities. Thus in the Divine office designated "Creation," exactly as in that denoted by "Redemption" or "Regeneration," the word is a metaphor; but in the one case as in the other, it symbolises a reality eternal and essential, of a significance no less than stupendous.

$\mathrm{X}$. The key to the whole view is found in its doctrine concerning the system of causation. It reduces Efficient Cause from that supreme place in philosophy which this has hitherto held, and gives the highest, the organising place to Final Cause instead. Final Cause becomes now not merely the guiding and regulative, but actually the grounding 
and constitutive principle of real existence; all the other causes, Material, Formal, Efficient, become its derivatives as well as the objects of its systematising control. A philosophy is thus presented in which the Ideal is indeed central and determining, and therefore real, and the measure of all other reality; a philosophy that, for the first time, might with accuracy be named Absolute Idealism, did not the title Personal express its nature still better.

For this metaphysical scheme I am not here arguing, of course. I am simply putting it forward in all its naked dogmatism, with no other object, just now, than to get its points apprehended. For this purpose it may be further helpful to point out its historical affiliations. A natural mistake would be to confound it with the theory of Berkeley; ${ }^{1}$ and certainly its first proposition substantially repeats Berkeley's main assertion, that nothing really exists but "spirits and their ideas," - taking Berkeley to mean by "ideas," in every spirit but God, conscious experiences, whether "inner" or "outer." But with this single proposition, the resemblance of the present theory to Berkeley's doctrine ends. Its kinship is rather with the system of Kant; and yet there would be a great misapprehension in identifying it

1 As a reviewer of The Conception of God, in the New York Nation, not Jong since did. 
with Kantianism. It certainly agrees with Kant, as it departs from Berkeley, in two chief matters: it maintains the a priori character of all the connecting and inference-supporting elements in human consciousness, and it consequently removes the centre of the permanent order in Nature from the Divine mind to the human, - understanding by the human the type of every mind other than God. It thus aims with Kant to avoid the merely theocentric or theological idealism of Berkeley, which rests on bare empiricism as an account of human knowledge; an idealism - or a sensationalism, rather - that at bottom is a mere assumption of a Divine Mind, as it permits to our intelligence no transcendental principle by which to reach the belief through a logical continuum.

Like Kant's, the present system finds the basis for its theory of knowledge in the native spontaneity of the human mind, -- of all minds not divine; and, again like Kant's, it provides for the "transcendental" efficacy of this spontaneous intelligence, for the power to go beyond past experience and judge of the future in perpctum with unreserved universality, by the hypothesis that Nature is a system of experiences, the "matter" of which is sensation, while the "form" or fixed order of it is determined by the elements - Space, Time, Cause, and so forth that the self-active consciousness supplies. But from 
this point onward its adherence to Kant ceases. It does not, like Kantian idealism, restrict the applicability of a priori principles to the world of sense, to mere phenomena, and thus confine knowledge to natural science; nor does it make of the distinction between our a priori scientific and our a priori ethical equipment a disjunct and impassable difference in kind. On the contrary, a leading aim with it is to break down the Kantian barrier between the "practical" and the "theoretical" consciousness, and to open a continuous theoretical highway for reason in both its scientific and its ethical uses. It seeks to raise our ethical intuition into the region of intelligence instead of feeling, and to do this by showing that the ethical first-principle is not only itself an act of knowledge, but is the principle of all knowledge, and of all real experience as distinguished from illusion.

In further consistency with this, in its philosophy of Nature it departs from Kant on the question of the origin of the "contents" in experience, the "matter" in natural objects. Whichever of the two views ascribed to Kant may really be his, - whether this "matter" of sensation, which he says is strictly "given," be taken as given (I) in the sense of being produced in us by the agency of some other being, or (2) in the sense of simply being there inexplicably, as a dead datum, back of which we cannot get, and 
from which we must take our whole cognitive start, - the theory here set forth accepts neither, but the rather abandons both. It neither accepts sensation as an unfathomable datum merely, nor does it entertain the hypothesis that it is an effect produced in the mind by some foreign agent acting as an efficient cause. Its aim, so far as explanation through cfficicnt causation is concerned, is to explain Nature wholly from the resources of the individual mind; and to explain it further, and in the full sense, by referring it beyond the individual to the whole world of minds in which every individual essentially belongs; but here the principle of explanation changes from efficient to final causation.

In cletail, the explanation is this: Each mind other than God no doubt organises its own sense-contents directly by its own a priori formative consciousness, for spontaneity is meaningless unless it is individual; and Nature is, in so far, a product of the individual's efficient causality. But all this organising of a senseworld, and the having of it, falls within the logical compass of each mind's central and eternal act of defining itself as individual; and this it does, this it can do, only in terms of the world of other mincls, - in the final resort, in terms of God, the Type of all intelligence. Thus the primordial self-consciousness of every mind with a sense-world, though receiving no contribution from the efficicncy of any 
other mind, has even with regard to Nature a spontaneous and constant reference to every other, and so to the Divine Mind. In this way, the mutual recognition of all minds which is essential to the very existence of each as a conscious individual, and which is the cognition that constitutes them ethically rational, becomes also the constitutive principle in the world of Nature. In fact, its entrance as a principle into the natural order is precisely what raises Nature out of being a mere private show for each mind into a universal experience, with an aspect common to all minds alike. It is this that lifts it out of resilicnt manifoldness and mere disjunction, and carries it into unity - the unity of $a$ communal system of cxperience, in which the dissents of individuals are reduced and harmonised by the deeper principle in their being, out of which their total nature flows by the self-defining act of each. Such an essential reference from each to other and to all, and from all to God, operates, however, and can operate, by no process of efficient causation. The whole operation is ideal; and what is called final causality, the influence of an ideal, which is now gencrally acknowledged to be the only causation in the moral world, is thus brought to be also the true primary causation in the world of Nature.

So much for the divergence from Kant. There is but one other modern philosophical theory with 
which readers would be likely to connect the present one, - the system of Leibnitz. The scheme certainly does approach to the Leibnitian monadology more closely than to any other form of idealism that has preceded it. But while it so largely agrees with Leibnitz, it also departs from him seriously, - if indeed one can always be sure of what Leibnitz really means by his persistently metaphorical expressions.

Upon three very important counts, at any rate, the present scheme aims to avoid what seems to be the shortcoming of the monadology :

(I) It dislodges the self-enclosed isolation of the individual, and finds a social consciousness, a tacit reference to others and a more or less developed recognition of them, to be inwrought in the very self-defining thought whereby each exists; it accordingly replaces the theory of Preëstablished Harmony by that of Spontaneous Harmony, and moreover provides for a world of efficient-causal communication between the individuals other than God - the real world of physical science - by its further development of the Kantian doctrine of Space as contrasted with the nature of Time, pushing the distinction between these two Sense-Forms to its foundations in the double aspect of self-consciousness itself, and reaching the proof, missing in Kant's own research, that the Sense-Forms must be two, and only two. 
(2) It thus parts company with that "gradation among the monads" which, as Leibnitz manages it, - with his conception of "body" as an assemblage of monads subject to a higher "regnant" monad, and of "God" as the Monad of monads, the Supreme Regnant under whom all these bodies are formed into a "System of Nature," - amounts to a system of caste in the world of real individuals, annulling: universal freedom, and therefore abrogating the asserted "System of Grace," by leaving to but one individual any being but process, and that a process directed exclusively by the so-called God, of whom all the other monads are but so many "fulgurations."

(3) It equally leaves aside that illusory character of extension and duration which Leibnitz so bluntly affirms, when he proposes to account for the apparent extending and lasting of sensible things by saying that these qualities are owing merely to "confusion and obscurity of thought": with thought distinct and clear, he holds, the real is seen as the monad, the bare "metaphysical point." The theory offered in these essays, on the contrary, gives to natural objects, as items in the real experience of minds, a reality, secondary and derivative indeed, but still unquestionable, and associated essentially with the self-defining activity of every mind other than God, while it provides for the great and signal 
fact of evolution, which Leibnitz appears to have been aiming at in his doctrines of "gradation" and "aggrandisement," by its view of the progressive character of the sense-world as a phase in the being of minds attracted by a divine Ideal.

These relations to Leibnitz, particularly when set in connexion with the higher rating of individuality and of final cause that characterises the theory now offered, suggest its close relationship with Aristotle, or even its direct derivation from him. Indeed, wcre it not for the profound ambiguity that marks Aristotle's thought, its cloudy vacillation between pluralism and monism, one might well find in his repcated insistence on the dominantly individual character of Substance and on the distinctness of God from the entire world of sense and passivity, joined with his emphasis on final causation, the complete anticipation of the central features of the present view. But, taken on the whole, the main clrift of Aristotle seems unmistakably to monism after all, and his frequent elevation of final cause, cn passant, to the apparently foremost place, is at last cancelled in the asserted efficient causality of God as the Prime Mover. Aristotle's "real world," combining ideal form with real matter, appears to be enclosed by him in the alldetermining single-conscious compass of his Divine $\theta \epsilon \omega \rho i a$, which he makes the synthetic "Entelechy" that unites in its action efficient and final causation 
at once, and thus besets all inclividual existence both behind and before.

The character of the present theory, relatively to Aristotle, is to be found in its attempt to carry out the individualistic tendencies in Aristotelianism to a conclusion consistently coherent; just as it likewise attempts a consistent continuation and development of the pluralism begun by Leibnitz and carried forward by Kant to his unfortunate point of arrest. In short, the new attempt may be described as an effort to relieve the cardinal new insights of Aristotle, Leibnitz, and Kant, alike, of a common group of inherited inconsistencies, and to continue the pluralistic aperçu, which undergoes a growing clarification in the thinking of these great minds, onward toward its proper fulfilment.

To all the great systems thus far mentioned, I am of course in a clebt that can never be cancelled. I am only too glad to acknowledge it, and my only hope is to have added to the borrowed capital, for the common use, some small increment that may render the whole more available for human demands. To the great representatives of monism, too, I feel a special indebtedness; for one owes a peculiar as well as great obligation to the thought from which he feels obliged to clissent. Particularly am I sensible of this in the case of Hegel, to whom I owe many years of light and guidance, and who must 
always remain for me one of the world's great minds. He has left us in his Logic, I am persuaded, a permanent inheritance, which despite his metaphysical abuses of it, and despite its sundry slips and gaps, only awaits the labours of some sufficiently powerful successor to become a complete system of our experiential ascent out of inadequate to adequate categories. May we not hope that this service may yet be performed for us by the Master of Balliol, or by our own National Commissioner of Education?

In the various essays, the new pluralistic theory of ultimate reality is presented now in one of its factors, now in another; in none of them, however, is any exposition of it as a systematic whole undertaken. Proofs of this or that part of it are attempted in each paper, and, in the course of the volume, of all its ten propositions above laid down, but no establishment of the system as such; this must wait for another place and occasion. The fullest discussions of important phases in the theory are contained in the first essay and the last; and for this reason these were given the two most prominent places in the book. The intervening essays are placed nearly in the order of their original production, though the central theme of the theory, which may very properly be called The eternal reality of the individual, undoubtedly comes out with increasing articulateness 
and emphasis as they go on towards the end of the volume.

The several papers have been very variously occasioned, and have been written at varying dates, covering a period of something like twenty years. The reader who cares to do so can follow up their chronology in the appended foot-notes. In the earlier papers considerable changes have here and there been made from the form in which they were originally printed, in order to bring all their statements into harmony with the governing view. In their original form, monism of an Hegelian type played no small part, side by side with the strongest affirmations of personal reality and individual freedom, a collocation, it would seem, rather characteristic of Hegelianism than not. At the date of their first production I had not become aware of the hopeless contradiction between the two views. Those who feel the curiosity, can dig the originals out of their hiding-places in the journals, and see them with all their sins of inconsistency upon their heads. But I trust these earlier attempts may be left to a natural oblivion. It is only to the form given them in this volume, that I should wish readers to refer for the expression of my mature opinions.

I have to thank the editors of the New World, the Journal of Spcculative Philosophy, and the Overland Monthly for their kindness in permitting me to use 
the matter printed as articles in their respective journals: more definite acknowledgments are made in the appropriate foot-notes. For the very full Index I am indebted to Mr. H. A. Overstreet, student of Balliol College, Oxford; earlier, B.A. of this University, and long an undergraduate member of its department of philosophy.

UNIVERSITY OF CALIFORNIA,

BERKELEY, November, rgoo. 


\section{PREFACE TO THE SECOND EDITION}

THE differences of the present edition from the previous one in no wise affect the substance of the views advanced. There are, indeed, both alterations and additions; but the former are merely verbal, confined to correcting misprints and amending slips of expression that involved some inconsistency or ambiguity, while the latter are all intended either to clear up misunderstandings on the part of reviewers, or to further elucidate the new view and its consequences, or else to answer objections made by some of my critics.

One prominent occasion of the additions, I may frankly say, was found in an occurrence which, if left without some emphatic public notice and explanatory cautions, could not fail to be seriously misleading. I refer to the appearance of a later volume, also bearing the title Pcrsonal Idcalism, ${ }^{1}$ yet presenting views very diverse from those covered by that expression in the present book. Throughout the many years that I have held the metaphysical

1 Personal Idealism: Philosophical Essays by Eight Nembers of the University of Oxford. Edited by Henry Sturt. London: Macmillan \& Co., 1902. 
theory here presented, I have called it by the name of Personal Idealism; and when, three years ago, I published these essays, I placed this name in their title-page and explained it at length in the Preface; I had also several times used the name, with the same explained meaning, in the volume called The Conception of God, published four years earlier in coöperation with Professors Royce, Le Conte, and Mezes. But some fifteen months after the publication of the present book, a group of Oxford writers issued a joint collection of Essays, on the fundamental problems of philosophy, and chose for it the same title, notwithstanding the fact that, as I have just said, their philosophical view is opposed to mine; indeed, on vital questions, almost diametrically opposed. So there are now going by the name of Personal Idealism two theories, quite divergent upon most of the prime philosophical issues, with little in common but the affirmation of a fundamental pluralism in the world of ultimate reality, and with profoundly different conceptions as to what that pluralism means. Such a confusion in the use of a prominent term is an unfortunate obstacle in the way of the very reaclers whom we all wish to enlighten and convince. Warning against it would accordingly seem in the highest degree pertinent, and to come with an especial justice from the writer who was first to employ the name, and whose view has there- 
fore the priority of right to it. On this account I ask the attention of readers to the Appendices, which serve to put my view in the clearest light, and especially to Appendix $\mathrm{C}$, in which the main differences between my own theory and that of the Oxford Essayists are pointed out, and the objections stated to which I think the Oxford view is exposed.

Of my reviewers I have surely no complaint to make but that of a pretty general failure to take in the full and exact meaning of the theory I present. This failure, I fear, is owing, at least in part, to the dismembered form in which the view is set forth - that of separate essays, occupied with topics not obviously connected, and addressed to readers generally cultivated rather than to philosophical experts. Accordingly, in the various Appendices I have aimed to correct these misapprehensions and to reply to objections which, almost without exception, are founded on misunderstandings. There are, in particular, two lines of objection upon which I feel it important to advert here in some detail.

The first is that which comes from confounding Personal with Subjective Idealism. I think I have the right to say that I have taken all pains to prevent the misapprehension upon which this confusion rests; but unfortunately to little purpose, it would 
seem, for most of my reviewers. Of course, the theory of Personal Idealism, in common with every other that detects the fallacy latent in the Natural Dualism of uncritical common-sense, has to face the wonder-waking question, What in truth does objectivity then mean, since "existence," per se and apart from being apprehended by intelligence, is not really thinkable? - what is it for a judgment, whether perceptive or reflective, to be "objective"? Thus an essential part of the theory is its new doctrine of the nature of objectiveness. This it finds in the essentially social character of that self-defining consciousness in which it fixes the real existence of each personal being: each is by its own self-certitude self-correlated with others, so that its reality carries theirs; and this society of primarily objective beings imparts a secondary objective character to all the judgments that are organic in each and thence indicative of community to all. It is this sociality of the primordial logic of self-consciousness, this intrinsic reference to other minds, that my reviewers, and perhaps other readers, - preoccupied with the other assertion essential to Pcrsonal Idealism, - the necessary self-recognition of every person, - have quite commonly overlooked; just as Descartes overlooked it, in seizing upon the great "first certainty" with which he broke out the pathway of modern philosophy; just as all his successors prior to Kant, 
save only Spinoza and Leibnitz, continued to overlook it; and just as Kant himself came to the conviction that it must be disregarded, so far as concerned any knowable objective, and consequently felt obliged to declare that the objective character of a cognition lay simply in its necessity, ${ }^{1}$ - a doctrine which, for the next obvious move, forced philosophy upon the awkward alternative of either (I) admitting this "necessity" to be merely the dominating proclivity of the isolated self, and so, as Hume had contended, merely a subjective necessity, or else (2) returning, though by the route of an idealistic cosmology, essentially to the view of Spinoza, translating the "necessity" into necessitation, operated upon (and in) each self, as a mode of the One Thinking Reality, by the all-inclusive and all-pervasive Absolute Self.

This latter branch of the alternative, Kant, as we all know, deliberately rejected, because he so clearly and correctly discerned its fatal inconsistency with personal autonomy, and thence with moral responsibility; and he chose, rather, to refer our consciousness of duty - that is, of devout obligation to other minds as the only strict Ends - to our good-faith, our pure fealty, toward a bare ideal. Consequently

1 See the various forms of his "Deduction" of the categories, passim, as presented in the first and second editions of the Critique, and in his Reflexions, edited by Benno Erdmann. 
he limited the field of our knowledge to the connecting judgments that link our sense-presentations into permanently identical objects in a permanent cosmic whole; that is, to physical things, and their physical laws, alone. But in so doing he failed to notice what Hume, had the Scottish sceptic lived to read him, could justly have told him reduced all knowledge to an isolated self-knowledge merely, and thus stripped science of the very quality of $t$ ruth, - which required an objective meaning; a meaning, that is, referred quite beyond any single self, and, indeed, to a world of total and absolute reality. When our assurance of such an absolutely real world is rested simply on our fealty to its idea, the world of supposed science must also, in its turn, become but a world of pure faith - of sheer belief. So futile does our inmost mind declare the endeavour to maintain a judgment of worth for what we cannot crown with the judgment of reality.

Thus, since the counter-attempts of Kant's great idealist successors, following the second branch of the alternative and culminating in the Absolutism of Hegel, philosophy is manifestly at fault before the much profounder dilemma of either winning an objectivity for physical and metaphysical judgment at the cost of casting out from the moral judgment the very principle of autonomy which Kant had triumphantly shown to be its quickening essence, or 
of resting this autonomy, with Kant, on subjective fealty alone, in the delusion that it is independent of knowledge, and that knowledge can be satisfied by a world of "phenomena" necessarily subject to it, while yet that world itself is only "necessary" in the sense of flowing spontaneously from the nature of each isolated self.

Now it is to the surmounting of this gravest of all dilemmas that the theory of Personal Idealism, as I intend it, is directly addressed. It proceeds by pointing out that the meaning of objectivity, while indeed to be sought in conscious and intelligent being alone, as taught by all idealism, must be found neither ( $\mathrm{I}$ ) in the self-consciousness of the solitary and disjunct self, which in disregarding necessary reference to others reduces morality to simple selfrealisation and introversive self-respect, nor (2) in the all-inclusive self-consciousness of the One $\mathrm{Ab}$ solute Minrl, in which each "finite" self, as one essential mode thereof, participates in such degree and with such "task" as the One assigns to it by his eternal Will or predestinating and exclusively selecting "Love," but (3) in an absolutely primordial altruism couched in the very logic of the fundamental act of self-definition by any mind, whereby its awareness of itself, demonstrated by Descartes to be the condition of any and all other knowledge whatever, - the condition necessary, no doubt, but 
not therefore sufficient, - is seen to involve, as the complemental condition making up sufficiency, its awareness of a whole society of minds, the genus against which it spontaneously defines itself, per differentiam, as individual. Thus the world of minds, as the sole world of Ends presupposed in all moral responsibility, the world of ultimate and standard Objects, becomes at one and the same stroke the warranting foundation of knowledge and of good-will alike: to refuse good-will is to violate the primary principle of each mind's own existence, and is therefore to convict oneself, in one and the same act, of irrationality and folly as well as of indifference or of ill-will. In this light, duty is seen to be the freedom of autonomy, instead of simply the freedom of sharing in a good lot, - freedom in a world of utter reality, where nothing is predestined otherwise than by the self's own thinking, so that each self thinks every other as an essential complement of himself, and sees that he cannot realise himself except as he realises all the others. In fine, the principle of self-recognition, as a condition of any and all knowledge, not only turns out to be the first principle of morality, but the first principle of morality becomes at once the first principle of knowledge and itself an act of knozuledge, not simply a sentiment of obligation. Objective knowledge and the intelligibly objective certainty of the moral judg- 
ment get vindicated at once and together. To think objectivcly, to know, is tacitly to refer the "necessity" of one's judgment to the universal society of minds as a standard, is to discern oneself as typical of a kind, and thus attain the certitude that the judgment is truly universal, because spontaneous in the nature of each as involving the nature of all.

Why this view of what constitutes objectivity, inwoven as it is in the very tissue of Personal Idealism, and reiterated time and again in my pages, in all sorts of contexts, should have escaped the notice of so many readers, is, I confess, a genuine puzzle to me. Over and over, it turns up in these essays that a person means a being who thus recognises others and relates himself to them, and that the Personal System, while rigorously idealistic, making all existence root in the existence of minds, is still always a Social Idealism, so that the objective judgment is always the judgment that carries the weight of the social logic, and the final test of any and every truth, though never so often discovered in the private chamber of the single spirit, is that it conforms to this principle of universal social recognition. And yet, also over and over, the new theory has been dealt with as if it were only a fresh form of isolated subjectivism.

On careful reflexion, I incline to think this must be owing, in part, to defective exposition of my own; 
and I now suspect it is my scant and quite insufficient treatment of the peculiar nature of Space, as involved in my general doctrine, that is responsible for this frequent failure of readers to catch the objective character of the theory. In the system of Personal Idealism, of course, Space is the principle a priori whereby each conscious self that has the phase of intelligent being which we call experience, comes into actual sensuous commerce with other selves of that species, or, in short, shares with them in a real located and pliysical world. As such, it is discriminated from Time, the principle $a$ priori that coördinates the private experiences of each self into a succession possibly necessary and predictable. Its nature, as thus a public principle in contrast to a private one, is in fact founded in the twofold aspect, self-referring and other-referring, essential to any individual self-consciousness; and the development of this doctrine of the origin of the space-consciousness, clearing up, as it would, the puzzle left over by Kant, - whether and why there arc two elemental Sense-Forms, and no more, - would of course form a very important part of the systematic discussion of the new theory. In the first edition, however, the doctrine was merely referred to in passing $;{ }^{1}$ and even in the present edition I must content myself with barely touching upon it as I have now done, and directing the reader's 1 See pp. xiii and xxii, and of. p. 352, note, and p. 353 . 
attention to the passage in Appendix $\mathrm{D}^{1}$ where I have dealt with it briefly in replying to one of the points of my reviewer in the New York Tribune. I have now also inserted in the original Preface ${ }^{2}$ a clause of preparatory reference to the subject. On account of the room required, any adequate treatment of this question must be left over to the systematic exposition of Personal Idealism which I still hope to accomplish.

The second line of objection charges me with failing to furnish proofs of propositions fundamental to my theory. This, too, I an sure, is based on misapprehension as to what the essential proofs are, - the proofs really required and actually offered. For instance, to designate one case of several, the far from hostile reviewer in the number of Nature for August I, I90I, makes the mistake of supposing that my problem in Essay VII is the demonstration of human freedom, and that the proof offered is the indispensableness of freedom to noral responsibility. This quite misses the governing aim of that essay, which is to exhibit the capabilities of Personal Idealism for solving, by a transcending conception, the pseudo-antinomy set up by the monistic Absolutism of Hegel and his later followers, on the one hand, and the pluralistic Fortuitism of Peirce and James and most 
of the Oxford Essayists, ${ }^{1}$ on the other. The point that absorbed the attention of my Nature reviewer is thus only a subordinate step in my procedure: there, I am simply showing what genuine freedom must really mean; pointing out that the freedom necessary and sufficient for moral responsibility,- - such responsibility and such freedom, of course, standing or falling together, - though it excludes predestination, cannot and must not be identified with empty indeterminism, but must be construed as sclf-determination; and that determinism, on the other hand, need not be taken to mean predestination, but has its conception satisfied rather by definiteness simply, as against the bare indefinite or indeterminate, which is in truth only another name for the unreal, the non-existent. In short, my object in that passage, quite preparatory, is to state in the sharpest way the question of the possible harmonisation of freedom and determinism, and to show that this is clearly possible if (but only if) the two are read off, respectively, as the obverse and the reverse of the conception Self-determination, reduced to identity with Self-definition; by this path I pass to the conception of a pluralistic and libertarian rationalism, as transcending the monistic and neces-

1 Though the official manifesto of these Oxford writers had not then appeared, I was familiar with their views through personal intercourse as well as acquaintance with certain of their previous publications, and I had then constantl; in min!. 
sarian rationalism of Hegel's school, and of a pluralism rationally organised by the self-definition of each mind in it, as transcending the irrational pluralism - confessed to repose at bottom on chance and unintelligibility - which is all that is attainable on the "radical empiricism" of Professor James and his associates. The freedom that consists in self-definition, I next proceed to show, implies the supertemporal (that is, the "eternal") coexistence of all minds, each a centre of origination for the definite connexions of the parts of its experience, - provided it involves experience in its self-definition, as we human beings do. Thus far, I am only dealing with the conception of such a world of genuine free-agents, spontaneously harmonised by a gencric rationality, and showing what it could do for the opening of the "no thoroughfares" come upon in the course of our past pliilosophical struggles, provided the reality of it could only be made out. The graver question, whether any such veritably self-defining being really exists, whether there is a real world of free-agents, and whether we belong in it, has not, to this point, been reached; it only comes up later in the essay, in the context of defending the conception of Personal Idealism, the supposed world of coeternal free-agents, against the accusations of atheism and of polytheism. There, at length, the bare conception of true freedom, as involving the coeternity of all minds with each other 
and with God, is carried over into reality by means of a clarified and reformed statement of Descartes's proof that any mind is necessarily certain of its own existence; personal existence, in its "distinct" idea (to use Cartesian language), being shown to imply the contrasted and complemental existence of others, and, further, the existence of God, as the ultimate standard involved in the entire round of self-definition by self-correlation.

In fact, my point is that the entire proof of our being free lies in showing that, mortals though we are, and subject in one aspect of our existence to the broken and tentative cognition called experience, we still do originate judgments, and judgments that are necessarily true, holding in perpetumm; we do cognise principles a priori, that is, spontancously, and not because we are so "framed" by some other being, or so impelled "from elsewhere," that we cannot do otherwise. Thus the entire warranty for Personal Idealism comes down, finally, to the affirmative settlement of the bottom question in epistemology : Do we, or do we not, set forth truths a priori? - and, at the foundation, what truths? If we do, and if at the basis of all of them lies the act of self-definition by self-correlation with others, then we are indeed free, our being is rationally self-active, and the entire system of Personal Idealism follows, in this high rational sense of the expression. If we do not, or if we only 
xliv

have necessary cognitions in the sense of tendencies "implanted" in us "from elsewhere," necessitated tendencies to judgment, which we merely follow as they coerce us, and if we can only "guess" or "have faith" that we are real and in real relation to others, then we are not free, and no genuinely idealistic system exists at all. The reader who cares enough to look as he should, will see that the scheme of proof for all my cardinal propositions consists in my reconsidering the whole question of a priori knowing, and vindicating its affirmative, in the light of all the objections really made to it since the enduring argument of Kant in its favour.

It is possible that this charge of omitting essential proofs was suggested by a somewhat incautious sentence in the original Preface, which I have now taken care to correct by a needed addition. ${ }^{1}$ This read, "Proofs of this or that part of it [the new pluralistic theory of ultimate reality] are attempted in each paper, but no establishment of the system as such." From this it was an easy, if inaccurate and unwarrantable inference, that only certain principles in the system were brought to scrutiny in the essays, while the rest were merely asserted for the sake of orienting the reader as to where he would find himself in the world of metaphysics if he once took Personal Idealism for granted. But such was far from being 1 See p. xxvii. 
my meaning. Systcmatic exposition the essays undoubtedly do not contain; for that would imply that I took up the system as a whole, that I began at its beginning, and went on, through all the intervening and successive steps, to the final result, having nothing directly in view but the orderly establishment of the logical whole that the system constitutes; and this, of course, I was not doing: I was occupied, rather, in exhibiting the Rational Pluralism in the light of its bearings upon the deeper human problems. But adequate exposition, in the sense of thorough proof of every essential principle, as well as clear enunciation of it, I certainly intended they should contain; and I am firmly persuaded that they do. I presumed that I should gain a wider and a more interested attention by the method of separate essays on questions that have always deeply engaged the most thoughtful; and I took it for granted - with good reason, as I still believe - that I should thus establish a favourable presumption, to say no more, in behalf of a theory that could show itself capable of casting a new and clarifying light upon our oldest and obscurest puzzles. But it could cast no lasting or solving light unless its sources were shown to be real, and this showing I still suppose the essays actually accomplish.

It will be pertinent to point out here, that, of the ten propositions in which I state the theory in out- 
line, ${ }^{1}$ all but the first and second are simply the elucidating consequences, or corollaries, of those two; if those are established, then all the others follow. What the advocate of Personal Idealism has to prove, then, is the pair of complementary principles contained in Proposition I, and the principle contained in Proposition II as to the nature of Space and Time and of the relation, transcending both, between minds themselves. The achievement of this task depends on attaining to the true distinction, the real relation, between the two orders of existence which to ordinary and uncritical reflexion - usual common-sense - appear as two substances, so called, or species of substance, and are named "mind" and "matter." What is to be shown is, that this common-sense contrast, read off as a hard-and-fast dualism, is not intelligibly interpretable except as the distinction between two aspects of one and the same total nature in the beings that possess it - the distinction, namely, between the whole and its dependent part; between the primitive, or unconditioned, or, more accurately, the self-defining, and the derivative, or conditioned, which is defined and determined by the first; or, again, if one chooses to say so, between the originating and the originated, the immutably causative and the causedly mutable; that is to say, finally, between (I) minds, actively thinking constitutors of experience

1 See pp. xii-xviii, above. 
and the objects in it, and (2) mere things, the passively constituted parts in experience. Plainly, then, the required proofs can only be brought by exhibiting minds, through the study of them in our human selves as types, in the actual exercise of spontaneous constitutive judgment, - framing a world of things perceivable, according to conceptions that derive in the last resort from concepts a priori; that is, from combinative and constitutive acts of cognition, that are strictly spontaneous with and in $z s$, or with and in any beings that are like us.

Thus, once more, the whole proof comes down to showing (I) that the doctrine of $\operatorname{cog}$ nition a priori is true and real, and (2) that the absolutely fundamental cognition of this sort is the self-defining consciousness of each mind that it exists just by being selfaware, and, in that very fact, aware of its correlation with a system of other minds. The steps in exhibiting these two main members of the system of a priori knowledge, the reader will come upon, more or less, in every one of the essays; but if he require a more specific direction, he may turn especially to pp. I9-2 I, 32 cf. I8, 46 seq., 300 seq., 306 seq., for the first; and, for the second, to pp. I73-I75, 310-312, 35I354, and 359. However, these are, so to spcak, only samples.

For the rest, to take a due notice of the critic who has brought forward, out of an evidently wide philo- 
sophical reading, and with the strongest emphasis, this charge of omitting vital proofs, I may refer again to Appendix $\mathrm{D},{ }^{1}$ as containing, in my reply to him, an additional showing of the fact that the establishment of a priori knowledge, and of what this at bottom consists in, supplies the entire proof required for the system of Rational Pluralism, or, as I still prefer to name it, Personal Idealism. For the removal, or at any rate the easing, of subtler and deeper-reaching difficulties which the system involves, I will refer to Appendix E, where I reply to Mr. McTaggart, to whom I am indebted for the most penetrating appreciation, and the most searching criticisms, that the book has received.

With the foregoing cautions, and the various other aids to a right understanding furnished in the present edition, I shall now leave these essays to their fate. But I must not close without expressing my obligations to the editor of Mind, the editor of Kantstudien, the editor of the Intemational Jonmal of Ethics, and the editor-in-chief of the New York Daily Tribune, for their kind permission to use the various material now printed in the Appendices.

UNiversity OF CAliforNia,

BERKELEY, July, I904.

1 See p. 4 I 4 seq., below. 


\section{CONTENTS}

I. The limits of Evolution . . . . I-55

II. Modern Science and Pantheisil . . 56-100

III. Later German Philosophy . . . ioi-178

IV. The Art-Principle as Represented IN POETRY . . . . . . . 179-216

V. The Right Relation of Reason to ReliGION . . . . . . . $217-278$

VI. Human Immortality: its Positive ArguMENT . . . . . . . 279-312

Vil. The Harmony of Determinism and FreeDOMI . . . . . . . 313-380

Yili. Appendices Explanatory and Defensive . 38I-430

A. The Essays in their Systematic ConNEXION, pp. 383-388.

B. The System in its Ethical Necessity and its PraCtical Bearings, pp. 389-404.

C. The System ws. THE VIEW OF THE OXFord ESSAYISTS, pp. 405-408.

D. Reply to a REview in tile New York TRIBUNE, pp. 409-4I9.

I. The System Pluralism, but not Chaotic Individualism, pp. 409-412.

II. The System not the Theory of Preëxistence, pp. $4^{\mathrm{I} 2-4 \mathrm{I}} 4$.

III. Real Proofs of the System, and True Role in it of Final Cause, pp. 4I 4-417.

IV. The System not a Subjective but an Objective Itlealism, pp. 417-419.

xlix 


\section{Appenuices - Continued}

E. Reily to CRITICISMS BY MR. J. M. E. MCTAGGART, pp. 420-430.

I. Freedom, Perfection, God, and the Proof of God, in the System, pp. 420-425.

II. Relations to Kant, Categories vs. SenseForms, Monotheism, Misuse of the Name God, pp. 425-430.

IX. INDEX . 


\section{SUMMARIES}

\section{THE LIMITS OF EVOLUTION}

Evolutional Philosophy: its Two Forms, their unfavourable bearing on IIuman Interests, and the Question of Limits thence arising .

I. Chasm between the Phenomenal and the Noumenal: Evolution cannot cross it, and does not seriously claim to do so

II. Break, in the Phenomenal World, between the Inorganic and the Organic: Evolution interrupted by it, and compelled to look for its own explanation to some changeless Noumenal Principle . . . . .

III. Further break between Physiological and Logical Genesis : Evolution, which as natural science is a matter of physiology or empirical psychology only, incapable of closing this; the only Evolutional Continuun a logical and ideal one

IV. Gulf between the Unknowable and the Explanatory: Philosophy, as explanation, should reach the latter, but Evolution, raised into the Principle of philosophy, itself declares that it can only reach the former . .

V. Transit from Nature in general to IIuman Nature viewed as essentially Reason: this impossible by Evolution; demonstration, in detail, that Human Reason, so far from being the result of Evolution, is required by it as the prior ground through which alone it can exist and be known as pertaining continuously to other things; proof of the strictly ideal character of the Phenomenal World and its evolutional law . . . . 30 
VI. The real relations between Nature and Human Nature now seern to imply an idealistic philosophy: man Noumenal, not inerely Phenomenal; and every human being thus absolutely, eternally, and unchangeably real, while the natural world is essentially fleeting . .

VII. Critical consideration of the question, so much and so loosely debated, Are the theory of Evolution and the Christian Religion really compatible?

\section{MODERN SCIENCE AND PANTHEISM}

The various aspects of the question, Is Pantheism the legilimate outcome of Modern Science? Detail of the subsidiary questions which it implies. . . . . .

I. What Pantheism exactly is, - the consolidation of the Divine Being with all possible being: distinction between the two forms of Pantheism, the Atheistic and the Acosmic; essential $\Lambda$ theism of both at root . .

II. Exact discrimination of Pantheism from Materialism and from Subjective Idealism: its superiority over hoth; its theistic deficiency, even in its Acosmic form, in regard especially to the idea of Divine Immanence .

III. Exact contrast between Pantheism and Deism, and eminent superiority of Pantheism: it breaks down the mechanical and irreducible separation of God from the world, which Deism sets up; the participation of popular Thaumaturgical Theism in this deistic fault . .

IV. The service of Pantheism in contributing toward the formation of genuine Theism: it suggests, though it necessarily fails to fulfil, the theistic ideal of God immanent in the world by the activity of his image in the mind of Man, the only Divine Immanence compatible with the moral freedom of the Soul . . . . .

V. Why Pantheism nevertheless rouses apprehension and aversion in the Modern Religious Consciousness: we are prescient of its antagonism to our Moral Freedom or Self-Activity 
VI. The war inherent between Pantheism and the characteristic interests of Human Nature: these identified with the belief in Individual Free-agency and Individual Immortality . . . . . . . . . $7^{6}$

VII. Is there anything in the nature of Modern Science that gives colour to the view that Pantheism is its only legitimate outcome? Apparent evidences for this vic:?; both from the Method and from the two most prominent Results of Modern Science: the theistic negations in the Empirical Method, and the pantheistic trend of the Principle of Conservation and the Principle of Natural Sclection . . . . . .

VIII. This apparent Pantheism of Science not really warrantable: its inciact and self-contradictory character; strictly speaking, Science is simply neutral in all such questions, and leaves the way entirely open for their settlement by higher methods than its own . . .

\section{LA'TER GERMAN PHILOSOPHY}

Striking movement in German Thought since 1865 : its general character that of Monism moving toward Pluralism, through Agnosticism and its Self-Dissolution . . . . . IOI

I. The pseudo-idealistic I'essimism of Eduard von Hartmann, known as the "I'hilosopliy of the Unconscious"

II. The optimistic Materialism of Eugen Dühring, or the "Philosophy of the Actual" . . . . . I2I

III. The Neo-Kantian Agnosticism of Friedrich Lange, and the so-called "Standpoint of the Ileal" . . . I $4^{2}$

IV. The Self-Supplanting of $\lambda$ gnosticism through the completion of its own implicit logic: passage to a complete Idealism; sketch, in outline, of what such an Idealism is . . . . . . . 159 


\section{THE ART-PRINCIPLE AS REPRESENTED}

\section{IN POETRY}

Introductory statement of the Problem and its Difficulties: the solution by an appeal to the Universal Principle of Art

PAGE

I. The Essential Principle of Art, in general: reduction of the usual antagonism between the Ideal and the Real in the schools of Esthetics, and arrival at their harmony in the Real-Ideal, the actual union between Irlea and Fact; Art the interpretation of the Fact in terms of its quickening Idea. . . . . . .

II. Further development and modification of this principle in the light of the maxim that Art is its own end: strictly creative character of Art; but this dues not mean its right to do as it pleases; it cannot make the ugly, or the guilty, or the vile, beautiful; essential correlation between the True, the Beautiful, and the Good, as expressions of the one Real-Ideal . . . .

III. Exact distinction between the True, the Beautiful, and the Good: they form a strictly Triune Group, inseparable; the ground of this in the indivisible Psychologic Trinity in the soul - the unity of its emotion and its will in its intelligence or reason; its final explanation to be found only in the correlation between the rational freedom of God and the rational freedom of man; every work of art thus an embodied Theodicy . .

IV. Art, as the embodiment of the Beautiful, in its difference from Philosophy, whose aim is the True, and from Religion, whose aim is the Good, has its essence turn wholly on its form; its proper theme always the same indivisible Real-ldeal as theirs, always true and good, but its form the form of Beauty - the address to our Rational Capacity for Joy . . . . . .

V. Application of these results to Poetry: the classification of the line Arts; ascending series of Architecture, Sculpture, Painting, Music, Poetry; the art of the Poet the culmination of the principle ruling in all the Fine Arts . . . . . . . . . 
VI. The summarised result as to the Art-Principle in Poetry: the specific criterion of Poetry, as such; whether the list of Fine Arts should be extended by including a sixth art - Prose Literature . . . . .

\section{THE RIGHT RELATION OF REASON TO RELIGION}

The varied views, Conceptual and IHistorical, of the relation between Reason and Religion: their Essential Antagonism vs. their Potential Harmony; the Three Doctrines of their possible harmonisation - the Old, the Niddle, and the New .

I. Detailed Statement of the New Doctrine, or Rationalism, and of the steps to be taken in proof of it; the two Religious Methods, (I) of Authority, or Declaration, (2) of Reason, or Conviction . . . . .

II. The Contrast between these Methods not to be confounded with that between Romanism and Protestantism; rather, a division between Two Schools of Thought in all religious Denominations . . . . .

III. Rejection of the Method of Authority on the ground (1) of its Logical Contradictions, and (2) of the Perpetual Elusion of Search, characterising its assumed Divine Source • • • • • • . 230

IV. Its conflict with the Essential Spirit of Christianity, the Religion founded in the recognition of the Free Reality of the Individual Mind . . . . . .

V. The argument, both Indirect and Direct, in behalf of the Method of Reason as the only one germane to Fulfilled Religion. The Direct Argument, (1) from the Tacit Admissions in the history of Apologetics, shown by their changes regarding External and Internal evidences; (2) from the Successive Steps in the Historical Development of religion ; (3) from the Logical Implication of Christian Theism in the method of Natural Science. The subtle indircctness of the real argument to God from the Rationality of the World . . . 260 


\section{HUMAN IMMORTALITY: ITS POSITIVE ARGUMENT}

l'rofessor James's Ingersoll Lecture: need of something more than a fairway for the "will to believe," in the case of Immortality. Can we advance beyond Answering Objections, and reach some Positive Proof ? . . . . .

I. The objection to Immortality from the maxim of modern psychology, that "mind is a function of the brain": logical flaw in attenpting to rebut it by the Transmission-Theory of this functional relation . . .

II. Stricter interpretation needed of the functional relation between Mind and Brain, if Personal Immortality, the only immortality significant, is to be reconciled with modern psychology; substitution of Simple Concomitance between brain-function and mind-state for Professor James's Transmission-Theory; passage to the a priori or self-active personal consciousness of each mind, as the implied gruund of this Concomitance .

III. Extension of the foregoing argument, from the single case of Time, as a priori, to the whole complex of the a priori conditions fur experience or Nature; the Soul the source and centre of these conditions, therefore determinant of Nature instead of subject to it, and hence not perishable by any of Nature's vicissitudes, of which Death is merely one . . . . .

IV. Reply to the Objection that the foregoing argument establishes nothing but a power intrinsic in the Soul to keep in existence merely, and fails to prove an immortality of rational and moral Worth 


\section{THE HARMONY OF DETERMINISM AND FREEDOM}

Some historical lights on the Difficulties of the Problem : radical changes needed in certain Theolugical Conceptions, if its solution is to be reached

I. General conditions of a Harmony between Determinism and Freedom: the genuine Definitions of both . . 318

II. Special conditions of harmonising Divine and other SelfDetermination; the coeternity of all Free Beings with

God . . . . . . . . .

III. Apparent contradiction between Causation in God and the Freedom of other beings; the Assumption at the basis of this.

IV. Reality of the Contradiction, so long as Divine Causation is conceived as Efficient. Need of some conception of Divine Causation consistent with the reality of Moral Freedom . . . . . . . . .

V. Solution of the Contracliction, by the substitution of Final for Efficient Cause, as the furm of I ivine relationship to the Real World, the Workl of Spirits

VI. Proof that the system of I'luialistic Freedom, or the World of Spirits subsistent through Final Causation, is neither Atheistic nor Polytheistic, but is Theistic and Monotheistic

VII. Explanation of Alternative, or Choice, in the World of Experience, and solution of the "Dilemma of Detcrminism" . . . . . . . 372 


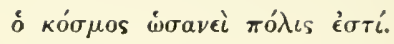




\section{THE LIMITS OF EVOLUTION. ${ }^{\circledR}$}

IT has become a commonplace, that in the thinking of the nineteenth century the characteristic and epochal fact is the conception of Evolution. This conception has at length been carried out into every province of human experience even, is now in some loose sense a general habit of thought, and seems on the eve of becoming all-dominant. Its raptest devotees have for some years demanded that the mind of man itself, in which the conception has its very origin and basis, shall confess its own subjection to the universal law, shall henceforth acknowledge itself to be simply a result of development from what is not mind, and shall regard all that it has been accustomed to call its highest attributes - its ideality, its sense of duty, its religion - as tracing their origin back to the unideal, the conscienceless, the unreligious, and as thus in some sense depending for their being on what has well been termed "the physical basis of life."

1 A lecture delivered at Stanford University, October, I 895. First printed in the New Worlat, June, $x S_{96} 6$. 
This doctrine of mental origins need not be taken, however, in the sense of materialism. Indeed, its able and exact advocates expressly repudiate the materialistic construction often put upon it; and to meet their views with precision and justice, one ought carefully and persistently to discriminate their doctrine from materialism. To do this may cost much exercise of subtlety; but the distinction is real, be it as subtle as it may. Rather, the new doctrine is in its exactest statement a mode of idealism; and this idealistic philosophy takes two different forms.

In the hands of most evolutionists, the philosophy is agnosticism - idealism arrested at the line of mere subjectivity and sceptical negation. It demands that the God of our familiar traditional religion, the omniscient Creator who sees in the beginning that consummate end when the children of his hand shall bear his perfect spiritual image, and who thus is eternally their Redeemer, shall abdicate in favour of the Unknowable - the omnipresent Power that doubtless is immanent in all things, and whose resistless infinity comes forth in the ever growing process of evolution, but whose nature and whose final goal are forever hidden from even possible knowledge; the Immutable Energy, of which we may declare neither that it is conscious nor unconscious, neither that it is material nor spiritual, but only that it is the Secret behind the Veil. 
But in the hands of others the philosophy of evolution becomes an affirmative idealism: the theory of the Unknowable gives way to the theory of Cosmic Theism, the Persistent Force to the Omnipresent Mind. God is made immanent in Natureas directly present throughout the immensity of the universe as each person's mind is to its own body. Every member in the vast whole, nay, every atom, is represented as instinct with God; yes, as being God in some limitation or other, and in some victorious expression or other, of his incessant energy. As declared in the threadbare lines of Pope, -

All are but parts of one stupendous whole, Whose body Nature is, and God the soul.

All things are accordingly but aspects in the selfvision of the one and only eternal Consciousness, whose ceaseless rending of his successive disguises, that he may at length appear to himself in his proper image, unconfined and unobscured, is the explanatory cause of that ever changing, ever broadening, and ever deepening stream of existences which we have come to name the Drama of Evolution:-

They change and perish all, but He remains; A moment guess'd - then back behind the fold Immerst of darkness round the Drama roll'd

Which, for the pastime of eternity, He doth himself contrive, enact, behold. 
One or the other of these philosophies now claims the right to supplant the venerable forms of old religion, and seems almost on the verge of effecting its desire. The science of our century, stimulated to unprecedented discovery by ideas derived from the philosophy that ushered the century in, comes at the century's close to the support of these ideas with its vast accumulations; and the new consensus of our time appears to gain its proper utterance, now in the philosophy of Herbert Spencer, and now in that Neo-Hegelianism regarding which the current question is, whether it can get its best expression by being read as Hegel darwinised, or as Darwin hegelised. The change that seems imminent, in whichever way interpreted, would be profound indeed, - far profounder than appears on the surface. Its revolutionary character is so little comprehended by the mass of the intelligent that many of the official teachers of Christianity, to say nothing of its less critical laity, not only dally with the new views, chiefly with Cosmic Theism, but openly embrace them, with no apparent suspicion of their hostility to the principles that are fundamental to the Faith. Yet the hostility is real; and it is not from any caprice of his merely private way of thinking, but from a genuine, even if obscure, apprehension of the things indispensable to this Faith, that Mr. Balfour in his Foundations of Belicf assails both forms of the new philosophy, which he 
prefers to designate Naturalism and Transcendental Idealism. Were the complete substitution of either for the philosophy underlying the older religion conclusively to take place, we of the Western civilisation should literally have entered a new world.

Many doubtless believe that we are in that new world already, and beyond return. But many, probably more, still hang back, disturbed by anxious questionings - by an inward struggle between the sense of authority in what seems truth declared by science and the sense of majesty in what is felt to be an ineffable good which the apparent truth seems to put in peril. For my own part, I side with those who feel that the vaunted new world of evolutional philosophy is of a portent so threatening to the highest concerns of man that we ought at any rate to look before we leap, and to look more than once. We ought to ask insistently what this new world really makes of mankind, of its vocation and its destiny, and we ought to insist upon an unevasive answer. Undoubtedly it may be said, and in so far said well, that the unfavourable bearing of a doctrine on hopes indulged by man cannot alter the fact of its truth. But we have at least the right, and in the highest case we have the duty, to demand that we shall know what its bearings on our highest interests are. If the truth bodes us ill, that very ill-boding is part of the whole truth; and though, unquestionably, we 
should have to submit to it even though it destroyed us, it cannot follow that we could approve of it or that we ought to approve of it. To glorify what is our destruction would be indeed to play the fool, and add to the tragedy of our being the anguish of selfcontempt.

It ought to be plain, and I think it will be plain on a careful and exact examination, that the so-called Philosophy of Evolution, when given such a scope as to make evolution the ground and explanation of the existence of mind in man, is destructive of the reality of the human person, and therefore of that entire world of moral good, of beauty, and of unqualified truth, which depends on personal reality for its being. This hostility to personality and its threefold world of ideal life is a trait belonging to every evolutional account of the mind in man, whether the account be made in terms of the agnostic or the cosmotheistic view of the Eternal Ground. Both views aim to explain the origin and progressive sustentation of the whole human consciousness by the merely productive causation exerted by that Ground. The Immanent God of the idealistic evolutionists is just as truly the sole real agent in producing and carrying on the consciousness of his creature, is just as incessantly and directly the creature's executive cause, as the Persistent Unknowable of the agnostic. The world of moral freedom, which is a fundamental 
postulate of the Christian Faith, is annulled by both conceptions alike; and while the theory of Cosmic Theism, if treated with such idealistic methods as those employed by Professor Joseph Le Conte in his later writings, may be made to provide for a quasi. immortality of the distinct single soul, we should nevertheless remember that the ever-present brooding of the immanent Cosmic Mind forever suppresses the possibility of real freedom, and consequently takes away from everlasting continuance all that could make the soul a genuine individual, and therefore all the moral worth that alone could give to continuance what religion means by Life Eternal.

Under a sheer evolutionary account of man, the world of real persons, the world of individual responsibility with its harmony of spontaneous dutifulness, disappears. With it disappears the genuine personality of God. An immanent Cosmic Consciousness is not a personal God. For the very quality of personality is, that a person is a being who recognises others as having a reality as unquestionable as his own, and who thus sees himself as a member of a moral republic, standing to other persons in an immutable relationship of reciprocal duties and rights, himself endowed with dignity, and acknowledging the dignity of all the rest. The doctrine of a Cosmic Consciousness, on the contrary, reduces all created minds either to mere phenomena or, at 
best, to mere modes of the Sole Divine Life, and all their lives to mere $\operatorname{eff} e c t s$ of its solitary omnipresent causation :-

When me they fly, I am the wings.

This discovery, that the leading conceptions of the evolutional philosophy are opposed to the vital conceptions underlying the historical religion of our Western civilisation, of course does not in the least settle the merits of the issue between these conceptions in the court of rational evidence. But the interests at stake touch everything that imparts to human life the highest worth, and all that our past culture has taught us most to value. These interests, it may well be contended, are so great as to justify us in challenging any theory that threatens them. Human nature is not prepared to face despair, until it shall have been proved beyond all question, and after a search entirely exhaustive, that despair must indeed be faced.

Amid all the clamour of the times in extolling evolution, then, it is eminently seasonable to ask, Just how much can the principle of evolution really do? Is it of such reach and such profundity as actually to serve for the explanation of everything known? To state the question more exactly, How far over the fields of being does evolution really go, and with unbroken continuity? Let us try to dis- 
cuss this question critically and definitively, and so let us ask, -

(I) Whether evolution really has no limits at all ?

(2) Whether it has not limits even within the universe of phenomena, and, if it has, what these limits are?

(3) If these limits, though recognisable, can still be passed, what is the only clue to the possibility of making evolution cosmically continuous?

But here many a reader will probably say, How can there be any serious question in this matter at all, at least for minds that have finally broken with external authority, and believe the human faculties, working upon the evidence of facts, to be the only judges of what is true? Has not science now spoken in this matter, and in words that cannot be reversed? To this I would reply, that on the question really started in the mind of our times, the question which I raise in this essay, science in its own proper function has absolutely nothing to say. The truth is, science never has said anything about it, and never will nor can say anything about it. Many scientific cxperts have no doubt had much to say in the matter, and oftenest in the interest of the evolutional philosophy. But they ought to get aware, and everybody else ought to keep aware, that when they talk of a universal principle of evolution, 
they have left the province of their sciences, and the very bounds of all science as such.

Of course, there is no longer any question at all as to the reality of evolution as a fact, within the specific region where it has been the subject of scientific inquiry. There is no question, either, of the use and importance of the hypothesis of evolution as a method of science, in that same definite and tested region. On this matter, it is the business of scientific experts alone to discover and to speak, and it is the privilege as well as the duty of philosophers, as of other people not experts in science, to listen to what the men of science report, and to accept it as soon as it comes with their settled consensus. But whatever some men of science may do in the way of philosophical speculation, science makes no claim whatever that evolution goes a hair's breadth farther than its scientific evidences carry it; and hitherto these evidences are strictly confined to the morphology and the physiology of living beings, and of living beings only - to the thread of descent by reproduction, convincingly traceable by observation and experiment from the lowest forms of plant life to the highest of animal. ${ }^{1}$

${ }^{1}$ It is of course not ignored here that the entire series of physiological phenomena is everywhere accompanied by a "parallel" or concomitant series of psychic or "mental" phenomena, which coördinately undergoes an evolution of its own. In fact, one might say, with many 
The extension of evolution from this limited and lowly scope in the region of life into a theory of cosmical reach, and, still farther, into a theory of the origin of life, and then of the origin of mind, is an act for which science furnishes no warrant whatever. The step into boundlessness is simply the work of philosophical speculation, as it always is. I do not mean to say that philosophical speculation is necessarily without warrant, or destitute of evidences of its own, more or less valid within its own field. But what I do wish to say is, that these evidences are not the evidences of science; that scientific eviclences must by their nature stop short of such sweeping universals; and that when either scientific men or the general public assume that such speculative extensions of principles reached in some narrow field of science have the support and the prestige of science, they are deluded by a soph. ism-a sophism really so glaring that its common prevalence is matter for astonishment, and might beforehand well be incredible. The correctness of this statement will appear as we go on.

No, our question is not in the least a question of science. It is only when men of science, or other of the biologists, that this psychic scries is but a part of "physiology" totally conceived; though the thread of genetic connexion is of course not at all the same as that in ploysiology proper. But this implication does not touch the question of the essential mind, the intelligent principle. See below, however, pP. I6-25. Cf. pp. 39-41. 
people fascinated by the powers of the scientific method, undertake to raise this into the universal method of philosophy that our question ever comes forward. Upon it science is reservedly silent. It is a question of philosophy alone; and philosophers, whether professedly such or not, who make this new and surprising claim for the method and evidences of science, must not expect to carry the day by mere proclamation. They must come to the bar of historic philosophy, and be judged by that Reason which is the source of philosophical and of scientific method both, and the sole authority to determine the limits of either.

Directing our attention first to the agnostic form of the new philosophy, and taking up the first of our foregoing questions, we find at once a fact of the greatest significance. Yet in the popular apprehension of evolution this fact is continually so ignored or neglected that its statement will likely enough come to many readers as a genuine surprise, and not improbably as a mystery hard to fathom. The fact is this: When the question is brought home whether evolution has no limits at all, the careful and really qualified advocates of the evolutional philosophy are found to be the most stringent deniers of the limitless range of evolution. Its 
limits, they say, are rigid and absolute: it reigns only in the field of phenomena, including the "outer" or physical world of the external senses, and the "inner" or psychical world open to mental experience, otherwise called "inner sense."

The distinction here implied is so very important that I shall surely be pardoned for going far enough into the explanation of philosophical technicalities to make it clear. It is the distinction between (I) the facts of direct experience - the realities that present themselves to our sensible apprehension, "outer" or "inner" as the case may be, forming a series of innumerable items arranged either by contiguity in Space or by succession in Time - and (2) a higher or profounder kind of reality which reason requires us to assume as the indispensable and sufficient ground for the occurrence and the ceaseless changing of the former, and, above all, for those changeless connexions of sequence and position which we observe among them, and which by common consent we designate as the laws of cause and effect, or of the uniformity of Nature. To mark the fact that the realities of the first sort are without other evidence than their presentation to our senses "outcr" or "inner," it is agreed in philosophy to call them "phenomena," that is, simply appearances in consciousness. To mark the counter-fact that the underlying Reality contrasted with appearances, 
and required as their explanation, is forever hidden from the senses, and is therefore without other evidence than that of pure reason, philosophical consensus names it a "noumenon," that is, a reality present simply to the reason.

Upon this distinction between the phenomenal and the noumenal the whole discussion hangs and turns. To the proposition maintained by evolutionist philosophy, that evolution has no application beyond phenomena and can have none, historic philosophy at once gives its assent and its authority. ${ }^{1}$ The dispute begins, only when the school of evolution goes on to place the whole of human or other living nature in the realm of the phenomenal, denying to the living, even as a psychic being, any noumenal reality of its own, and treating even the human person as a mere form in which, as in all other phenomena, the supersensible Noumenon, one and sole, appears; or, in other words, as a mere manifestation or effect of the Noumenon, which is held by the school to be omnipresent, immutable, immanent in all phenomena, indivisible and all-embracing, solitary and universal.

Beyond this point of agreement among all evolutionists, agnostic and pantheistic alike, the dispute opens further, and within the evolutionist school

1 Just as, at the same time, it condemns and discredits Positivism for its attempt to ignore this fundamental distinction, essential to the being of philosophy and expressive of the very nature of reason. 
itself, when those of the agnostic party go on to declare that the Reality beyond phenomena - which they insist exists as an "immutable datum of consciousness" - must be regarded as permanently the Unknowable. The dispute gets to its keenest when they base this agnostic dogma on the claim that nothing deserving the name of knowledge is attainable in any way except the method of natural science. To this extravagant estimate of scientific method, to the superficial philosophy of this method which it implies, and to the consequent construing of the Noumenon as unknowable, the pantheistic idealists demur, and go on to vindicate the complete knowableness of the Reality at the basis of experience by attempting to show Reason itself to be that Reality, which as perfectly self-knowing must be perfectly knowable to reason in men. The issue thus becomes implacable between the agnostics and these affirmative idealists; and it is only just to say that in the demurier to the overestimate of natural science and its method, in the criticism of the shallow analysis of the method, and in the protest against the finality of agnosticism, historic philosophy sides with these quasi-theists. The agnostic position, the largest historic view of philosophy would say, is an unwarrantable arrest of the philosophic movement of reason; and its unjustifiable character appears in the fact, which can clearly be 
shown, that it involves at once a petitio and a selfcontradiction.

This largest philosophy would no doubt also convict pantheistic idealism of an undue arrest of reason; but its first concern is to approve the protest of this form of idealism against the assault on the power of reason to reach absolute reality. It approves, too, when this idealism criticises the agnostic interpretation of the method of science, as a shallow analysis of what the method presupposes. Still, its condemnation of pantheism, even when pantheism is idealistic, is unyielding, and renclers its discredit of the logic employed by agnosticism only the more inexorable. Its justification in both of these adverse judgments will be our main occupation for the rest of this essay, but our first attention must go to what it declares against agnostic evolutionism. And let us turn, first of all, to the proof that this agnosticism, as just alleged, involves a self-contradiction and a begging of the question.

If it were indubitable that we can only know what our inner and outer senses tell us, - only the facts of present and past experience, - then "it needs must follow as the night the day" that we can know only phenomena, and that the noumenal Reality behind phenomena must remain forever unknowable. But to say, even with deep Tennyson (God save the mark!), that "we have but faith," that "we cannot know," that 
"knowledge is of things we see," is to dogmatise in the very premises of the debate, and to raid upon the central matter at issue. The question whether we have not some knowledge independent of any and all experience - whether there must not, unavoidably, be some knowledge a priori, some knowledge which we come at simply by virtue of our natureis really the paramount question, around which the whole conflict in philosophy concentrates, and on the decision of which the settlement of every other question hangs. To cast the career of a philosophy upon a negative answer to it, as if this were a matter of course, - which the English school from Hobbes onward has continually done, - is to proceed not only upon a petitio, but upon a delusion regarding the security of the road.

This placid and complacent delusion might far more fitly be called an isnoratio clenchi - an "overlooking of the thumbserew" - than the fallacy which actually has that name; for those who entertain it are blind to the snare laid for them in the very strueture of that experience on which they build their doetrine, and risk unawares the thumbscrew prepared by Kant. He suggested that experience may be not at all simple, but always complex, so that the very possibility of the experience which seems to the empiricist the absolute foundation of knowledge may depend on the presence in it of a factor that will 
have to be acknowledged as a priori. This factor issues from the nature of the mind that has the experience, and introduces into experience all that distinguishableness, that arrangedness, and that describable form, without which it could not be conceived as apprehensible or intelligible, that is, as an experience at all.

The almost surprisingly happy thought of $\mathrm{Mr}$. Spencer and his school at this juncture - to turn the flank of Kant and his "pure reason" by applying the conception of evolution to the origin of ideas, and thus explaining a priori knowing away - does not do the work it was contrived for. It is certainly adroit to say that cognitions which in us human beings are felt as irresistible, as if part of the nature of things and incapable of change or of alternative, are simply the result in us of transmitted inheritance; that our remote ancestral predecessors had these cognitions at most as associations only habitual, regarding which no incapability of exception was felt, and that our feeling them as necessities is merely the result of their coming to us through generation after generation of successive ancestors, handing on their accumulated associations in ever increasing mass and cohesion. But this clever stroke cannot get rid of Kant's suggestion, that in order to the solidifying of associations in any consciousness there nust be some principle-some 
spring - of association, of unification, of synthesis, in that consciousness itself. Nor can anybody merely by the suggestion of a counter-theory, however plausible, dispose of those profound and penetrating arguments of Kant's by which the great Königsberger shows Time and Space, for instance, to be a priori, and exposes the fact that every attempt to explain them as generalisations from experience must tacitly assume them already operative in the very formation of the experiences from which the generalisation is made. Without them, Kant's point is, the thinker could not make use of the experiences to generalise to them; he must have had them, and in forming cxperiences employed them already, in order to his having in the experiences the requisite characters on which to rest and support the generalisation.

The theory that the synthetic processes in our human consciousness are merely associations of habit, Hume, to be sure, construed as referring to each single mind only; and Kant's force in replying to him might at first seem owing to this neglect of the evolutional series in which experiences really run. But adding the vast enginery of xonic evolution to Hume's views really does nothing toward removing that weighty and piercing objection of Kant's. For even supposing all other cases conceded, whatever secming necessity of other ideas 
evolution and heredity might be assumed to explain, the attempt to explain by them the origin of our consciousness of Time must fall under the ban of Kant's saying. Time is presupposed in any association of sensible items at all; myriadfold is it presupposed in the ever accumulating, ever consolidating associations in the drift of evolution. It is the indispensable presupposition of our even figuring to ourselves the process of evolution, and it cannot have been transmitted to us except by having previously been acquired somewhere among our progenitors, more or less remote. Whan did it enter the stream of cvolution, and how?

Strive as one may, there is no escape from Kant's implication that not even evolution ${ }^{1}$ can produce Time in our consciousness - the perception of the infinite possibility of succession. For Time is the necessary presupposition without which evolving consciousness could not have the groupings of succession, hardening evermore, that are supposed to lead slowly on to the consciousness of Time as a neces. sary and immutable condition of experience. There is for the evolutionist no escape from Kant's

${ }^{1}$ Even the cosmic conception of evolution was perfectly familiar to Kant. In fact, Kant was the first to expound it in grand detail (in his Unizersal Ilistory of Nature and Theory of the Heavens), and he therefore cannot have failed to include it mentally in his sweeping assertion that there is a vicious circle in every attempt to found our consciousness of Time on generalisation. 
clutches, except he maintain either that succession can exist without Time, or else that Time is per se itself a thing, instead of a relating-principle for things. If he take the former alternative, he falls into Kant's clench more hopelessly than ever, for he will have to tell what, in that case, succession intelligibly is. If he take the latter, he will recede into antiquated metaphysics, which talks about existence per se, out of all relation to minds, and which, at any rate in respect to the nature of Time, received its quietus in Kant's Transcendental Asthetic.

The cautious thinker, then, who would estimate the value of agnostic evolutionism in the light of the history of philosophical discussion, will join in the verdict that the current philosophy of evolution is guilty of the fallacy of petitio when it offers its argument for the Unknowable as if it were a proof conclusive. The argument rests on a parti pris in the funclamental dispute in philosophy, especially in modern philosophy, and so leaves in the air the whole system built upon it. A much more serious matter is, that by its neglect of Kant's profound and hitherto unrefuted considerations, and by disregarding the presumption thus established in favour of the opposing view, agnosticism draws upon itself the discredit of philosophising somewhat in the lark, and not in the wide daylight of entire historic thought. Far from being the conclusive truth which its tone of so conficlent 
propagandism would imply, and which the throng of its generally intelligent but inexpert readers are prone to take for granted, the agnostic system appears to the critical student of philosophy as logically an open question at best.

The self-contradiction of agnosticism - to pass now to its second alleged defect - is a characteristic which it shares in common with other philosophies that fall short of a view completely comprehensive. The selfcontradiction comes out in a peculiar way, particularly interesting for the critical history of thought. It may be made apparent as follows. The system maintains at once the two propositions, (I) that all knowledge is founded wholly on sense-perception, physical or psychic, and is consequently restricted to the objects and items of experience, that is, to phenomena merely; and (2) that the Reality beyond phenomena is nevertheless an immutable datum of consciousness, that is, an unquestionable certainty, or, in equivalent words, a matter of unqualified knowledge. In short, it is maintained that we can only know by means of sense, and yet can really know that the supersensible exists; that our cognitive powers are confined to the field of phenomena, and yet that they somehow penetrate beyond that field sufficiently to know that a Noumenon is real. We are naturally led to ask, By what strange power is this feat accomplished? - by what criterion of truth is this certainty tested? Of 
course it cannot be by sense, for the object is supersensible; how, then, is it managed? We get this answer: We know the truth that the Unknowable exists, by the criterion of all truth, namely, the "inconceivability of the opposite." But if this criterion really says anything in support of genuine certainty, it says that a pure conception of the mind, going quite beyond the literal testimony of sense, is objectively valid, in and of itself.

Manifestly, the only way of escape from this very awkward conclusion, so plainly contradictory of the prime thesis that our knowledge rests on sense alone and is confined to things of sense, is to say that inconceivability means nothing but the incapacity which limited experience begets in us - our impotence to think beyond the bounds built for us by the accumulated pressure of hereditary impressions. But here, if we would maintain the empiricist theory of knowledge in its consistent integrity, we are confronted with two difficulties: (I) How can impotence to pass the limits of experience suddenly be transformed into power to pass them and pierce to a Noumenon, even as barely existent? (2) How can our incapability of conceiving the opposite of cxistence for the Noumcnon mean anything more than that we are so hemmed in by the massed result of our sense-impressions as to be incapable of relcasing our thoughts from their mould? - that we must think as sense compels us, 
and are unable to tell whether the thinking means anything more than its own occurrence, or not? Construed with rigorous consistency, then, the existence of a noumenal Unknowable as "an immutable datum of consciousness" turns out to mean nothing but this : That our conceptions are built for us in such irresistible fashion we cannot help supposing there is such a Noumenon; but whether a genuine Reality answers to this helpless thought, there is nothing to indicate.

There thus comes to light a more secret and more deeply constitutional contradiction in this agnostic scheme - the contradiction between the merely evolutional origin of our power of thought and the reality of that Unknowable from which the system derives its main agnostic motif. Here we learn, if we attend to what the situation means, that we cannot affirm an absolute Reality and then stop short, with the result of leaving it entirely vacuous and blank. If we can trust our conceiving powers or our judgment in the transcendent act of asserting the reality of the Noumenon, why should we be smitten with sudden distrust of these supersensible powers when we come to the problem of knowing the nature of this transcendent Being? Surely there ought to be shown some justification for this arrest of the transcending cognition, this apparently arbitrary discrimination between one of its acts and other possible similar acts. It will not do to plead here that the Noumenon 
is $p o r s c$ supersensible, but that the reach of our conceptive powers, on the contrary, is limited to the world of sense. If we assume that our cognising the existence of the Noumenon is anything more than an illusion, we have already granted to one of our conceptions the privilege of overstepping this limit.

Thus at every turn the inherent inconsistency and inner contradiction lurking in the evolutional explanation of mind, with its consequent doctrine of mental limitation, comes into light. The noumenal changeless Energy, incessant and ubiquitous, is rightly felt by Mr. Spencer and his school to be indispensable to the explanation - yes, to the very existence - of evolution. Without it no new form could arise among phenomena; nor could there be such a fact as variation of species in response to varying environment, or as natural selection resulting from a struggle for existence. In short, the Unseen Power must be a certainty, if evolution is to be, and is to work; yet when evolution exists, when it works with the unbounded sweep clesired, and mind becomes its product, then mincl can have no faculty by which to reach the certainty of an Unseen Power, since consciousness is then reduced to sense alone, to senseperceptions and abstractions from them.

In this impotence of the principle of evolution to cross the break between the phenomenal and the 
noumenal, displayed, as it is, in such an apparel of contradictions and assumptions, the philosophic range of evolution finds its First Limit.

\section{II}

Passing to our sccond question, we ask: Can evolution be made validly continuous throughout the world of phenomona? Here we speedily become aware that it cannot have even this compass, except at the cost of undergoing a change of meaning in kind. The primary meaning of evolution is the meaning proper to the world of living beings, in which it had its first scientific suggestion, and where alone its scientific evidences are found. But biological evolution - the only evolution thus far known to science - means not only logical community, or resemblance for observation and thought, but also likeness due to descent and birth; due to a physiological community, through the process of reproduction. It is directly dependent on the generative function, ${ }^{1}$ and its native meaning is lost when we pass the bounclaries of the living world. What is it to mean when it has lost its first and literal sense? What is the continuous thread by which a unity of development is to hold, not only among living beings, but also among those without life, since it cannot any longer be physiological descent? How is this

1 Either sexual or asexual (by fissure, etc.), as the case may be. 
chasm, that now comes into view between the inorganic and the organic, to be bridged?

Empiricist principles would fain bridge it with some element of sensible experience, by some hypothesis made in terms of such experience alone. There is no hypothesis of this kind, however, but that of "spontaneous generation," - whatever this handy phrase may mean. This hypothesis historic philosophy and recent science alike correctly designate as a generatio aquivoca, and they show that all the indications of careful biology are steadily more and more against the assumption which it covers. The logical march of the notion Evolution here suffers a certain arrest; the thread of continuity disappears from the region recognised by agnosticism as verifiably known, and it seems to vanish into something unknowable. We instinctively ask, as we before asked about the unknowable Noumenon, Why should we believe that such a continuity exists at all ? How can there be any evidence of its actuality, if there is no real evidence but the evidence of experience?

In this break between the inorganic and the organic, evolution, as a principle of such continuity as philosophic explanation requires, finds its Second Limit.

\section{III}

But, coming now to our third question, continuity in some sense or other - a logical or intelligible 
resemblance, and a continued progression of resem. blance, among all the parts of the inorganic world, and between the parts of the inorganic and those of the organic too - is to our mental nature indispensable. What is the true sense in which the reality of this continuous connexion ought to be taken? Some explanation of it is for our intelligence imperative. It cannot mean literal descent by physiological generation; it cannot be by reproduction through sap or through blood. What, then, can it mean - what alone must it mean? Inexplicability by anything merely sensible - even psychic, when this is taken simply as the sensibly psychic-here shows up plainly. If the notion of continuous genesis is to be made apprehensible to our understanding, if it is not to vanish into something utterly obscure and meaningless, the meaning for it must be sought and found in some mode of mind - of our mind - quite other than the mode of sensc. But such a mode the agnostic interpretation of evolution, and, reciprocally, the evolutional interpretation of mind as originating out of non-mind, necessarily denies.

At this juncture, then, where a new break is discovered, - the break between physiological and logical genesis, - the philosophical reach of evolution betrays its Third Limit. 


\section{IV}

The preceding result is recognised-in fact, is proclaimed - by agnostic evolutionism itself, in its tenet of an Omnipresent Energy, whose existence it maintains as a certainty, but whose nature it declares inscrutable. This inference of some necessary noumenal Ground is the deep trait in $\mathrm{Mr}$. Spencer's doctrine, answering to the true nature of the philosophic impulse, and constituting the profoundest claim of his scheme to the title of a philosophy. But the dogma that the nature of this Ground is past finding out really means that the universal resemblance among phenomena of every order - the mysterious kinship, not only of the inorganic and the organic, but of the entire physical and physiological world and the psychic world - must be accepted as a dead and voiceless fact, a "final inexplicability," as Stuart Mill used to say. But surely philosophy means explanation, else it is not philosophy; surely, too, a "final inexplicability" does not explain. While, then, historic philosophy, disallow as it may their theory of knowledge, goes heartily along with Mr. Spencer and his school in their metaphysics thus far, it declines to arrest its progress with them here, and pronounces that in the Something at the heart of universal phenomenal resemblance, still to be explained, but by thcir 
form of evolutionism confessedly inexplicable, evolution as an explanatory principle comes upon a fatal check.

In this self-confessed inability to supply any final explanation of the great fact upon which its own movement rests, evolution as a principle of philosophy, that is, of thorough explanation, exposes its Fourth Limit. There is a bottomless chasm between the Unknowable and the Explanatory.

\section{V}

When the philosophic progress has arrived at this point, however, its further pathway becomes evident, and consistent thought will discover what this limiting Something is. It may provisionally be called, correctly enough, the Omnipresent Energy; it might well enough be called by the apter and still less assumptive title of the Continuous Copula. We can now determine the real nature of this undefined Something; and I say its nature purposely, and with the intention of discriminating; for our immediate settlement will only be in regard to its kind, and not as to the specific being or beings, amid a possible world of noumena, in which that kind is presented. We cannot, by our next philosophic advance, determine forthwith whether the being having the nature referred to is the absolutely Ultimate Being of that kind; but the kind may be ultimate, even 
though the being be not so. It will be an important step, however, if we can show now what the nature of the yet undetermined Copula is. Moreover, it will at once appear in what being, known to us, the proximate seat of that nature is - the seat first at hand, relatively to the connexion between the parts and species of Nature, and to the evolutional character which that connexion undeniably wears.

It is a common characteristic of most philosophies that they proceed somewhat precipitately with the act of noumenal or metaphysical inference, and, passing human nature forgetfully by, leap at once to the being of what they call the Absolute Reality, and to the determination of the nature belonging to that. This is like settling the nature and reality of the landscape while ignoring the nature and existence of the cye that sees it and in truth gives it being, or helps to give it being. Not the Absolute Being, not the Absolute Mind, or God, which the reality of evolution may finally presuppose, but rather mind as a nature or kind, and, proximately, mind in man, as the immediate and direct expression of the Copula whose nature we seek to know, must be the first and unavoidable Reality reached by metaphysical cognition.

That this is the accurate truth will become apparent by analysing the conception of evolution and 
noting in the result the conditions essential to the conception if it is to be taken as a real principle as wide as the universe of possible phenomena. It will readily become evident that the elements uniting in the notion Evolution are the following:

(i) Time and Space. - The conception of evolution is a serial conception, relating only to a world of items arranged in succession, or else in contiguity more or less close, or more or less remote. But Time and Space are the media without which this seriality essential to evolution could neither be perceived nor thought.

(2) Change and Progression. - Evolution is not a static but a dynamic aspect of phenomena. Under evolution, the items in the time-series and the spaceseries are viewed as undergoing perpetual change; and not simply change, but change that on the whole is marked by stages of increase in complexity and diversity of being, so that the world of phenomena, as a whole, is conceived as gradually attaining a greater and greater fulness and richness of life. The expert in biology would very rightly tell us that the "ascent of life" is extremely irregular; that there is decline and decadence as well as growth and aggrandisement. But cven the biologist finds the persistent ascent in life when life is regarded in the large, in the range from the lowest plant to the highest animal, and through the series 
of the great genera within these kingdoms. And when we take the still larger view of cosmic evolution, this element of progression or ascent becomes the central one in the conception.

(3) Causation. - This would be better described as natural causation or physical causation, in order to distinguish it, by an apt term, from another element which, we shall presently see, enters into evolution, and which we should correspondingly name metaphysical or supernatural ${ }^{1}$ causation. The causation we are considering now is directly involved in evolution by the preceding elements - Change and Progression. We should mean by it the Mechanism, the Chemism, or the Association, involved in the changes of phenomena. The habit of popular speech and surface thought is to regard and describe causation as a process by which one phenomenon "produces" another. But an exacter thought states the two as simply in a certain relation, the relation of Causc and Effect. To such thought, causation holds both in physical and psychical succession, and means a peculiar connexion, or nexus, between phenomena. The philosophy of evolution most current, based on the dogma of the sense-origin of all knowledge, and on the sole and final efficiency of the method of

1 The reader is warned that in interpreting this word in the present volume, he must divest himself of all its magical and thaumaturgical associations. It means nothing but supersensible, rational, or ideal. 
science, unanalysed to its true presuppositions, consistently interprets this connexion into the merely regular succession of the past - a sequence merely de facto; but if we thoroughly consider what is logically presupposed in scientific method as actually used by the competent, we shall readily see that it should be interpreted as nccessary and irreversible succession, a sequence inevitable forever. For the vital process in scientific method is induction, or generalisation; and the secret of it, as actually employed in scientific practice, lies in taking observed successions in phenomena, and when with the help of the various methods of precision-agreement, difference, joint agreement, concomitant variation - they are brought to represent exactly what occurs, then suddenly giving to these merely historical successions the value of universal laws, having a predictive authority over the future in perpetumm.

If in this process there is always a cautious reserve in the mind of the practised and seclate man of science, - as indeed there is, - the reserve has no reference to the amazing final act of generalisation: all the anxieties of the expert are about the precision of his facts. His instinctive assumption about the gencralisation is, that, when once the particulars are settled, this process takes place of itself, is matter-of-course, is resistless and flawless: if there is error anywhere in the scientific proced- 
ure, it is in the observations and experiments, or in the sifting and correcting of them by the methods of precision. The moment we are satisfied that our particulars are exactly settled, that moment the generalisation becomes irresistible, and we declare that a law of Nature is disclosed.

But now the crucial question is on us: What prompts and supports the generalisation? It cannot be just the facts; for, simply by themselves, they can mean nothing but themselves. What is it, then? The implication is not to be escaped: the ground of every generalisation is added in to the facts by the generalising mind, on the prompting of a conception organic in it. This organic conception is, that actual connexions between phenomena, supposing them to be exactly ascertained, are not simply actual, but are necessary. The logic of induction thus rests at last on the mind's own declaration that between phenomena there are connexions which are real, not merely apparent, not simply phenomenal, but noumenal; that the reality of such connexions lies in their necessity, and that the processes of Nature are accordingly unchangeable. But the implication most significant of all in this tacit logic is the indispensable postulate of the whole process; namely, that this necessity in the conncxion of phenomena issues from the organic action of the mind itself. The mind itself, then, if the processes 
of science are to be credited with the value of truth, is the proximate seat of that nature for which we are seeking as explanatory of what the Continuous Copula really is. At next hand to Nature, our mind itself - the mind of each of us - is that Copula. This truth will become clearer as we proceed with the analysis of evolution.

(4) Logical Unity. - It is of course obvious that evolution, like every other scheme of conception, must have its parts conformed to the laws of logical coherence, and that in this sense Logical Unity is a factor in the very notion of evolution. But we can now see that it is present there in a sense far profounder and more vital. In fact, according to the result of the preceding step in our analysis, Logical Unity is simply the direct and manifest version of causation in terms of mind, which we just now came upon as the authentic meaning of the causal Copula. As the logic of induction sends us directly to the organic or a priori activity of thought for a warrant of science, and thus indicates mind to be the real nature of the Omnipresent Energy, it now becomes evident that the vague thread of kinship running through all phenomena is the thread of logic, and that the suggested common parentage of all is just the parentage of thought. The unity of logic, the unity of congruous conceptions, is the only unity that joins by one unbroken tie the diverse forms of 
the inorganic, the organic, and the psychic, and thus spans all the breaks between mechanical, chemical, physiological, and psychic genesis, by a continuous logical genesis, and at the same time closes the gap profound between the so-called Unknowable and explanation.

The bond of kindred uniting all these beings and orders of being, so contrasted and divergent, so incapable of any merely natural or physical generation one from the other, is the inner harmony between the lawful members in a single intelligible Plan, issuing from one and the same intelligent nature. In short, the only cosmic genesis, the only genesis that brings forth alike from cosmic vapour to star, from star to planetary system, from mineral to plant, from plant to animal, from the physiological to the psychic, is the genesis that constitutes the life of logic - the genesis of one conception from another conception by virtue of the membership of both in a system of conceptions organised by an allembracing Idea. This all-determining Idea can be nothing other than the organic form intrinsic in the self-active mind, whose spontaneous life of consciousness creatively utters itself in a whole of conceptions, logically serial, forming a procession through gradations of approach, ever nearer and nearer, to the Idea that begets them each and all. By this it becones plain that the theme of evolution, if it is to be indeed 
cosmic and reign in all phenomena, must have all its previous elcments - succession, contiguity, causal connexion, generation (mechanical, chemical, physiological, and psychic) - translated upward into this logical genesis. We have just seen that this has its source in the mind's organic Idea, or primal selfconsciousness of its own intrinsic coherence, its own variety in unity.

(5) Final Cause, or Ideality. - This, the mind's consciousness of its own form of being as selfconscious, - that is, spontaneously conscious and spontaneously or originally real, - is the ultimate and authentic meaning of causality. In the cause as self-conscious Ideal, the consciousness of its own thinking nature as the "measure of all things," - as "source, motive, path, original, and end," - we at length come to causation in the strictest sense, Kant's Causality with freedom. It might happily be called, in contrast to natural causation, supernatural ${ }^{1}$ causation; or, in contradistinction from physical, metaphysical causation. The causality of self-consciousness - the causality that creates and incessantly re-creates in the light of its own Idea, and by the attraction of it as an ideal originating in the selfconsciousness purely - is the only complete causality, because it is the only form of being that is unqualifiedly free.

1 Again a caution against false associations with this word. 
Here, in seeing that Final Cause-causation at the call of self-posited aim or end - is the only fuli and genuine cause, we further see that Nature, the cosmic aggregate of phenomena and the cosmic bond of their law which in the mood of vague and inaccurate abstraction we call Force, is after all only an effect. More exactly, it is only a cause in the sense in which every effect in its turn becomes a cause. Still more exactly, it is the proximate or primary effect of the creating mind; within and under which prime effect, and subject to its control as a sovereign conception in the logic of creation, every other effect - every phenomenon and every generic group of phenomena - must take its rise, and have its course and its exit. Throughout Nature, as distinguished from idealising mind, there reigns, in fine, no causation but transmission. As every phenomenal cause is only a transmissive and therefore passive agent, so Nature itself, in its aggregatc, is only a passive transmitter. But because of its origin in the Final Causation of intelligence, its whole must conform to the ideal that expresses the essential form of intelligent being, and all its parts must follow each other in a steadfast logical ascent toward that idcal as their goal. Thus Teleology, or the Reign of Final Cause, the reign of ideality, is not only an element in the notion Evolution, but is the very vital cord in the notion. The conception of evolution is founcled at 
last and essentially in the conception of Progress: but this conception has no meaning at all except in the light of a goal; there can be no goal unless there is a Beyond for everything actual; and there is no such Beyond except through a spontaneous ideal. The presupposition of Nature, as a system undergoing evolution, is therefore the causal activity of our Pure Ideals. These are our three organic and organising conceptions called the True, the Beautiful, and the Good. They are the fountains, severally, of our metaphysical and scientific, our asthetic, and our moral consciousness. ${ }^{1}$ They are the indispensable presuppositions without which our judgment that there is progress would be impossible : this judgment once vacated, the reality and even the conception of evolution alike disappear. Yet there is no existence for them, and therefore no authority, cxcept the spontancous putting of them by and in our thought. Here we reach the demonstration that evolution not only is a fact, and a fact of cosmic extent, but is a necessary law a priori over Nature. ${ }^{2}$ But we learn at the same time, and upon the same evidence, that it cannot in any wise affect the a priori self-con-

1 It must not be supposed, however, that they do not themselves constitute a system, in which the Good is the organic principle, and this itself the first principle of intelligence.

${ }^{2}$ As is maintained also by Professor Joseph Le Conte. See his Evolution and its Relation to Religious Thought, p. 65. New York: D. Appleton and Cu., r\$92. 
sciousness, which is the essential being and true person of the mind; much less can it originate this. On the contrary, we have seen it is in this a priori consciousness that the law of evolution has its source and its warrant. Issuing from the noumenal being of mind, evolution has its field only in the world of the mind's experiences, - "inner" and "outer," physical and psychic; or, to speak summarily, only in the world of phenomena. But there, it is indeed universal and strictly necessary.

In the light of the foregoing analysis, a thorough philosophy would now move securcly forward to the conclusion that the Continuous Copula required in evolution, the secret Active Nexus without which it would be inconceivable, is at nearest inference the spiritual nature or organic personality of man himself. ${ }^{1}$ Whether there is not also involved a profounder, an absolute Impersonation of that nature, to be called God, is a further and distinct question, legitimate no doubt, but not to be dealt with till the immediate

1 The reader will notice that all the argumentation which follows really proceeds upon the tacit implication that this intelligent nature is not limited to man, but is, in whatever degree of phenomenal manifestation, common to all living beings. It is stated in terms of human nature, first, because, as brought out below, it is the human being who raises the question here argued, and argues it; and, secondly, because in man alone do we come by the path of experience upon its rounded Type. 
requirements of the logic in the situation are met. These requirements point us, first and unavoidably, to the intelligence immanent in the field of evolution, the intelligence of man and his conscious companions on the great scene of Nature; and, at closest hand of all, - first of all, - to the typical intelligence of man simply. The whole question, so far as anything more than conjectural evidence is concerned, is man's question: he is the witness to himself for evolution; in lis consciousness, directly, and only there, does the demand arise for an explanation of it; in himself he comes upon the nature of mind as directly causal of the form in Nature - of the ideally genetic connexion holding from part to part in it and of the reality of progress there as measured by his ideals of the True, the Beautiful, and the Good.

Here, now, we arrive at the point where we naturally pass from the criticism of agnostic evolutionism to that of pantheistic idealism, or Cosmic Theism. We promised, you will recollect, to attend carefully to what the fullest historic philosophy has to say in judgment of this theory of the world as well as of the other. We shall see that this world-view gains much over the agnostic, and yet that it falls short of the explanatory ideal.

The commanding question, let us remember, is whether the mind in the world, and preëminently the mind of man, is only a phenomenon like the objects 
it perceives in Time and in Space, or is transcendently different from these, and noumenal. The favourable significance of Cosmic Theism for man and his supreme interests, and of every other species of affirmative idealism, lies in its passing beyond the agnostic arrest at the Omnipresent Energy, by its recognition that the logic of evolution, as depicted in such an analysis as we have just made, requires in the Noumenon a self-conscious nature. This is a step greatly human, because it opens somewhat more widely than agnosticism, and certainly more affirmatively, the chance for hope that the existence of no conscious beings may fail of everlasting continuance and fulfilment. Yet it has also an unfavourable bearing on the highest human aspirations, not only because it fails to reach immortality as an assured and necessary truth, ${ }^{1}$ but for the far graver reason that it decidedly tends to leave all individual minds in the world of mere phenomena; or, if it permits them to be conceived of as sharing in absolute reality, by being parts or modes of the Sole Noumenon, deprives them by this very fact of that real freedom which is essential to personality and to the pursuit of a genuine moral icleal. ${ }^{2}$ It is there-

1 See I'rofessor Royce in The Conception of God, pp. 322-326. New York, The Macmillan Company, $1 \$ 97$.

2 For the thorough, if unwitting and unwilling, acknowledgment of this by a leading representative of this philosophy, see Professor Royce's 
fore all-important for true human interests that a reality unqualifiedly noumenal shall be vindicated not only to human nature, but to each particular human mind. If the reasoning about to be employed for this purpose should seem to the reader to carry its conclusions widely beyond man, - as wicle as all conscious life, of which human consciousness must now be regarcled as only the completed Type, - I know no rcason why men should hesitate at this, or grudge to living beings whose phenomenal lives are at present less fulfilled than their own the chance for larger existence that immortality and freedom give. But let us come to the argument.

Reverting to our analysis, we may now elearly see that the elements essential to evolution are simply the elements organic in the human mind. - Evolutional philosophy, of whatever form, teaches that these elements - Time, Space, Causation, Logical Unity, Ideality - are, in the human mind, the results of the process of evolution. The agnostic evolutionist holds that they are gradually deposited there through associations ever accumulating in the long experience of successive generations, until at length they become in us practically inclissoluble, though theoretically not. The pantheistic idealist

discussion of this question in The Conception of God, pp. $292 \mathrm{f}$., $305 \mathrm{f}$, 315 mid. (where the last sentence, if logically legitimate, would read, "The antinomy is [not] solved"), and $32 \mathrm{I}$, cf. the foot-notc. 
penetrates behind the associations, to explain their possibility and their origin by his doctrine that the rational elements have their seat, not directly in the mind of each man, but in the eternal and universal Mind to which he gives the name of God. In neither view is a priori consciousness admitted in the individual person as individual, nor in the human mind at all, as spccifically human. In fact, by the associative agnostic method, which would build these elements up outright in the course of evolution from what seems to be their assumed non-existence, they are all put as if explicable by evolution. But as our analysis has shown, they are all, on the contrary, prerequisites to the existence of evolution as well as to our conceiving of it. Legitimately, they are likewise incxplicable by the pantheistic method of seating them a priori in God, to be thence gradually imparted to minds as they are slowly created by the process of psychic evolution; for this ignores the fact that a priori cognition, by virtue of its pertinent proofs, is an act in the mind of each particular conscious being, be the development of the mere experience of such being as low as it may. The proper interpretation of a priori consciousness, at the juncture where it is established, is at most, and at next hand, as a human, not a divine, original consciousness, and, indeed, as a consciousness interior to the individual mind. 
As for the proofs of a priori consciousness in us, these have perhaps been clearly enough given in the analysis by which it was shown that the several elcments are'prerequisite not only to the conception of evolution, but to our human experience itself, and to the system of Nature into which they organise that experience. This is the case, at any rate, with all the elements except Time and Space, and is emphatically so with the most important conditions of the notion Evolution, namely, the Pure Ideals; and, among these, preëminently with the Moral Ideal. But as a difficulty about the a priori or ideal character of Time and Space disturbs many minds, it may be necessary in part to restate what has already been said in proof of the idcality of Time, and to reinforce this by certain new points. I speak only of Time, because the same reasoning, obviously, must also apply to Space.

The necessarily a priori nature of Time can be shown, even should we grant for the sake of argument that the dispute over hereditary transmission of acquired characters, now going on in the school of evolution between the Spencerians and Weismann, were decided in favour of the former, and that transmission were a fact. For transmission of acquired habit can never explain the infinity and necessity of Time. Nor can this infinity and necessity be explained away by the theory that it arises from a confusion of 
conceptions - of infinity with mere indefiniteness, and of necessity with mere subjective inability to get rid of a hardened habitual association. These properties of Time, taken, too, in their unrestricted meaning, are unreservedly true by Mr. Spencer's own criterion the "inconceivability of the opposite."

Moreover, as pointed out near the beginning of the present essay, they are conditions precedent to forming any habitual association at all. It is just in thinking all these elements in an active originating Unit-thought, or an "I," that the essential and characteristic nature of man or any other real intelligence consists. Such an originating Unit-thinking, providing its own element-complex of primal thoughts that condition its experience, and that thus provide for that experience the form of a cosmic Evolutional Series, is precisely what an intelligent being is. Thus creatively to think and be a World is what it means to be a man. To think and enact such a world merely in the unity framed for it by natural causation, is what it means to be a "natural" man; to think and cnact it in its higher unity, its unity as framed by the supernatural causation of the Pure Icleals, supremely by the Moral Ideal, is what it means to be a "spiritual" man, a moral and religious man; or, in the philosophical and true sense of the words, a supernatural being - a being transcending and yet including Nature, not excluding or annulling it. 
Evolution itself, then, and not evolutional philosophy merely, in finding in this rational nature of every mind its proximate source and footing, finds there its Final Limit.

\section{VI}

We have here reached the proof that what is most distinctively meant by Man is not, and cannot be, the result of evolution. Man the spirit, man the real mind, is not the offspring of Nature, but rather Nature is in a great sense the offspring of this true Human Nature. As we have seen, the only thing that can overspan all the breaks which evolution must pass if it is to be a cosmic principle, is idealising thought - the humane nature, in its highest, largest sense. It is this that adds in to the chaotic insignificance of the mere mass of things the lofty theme of ever-ascending Progress. Apart from this ideality, there would be no cosmic order at all, no Manward Procession. Yet, that the whole of Nature cannot be referred to men alone, or to other conscious beings directly on the scene of Nature; that the existence of an absolutely universal form of their nature is required for her cosmic being, - this will not be denied when our psychology is as exact and all-recognising as it should be. Such a psychology will discover within the complex of experience, human or other, in addition to the system of a priori elements 
that constitutes the core of intelligence, another component. This other component, which Kant named "sensation," to mark the fact that it expresses something insufficient in us, something which must be supplemented to us by reception ${ }^{1}$ from what is not ourselves, is best interpreted as a limit which points to the coöperation ${ }^{1}$ of some other noumenal being with men and other conscious centres. But when once the conditioning relation is shown to exist from man toward Nature, as the scene of evolution, instead of from Nature toward man; when once it is seen as Huxley, the protagonist of evolution, at last came so clearly, if so unawares, to imply ${ }^{2}$ - that in Conscience at least, the ideai of Righteousness, man has that which no cosmic process can possibly account for, but to which, rather, the cosmic process presents an aspect of unmistakable antagonism, then our way will come open to determine the coöperating Noumenon, the Supreme Reality, as also having this higher human nature, as having it in its ideal perfection, and

1 The reader should beware not to interpret these terms "reception" and "coöperation" literally, that is, in the light of ordinary natural or efficient causation only, as it is our bad uncritical habit to do. Their genuine interpretation must be by means of final cause. But see the essay on "The IIarmony of Determinism and Freedom," pp. 332-351.

2 See his Romanes Lecture on "Evolution and Ethics," in his Collected Essay's, vol. ix ; especially pp. 79-\$4, and Note 20 . In these pages and in this Note, their great author holds out for the inclusion of Conscience, in some vague way, in the evolutional process as a whole; but he has demonstrated an antagonism that is fatal to the hypothesis. 
we shall have found the entrance to the path toward the demonstration of God. For the survey and the tracing of that path, this is neither the place nor the occasion. 1

\section{VII}

Let us turn back now to the point struck upon near our beginning, - to the question, Is evolution consistent with the Christian religion? It is a trite question now, perhaps overworn; and probably very many readers think that it is already settled in the affirmative. Yet it is a question of the utmost pertinence, and ought to be pushed to a decisive but discriminating answer. There are those who are only too ready with an answer decided enough, but unfortunately they are of two opposed extremes. Both parties are of one mind as to the incompatibility of Christianity and evolution; but while the one says that all evolution must therefore be anathema, the other jeeringly retorts, "So much the worse, then, for your religion!" And the loose verdict of the times is doubtless in favour of whatever can be made to appear as the cause of science. The trouble with such disputants is, that their assertions are far more decided than discriminating, and so are not in any final sense decisive. We may justly clain, however, that the outcome of

${ }^{1}$ For one form of the argument here alluded to, see pp. $35 \mathrm{I}-359$, below. 
our inquiry into limits enables us to answer this question with the definite discrimination required. This outcome shows us the narrow limits of evolution as a doctrine of unpretending science. Still more significantly, it brings out the unavoidable limits of evolution as a philosophy, as regards the origin of man and the nature of the eternal creative Power. In short, it teaches us that the answer to the question whether Christianity and evolution are compatible, turns wholly on the stretch that evolution has over existence, especially over human nature.

But it is time we all understood how finally at variance with the heart of Christian faith and hope is any doctrine of evolution that views the whole of human nature as the product of "continuous creation," - as merely the last term in a process of transmissive causation. The product of such a process could not be morally free, nor, consequently, morally responsible. It must needs be merely a mass of "inherited tendency"; and, howsoever fair its effect might appear, no life of genuine dutifulness, no life of goodness freely chosen, could enter into its being. As a speculative possibility there may be ways of conceiving man thus "continuously created" and yet in such relations to the Creator as would provide for his immortality, in the sense merely of his everlasting duration; Pro- 
fessor Le Conte has expounded some of them impressively. ${ }^{1}$ It is doubtless with a view to such conceptions that ministers of religion nowadays so often say, "The evolution of man is well enough, if biologists will only leave us a Personal God at the beginning of the process." But that if, when conjoined with that consequent, is an if of tragic meaning: the Power behind evolution, were the whole of man evolved, could never be a personal God - in short, would not be a God at all. For it is the essence of a person to stand in a relation with beings having an autonomy, in whom he recognises rights, toward whom he acknowledges duties. No conception of a professed God that fails to give this moral quality, can by providing continuance of existence, however lasting, compensate for the loss; since it should never be forgotten, that, when moral freedom is cancelled, immortality can have no moral worth, no genuinely human dignity, and consequently cannot answer to what we mean by the hope of Eternal Life. But hope of immortality as Life Eternal and faith toward Duty - fealty to our human dignity as moral free-agents, quickened by fealty to God as the grounding Type of that freedom - are the very soul of Christian Faith. The impartial philosophical observer cannot but be filled

1 See, especially, the statement in his contribution to The Conception of God, pp. 75-7S. 
with surprise, then, at seeing official teachers of the Christian Religion so strangely oblivious of real bearings as to accept - yes, sometimes proclaim an evolution unlimited with respect to man as consistent with their faith. Plain in the doctrinal firmament of every Christian, clear like the sun in the sky, should shine the warning: Unless there is a real man underived from Nature, unless there is a spiritual or rational man independent of the natural man and legislatively sovereign over entire Nature, then the Eternal is not a person, there is no God, and onr faith is wain.

Doubtless, as I have already said, planting the contrast between Christianity and evolutional philosophy in this firm way, in itself settles nothing as to which of the two is true. Indeed, responding to the impression so strongly made by later science, one might well say that the onus probandi had been shifted, and that the true form of the pressing question should be, Is Christianity consistent with evolution? But the truth can never be settled until issues are rigorously defined. And if our inquiry in this essay has a solid result, it establishes the fact that evolution cannot have the universal sweep essential to a sufficient principle of philosophy. The professed Philosophy of Evolution is not an adult philosophy, but rather a philosophy that in the course of growth has suffered an arrest of 
development. The result of our inquiry here, in making this plain, goes far toward settling the issue between such philosophy and the Christian belief in personality. Does it not in fact settle it against evolutionism, and in favour of the older and higher view? Fulfilled philosophy vindicates our faith in the Personality of the Eternal Ideal, in the reality of God, by vindicating the reality of man the Mind, and exhibiting his legislative relation to Nature and thence to evolution. It thus secures a stable footing for freedom, and for immortality with worth, and thereby for the existence of the Living God who is Love indeed, because the Inspirer of an endless progress in moral freedom.

Let men of science keep the method of science within the limits of science; let their readers, at all events, beware to clo so. Within these limits there is complete compatibility of science with religion, and forever will be. Let science say its untrammelled say upon man the physical, the physiological, or the experimentally psychological; upon man the body and man the sensory consciousncss, - these are all doubtless under the law of evolution issuing from man the Rational Soul. But let not science contrive its own destruction by venturing to lay profane hands, vain for explanation, on that sacred human nature which is its very spring and authorising source. And let religion stay itself on the sover- 
eignty of fulfilled philosophy, on man the Spirit, creative rather than created, who is himself the proximate source of evolution, the coöperating Cause and Lord of that world where evolution has its course. 


\section{MODERN SCIENCE AND PANTHEISM}

IN response to your invitation, ${ }^{1}$ I willingly take part in discussing the question, Is pantheism the legitimate outcome of modorn science? While turning it over for some months past, I have become more and more convinced that any satisfactory answer to it depends upon clearing up the meaning of its terms. What is pantheism? And what actual features in modern science can give colour to the suspicion that pantheism is its proper result? Or if such a suspicion is well founded, what leads us to regard it with a certain aversion? If science establishes or clearly tends to establish the pantheistic view, why should this stir in us alarms? Is there some secret hostility to the interests of human nature in a pantheistic

1 The essay was read at the Concord School of Philosophy, July, I885. Under the title "Is Modern Science Pantheistic ?" it was printed in the Overland Monthly, December, $188_{5}$, and reprinted, with some slight changes, in the Journal of Speculative Philosophy, vol. xix, No. 4 , nominally for October, $188_{5}$, but not issued till the spring of 1886. It formed a member in a "symposium" to which the other contributors were Mr. John Fiske, Dr. F. E. Abbot, Dr. A. P. Peabody, Dr. Edmund Montgomery, and Dr. IV. T. Harris. Mr. Fiske has published his contribution in his well-known work, The Idea of God as affected by Modern Knowledge; and Dr. Abbot his, in his volume called Scientific Theism. 
science? Can there be antagonism between the truth and the real interests of man? - is not truth our highest interest? Or, is truth of mere fact perchance not our highest interest? - is there perhaps such a thing as gradation in truths, and an inward truth that nust be supreme for ws, but which yet may be antagonised by the truths of Nature? And if our nature looks both to truths of fact and to truths of worth, is there some ghastly gulf in our being? - are we the victims of a tragic chasm between two indestructible wants of ours? Or if again not so, if deeper knowledge harmonises these wants, what is this rational path to our peace?

Your present question can hardly have for most minds the interest which so directly belongs to the question of Immortality, discussed by you last year; at least, not on its surface. Yet a study of it in the detail of the subsidiary questions just stated will not only secure the clearness needed for an intelligent answer, but will bring to view how really deep its interest is. It will show this to be no less profound, while far more inclusive, than that of your earlier problem. For this reason, I venture to offer you the reflexions that have passed in my mind in the endeavour to clear up these more detailed questions. These defining questions I will ask you to consider with me in their proper succession. 
Of all the questions, perhaps none is surrounded with more vagueness than the first - IVhat is pantheism? The recognised defenders of religion, the theologians who speak with the hoary authority and the presumptive weight that naturally belong to historic and instituted things, are indeed in the habit of drawing a sharp verbal distinction between theism and pantheism, as they also do between theism and deism; but when the unbiassed thinker, anxious for clearness and precision, inquires after the real distinction intended by these names, he hardly finds it in any sense at once intelligible and reasonable. We constantly hear that theism is contradicted by both deism and pantheism: by deism, through the assertion of God's distinctness at the expense of divine revelation and providence; by pantheism, through the assertion of the divine omnipresence at the expense of the distinctness of God from the world. We hear constantly, too, that theism, to be real, must teach that there is a being who is truly God: that the Principle of existence is a Holy Person, who has revealed his nature and his will to his intelligent creatures, and who superintends their lives with a providence which aims to secure their obedience to his will as the only sufficient condition of their blessedness. Yet all this is but an abstract and very 
vague formula, after all. Of how the contradiction whose extremes are represented by deism and pantheism is to be transcended and reconciled, it has nothing to say. How the divine personality is to be thought consistently with the divine omnipresence, or how the omnipresent providence of God is to be reconciled with his distinctness from the world, this merely general proclamation of orthodox theism does not show, and in itself has no power to show. When we pass from the general formula to the attempted supply of the desired details, we are too often made aware that the doctrine professedly theistic is encumbered with a mass of particulars profoundly at variance with its own principle. We notice that confusion or contradiction reigns where consistent clearness ought to be; that faultily anthropomorphic or really mechanical conceptions usurp the place of the required divine and spiritual realities.

We too often discover, for instance, that every doctrine is construed as deism which refuses its assent to a discontinuous and special providence, or to an inconstant, localised, and miraculous revelation. On the other hand, we find every theory condemned as pantheism that clenies the literal separation of God from the world and asserts instead his imma. nence in it. ${ }^{1}$ We find that in the hands of such

1 This apparent assent, cn passant, to the expression of theisin in terms of immanence is liable to great misinterpretation; but 1 think it 
interpreters theism is identified with belief in artificial theories of the quomodo of atonement, or, as such writers are fond of calling it, "the plan of salvation," - theories which in some way or other rest on the merely legal conception of ethics, involving the quid pro quo of a substitutive responsibility.

Into the place of the all-pervading providence and all-transforming grace that makes eternally for rightcousness, are set hypothetical schemes of expiation by sacrifice, of appeasal by the suffering of the innocent, of ransom by blood, of federal covenant and imputation, of salvation by faith alone. Theories of the divine nature and administration which omit these details, or refuse to take them literally, are stamped as deism or as pantheism, even though the omission or refusal be dictated by a perception that the rejected schemes are incompatible with the fun. damental principles of morals, and therefore with any divine revelation and government at all. Thus, by mere confusion of thought, or by inability to rise above conceptions couched in terms of space and

best to leave the statement standing as originally written and printed, and to guard the reader by a warning not to take the word "immanence" literally. Most theories of the divine immanence are unquestionably pantheistic, and all that is meant in the text above is to indicate there may be a way of conceiving immanence which would not be so. But of this further, when we reach the point of settling the distinction between genuine theism and pantheism. See the foot-note on p. 74, bclow, and the text corresponding. Cf, also pp. 6r, 69, and 72 . 
time, the original theistic formula - which in its contrasting of theism against deism and pantheism is unobjectionable, and correct enough so far as it goes - is brought in the end to contradict its own essential idea.

Still it must never be forgotten that these illconceived efforts at the completer definition of theism are made in behalf of a real distinction. We shall find it true that there is a conception of the world, for which cleism may be a very proper name; and another, for which pantheism is the only title really fitting. We shall see that they are both radically distinct from theism, which may be defined as the doctrine of a Personal God who reveals himself by such an immanence in the world as contributes to transform it into his own image throngh the agcncies of moral frectom; a God indwclling, as the central guiding Light, in a realm of self-governing persons who immortally do his will in freely doing their own, and fulfil their own in doing his. Nor shall we fail to find that the doctrines named deism and pantheism are historic doctrines. They are not abstractions merely conceivable, but have been advocated by actual men of a very real persuasion and a very discernible influence. Neither can I doubt that these two doctrines, in their deviations from the theistic thcory, will be recognised by our sound 
judgment as defective, and consequently be reck. oned opinions injurious if taken as final.

But let us now ask in earnest what pantheism exactly is. In beginning our answer, we may avail ourselves of a useful clue in the structure of the name itself. The derivation of this from the two Greek words $\pi \hat{a} \nu$ (all) and $\theta$ éos (God) would seem to make it mean either (I) that the All is God, or else (2) that God is all - that God alone really and actively exists. The name, then, hints at two quite different cloctrines. It may signify either (I) that the total of particular existences is God, in other words, that the universe, as we commonly understand it, is itself the only real being; or (2) that God, the absolute Being, is the only actively real being - all particular existcnces are merely his forms of appearance, and so, in truth, are either illusions or have an aspect of illusion haunting such partial reality as they possess. Of these diverse doctrines we might convey now the one and now the other by the name, according as we pronounced it pantheism or pantheism. In either way the word unavoidably covers an absolute identification of God and other being. In the first way, God is merged in the universe; in the second, the universe is merged in God.

As a matter of listory, too, pantheism has actually presented itself in these two forms. The doc- 
trine has come forward in a great variety of expressions or schemes of exposition, such as those of Heraclitus, Parmenides, and the Stoics, in ancient times, - not to speak of the vast systems lying at the basis of the Hindu religions, - or as those of Bruno and Vanini, Schelling, Oken, Schopenhauer, and Hartmann, in our modern era. ${ }^{1}$ But various as these schemes are, they may all be recognised as falling into one or other of the two forms suggested by the common name. The two forms, evidently, may be respectively styled the atheistic and the acosmic, as the one puts the sensible universe in the place of God, and thus cancels his being;

1 The names of Plato and Aristotle, among the ancients, and of Spinoza, Fichte, and Hegel, among the moderns, are omitted from this list because the question of their pantheism is with many still in dispute. As to Plato and Aristotle, of course the dispute is well founded, their position being more or less ambiguous, presenting a struggle between pantheism and individualism; though my own conviction now is that the drift of both is unquestionably pantheistic. At the time of writing the essay ( $13 S_{5}$ ), I still held the opinion that an idcalistic monism such as Hegel's was compatible with moral freedom; the persuasion that theism involves such an inmanence of God in souls, more or less pervades the paper in its original form. This explains still more pertinently why I then ornitted the names of Spinoza and Fichte from the list. I regarded Plato, Aristotle, Spinoza, lichte, and Hegel as forming a single growing but clear tradition of genuine rational theism. I hardly need add, that in getting convinced of the inconsistency of this whole tradition with moral freedom, I have changed my view both of theism and of the relation borne to it by these noted thinkers. I should now list all of the modern names among them as pantheists. 
while the other annuls the active reality of the cosmos, or world of existences other than God, by reducing these to modes of the one and only Universal Life.

Both forms are manifestly open to the criticism visited upon pantheism by the standard defenders of theism: they both contradict the essence of the divine nature by sacrificing the distinctness of the divine personality to a passion for the divine omnipresence. The sacrifice of the distinctness is obvious, at any rate, even if such a loss of distinct being is not so evidently incompatible with the true nature of godhead; though that this loss is incompatible with real deity will erelong appear.

Further, both forms are in the last analysis atheisms; the one openly, the other implicitly so. The one may be more exactly named a metaphysical or theoretical atheism, as it dispenses with the distinct existence of God in his office of Creator; the other may properly be called a moral or practical atheism, as in clestroying the freedom and the moral immortality of the individual it cancels God in his greater office of Redeemer. Under either form the First Principle is emptied of attributes that are vital to deity. In the first, the cntire distinct being of God disappears; in the second, all those attributes are lost that present God in his adorable characters of justice and love, and in the 
ultimate terms of his omniscience and omnipotence. For genuine omniscience and omnipotence are only to be realised in the control of free beings, and in inducing the divine image in them by moral influcnees instcad of metaphysical and physical agencies: that is, by final instcad of cfficient causation.

\section{II}

It will help us toward an cxacter understanding of pantheism to appreciate its relations to other anti-theistic forms of philosophy, particularly to materialism, and also to objective and to subjective idealism. With this appreciation, it will become clear that pantheism constitutes a synthesis of thought higher than either of these theories. The pantheistic conception of the world may indeed be read off in cither materialistic or idealistic terms, but neither reading reaches its whole meaning. Besides, the twofold reading holds good whether we take pantheism in its atheistic or its acosmic form. On a first inspection, to be sure, this double interpretability hardly seems to be the fact. On the contrary, one is at first inclined to identify atheistic pantheism with materialism outright, and to recognise in acosmic pantheism a species of mysticism or exaggerated spiritualism $;^{1}$ hence, to con-

1 "Der pantheistischen Mystik ist wirklich Gott Alles, dem gemeinen Pantheismus ist alles Gott," - quotes Dr. Martineau from Rothe, very significantly, in the title-page of his Spinoza. 
trast the two forms as the materialistic and the idealistic. Nor does further reflection at once disabuse us of this mistake; for the seeming identity of atheistic pantheism with materialism is very decided, and the only correction in our first judgment that we next feel impelled to make, is to recognise the ambiguous character of acosmic pantheism. The Universal Substance, we then say, in order to include an cxhaustive summary of all the phenomena of experience, must of course be taken as both extending and being conscious; but is this Substance an extended being that thinks, or is it a thinking being that apprehends itself under a peculiar mode of consciousness called extension? In other words, is the thinking of the Substance grounded in its extended being, or has its extension existence in and through its thinking only? Which attribute is primary and essential, and makes the other its derivative and function? Under the conception of the all-embracing existence of the Absolute, this question is inevitable, irresistible-will not down. According as we answer it in the first or the second of the two suggested ways, we turn the pantheism into materialism or, as we shall see presently, into objective idealism.

It thus becomes plain that the acosmic form of pantheism may carry materialism as unquestionably as it carries idealism, though incleed not so naturally 
or coherently. ${ }^{1}$ Still sharper inquiry at last makes it equally clear, too, that atheistic pantheism will carry idealism as consistently as it carries materialism, if doubtless less naturally. For although in the sum-total of the particular existences there must be recognised a gradation from such as are unconscious up to those that are completely conscious, and it would therefore be the more obvious step to read the series as a development upward from atoms to mind, still the mystery of the transit from the unconscious to the conscious cannot fail to suggest the counter-hypothesis, and the whole series may be conceived as originating idcally, in the perceptive constitution and experience of the conscious members of it. There is a marked distinction, however, between the idealism given by acosmic pantheism and the idealism given by the

1 There might be added here, in connexion with acosmic pantheism, a third hypothesis - that, namely, of the simple "parallelism" or concomitance of the two attributes, extension and thought. This third hypothesis would land us either (I) in agnosticism, as with Spencer, or (2) in "absolute" idealism, as with Hegel, - in the Idee as the transcending synthesis of objective and subjective idealism. We should thus get two additional species of non-atheistic pantheism. [The real effect of the preceding note is doubtless a criticism of the twofold division in the text. The fact is, this division is a relic of the IIegelian monism by which the original paper was in one side pervaded; but let it remain standing, - in part as a piacular memorial! The exclusion of "absulute" idealism from the list of pantheisms meant the lacit as. sumption that it had transcended pantheism. But see foot-note to p. 74 below.] 
atheistic. The idealism of acosmic pantheism, grounded as it is in the consciousness of the Universal Substance, has naturally a universal and in so far an objective character. The iclealism of atheistic pantheism, on the contrary, has no warrant except the thought in a particular consciousness, now this, now that, and no means of raising this warrant into a character even common to a class of conscious beings, much less into unrestricted universality; hence it is particular and subjective.

Pantheism, then, in both its forms, is not only a more comprehensive view of the world than either materialism or any one-sided idealism, inasmuch as it provides a chance for both of them, but it is also a deeper and more organic view, because it does bring in, at least in a symbolic fashion, the reality of a universal. This advantage, however, it does not secure with any fulness except in its acosmic form. Indeed, the atheistic form is so closely akin to the less organic theories of materialism and subjective idealism that we may almost say we do not come to pantheism proper until we pass out of the atheistic sort and get into the acosmic.

An additional gain afforded by pantheism, eminently by the acosmic sort, is the idca of an intimate union of the First Principle with the world of particular beings: the creative Cause is stated as spontaneously manifesting its own nature in its 
creation; it abides immanently in this, and is no longer conceived as separate and therefore itself limited in space and in time. This faulty conception of God as temporally and spatially conditioned, characteristic of the cruder dualistic view of things with which human efforts at theological theory begin, is overcome by pantheism, at least in part. But the pantheistic interpretation of immanence, as will appear farther on, is itself very gravely deficient: quite irreconcilable, in fact, with the conditions of a genuine theism, or with those of a genuine religion.

\section{III}

But the eminent merit of pantheism as contrasted with deism, we have now reached the position to see. By the name "deism" it has been generally, if tacitly, agreed to designate that falling short of theism which stands at the opposite pole from pantheism. If pantheism is defective by confounding God and the world in an anti-moral identity, deism comes short by setting God in an isolated and impassable separation from the world. Deism thus falls partly under the same condemnation of materiality that a rational judgment pronounces upon sensuous theism, with its zoomorphic ${ }^{1}$ con-

1 Falsely called "anthropomorphic," since the properly human form of being is the rational, not the physiological, and the faulty "antliro- 
ceptions of a producing Creator, dwelling in his peculiar quarter of space called Heaven, and its mechanical theory of his communication with the world by way of "miracle" alone-by way, that is, independent or even subversive of the process from means to end in Nature. ${ }^{1}$

But while thus marred by mechanical limitations, deism must be allowed its relative merit too. This lies in the judgment it passes upon the mechanical method of sensuous theism. If in the interest of distinguishing the Creator from the creation, God

pomorphisin" of which nowadays we hear so much complaint, consists exactly in construing the nature and action of God in terms of our sensuous life and its conditions.

I I must be understood here as reflecting only upon the popular thanmaturgical conceptions of the supernatural. The genuine doctrine of miracle has a speculative truth at its basis, profound and irrefragable: namely, that the causal organisation of Nature - the system of evolution, ever ascending from cause to differing effect - can never be accounted for in terms of the sensible antecedents alone, but requires the omnipresent activity of a transcendingly immanent personal cause; and that the system of Nature is therefore in this sense a Perpetual Miracle. But the natural order flowing from this Intelligible Miracle is immutable, and irreconcilable with "miracle" in the usual sense. [I would now add (IS99) that this immanent personal cause is, at closest hand to Nature, humun nature; or, more generally, the intelligences other than God, in coöperation with the remoter and quite indirect causality of God as their Type and Ideal. The operation of the non-divine causation in Nature is alone direct and efficient; the divine causation is indirect and final only. But see, for the fuller account of this, the essays on "The Limits of Evolution" and "The Harmony of Determinism and Freedom."] 
is to be thought as capable of existing without a world, and as literally scparated from the world in time and space, then deism says it is purely arbitrary to declare the separation overcome by means of miracle. Consistency, and in so far rationality, would rather require that the separation be kept up; and the folly of the zoomorphic dualism is made to display itself in the deistic inference, which such dualism cannot consistently refute, that divine revelation and providence, without which the practical religion indispensable to the reality of theism cannot have being, are by this literal separateness of the divine existence rendered impossible.

The comparative virtue of pantheism here, as against deism and sensuous theism alike, is that it transcends, in a certain sort at least, this mechanical rigidity in divine relations. However faulty its way of accomplishing this may be, - and we shall presently see this is indeed faulty, - it does us the service of calling attention to the religious need of cancelling this mechanical view; and it habituates our thoughts to an inseparable union and communion between God and the world. It teaches us the great and lasting lesson, that the relation between God and the world of souls is in no wise contingent or temporal, but is necessary, essential, eternal. 


\section{IV}

Now we face the question, Why then is pantheism regarded by so many with instinctive inhibition - as if indeed a doctrine to avert? In coming to this after what we have just discerned, we must not neglect the fact that pantheism plays an indispensable part in the forming of a genuine theistic theory. It is the transitional thought by which we ascend out of the idolatrous anthropomorphism of sensuous theism into that rational and complete theism which has its central illumination in the comprehended truth of the Divine Omnipresence. In the morally interpreted immanence of God in the world, this completed theism finds the true basis, the pure rational theory, of the divine perpetual providence. In God's dwelling with the society of spirits, as "the Light which lighteth every man that cometh into the world," it finds the rational basis for the universal and perpetual divine revelation. Even this higher, this ethically rational view of Divine Immanence, we must not forget, has come to us through the suggestion in the lower immanence taught in pantheism.

Indeed, in this suggested omnipresence of God, this indwelling of God in the world by the activity of his image in the soul, - pantheism lays a foundation for the rational conception of a Perpetual Incar- 
nation, the cloctrine of a Divine Humanity. So when theology sets the doctrine of the Triune God at the centre of practical religion, pantheism has prepared the way for vindicating it as in so far the genuine interpreter of rational theism. That the Eternal is eternally generated in our higher human nature; that this Son of Man is in practical truth the Son of God, and the Son only-begotten; that by the discipline of life in worlds of imperfection, men and, following men, the whole world of conscious beings - ascend, through fealty to this Son, immortally toward the Father in the Holy Spirit, - this, the epitome of Christian theism, first gets apprehended, or at least suggested, in the insight which pantheism brings, that God is not separate from the world, but effectually present in it, and that the distinction between the soul and the God who recognises and redeems it can never be truly stated as a distinction in place and time, a separation in space and by a period, a contrast between efficient cause and produced effect. On the contrary, the distinction must be made in terms of pure thought, which is essentially timeless and spaceless, neither lasts nor extends, nor is dated nor placed, but simply is. It must be viewed as a contrast (and yet a relation) between different centres of consciousness, each thoroughly sclf-active; and further, as a distinction in the mode by which each conscious centre defines 
its individual being in terms of its Ideal. In short, it must be thought in terms of final cause alone. No mind can have an efficicnt relation to another mind; efficiency is the attribute of every mind toward its own acts and life, or toward the world of mere "things" which forms the theatre of its action; and the causal relation between minds must be that of ideality, simply and purely.

This is a religious truth so clearly fundamental that when once our attention is brought to it we cannot but give it assent. So far from denying it, we incline, rather, to say - and rightly - that we have in somewise always known it. Yet it is directly violated by our ordinary and sensuous theistic conceptions; and not until the pantheistic insight has been realised in our minds, whether by name or no it matters not, - realised even if transcended, and, indeed, only to be transcended, - do we clearly discover that this violation exists. ${ }^{1}$

\section{V}

But while this permanent insight of pantheism must be carried up into all genuine theistic thought, it is also true that in itself the insight falls fatally

1 The preceding paragraphs have been much rewritten from the form in which they were $\left(\$ 88_{5}-6\right)$ originally printed, in order to remove the risk of misinterpretation in regard to the doctrine of "immanence." Cf, the foot-note to p. 6o. See also The Conception of God, pp. 97-IOO, I 4 -132, especially I3I-1 32 . 
short of the conception demanded by the highest practical religion. For religion as a practical power in human experience - the very conception of theism as an operative life in the spirit-depends not merely on the omnipresent influence of God, but equally on the freedom and the immortality of the soul: on its freedom in the strictest sense; that is, its unqualified autonomy and self-activity. In fact, not only is it impossible for souls to be souls, apart from freedom, immortality, and God, but it is just as impossible for God to be God, apart from souls and their immortality and freedom. In other words, the self-existent perfection of deity itself freely demands for its own fulfilment the possession of a world that is in God's own image, and such a control of it as is alone consistent with its being so : a divine creation must completely reflect the divine nature, and must therefore be a world of moral frecdom, autonomous, and, in the last resort, selfactive or eternal.

But this requirement of genuine and fulfilled theism, pantheism cannot meet. Its theory, whether atheistic or acosmic or agnostic or absolute-idealistic, is the radical contradiction of real freedom and significant immortality. ${ }^{1}$ Indeed we may say,

${ }^{1}$ For some detailed illustrations of this, especially with reference to "absolute" idealism and evolutional idealism, see The Conception of God, pp. 89-127. 
summarily, that the distinction between theism and pantheism lies just in this - that theism, in asserting God, asserts the freedom and the moral immortality of the soul; but that pantheism, while apparently asserting God to the extreme, clenies his moral essence by cancelling all real freedom and therefore all immortality of worth - all that "life eternal" which means imperishable and continual progress in fulfilling freedom by universal growth in the image of God. The conclusive proof of this is, that, even in its highest form, pantheism necessarily represents what it calls God as the sole real agent in existence. Every other being exists but as part or mode of the eternal One.

\section{VI}

At length we see why pantheism is at war with the characteristic interests of human nature. Our abiding interests are wholly identified with the reality of freedom and immortal moral life; and this, not on the ground of any passion we may have for mere unconstraint or for permanence of mere existence a ground of course not worthy of a rational being - but on the immovable foundation laid by reason as Conscience. For when this highest form of reason is thoroughly interpreted, we know that the value of freedom and immortality lies in their indispensableness to our discipline and growth in our 
ideal or divine life. To no theory of the world can man give a willing and a cordial adhesion, then, if it strikes at the heart of his personal reality and contradicts those hopes of ceaseless moral growth that alone make life worth living. Not in its statement of God as the All-in-all, taken by itself, but in its consequent denial of the reality of man - his freedom and inmortal growth in goodness - is it that pantheism betrays its insufficiency to meet the needs of the human spirit.

It is no doubt true that this opposition between the doctrine of a Sole Reality and our natural longings for permanence, our natural bias in favour of freedom and responsibility, in itself settles nothing as to the truth or falsity of the doctrine. It might be that the system of Nature, it might be that its Ground, is not in sympathy or accord with "the bliss for which we sigh." But so long as human nature is what it is, so long as we are by essence prepossessed in favour of our freedom and yearn for a life that may put death itself beneath our feet, and with death imperfection and wrong, so long will our nature reluctate, so long will it even revolt, at the prospect of having to accept the cloctrine of pantheism; so long shall we instinctively draw back from that vast and shadowy Being which, be it conscious or unconscious or simply the Unknowable, must for us and our highest hopes be verily the 
Shadow of Death. Yes, we must go still farther, and say that even should the science of Nature prove pantheism true, this would only array the interests of science against the interests of manthe interests that man can never displace from their supreme seat in his world, except by abdicating his inmost nature and putting his conscience to an open shame. A pantheistic edict of science would only proclaim a deadlock in the system and substance of truth itself, and herald an implacable conflict between the law of Nature and the law written indelibly in the human spirit. The heart on which the vision of a possible moral perfection has once arisen, and in whose recesses the still and solemn voice of Duty has once resounded with its majestic sweetness, can never be reconciled to the decree, though this issue never so authentically from Nature, that bids it count responsible frecdom an illusion and surrender existence on that mere threshold of moral development which the bound of our present life affords.

Such a defeat of its most sacred hopes the conscience can neither acquiesce in nor tolerate. Nor can it be appeased or deluded by the pretext that annibilation may be accepted devoutly, as self-sacrifice in behalf of an infinite "fulness of life" for the universe - a life in which the inclividual conscience is to have no continued living share. The 
defence of this pantheistic piety by quoting the patriarch of many tribulations, in his impassioned cry, "Though He slay me, yet will I trust in Him!" is as vain as it is profane. This is only to repeat in a new form the fallacious paradox of those grim and obsolete sectarians who held that the test of a state of grace was "willingness to be damned for the glory of God." The spirit that truly desires righteousness longs with an unerring instinct for immortality as the indispensable condition of entire righteousness, and when invited to approve its own immolation for the pretended furtherance of the Divine glory will always answer as a noble matron applying for admission to the church once answered the inquisitorial session of her Calvinistic society, "I certainly am not willing to be damned for the glory of God; were I so, I should not be here!"

This sense of our vocation to moral perfection, and of all it implies as to freedom and continuance, is what makes our main question of such thrilling concern. The question starts a ghastly fear, lest science may be the doom of our loftiest hopes. If so, it will quench the aspirations which have been the soul of man's grandest as well as sublimest endeavours; for the beliefs it will destroy are the real founclation of all that has given majesty and glory to history. To present universal Nature as the deep in which each soul with its moral hopes 
is to be engulfed, is to transform existence into a system of radical and irremediable evil, and thus to make genuine religion impossible; and not only religion, but also all cordial political union and order, for this gets and keeps a footing amid the shifting affairs of this sense-world, only because it is the outward image of the religious vision. Belief in the sovereign goodness of the universe and its grounding Light is the life alike of religious faith and of political fealty. It is impossible that either faith or fealty can long endure after we have come to the realising conviction that the whole of which we form a part, and the central Principle of the whole, are hostile, or even indifferent, not simply to the permanent existence of the soul, but to its aspirations after completion in moral life. A nominal God, who either cannot or will not bring to fulfilment the longing after infinite moral growth that has once arisen in a spirit, is not, and cannot be, for such a spirit, true God at all:--

The wish that of the living whole

No life may fail beyond the grave,

Derives it not from what we have

The likest God within the soul ?

$$
\text { ... And he, shall he- }
$$

Man, the last work, who seemed so fair,

Such splendid purpose in his eyes,

Who rolled the psalm to wintry skies,

Who built him fanes of fruitless prayer - 
Who trusted God was love indeed,

And love Creation's final law,

Though Nature, red in tooth and claw

With ravine, shrieked against his creed -

Who loved, who suffered countless ills,

Who battled for the True, the Just -

Be blown about the desert dust,

Or sealed within the iron hills?

No more ? - A monster, then, a dream,

A discord! Dragons of the prime,

That tare each other in their slime,

Were mellow music, matched with him !

The profound feeling which Tennyson has here so memorably expressed, gives your question of this year a significance as wide as all mankind, as deep as man's unfathomable heart, and makes its interest surpass the interest of every other; for every other quickest question is involved in this. Let us not fail to realise that pantheism means, not simply the all-pervasive interblending and interpenetration of God and other life, but the sole causality of God, and so the obliteration of freedom, of moral life, and of any immortality worth the having; in a word, of the true being of God himself.

\section{VII}

It is urgent to ask, then, whether there is anything in the nature of modern science that really gives colour to a pantheistic philosophy. Obviously 
enough, there are not wanting philosophers, and schools of philosophy, who read pantheism in science, as science appears to them. But the question is, Is such a reading the authentic teaching of science itself? Here we must not mistake the utterances of men of science for the voice of science as such. For on this borderland of science and philosophy it need not be surprising if men only familiar with the method of investigation which science pursues, and not greatly at home in the varied and complex history of philosophical thought, should sometimes incline to a hasty inference when the borderland is reached, should overlook the fact that their science and its method have necessary limits, and in philosophy take the view which an illegitimate extension of their method would indicate. So, disregarding the opinions of certain cultivators of science, we are here to ask the more pertinent question, What is there - if indeed there be anything - in the nature of science itself, as science is now known, what is there in its results or in its method, that points to a pantheistic interpretation of the world?

To this question it must in all candour be answered, that both in the method of modern science, and in the two most commanding principles that have resulted from the method, there is that which unquestionably suggests the pantheistic view. Nothing less than the most cautious discrimination, 
founded on a precise knowledge of the history of philosophical inquiry, can detect the exact reach, the limits, and the real significance of this suggestion, or expose the illegitimacy of following it without reserve. The trait to which $I$ am now referring in the method of science is its rigorously observational and experimental character; indeed, its strictly empirical or tentative character. The two commanding results, which now in turn play an organising part in the subsidiary methods of all the sciences, are (I) the principle of the Conservation of Energy, and (2) the principle of Evolution, manifesting itself in the concomitant phenomenon of "natural selection" - the "struggle for existence" between each species or individual and its environment, and the "survival of the fittest." In these two principles, and also in the general method of science, there are certain implications that seem to point strongly in the pantheistic direction. These implications accordingly deserve, and must receive, our careful attention.

How, then, docs the experimental - or, more accurately, the empirical - method of science suggest the doctrine of pantheism? I answer: By limiting our serious belief to the evidence of experience, and chiefly to the evidence of the senses. The method of science demands that nothing shall receive the high credence accorded to science unless it is attested 
by unquestionable presence in sensible experience. All the refinements of scientific method - the precautions of repeated observation, the probing subtleties of experiment, the niceties in the use of instruments of precision, the principle of reduction to mean or average, the allowing for the "personal equation," the final casting out of the largest mean of possible errors in experiment or observation, by such methods, for instance, as that of least squares - all these refinements are for the single purpose of making it certain that our basis of evidence shall be confined to what has actually been present in the world of sense. We are to know beyond question that such and such conjunctions of events have actually been present to the senses, and precisely what it is that thus remains indisputable fact after all possible additions or misconstructions of our mere thought or fancy have been cancelled out. Such conjunctions in unquestionable experience, isolated and then purified from foreign admixture by carefully contrived experiment, we are finally to raise by generalisation into a tentative expectation of their continued recurrence in the future; tentative expectation, we say, because the empirical method in its rigour warns us that the act of generalisation is a step beyond the strict evidence, and must not be reckoned any part of science except as it continues to be verified in subsequent experience of the event 
under examination. Thus natural science climbs its slow and cautious way along the path of what it calls the laws of Nature; but it only gives this name in the sense that there has been a constancy in the conjunctions of past experience, a verification of the tentative generalisation suggested by this, and a consequent continuance of the same tentative expectancy. This expectancy, however, waits for renewed verification, and refrains from committing itself unreservedly to the absolute invariability of the law to which it refers. Unconditional universality of its ascertained conjunctions, natural science, in its own sphere and function, neither claims nor admits; and a fortiori not their necessity. ${ }^{1}$

Now, to a science which accepts the testimony of experience with this undoubting and instinctive confidence that never stops to inquire what the real grounds of the possibility of experience itself may

1 The account here given of scientific method may appear to some readers different from that presented in the essay on "The Limits of Evolution" (sce pp. 33-36). There is no real inconsistency between the two, however. Here, I am stating the method of science strictly as such - stating it as the scientific expert uses it and states it to himself. In the former place, I was stating the philosophy of the method - bringing out its real presuppositions. I was representing the method, not simply with reference to its practical objects, not purely as a means to a result in science, but as a step in the theory of knowledge, a link in the chain not of science but of philosophy. Nor does the above-mentioned holding-back of science from necessity in its judgments mean anything but its just recognition of the unavoidable insecurity of its basis of fact. 
be, or whence experience can possibly derive this infallibility of evidence, but assumes, on the contrary, that the infallibility of the evidence, could this once be certainly got, is immediate and underived - to such a science it must seem that we can have no verifiable assurance of any existence but the Whole; that is, the aggregate of particulars hitherto actual or yet to become so. Thus the very method of natural science tends to obliterate the sense of the transcendent, of what lies beyond the bounds of possible experience, or at least to destroy its credit at the bar of disciplined judgment. In this way the method brings its too eager votaries to regard the Sum of Things as the only reality.

On this view, the outcome of the scientific method might seem to be restricted to that form of pantheism which I have named atheistic. Most obviously the inference would be directly to materialism, the lowest and most natural form of such pantheism; subtler reasoning, however, recognising that in the last resort experience must be consciousness, sees a truer fulfilment of the empirical method in the subjective idealism which states the Sum of Things as the aggregate of the perceptions of its conscious members. But beyond even this juster idealistic construction of atheistic pantheism - beyond either form of atheistic pantheism, in fact - the method of natural science would appear to involve consequences 
which render the Absolute, whether interpreted as the Unknowable or as God, the sole causal reality. That is, scientific method would in this way bring us to acosmic panthcism. For the empirical method, so far from vindicating either the freedom of the personal will or the immortality of the soul, withholds belief from both, as matters that can never come within the bounds of possible experience. The habit of regarding nothing but the empirically attested as part of science dismisses these two essential conditions of man's reality beyond the assumed pale of true knowledge into the discredited limbo of naked and unsupported possibilities.

But it is not till we pass from the method of natural science to its two chicf modern results, and take in their revolutionary effect as subsidiaries of method in every ficld of natural inquiry, - it is not till then that we feel the full force of the pantheistic strain which pulls with such tension in many modern minds. Only in the principle of the Conservation of Energy, and in that of Evolution, particularly as evolution is viewed in its aspect of natural selection, do we get the full force of the pantheistic drift. This drift, at the first encounter, seems almost irresistible. That all the changes in the universe of physical experience are resolvable into motions, either molar or molecular; that in spite of the incalculable variety of these motions, the sum-total of 
movement and the average direction of the motions is constant and unchangeable ${ }^{1}$ that an unvarying correlation of all the various modes of motion exists, so that each mode is convertible into its correlates at a constant numerical rate, and so that each, having passed the entire circuit of correlated forms, returns again into its own form undiminished in amount: all this seems to point unmistakably to a primal energy - a ground-form of moving activity in itself one and unchangeable, immanent in its sum of correlated forms, but not transcending them, while each instance of each form is only a transient and evanescent mode of this single Reality.

Nor is this inference weakened by the later scholium upon the principle of conservation, known as the principle of the Dissipation of Energy. On the contrary, the pantheistic significance of the principle of conservation seems to be greatly deepened by this. Instead of a constant whole of moving activity, exhibited in a system of correlated modes of motion, we now have a vaster correlation between the sum of actual energies and a vague but prodigious mass of potential energy - the "waste-heap," as the phy-

1 The principle of conservation is very commonly stated as the invariability of the sum-total of vis viva in the world, and is expressed in the formula $\frac{1}{2} m v^{2}=$ constant. But the statement in the text, which returns to the formula of Leibnitz, is more comprehensive as well as more philosophic, and is for these reasons preferred by some of the latest physicists. 
sicist Balfour Stewart has well named it, of the power of the universe. Into this "waste-heap" all the active energies in the world of sense seem to be continually vanishing, and to be destined at last to vanish utterly. Under the light of this principle of dissipation, we shift from a primal energy immanent but not transcendent to one immanent in the sum of the correlated actual motions and also transcendent of them. Very impressive is the view that here arises of a dread Source of Being that engulfs all beings. It is Brahm again, issuing forth through its triad, Brahma, Vishnu, Siva, - creation, preservation, annihilation, - to return at last into its own void, gathering with it the sum of all its transitory modes. And let us not forget that the conceptions out of which this image of the One-and-All is spontaneously generated are the ascertained and settled results of the science of Nature in its exactest empirical form.

When to this powerful impression from the principle of conservation, as modified by that of dissipation, we now add the proper effect of the principle of evolution, the pantheistic inference appears to gather an overpowering weight, in no way to be evaded. As registered in terms of a rigorous empirical method, evolution presents the picture of a cosmic Whole, constituted of varying members descended from its own primitive form by differentiations so 
slight and gradual as not to suggest difference of origin or distinction in kind, but, on the contrary, to indicate clearly thcir kinship and community of origin. Still, these differentiations among the members, and the consequent differences in their adaptation to the Whole, involve a difference in their power to persist amid the mutual competition which their common presence in the Whole implies. In this silent and unconscious competition of tendencies to persist, which is called, in a somewhat exaggerated metaphor, the "struggle for existence," the members of the least adaptation to the Whole must perish earliest, and only those of the highest adaptation will finally survive. Accordingly, by an exaggeration akin to that of the former metaphor, we may, in another, name the resulting persistence of the members most suited to the Whole the "survival of the fittest"; and as it is the Whole that determines the standard of adaptation, we may also, by figuratively personifying the Whole, call the process of antagonistic interaction through which the survivors persist, a process of "natural selection." Here, now, the points of determining import for inference are these: (I) That the "survival" is only of the fittest to the Whole; (2) that it is the Whole alone that "selects"; (3) that no "survival," as verifiable by the strictly empirical method, can be taken as permanent, but that even the latest must be reckoned 
as certified only to date, with a reservation, at best, of "tentative expectancy" for hope of continuance; (4) that "natural selection," as empirically verified, is a process of canccllation, in the end a selection only to death; and (5) that the Whole alone has the possibility of final survival. The "tentative expectation" founded on the entire sweep of the observed facts, and not extended beyond it, would be that the latest observed survivor - man - is destined like his predecessors to pass away, supplanted by some new variation of the Whole, of a higher fitness to it. And so on, endlessly.

This clear pointing toward the One-and-All that devours all, secms but to gain still further clearness when the principles of conservation and of evolution are considered, as they must be, in their inseparable connexion and interaction. They work in and through each other. Conservation and correlation of energy, and their "rider" of dissipation, are the secret of the mechanism in the process of natural selection, with its deaths and its survivals. Evolution is the field, and its resulting forms of existence, more and more complex, are the outcome, of the operations of the correlated, conserved, and dissipated energies. Evolution, in its turn, by its principle of struggle and survival, works in the very process of the correlation, dissipation, and conservation of energy. It therefore seems 
but natural to identify the potential energy of correlation - the "waste-heap" of power - with the Whole of natural selection. And thus we appear to reach, by a cumulative argument, the One-andAll in which all must be absorbed.

If we now add to these several indications, given by the method and the two chief results of modern science, the discredit that the principles of conservation and evolution appear to cast directly upon the belief in freedom and immortality, the pantheistic note in modern science will sound out to the full. In the case of free-agency, this discredit comes (I) from the closer nexus that the correlation of forces seems plainly to establish between every possible conscious action and the antecedent or environing chain of events out of which the web of its motives must be woven, and (2) from the pitch and proclivity that, according to the principle of evolution, must be transmitted by the heredity inseparable from the process of descent. In the case of immortality, the discredit comes first by way of the principle of evolution, through its indication of the transitoriness of all survivals, and its irremediable failure to supply any evidence of even a possible survival beyond the sensible world, with which empirical evolution has alone to do. But it comes also by way of the principle of the conservation and dissipation of energy, 
because of the doom that seems manifestly to await all forms of actual energy. Besides, both immortality and freedom must share in that general discredit of everything unattested by experience which the persistent and exclusive culture of empiricism begets.

In effect, while the empirical method ignores, and must ignore, any supersensible Principle of existence whatever, thus tending to a loose and careless identification of the Absolute with the Sum of Things, evolution and the principle of conservation have familiarised the modern mind with the continuity, the uniformity, and the unity of Nature in an overwhelming degree. In the absence of a conviction upon independent grounds that the Principle of existence is rational and personal, the sciences of Nature can hardly fail, even upon a somewhat considerate and scrutinising view, to convey the impression that the Ground of Things is a vast and shadowy Whole, which moves towards some unknown destination; sweeping forward, as one of the leaders of modern science has said, "regardless of consequences," unconcerned as to the fate of man's world of effort and hope, which looks so circumscribed and insignificant when viewed from the outlook of sense only - from the vanishing shore of Time, giving upon the boundless expanses of Space. 


\section{VIII}

But now we come to the last and closest question: Is this impression of pantheism really warranted? And here we stand in need of sharp discrimination: there is a way of looking at the course of science, the way we have just been examining, that seems to find the warrant asked for; and there is an exacter way which will show that the supposed warrant is only an illusion. With the right discrimination, and using the exacter way, we shall find that the inference to pantheism from the method and principles of science, decided as it seems to be, is after all illegitimate.

Our first precaution in this home-stretch of our inquiry must be to remember that it is not science - not exact and rigorous knowledge - in its entire compass that is involved in our question. It is only "modern science," popularly so called; that is, science taken to mean only the science of Nature. Not only so, but science is in the new context further restricted to signify only what may rightly be described as the natural science of Nature--so much of the possible knowledge of Nature as can be reached through the channel of the senses critically used; so much, in short, as will yield itself to a method strictly empirical. Hence the real question is, Whether 
empirical science, confined to Nature as its proper object, can legitimately assert the theory of pantheism?

With regard now, first, to the argument drawn with such apparent force purely from the method of natural science, it will be plain to a more scrutinising reflexion, that shifting from the legitimate disregard of a supersensible Principle - a disregard in which the empirical method is entirely within its right - to the denial or the doubt of it because there is and can be no scientific evidence for it, is in fact an abuse of the scientific method, an unwarrantable extension of it to decisions lying by its own terms beyond its reach. The shift is made upon the assumption that there can be no science- no cxact and conclusive knowledge - founded on any but empirical evidence. Now, that there is no science deserving of the name except such as follows the empirical method of natural science is a claim which experts in natural science are rather prone to make; but the profoundest thinkers the world has known - such as Plato, Aristotle, Bacon, Descartes, Spinoza, Leibnitz, Kant, and Hegel - have certainly pronounced the claim unfounded; indeed, a sheer assumption, contradicted by evidence the clearest, if oftentimes abstrusc. When instead of blindly following experience we raise the question of the nature and the sources of experience, and push it in earnest, it then 
appears that the experience which seems so rigorously to exclude supersensible principles, and particularly the personality of the First Principle, is itself dependent for its existence on a personal Principle and on supersensible principles; that, in fact, these enter into the very constitution of experience. But in any case this question of the nature of experience and the limits of knowledge-the question whether the limits of knowledge are identical with the limits of experience - is a question which if we take up, we abandon the field of natural science, and enter instead the field of the theory of cognition. In this, the expert at natural science, as such, has not a word to say. Here his method is altogether unavailing. If the problem can be solved at all, the solution will be by methods that transcend the bounds of empirical evidence. The scientific expert may be competent to the solution in his capacity of man, but in his capacity of man of science he certainly is not.

So again, with regard to the inferences to pantheism from the conservation of energy and the principle of evolution. Strong as the evidence seems, it arises in both cases from violating the strict principles of the scientific method. All inferences to a Whole of potential energy, or to a Whole determinant of the survivals in a struggle for existence, are real inferences - cases of passing beyond 
the region of sensible and experimental facts into the empirically unknown, empirically unattested, empirically unwarranted region of supersensible principles. The exact scientific truth about all such inferences, and the supposed realities which they establish or displace, is simply that they are not warranted by natural science; and that this withholding of warrant is only the expression by natural science of its incompetency to enter upon such questions.

Natural science must therefore, in truth, be declared silent on this question of pantheism; as indeed it is, and from the nature of the case must be, upon all theories of the supersensible alike - theistic, deistic, atheistic, pantheistic. Natural science has no proper concern with such theories. Science may well enough be said to be non-pantheistic, but so also is it non-theistic, non-deistic, non-atheistic. Its position, however, is not for that reason anti-pantheistic, any more than it is anti-theistic, or anti-deistic, or anti-atheistic. Rather, it is merely agnostic; not in the sense of the dogmatic philosophies of agnosticism, but simply in the sense of declining to affect knowledge in the premises, seeing they are beyond its method and its province. In short, its agnosticism is simply its neutrality, and doesn't in the least imply that agnosticism is the final view of things. The investigation of the final view, the research concerning the First Principle, science leaves to methods 
quite other than its own of docile experience and patient reflexion upon experience-methods that philosophy is now prepared to vindicate as higher and still more trustworthy. For the primacy of mind over Nature, the legislative relation of mind to the world, has been found to be the real presupposition of science itself, and the tacit recognition of this truth to be the clue to the first sudden advance of modern science, and to its unparalleled subsequent progress. ${ }^{1}$

I The epochal sentences of Kant, in his preface to the second edition of the Critique of Pure Reason, have been more than verified by the century of science and philosophy that has passed since they first saw the day: "When Galilei made his balls roll down the inclined plane with a gravitation selected by himself, or Torricelli had the air support a weight which he had previously taken equal to a known column of water, or Stahl later converted metals into lime, and this into metal again, by withdrawing something and then putting it back, a light dawned on all investigators of Nature. They comprehended that Reason only sees into what she herself produces after her own design; that with her principles of judgment according to invariable laws, she must take the lead, and compel Nature to answer her questions, not let herself be merely taught by Nature to walk, as if in leading-strings; for otherwise she would be left to observations only casual, and these, made on no plan designed beforehand, do not at all connect in a necessary law, which yet is what Reason seeks and must have. With her principles in one hand, solely by accord with which can agreements among phenomena get the value of laws, and with experiment in the other, which she has devised according to them, Reason must approach Nature, to learn from her, indeed, but not in the quality of a pupil, who submits to be prompted as the teacher pleases ; on the contrary, in the quality of an invested judge, who compels the witnesses to reply to questions which he puts to them himself." - The Critique of Pure Reason, edition of 1787 , pp. xii, xiii. 
Hence, when once the personality of the First Principle is reached in some other way - the way of philosophy as distinguished from that of sciencescience will then furnish the most abundant confirmations, the strongest corroborations; the more abundant and the stronger, in proportion as the First Principle reached by philosophy ascends continuously from materialism through deism and pantheism to personal theism. For the traits in Nature and in natural science that seem to point to a lower Principle, especially those that look so plausibly toward pantheism, are better explicable by the theistic Principle, when once true theism is reached; and science accords best with this purified theism, though in itself quite unable to attain to the view.

But the theism that science will corroborate, or that thorough philosophy can approve and establish, must be a theism that assumes into its conceptions of God and man all the irrefutable insights of materialism or of deism, and of pantheism most of all. These insights reached on the planes of lower philosophies have an unquestionable reality and pertinence, if also they are marked by undeniable insufficiency. Their insufficiency, when they are seen in the higher light of genuine theism, is indeed so great that they seem by themselves to have hardly any religious import at all. By themselves, they afford the soul neither outward hope 
nor inward peace. Still, the religious conviction that does make hope and peace secure is not to be attained without their aid. The mind that has never discerned the meaning in these lower levels of thought upon religious problems has not yet entered into the inner meaning of theism, nor seen it in the light where its proofs become transparent. 


\title{
LATER GERMAN PHILOSOPHY
}

\author{
MONISM MOVING TOWARD PLURALISM, THROUGH \\ AGNOSTICISM AND ITS SELF-DISSOLUTION ${ }^{1}$
}

IN Germany, the central home of modern thought, there began, about the year I865, a philosophical movement, or a group of related movements, of a more novel and striking character than any since the time of Kant and his four chief successors, Fichte, Schelling, Hegel, and Herbart. It has not yet entirely run its course, for two of its inaugurators are still (1900) living and productive, while the third, though he passed away a quarter of a century ago, left behind him a decided influence. The movement is indicative of the prevailing Zeitgeist, and worth our study as an expression of the tone of current culture. Our chief interest in it, however, will be for its significant drift beyond its own prepossessions, and toward a deeper view, through its own inner dialectical dissolution.

1 The essay is a revision of part of an article printed in the Journal of Speculative Philosophy, January, 1883 , with the title "Some Aspects of Recent German Philosophy." Originally, it was a lecture before the Concord School of Philosophy, read in July, 1882. 
In the total stream of this movement there are discernible three main currents, the idealistic, the materialistic, and the agnostic, - or "critical," as its adherents prefer to name the last. This division, however, is not distinctive of the period, being merely the continuation of a world-old divergence in doctrine. But it is distinctive of the new situation that these several views are all defended from standpoints more or less empirical. The rallying-cry of "Back to Kant!" with which the movement began, was soon succeeded by a more adventurous cry of "Beyond Kant!" This "Beyond," owing mainly to the predominant interest in the theories of evolution and natural selection, was construed as lying in the region indicated by the empirical method of which these theories are the extolled result. In the case of materialism, to be sure, this empiricism is natural and nowise unexpected; but the occurrence of it in the case of idealism and of agnosticism, after Kant's day and in his own land, and among thinkers long given to the study of his works, is a genuine surprise. That the very principles of the Critique of Pure Reason, the historic stronghold of the a priori, should suffer the complete transformation of being made to support a posteriori philosophy, is a performance not far from astonishing. Yet it was managed, and constitutes the distinguishing feat of the school calling themselves Neo-Kantians. 
Each of these three main currents has had a leading representative. There are thus three men who command our attention, as in their several ways typical of the dominant intellectual interests of their time, - Eduard von Hartmann, Eugen Dühring, and Friedrich Albert Lange. The first stands for such idealism as is now in vogue, derived in a long line of degeneration from Hegel, through such "left-wing" adherents as Strauss and Arnold Ruge, Bruno Bauer and Feuerbach, and from Kant through the distorting medium of Schopenhauer. The second represents materialism, with the singular trait of blending with the legitimate line of its empirical defences certain remarkable elements of a transcendental logic. The third illustrates agnosticism, with the additional and peculiar interest of being the Neo-Kantian par excellcnce. $^{1}$

Hartmann was born in Berlin, in I842, the son of a general in the Prussian army, in which he held a commission himself till disease that left him a permanent cripple turned him aside into the career of letters. Duihring, also born in Berlin, in 1833 , began his career in the Prussian department of justice, but

1 Prominent among the Neo-Kantians, after Lange, are Professors Cohen of Marburg, Bona Meyer of Bonn, Benno Erdmann of Kiel, and Dr. Hans Vaihinger of Strassburg. [Since the foregoing was written (1882), Dr. Vaihinger has become professor at Halle, and widely known as the author of the learned and acute Kant-Kommentar and the editor of Kantstudien.] 
was erelong compelled to abandon this, through loss of his sight. In spite of his blindness, however, he has kept up the most copious production and publication. ${ }^{1}$ In contrast to Hartmann, who leads the quiet life of a man of letters well-to-do, he has tasted no little of the bitterness of the human lot. For many years he won much reputation as a privat-docent at the University of Berlin; but in $\mathrm{I} 877$ he was dismissed from this office on account of his persistent and galling attacks on some of the scientific and philosophical performances of certain of his colleagues, particularly Helmholtz, and since then he has remained in the comparative quiet of private life. Lange, born near Solingen, in I \$28, made his university course chiefly at Bonn, where his principal interest seemed to be in philology and pedagogics. He then passed some years in practical life, partly as bookseller, partly as secretary of the Duisburg chamber of commerce. Later, he was made professor of philosophy at Zurich, where, in his case too, disease left its lasting marks in the effects of a surgical operation that nearly cost him his life. In 1872 , he was called from Zurich to Marburg, but died there, in I875, after prolonged sufferings, in the bloom of his intellectual powers, to the unceasing regret of that large body of his younger

${ }^{1}$ His works already comprise no less than twenty octavo volumes, in the various departments of metaphysics, economics, sociology, mathematics, and criticism. 
countrymen who were beginning to see in him a philosophic force of far-reaching effect.

Though the three men were so considerably separated in years, they began to act upon the public almost simultaneously. Lange's History of Materialism, so noted in its later form, first appeared in 1865 ; Dühring's first important work, the Natural Dialectic, was published the same year; while Hartmann's Philosophy of the Unconscions came first from the press in $\mathbf{1} 868$. The main lines of their several theories we are now to trace and endeavour to value.

\section{I}

In opening a study of Hartmann and his large circle of readers, we come at once upon the sphere of an influence whose reach in the present "enlightened public" of Germany it is impossible to overlook; I refer, of course, to Schopenhauer. Hartmann is generally and justly recognised as the mental heir of Schopenhauer, in direct succession. His so-called system, however, is far inferior in intellectual quality to that of his predecessor. He differs from Schopenhauer in giving to the empirical a great predominance over the a priori method, ${ }^{1}$ and in his doctrine concerning the nature of the Absolute. The former fact expresses his deference to the "stupendous

'The reader will easily recall his significant motto: "Speculative results by the inductive method of the natural sciences." 
achievements" of recent science; the latter, his ambition to frame a system that should blend in a single higher unity whatever of preceding theory he knew - Schopenhauer's pessimism and sundry idealistic gleanings and fragments, no doubt also first suggested by Schopenhauer, but in detail borrowed largely from Schelling and the "left-wing" adherents of Hegel.

Schopenhauer, seizing upon Kant's doctrine of the ex mente origin of Nature, and the consequently phenomenal character of the world, asked the question that cannot but rise upon Kant's results, What, then, is this "Thing-in-itsclf," assumed as the source $^{1}$ of the sensations that our a priori reason coördinates into a cosmos? He felt the force of Kant's arguments for the limitation of knowledge to the world of experience, the force of the contradictions into which reason was apparently shown to fall when attempting to apply its categories to a Thing-in-itself supposed to lie beyond that region. But he also felt the necessity of the Thing-in-itself, of an Absolute, in order to the relativity which, according to Kant, was an essential feature of knowledge. He perceived, too, the chasm that separated Kant's cloctrines of the will and of the intellect.

1 The reader must understand that this phrase represents Schopenhauer's interpretation of Kant, rather than Kant's own view. So, also, regarding much else that follows. 
Accordingly, he proposed to remedy both defects of the Kantian theory at once, by the doctrine that reason is only theoretical and the will not phenomenal but noumenal. In short, he comes to the dogma that the Absolute is simply Will, or what might more fitly be called Desire - a darkling, dumb outstriving, in itself unconscious, whose impulsions, under a perpetual thwarting from some mysterious Check, ${ }^{1}$ give rise to what we call consciousness.

The whole of being was thus reduced to terms of inner or subjective life. There was the dark undertow of the ever-heaving Desire, and woven over it the shining image-world of Perception: the universe was summed up as Will and Representation. Of this Will we knew nothing, save that it was insatiable; the forms of consciousness were not its expression, but its repression-its negation. Ever the higher these rose in the ascending cvolution of Nature, in reaction against its wilcler and wilder throbbings, ever the more bitterly must their necessary finitude thwart the infinity of its blind desire. Universal life was thus, from its own conditions and essence, foredoomed to miscry. Its core was

1 Schopenhauer nowhere expressly admits the existence of this; rather, he continually evades it, putting forward the essential insatiability of the Will as the explanation of pain, and so of consciousness. But the implication seems tacitly and unavoidably present everywhere. So also, as Hartmann has rightly noted, is the implicit assumption that the Will is intrinsically conscious, after all. 
anguish, its outlook was despair. And all the facts of existence, from wheresoever taken in the ascending levels of consciousness, confirmed but too darkly this haggard prophecy of a priori thought: everywhere the overplus of pain, everywhere illusion dispelled in disappointment. There was, and could be, but one avenue of escape - death and oblivion.

Upon this fact rose the whole structure of ethics. The "whole duty of man" was simply: Suppress the will to live. All moral feeling was summarised in Pity, and all moral action in ascetic living, to the end that, the tone of life being perpetually lowered, the Will might slowly sink into quiescence, and so life itself at last fade out into the repose and silence of annihilation.

Such was the philosophy, no doubt at bottom theoretically hollow, but still wearing on its surface a certain tragic fascination, that stirred Hartmann to attempt a new composition of similar tone on the ancient theme of Man. In the minds of Schopenhauer and Hartmann, let it be noted in passing, the philosophic problem takes for its leading question a phase of Kant's "What may I hope for?" The chief concern for them is, What is life all worth? They are both possessed by a profound sense of the misery of existence; but while, under Schopenhauer's treatment, the pessimistic strain seems to sound out only at the close, and appears 
to issue from conditions that bear solely on the purely theoretical question of the origin of experience, there can hardly be any doubt that with Hartmann the pessimism was first, and the hypothesis of the Unconscious an afterthought to explain it. ${ }^{1}$ His problem has the look of being this: Given misery as the sum of existence, what must be presupposed in order to account for it?

The method and the contents of his solution both show what a weight empirical evidence has with him, in contrast with dialectical. He professes a certain allegiance to the latter, and also makes free resort to a priori deduction of a somewhat antiquated type; but his general drift to fact, induction, and analogy is the patent and distinguishing feature of his book. ${ }^{2}$ As the explanation of his problem, and, indeed, of life itself, he seizes upon a striking but occult class of facts in physiological and psychological history. There is given directly in our experience, he says, the manifest presence of an unconscious agency. He refers in this to the class of experiences com-

1 This is quite evident in the earlier editions of Hartmann's first work, but becomes less and less so as the editions multiply and his thought gets more critical. In fact, in its latest form, his philosophy supplements this pessimism with a sort of concomitant optimism, operative in the present, while the effective pessimism is relegated to a remote future.

2 E. von Hartmann: The Philosophy of the Unconscious. Translated by W. C. Coupland. London: Triibner and Co., 1883 . 
monly grouped under the term "reflex action": facts of somnambulism, trance, clairvoyance, mem. ory independent of conscious perception, and instinctive knowledge - all those "unconscious modifications," in short, the emphasising of which formed such a memorable dissonance in the thinking of Sir William Hamilton. The recognition of "unconscious ideation" he traces clearly, too, to Leibnitz, to Kant, to Schelling, and to Schopenhauer. The Unconscious is actually here with us, Hartmann holds: there is a something beneath our consciousness, that performs for us, even when consciousness is suspended, all that is most characteristic of life, and that, too, with a swift and infallible surety and precision. What less can we do, then, than accept this Unconscious as the one absolute reality? We accept, and so come by the Philosophy of the Unconscions.

Just here, however, Hartmann is confronted by the warning of Kant. On grounds of a critical determination of the limits of reason, Kantianism forbids the philosopher to undertake the discussion of an object thus removed beyond the bounds of possible cxperience. This warning must first of all be silenced. So Hartmann now provides a metaphysics to meet the Kantian thesis that knowledge can only be of the phenomenal. Here he unavoidably leaves his favourite basis of facts, and resorts to hypotheses purely 
a priori. He proceeds in the light of the supposed contradiction involved in any transcendent Thing-initself - an assumed background, as it were, hid behind the vision-world of experience, this phenomenon rising thus between the Thing and the mind, and so veiling it. Hence he proposes as the remedy the bringing of the Absolute within the veil of the phenomenon, and, so to speak, between it and the mind, to lie there as if an originative tissue, connecting the two as it begets them. In other words, he makes the Absolute, construed as his Unconscious, the immancnt source of two concomitant streams of appearance: the one objective, the sensible workd itself, the other subjective, the stream of the conscious perceptions of the world. ${ }^{1}$ These two streams, as both flowing from the one Unconscious under identically corresponding conditions, are in incessant counterpart. Thus knowledge, though not a copy from natural objects, is an exact counter-image to them, engendered from a common source. Consciousness and Nature are both pure show (Schcin). The world is an "objective apparition" (cin objcctiver Schcin), perception is a duplicate "subjective apparition" (cin subjectiver Schcin), and both are exhaled from the depths of the Unconscious: phenomenal existence is thus doubled throughout. Space, Time, and the Causal Nexus are also duplicated, as well as the items they contain or connect.

1 A reminiscence here of Spinoza, or of Spinoza hegelised. 
All, instead of being merely subjective, are objective also.

The Kantian doctrine - that Space, Time, and Causation are merely subjective - being thus disposed of, its corollary of the empirical limitation of knowledge likewise falls away, and Hartmann assumes he may proceed with his metaphysical programme. First, however, the method of philosophy must be more precisely accentuated. How can knowledge of the Absolute, which (as the Unconscious) lies wholly beyond our consciousness, ever arise? By virtue of two facts, replies Hartmann : our "mystic sense of union with the Unconscious," and that uniformity of Nature which constitutes the basis of induction. The organon of philosophy has thus two factors, Mystic and Induction. From the former come all the clues to knowledge, the mysterious "suggestions" of the Unconscious itself; from the latter, the verification of the clues, as they are followed into the complicated system of experience. It is by induction alone that philosophy distinguishes itself from religion; for religion and philosophy both alike take their origin from the mystic of the "suggestions," though religion keeps these mysterious whisperings in the obscure but kindred form of myth, while philosophy, following the self-revelation of Nature in induction, lays them bare in their clear and literal truth.

By the light of this method, now, the Unconscious 
so far reveals its real nature that we know it is something infallibly and infinitely intelligent. Strictly, it is not the Unconscious, but rather the $S u b$ conscious, the Unbeknown (das Unberunsste). ${ }^{1}$ In its infallible infinite-swiftness of perception, however, as experience testifies of it, there is a transcendent type of the flashing inspirations of genius. It is therefore not self-conscious; its intelligence is clairvoyant, and has no "large cliscourse of reason, seeing the end in the beginning." But as intelligent energy, it must contain grounds for the two constituents that we find present in all intelligent activity within experiencewill and representation; and here is the point at which to correct and complete Schopenhauer's doctrine of the Absolute. Will is not the Absolute : for will as well as representation is part of conscious experience; will is itself phenomenal. Rather are will and representation the two coördinate primal manifestations of the one Unconscious; and we thus get an inductive basis for Will and Idea as metaphysical realities, both unconscious, however, - factors inherent in the being of the Unconscious.

Here in the Unconscious, too, is the truth of Schelling's famous Neutrun - the something neither subject nor object, that he set up for the Absolute; and no longer, Hartmainn thinks, a target for Hegel's "the

1 Zekle crep' up quite unbeknown.

Loweln: The Courtin'. 
Absolute popping up as if shot out of a pistol," since it is now construed in terms vouched for by actual experience. Moreover, the conception is here found that will embosom the system of Hegel himself : the "logical Idea" (das logische Idee) falls as a mere constituent into the vaster being of the Unconscious. For what is the Unconscious, as revealed in experience, but that which works by the incessant interplay of representation and will? And just as will in its essence is only blind Struggle, so is representation in its essence nothing other than luminous Idea - the all-embracing logical bond that grasps the vague of sensation into distinct objects, and these objects again into genera, and these genera at last into a single organised whole of being. ${ }^{1}$ The Unconscious, then, is primordially Will and Idea ; and from the connexion of these arises the twofold world of finitude, pouring forth from the Unconscious in the counterpart streams of object and subject, of sensible world and conscious perception.

${ }^{1} \mathrm{~A}$ one-sided and superficial construction is here put upon Hegel's theory. Justice to Hegel requires us to remember that his Idea (Idee) is never represented as a bond merely "logical," in contradistinction from the "will," but always as the "negative" or "sublating " unity of intellect and will - a unity that takes up and solves the antinomy that appears between them when their distinction and contrast is taken abstractly; taken, that is, in neglect of their correlative union, and so viewed partially instead of in the whole. Hartmann's leap, too, from idea as representation (Vorstellung) to the hegelian Idea (Idee) is, to say the least, a bit sudden and violent. 
Hartmann is now at length well ashore on the familiar coasts of Schopenhauerland. This Worldchild of clairvoyant virgin Idea and darkling brutal Will is no product of far-sighted love, endowed with an exhaustless future of joy. It is the offspring of violation, of a chance burst of passion, and its being carries in it the germs of misery ever expanding. This gloomy theme Hartmann now pursues statistically over all the provinces of experience, seeking to prove that suffering everywhere outbalances happiness, that "he that increaseth knowledge increaseth sorrow," the pitch of anguish rising higher and higher as Nature ascends in the scale of consciousness, and especially as man enlarges and quickens that intelligence whose chief result, from the nature of the case, must be the keener and keener sense of the deceitfulness of life.

Nor, continues Hartmann, let any one hope to cvade this conclusion by theories of possible compensation. Men no doubt usually live in one of Three Stages of Illusion in regard to this essential misery of life. They either think that even in this world the sum of joy so far exceeds the sum of sorrow as to make existence here substantially good; or, if sobered out of this by inexorable experience, they takc refuge in the Hercafter, in the prospect of an endless opportunity beyond the grave, - a refuge of lies, for the one Unconscious is the sole basis 
of consciousness, there is no indestructible self, death is simply subsidence into the absolute vague, and immortality is therefore a delusion; or, finally, surrendering both of these dreams, they resort to the future, and indulge in the illusion of hope, this world can yet be made the abode of happiness, and let us make it so. But, admonishes Hartmann, all these fancies ignore the contradiction that lies in the very heart of existence; there is but one plain moral in the drama of experience, and that is the utter hopelessness of life. The world may not, indeed, be the worst world possible, but its being is certainly worse than its not being. It were better if the world had never come to be. Ethics consequently is summed up in the single precept, Make an end of it!

For the Will being in its essence but wild unrest, both metaphysics and experience teach that the only way of escape from the misery inherent in life is to bring the Will to quiescence; or rather, speaking plainly, to blot it out. And in consciousness, seat though this is of sorrow while it lasts, we have the light to the one sure way of deliverance; as consciousness is the preparation for the rescue of the Idea from the clutch of the Will. The way of salvation is the way of annihilation. Our sole intelligent desire, won in the bitter school of experience, is the longing for release from struggle, the wish to be delivered from this delusive Maya of consciousness 
and to pass into motionless Nirvana. Hasten, then, the day when the pitch of misery shall have brought the race to the saving anguish of despair, and mankind in united and complete renunciation shall execute a universal auto $d a f e ́$, by final self-immolation ${ }^{1}$ ending the tragedy of existence forever!

Nevertheless, while this is the sum of its theory, ethics may have the important practical question to settle, How shall we make an end of things the surest and soonest? There is here indeed no duty, there is no such thing as duty; there is simply a possible satisfaction of the desire for release from misery. But to this end there may be an alternative of means. We may each promote the end, either by an indirect and negative or else by a direct and positive agency. By following the traditional standards of virtue, we may advance society in order, peace, prosperity, and apparent welfare, the indirect though real outcome of which is however but the profounder despair; or we may by passion, fraud, and violence heighten the rising flood of misery directly. Which each will do is in fact a matter of

1 Hartmann, like Schopenhauer, requires us here to make a refined distinction between this final "act of devotion" and suicide. Suicide, both say, is only an enraged and disappointed form of the "will to live." The real difference, however, is that suicicle, directly, fails to go far enough; nothing short of self-annihilation will answer. But it is difficult to see why, with their doctrine of individual transiency, suicide doesn't "get there all the same." 
temperament and circumstance. For pessimism does nothing actively to promote what traditional ethics would brand as immorality; it merely leaves the so-called morality or immorality to be dealt with by the fate inherent in existence. The interaction of both is the compound force that drives the universe surely to the desired dissolution.

Moreover, the negative or indirect method of pessimist ethics gives rise to problems of history, of politics, of religion; for one theory of these matters, put in practice, may promote the final catastrophe more surely and swiftly than another. Thus pessimism has its Philosophy of History, in which history appears as the evolution of the Three Stages of Illusion mentioned above. The great scene of the first stage was the pagan world, typical in which was the Hellenic joy in sensuous life, and the Roman glory in conquest and organisation. The scene of the second is Christendom, so far as it is untouched by decay of its essential dogmas. The scene of the third is the modern world of "enlightenment," of "advanced" thinking, of political and economic reorganisation in the interest of "the good time coming." Following this is the surely predestined disillusion that is to lead to the final dissolution.

Pessimism has also its Philosophy of Politics. Its ideal polity is a "strong government," based on the 
theory of socialism and administered in the socialistic interest to the remotest detail.

Finally, pessimism has, as a rounded philosophy must have, its Philosophy of Religion. According to this, religion is the consecration in myth and mystery of the meaning that philosophy puts rationally. Religion therefore undergoes an evolution side by side with the development of philosophy. Accordingly pessimism sees all religions arrayed in two successive groups, - the Religions of Illusion and the Religion of Disillusion. The former break up again in accordance with the Three Stages. Paganism is the religion of the first stage; Christianity, untainted by rationalism, the religion of the second; "free religion," "liberal Christianity," the "positive religion," "ethical culture," the "church of humanity," - all the manifold experiments at making a "religion" whose interest is to be centred in this world alone, constitute the religion of the third. Over against all these stands Hartmann's "religion of the future," the Religion of Intelligence (die Religion des Geistes), as he likes to call it, whose priests are to celebrate the doctrine, solemnise the rites, and inspire the devotees of the great Nirvâna - the eternal Silence and Blank.

These are the main lines of the theory that enlists the adhesion of the throng of jaded or faded 
sentimentalists who make up the body of Hartmann's admirers. In contrast with the Germany that responded to the sober and invigorating views of a Kant, a Fichte, or a Hegel, these people are a curious and disheartening study. Apart from the revulsion that minds of moral vigour must feel at such results, the lack of critical logic exposed in the acceptance of such a net of contradictions is a telling evidence of the decline in theoretical tone among the "cultivated classes." Limp as this doctrine hangs, with its astonishing attempt to construe the Absolute by means of pictorial thought, by adjustments of components set in serial concomitance (the duplicate worlds of object and subject), by a temporal antecedence to the world of Nature (the Unconscious in its "privacy," before the world arose), in short, by means of categories in reality mechanical, flung on the screen of Space and Time, - to say nothing of its vain struggles to bridge the chasm between consciousness and the Unconscious, of its Absolute at once unconscious and conscious, of its proving the reality of transcendent knowledge by the immanence of the Unconscious in the duplicate worlds and therefore in the world of cognition, when it had already assumed this transcendency of knowledge to establish the existence of the Unconscious, - despite all this, there seems to be a sufficient multitude to whom it gives a satisfaction, and who are even will- 
ing to do battle, at least on field of paper and under fire of ink, for the high privilege of a general selfannihilation in the considerably distant future.

It is true, however, and encouraging, that this class of minds does not form the whole of the German or other public; that authority goes by weight and not by numbers; and that Germans of the higher and more thorough order of culture early discerned the bubble, and pricked it without ado. ${ }^{1}$ On the other hand, it would be materially unjust to take leave of Hartmann and Schopenhauer without emphatically acknowledging the service they have both rendered by so completely unveiling the pessimism latent in any theory that represents the Eternal as impersonal. They cast a light far back of their own work, and illuminate for our instruction the void which confronts us, in the systems of their greater predecessors, when we look for a doctrine of the Real that answers to our need of a Personal God.

\section{II}

When we turn now to Dühring, we find ourselves suddenly in the opposite extreme of the emotional climate. Dühring is materialist, but he is optimist still more. Indeed, it seems not unlikely that he is optimist before he is materialist, just as Hartmann

1 Compare Professor Wundt's article on "Philosophy in Germany," in Mind, July, $1 \$_{77}$. 
is pessimist first and expounder of the Unconscious afterward. In taking him as the representative of materialism, I have purposely passed by names far more widely known, - those of Moleschott, Büchner, and Carl Vogt, for instance, - not only because these are all men of popular rather than of severe methods, having far less weight in the scientific world than he, but because he is a man of far more scope, of really thorough attainments, of positive originality, and of a certain delicacy of intellectual perception characteristic of the true thinker. ${ }^{1}$ Haeckel, who by his extravagant ardour in advocating atheistic evolution, his vast knowledge of biological details, and his high repute among his associates in science, fills so large a place in the minds of most readers as a representative of materialism, must be counted out, according to his own public and repeated protests, as not intending or teaching materialism at all, but a monism

1 A writer more correctly to be compared with Dühring is Czolbe, of Königsberg, author of a naturalistic theory expounded in his Limits of Human Knowledge on the Basis of the Mechanical Principle, who died in 1873 . But he did not, like Dühring, develop his views into a comprehensive philosophy, applied to all the provinces of life. He belonged, too, rather to the previous generation of thinkers than to this, and was known there as an opponent of Lotze. Lotze, gifted and infuential as he was, I have also passed by, later in the essay, in the agnostic-idealist connexion, in spite of his acknowledged bearing on the position of Lange, mainly for reasons similar to those that led me to disregard Czolbe : he belongs to a movement earlier than the one here considered. 
of "substance at once conscious and material," so that everything is for him "ensouled." Besides, even were his protests disregarded, he would here have to give way to Dühring, on the ground of not concerning himself seriously with the philosophic foundations of materialism, but only with such of its phenomenal details as belong more especially to organic existence.

Dühring names his system the Plillosophy of the Actual. This title sounds almost like a direct challenge to Hartmann, as much as to say, "No mystical Subconscious, no incognisable Background here!" And to have this really so is Dühring's first and last endeavour. The Absolute for him is just this world of sense, taken literally as we find it; briefly and frankly, matter. As we perceive and think it, so it is-extended, figured, resistant, moving, a total of separate units collected into a figured whole, and into a uniformity of processes, by mechanical causation; in short, a variable constant, a changeless substantive whole undergoing by changeless laws ceaseless changes in form and in detail.

This striking conception of an indissoluble polar union between Permanence and Change is according to Dühring the vital nerve of the Actual, and the key to its entire philosophy. ${ }^{1}$ But this polar

1 In this he apparently presents a one-sided reflection from Hegel, with whom Identity and Difference are the elementary dynamic "mo- 
coherence, he thinks, is only possible by the Actual's consisting of certain primitive elements, definite in size, figure, and number, subject to definite laws of combination and change of combination. The permanent in the Actual is thus (I) Atoms, (2) Types, or the primitive Kinds of the atoms, the origin of species in Nature, and (3) Laws, determining the possible combinations of the types and the order of succession in these combinations. The variable, on the other hand, is the series of changing combinations as they actually occur; these amount simply to a change in the form of the Actual, in its parts and in its whole. The evolution of this form moves toward a certain result, which, as necessarily evolved from the primitive conditions and therefore involved in them, may be regarded, though only in the sense of a mechanical destination, as the Final Purpose of the IVorld.

The Actual, then, taken in its entire career and being, presents the form of a self-completing system of relations. In other words, there is a Logic of Nature, inherent in the world itself. To reproduce this logic in the form of our knowledge is the aim and sum of science; to reproduce it not only so, but also in disposition and life, is the sum of philosophy. Philosophy being thus the aim and ments" of the absolute Idea. But the relationship really goes back to Greek philosophy, in which Dühring seems much at home. 
the distilled result of all the sciences, its method and organon must be identical with theirs. The method is hypothesis, verified by experimental induction and criticised by thought. The organon is the imagination checked by the understanding, and the understanding checked by dialectic. The imagination gives us the requisite hypotheses; the understanding tests and settles their rival claims, dialectic purging it from the illusory contradictions into which it naturally runs when facing the problenus of ultimate reality. These problems all concern the notion of infinity, either in the form of the infinitely great or the infinitely small; and the contradictions, seemingly unavoidable, to which they give rise, are in truth, says Dühring, mere illusions, springing from the lack of a First Principle that has genuine reality. These contradictions, he continues, formed the basis of Kant's boasted dialectic, by which he is thought to have exposed the illusion hiding in our very faculties. Kant would have it that these contradictions issue from the inmost nature of the understanding itself, when it presumes to grapple with things as they are; but their appearance in the form of his famous "antinomies" was in fact owing to his imperfect concep. tion of the origin of knowledge, and his consequent falsification of Nature into a mere phenomenon.

With this assertion, Duhring confronts Kant's 
standing challenge, "How can you make out that perceptions and thoughts are true of the Real, when from the nature of the case they must be products of our a priori cognition, and therefore shut in to the perpetual contemplation of themselves?" "By searching in the right place," Dühring answers in substance, "and finding that 'common root' of sense and understanding of which you yourself, Kant, have more than rarely spoken, but the investigation of which you have found it so much easier to evade." What sort of "criticism of reason" is it, he goes on in effect, that stops with thrusting experience into the limbo of an abstraction called the a priori, and never asking what the Prius thus implied must be? Man brings his perceptive and thinking organisation into the world with him, doubtless; but from whence? Whence indeed, if not from the bosom of Nature? Let us but once think the Actual as the Actual - as a continuous whole, unfolding toward its Final Purpose - with man and his conscious organism verily in it, and the reality of knowledge becomes intelligible enough. For consciousness is then no longer an imprinted copy of things, as the truth-cancelling and unthinkable theory of dualism makes it, but becomes instead a new setting of them, pushed forth from the same original stock. Man thus inherits the contents and the logical system of Nature by direct 
transmission, and consciousness, while remaining self-converse, becomes self-converse in which the process of the world is rënacted. ${ }^{1}$

Not only do we reach in this way the reality of knowledge, but we discover at the same time the ground for the occurrence of contradictions in it, and the principles of a dialectic that will solve them. This Natural Dialectic, proceeds Dühring in his treatise with that title, moves in the following manner. Knowledge, though identical with the Actual in contents, cliffers from it in form; it is, in fact, just the translation of these contents from the form of object into that of subject, from the form of being into that of knowing. Now, a leading trait of this subjectivity is its sense of possibility - of the power to use the active synthesis that works in Nature, and that now in mind works as the secret of its thinking, with an indefinite freedom. In short, it possesses imagination. As a consequence, it falls under the illusion of the false-infinite (Spinoza's infinitum imaginationis), and assumes that the principles of its logical synthesis - space, time, and causation — are as infinite in the object-world as they ever appear to be in itself. But to suppose causation, time, and space to be really infinite would strip the Actual of the quality of an absolute, and thus annul reality altogether.

${ }^{1}$ Notice the reminiscence here of Leibnitz's monadology. 
For, first, the chain of causation cannot in fact run backwards infinitely, but must at some time or other have absolutely begun; and it must break off its retrograde in logic as well as in timemust cease in respect to "grounds" as well as in reference to "causes." For real causation belongs only to events and change, not to Being and identity, and hence there must come a point where the questions What causcd it and Why are finally silenced, else there would be nothing absolute; whereas the underived necessity of Being, and of its clements and laws, is the first condition for a rational view of the world.

Secondly, it is quite as clear that real time cannot be infinite; for real time is nothing but the total duration of causal changes, and to suppose this infuite would, reckoning backwards, make the beginning of causation, just now established, close an infinite duration.

Finally, real space is manifestly just the extent of the sum-total of atoms; and this must be finite, because the number of atoms is necessarily definite; for, if it were not, the Actual of perception, as a scries of changes by definite combination, would be impossible.

Real or objective space, time, and causation are thus all finite; the persuasion that they are infinite, with all the consequent array of counter- 
part propositions contradicting the foregoing, is an illusion arising from neglect of the differences between object and subject. Subjective space, time, and causation have, to be sure, a quasi-infinity; yet our authentic thought, even about them, dissolves this illusion, and agrees with reality, as soon as the understanding brings its dialectic to bear. Here, then, concludes Dühring, the whole Kantian fog-bank of "antinomies" is explained and scattered. One series of Kant's pairs of counter-judgments is entirely true; the other comes from the false-infinite, and is the work of the imagination, uncritically mistaken by Kant for the understanding.

From this point onward, then, the metaphysics of the Actual may freely proceed. The Actual as absolute, as to its veritable Being, is eternal; time and causation apply, not to its inmost existence, but only to its processional changes. Nevertheless, this differentiation is just as necessarily involved in its nature as its abiding identity. The system of changes called the sensible world must accordingly, at some instant or other, have strictly bcgun. Thenceforward the Actual, poured in its entirety into these changes, moves in a gradually varying, many-branching Figure, whose elementary components are of constant dimensions and number, but whose shape is undergoing incessant alteration, giving rise, from epoch to epoch, to forms of 
existence constantly new. The series of elementcombinations is not recurrent, and the world-whole moves, not in a circuit, but in a continual advance. This movement is carried forward by the Logic of Nature, that is, by the combined action of causation, space, and time, which are its only ultimate principles. Hence real causation is the transfer of motion by the impact of extended parts, and the evolution of the world proceeds by the single principle of mechanism. Strictly, then, universal logic is simply a Mechanics of Nature. ${ }^{1}$ This cosmic principle unfolds itself, primarily, in two auxiliary ones, - the Law of Difference and the Laze of Definite Number. The logic of the universe, bearing onward in obedience to these, must move, however, to a clefinite result, the above-named Final Purpose of the World: this real logic must play the form inherent in it out to completion. Thus the universe moves to a self-predestined close, and is therefore under a third and final law, - the Law of the Whole.

These three laws, now, are the Open Sesame to all philosophy, theoretical or practical. They are, for instance, the secret of that Natural Dialectic

1 Dühring's earliest book of mark was his Critical History of the General Principles of Mechanics, a work crowned by the University of Göttingen, and held, generally, in the highest esteem. It passed to its second edition in 1877 . A third edition has recently appeared. 
which is to purge our understanding of its subjective illusions. Exactly as the Law of Sufficient Reason ${ }^{1}$ must limit itself, as we just now saw, by the real and higher Law of Causation, so that the universe-process may strictly begin, so must the other subjective logical principle, the Law of Contradiction, ${ }^{2}$ be construed not to exclude, but to include, the Law of Natural Antagonism; otherwise the Mechanics of Nature would be impossible.

The three laws teach us, too, not only to recognise the presence of continuity throughout existence, but how to interpret it with precision, and not to obliterate difference in our anxiety to establish identity. The Law of Difference and the Law of Definite Number not only provide for the movement of Nature through the determinate steps of the inorganic and the organic, but also for the ascent by a specifically new element from the lifeless to the living, then from the plant to the animal, and finally from animal to man, with his rational consciousness. The whole, to be sure, must be developed through the single principle of mechanism, but the now favourite doctrine of the "persistence of force" violates the essential principle that specific differences - primitive Types-

1 That every occurrence must have a reason, and a reason sufficient to explain it.

2 That no subject can have contradictory predicates. 
inhere in the primordial being of the Actual, and is therefore false. So, too, the Darwinian pseudolaw of the "struggle for life," with its unsocial corollary of the supreme right of the strongest, must be rejected, not simply as striking at the root of ethics, but as violating the Law of the Whole. Species can arise neither by the transfer of a mere identity of force nor by any number of "survivals" of what merely is or has been, but must come from Kinds in the primitive constitution of the Actual.

At this juncture, however, Dühring feels called upon to reconcile the fact of ascending differences with his principle of mechanical continuity, and to explain, moreover, the original transit from identity to difference - from the primal repose of the Actual to its unresting career of causation. But after manifold attempts, which all imply the unmechanical hypothesis of a conscious primal purpose in his Absolute, he finally takes refuge in the "mechanics of the future," which is sure some day to unravel the mystery.

But at any rate, he goes on to say, our three laws lead us steadily and securely to the needed completing term in the theory of the world, by settling the supreme question of the character and value of life. This question he discusses in his work entitled The Worth of Life. He solves the 
problem in the optimistic sense, by means of the principle of compensation: Existence is unquestionably marred by evil, by real evil; but its dominant tone, its resistless tendency, its net result, is genuinely good. And this solution does not rest on any merely subjective accidents of temperament, but directly on the objective principles of existence itself. It is found, in short, in the Law of Difference and the Law of the Whole, and in the essential necessity, the inevitableness, of the being of the Actual.

Existence, if it is to be understood, must be judged, not by the morbid cravings of sentimentalism fed on fantasy, but by sound sentiment which is founded on clear comprehension. When we once see distinctly into the nature of the world, and adjust our tone and conduct to that, we shall find a sufficient comfort in life; there is a bracing satisfaction in the discriminating insight into that which must be. Existence has, too, a cham, in itself, and the secret of it lies in that very variety, or difference, which constitutes the principle of its movement. Moreover, life mounts in differentiation, and the increased objective good of the higher levels of consciousness outweighs the increase of subjective susceptibility to pain. Further, contrast not only heightens pleasure, but is the source of it: the sense of resistance overcome 
is the very root of joy; evil is the requisite foil for the reaction essential to life.

Still profounder elements of good - subtle, pervasive, even mystic - are contributed by the Law of the Whole. Not only does the ascent of life to higher and higher levels point clearly to the greater fulness of existence as part of the Final Purpose, and so give play to the "influence of the ideal" in the encouraging prospect of the future, but our inseparable union with the Whole, our direct descent from Nature, and our reproduction of its life in ours, impart to us a certain Cosmic Emotion-Dühring calls it der universelle Affect-which, stirring at the foundations of our being, fills us with a dumb sense of the oneness of all things, and by forces coming from beneath consciousness, nay, from the beginnings of the world, binds us to the totality of existence with an attachment that no sum of ills can utterly destroy. It is from this Cosmic Emotion that the inborn love of life and the instinct of self-preservation arise. Our joy in the landscape comes from it; also our delight in art; our capacity for poctry; our bent to science ancl philosophy, by which we would figure to ourselves the form of this treasured All. It is, finally, the source and the reality of the set of feelings consecrated by the name of religion. To deny the worth of life is therefore to put ourselves in con- 
flict with the elemental forces of our being, which will subdue us in spite of our struggles.

Nevertheless, Dühring continues, though life is essentially good, there is real evil in it, and one condition of its good is that we shall rise to higher good by the spring from overcoming the evil: the world makes itself better through us as channels. In this fact we pass from theory to practice, finding in it the basis of ethics. The first principle of ethics follows from the law that contributes so much to the excellence of the Actual - the Law of the Whole. The highest practical precept is, Act with supreme reference to the Whole. But inasmuch as we are members not only of the Absolute Whole, but of the lesser whole called society, we can only act in and through that. Accordingly, first in the order of his practical theories comes Dühring's sociology.

His writings in this field are voluminous, especially in political economy, in which he adopts and develops the views of our countryman Carey. Carey, he thinks, has revolutionised this subject. The doctrines involved in the free-trade view, especially the principle of unrestricted competition, he considers a deification of mean self-interest. They strike at the foundation of rational ethics - the supreme moral authority of the Whole. Away with them, the11, and substitute instead the doctrines of benignant coöperation! This sentiment is carried 
out in a corresponding Philosophy of Politics, in which Duihring develops an extreme socialism. That the social whole, however, is conceived in the sense of a dominant atomism, very presently appears. The "whole" aimed at is simply a greater mass of force, to give effect to the caprices of that style of "enlightened" individual who so ignores the great historic whole as to see in the organic institutions of reason - the family, the state, the church nothing but barriers to the career of humanity.

The end of government, Diihring holds, is "to enhance the charm of life"; and here, unfortunately, in settling the practical test of enhancement, he is betrayed into destroying the profound principle on which he rested his case for the worth of life - that we must be guided by objective values, and ignore the outcries of subjective caprice. It appears to him that hitherto there has been no considerable political or social wisdom in the world. Social organisation, as well as political, ought now to undergo a complete re-creation, with the aim of giving the greatest possible range for each individual to act according to his own views of what regard for the whole requires. For example, all governments armed with force are to be done away. In their stead is to come voluntary association. Democratic communes are everywhere to replace organic states. There is to be no centralisation, no one 
great Commune, but numbers of little communes, to suit the convenience of individual preference. There is to be universal "equality," and women a redeeming stroke of justice - are to share in all the vocations, offices, emoluments (and the few burdens) of society, equally with men. Instead of compulsory wedlock, there is to come voluntary union from love, the bond to cease when the passion ceases.

We are now certainly at a long remove from the hostility to self-interest that erewhile would prohibit unrestricted competition, and revolted at the selfishness of free-trade. Education is to be reorganised in behalf of these conceptions, which are further supported by an appropriate Philosophy of History. History is simply a continuation of the drama of Nature; it tends to life, the variation of life, and the enhancement of its charm. The test of historic progress is the heightening of self-consciousness; but this Duihring seems to take as the greater and greater accentuation of the individual's sense of his validity just as he stands at each instant. The career of history has, accordingly, three periods: that of the ancien regime, that of the transitional present, and that of the free and exhilarating future. This future, however, is to be conducted by tolerably dry logic; much sentiment and refinement are "aristocratic." 
A suitable Philosophy of Religion closes the general view. Religion, Dühring maintains, is really nothing but the "Cosmic Emotion." Historic religions are only superstitious misconceptions of this profound pulse of the universe; they are all to disappear, as essentially worthless pseudo-philosophies. The "society of the future" will neither worship nor sublimely hope: the Philosophy of the Actual has dispensed with immortality as well as with God. For, to say nothing of the predestined catastrophe of the universe, the individual consciousness must cease at death. There is for conscious beings no common basis in the cosmic whole of the Actual; each conscious being is a perfectly self-enclosed circuit. Nor is there any individual basis of consciousness except the body. An individual consciousness is merely a clefinite "situation"-one specific combination - of the world-atoms. Death is its dissolution, and is therefore final extinction.

The system which opened with such keen vigour of theoretic purpose, and which, as contrasted with Hartmann's, exhibits so many points of a higher, firmer-knit, and subtler intelligence, has ended in a moral atomism as it began in a physical - in utter social dissolution. It is, however, only paying the penalty of inadequacy in its theoretical principle. Its root of irrationality is identical with the irrational 
principle in Hartmann's theory - the undertaking to construe the absolute with the categories of the relative, to think the eternal in relations of time and space and motion.

It is a notable merit in Diihring that he himself, and with no light emphasis, lays down the principle here implied; but his conception of absolute being forces him fatally to contradict it. $\mathrm{He}$ will have the chain of causation once on a time begin. But a beginning is necessarily a point in time, and a point in time is necessarily related to a before as well as to an after. Dühring consequently finds it impossible even to state his beginning of change without referring it to a supposed rest preceding it; in no other way can he make room for a continuous mechanical nexus in the whole of his Actual. The Actual is thus necessarily brought wholly under time; time and causation are carried back, whether or no, into "Being and identity," and Dühring is asserting in onc breath that the absolute is not subject to relative categories, and yet is so. After his scruples about time and causation, it is remarka. ble that he manifests no hesitancy in applying space to his absolute. He maintains real space to be finite, and thus annuls his absolute once more. For so, his total Actual has a limited extent; but an extent, like a beginning, must be defined by something other than itself, is unthinkable except 
in contrast to a beyond, and therefore the absolute, as really extended, is undeniably made relative. Should it be replied that this relativity is fallacious because it is only a relation to unreality, as real space is finite, and so the pretended beyond on which the Actual is said to depend is a pure illusion, the empty "infinite of the imagination": then we should have the worse case, that the Actual has to be relative to this phantasmal act of consciousness; and we should end in the contradiction, that the absolute is conditioned by its own unreal product. So impossible is it to define the Real except in terms of thought.

The insufficiency of the Actual exposes itself still further, when Dühring comes to discuss the origin of consciousness and the reach of knowledge. He takes a fatal step when he seeks the "common root" of sense and understanding in a time-and-space prius, ignoring the fact that he has given no answer but bald denial to the Kantian doctrine of the ideality of space and time; and that, until the supports of this doctrine are removed, there can be no use of these elements to locate a root of consciousness: to search for the prius of something, in a region still presumably the result of that something, is an industry not likely to be largely rewarded. Dühring's entire dialectic, like the part of it shown in his attempted refutation of the Kantian antinomies, rests on the assumption, which 
he does not argue, that there is a space, a time, and a causal progression distinct from the thoughts to which we give those names - an assumption which he may have hoped to warrant by establishing afterwards a mechanical transit from mere vitality to consciousness. From any serious attempt at establishing such a transit, however, his clear insight into the limitation of the "persistence of force" prevented him from making.

But, as with other partial philosophies, it is in the practical sphere that the self-contradiction in his principle shows at its worst. This principle compels him at the outset of his ethics to set up the supreme authority of the Whole, but its lack of ethical substance brings him at the end to bare individualism. At first we feel as if he had failed to draw from it the high consequences of which it seemed capable. Why, we say, should he sink from the stern ethics of devotion to the Whole into this wretched atomism of private caprice? But we have here the genuine drift of his scheme; for real morality is impossible on a pessimistic basis, and Dühring's principle, in spite of his subtle and imaginative plea for it, is optimistic only by illusion. The very Whole which he makes the ground and the sovereign object of our duty is in fact but a monstrous Power, whose self-centred "Final Purpose" is the burial of the moral life, while yet only on its threshold, in a 
hopeless oblivion. The yearnings of her offspring, imparted to them by her "Cosmic Emotion," Nature does not share. She brings them forth, "to laugh and weep, to suffer and rejoice" for a season, then to pass to the Abyss, whereto she also, with her latest and highest, too surely is speeding.

Life upon such terms is essentially worthless, let it be painted in what bewitching colours it may. The resistless drift of such a theory is either to despair, as in the case of the frank pessimism of a Hartmann, or else to illusions of reconstructing the future in behalf of capricious desire. We cannot hope for the abiding: let us then turn to the satisfactions of the hour! In effect, the professed hedonism of Dühring's theory is at the last pure egoism. Covering the horror in the depths of life with an optimistic gloze upon the surface, Actualism can have no final precept but to cultivate the Whole so far, and only so far, as it may be means to the greatest sum of individual enjoyment: therefore, "zohatsoever thy hand findeth to do, do it with thy might; for there is neither wisdom nor device nor knowledge in the grave - and thither thou goest."

\section{III}

We have now seen monism, in two of its most strongly contrasted forms, undergo dissolution by the inner necessities of its own logic. Pseudo-idealism 
and intellectualised materialism have alike brought monism to a reductio ad absurdum when they faced those problems of practice which are the touchstone of all philosophy. It was only natural that metaphysics of this order should give way, then, to an agnostic interpretation of the critical principle, and that philosophy should at length undertake a return to Kant, in the hope of some sounder development from his doctrines. We have next to see how this renewed agnosticism, in its aim to be completely rigorous, also comes to self-dismemberment, and supplants itself against its own intent.

In passing thus to Lange, it is not surprising to find him animated by the desire to lay a better foundation for ethics than either pseudo-idealism or materialism has proved able to build. His History of Materialism is not properly a history, but a philosophy buttressed by history, in which, by exhibiting materialism in the utmost possibilities that ages of restatement have been able to give it, he aims to expose its deficiencies exhaustively, and to assign the true weight which its principle and the principle of idealism respectively should have in a rational theory.

There must be sought, Lange begins, some higher standpoint than either materialism or current idealism affords; and this, he is convinced, is to be found in the doctrine of Kant, provicked it be rigidly main- 
tained and consistently carried out. In his own words, "As a beaten army looks about for some strong position on which it may hope to rally, so now for some time the signal has been heard on all sides, Fall back on Kant! Still, not till recently has this retreat been really in earnest, and now it is found that Kant's standpoint could never in strict justice be described as left below. To be sure, misconceptions of his meaning and the pressure of the impulse to metaphysical invention did for a while tempt his successors to endeavour the rupture of the strict limits he had drawn to speculation. But the sobering that has followed this metaphysical debauch has compelled a return to the abandoned position; and all the more, that men see themselves again confronted by the materialism which once, on Kant's appearance, had fled and hardly left a trace." Lange is deeply sensible of the deficiencies of materialism, but at the same time appreciates the truth of a certain phase in it, as against the pretences of what he takes for idealism. He says: "Materialism lacks for rapports with the highest functions of man's intelligence. Contenting itself with the mere actual, it is, aside from the question of its theoretic admissibility, sterile for art and science, indifferent or else inclined to egoism in the relations of man to man."

And yet, on the other hand, "the whole principle of modern philosophy, outside of our German 'spell' 
of romancing with notions (Begriffsromantik), involves, with scarce an exception worth naming, a strictly natural-scientific treatment of everything given us by sense. . . Every falsification of fact is an assault upon the foundations of our intellectual life. As against the metaphysical poetising that arrogates the power to penetrate to the essence of Nature, and determine from mere conceptions that which experience alone can teach us, materialism as a counterpoise is therefore a real benefaction." But on the other contrary again, idealism met a want that mere empiricism cannot supply. "The endeavour," he adds, "is almost as universal to overcome the one-sidedness of the world-view arising from mere fact. ... Man needs a supplementing of this by an ideal world created by himself, and in such free creations the highest and noblest functions of his mind unite."

In these words Lange's general position already reveals itself. If Hartmann calls his view the Philosophy of the Unconscious, and Dühring his the Philosophy of the Actual, Lange's might in analogy be named the Philosophy of the Idcal. He prefers, however, to speak of the Ideal not as a philosophy, but only as a standpoint; because he wishes to include in philosophy not only the means for satisfying the craving after icleality, but the means for closing with the demand for certainty. The aim of 
philosophy, he holds, is not a doctrine, but a method; and philosophy itself, when precisely defined, is simply the critical determination of the limits of the main tendencies in our faculty of consciousness. These tendencies are two: the investigation of phenomena, and speculation upon assumed realities beyond them. Philosophy has thus two functions: the one negative, resulting in the critical dissolution of all the synthetical principles of cognition, and the stripping them of all competence to the absolute, leaving their outcome purely phenomenal; the other positive, affirming the right and the uses of the free exercise of the speculative bent, when taken no longer as knowledge but only as poesy.

The supports of this "Standpoint of the Ideal" are sought in a critique of the Critique of Pure Reason, or a sort of "new critique of reason," whose ambition it is to bring to the needed consistent fulfilment what Lange regards as the first principle of Kant's undertaking. This principle is assumed to be the rigid restriction of our knowledge to experience: we have a priori forms of cognition, but they become futile when applied beyond phenomena. That Kant himself regarded this as only the principle of his thcoretical view is, to be sure, unquestionable; but his setting up the practical reason as in itself absolute was, Lange maintains, a direct violation of the principle, and was in fact rendered 
logically impossible by it. Will, like cognition, Lange holds to be merely phenomenon; we cannot, then, aver with Kant that we must $b c$ free, but only that we must think ourselves free.

But with this granted, Kant's way of grounding ethics comes to an end, and we must seek, says Lange, to frame a right world-view by consistently carrying out our only initial certainty. We must return to the problem of the source and limits of cognition, where, fortunately, we can assume an $a$ priori organisation as having been established by Kant. The elements, too, that Kant assigned to this organisation - Space, Time, Cause, and the rest -all belong there. But Kant's attempt to settle a priori the exact number of such forms was necessarily futile: there is no way to determine what the contents of our a priori endowment are except induction. Besides, the gradual progress of the natural sciences, particularly the modern physiology of the senses (in which the primary sensations light, colour, heat, sound, taste, odlour, etc. - have all been reduced to modes of motion), points clearly to the probable omission of an essential form from Kant's list: Motion should take its place among the a priori forms of sense.

Indeed, one principal aim of any attempt at a reconstruction of the Critique of Pure Reason should be to bring its doctrine into thorough accord with 
the results of the latest natural science. This we can do by insisting, first, on a strict observance of the limits the Critique assigned to knowledge, and, secondly, on defining these more exactly, in accordance with the mechanical nature of sensation. In fact, we here arrive at the true import and value of materialism; for that the actual of expericnce is only explicable on mechanical principles is the clear outcome of the latest science, with which it only remains to set our theory of knowledge into agreement, in order at one stroke to give materialism its due, and yet its quietus as a scheme of interpreting the absolute.

For the world of actual experience, extended, moving, interacting in all its parts, and transmitting energy from part to part under the universal law of the "persistence of force," is from beginning to end simply our conscious presentation (Vorstellung). The derivation of mind from actual matter is therefore impossible, as it would involve the absurdity of the object's producing the subject whose testimony is the sole eviclence that there is any object. ${ }^{1}$ And as for hypothetical matter - a conjectural substrate beneath the actual - that is shut out of the ques-

1 This seems, at a single happy stroke, to dispose of the attempt, common to Schopenhauer, Hartmann, and Dühring, to explain consciousness as a phenomenon arising from the earlier and more real existence of the object, or "matter." 
tion by the limits of knowledge. Once we are certain that our objects are strictly ours, are but the framing of our sensations in our a priori forms, we are thenceforth confronted with the limiting notion called the thing-in-itself. The doubt, thenceforward ineradicable, of our power to pass this limit turns into certainty of our impotence to do so, when we find, as Kant shows us, that the attempt must cast reason into systematic contradictions.

Our knowledgc, then, is confined strictly to the field of phenomena; to knowing, not what is, but only what exists relatively to $u s$; and within this field it is further restricted to the tracing of mechanical causation. For, again by Kant's showing, its highest category is action and reaction, and so all the terms conjoined by its synthesis must be extended objects of sense. Hence Du Bois-Reymond's "limits of the knowledge of Nature" become the limits of all knowledge whatever. While, then, our philosophy thus falls into step with natural science, it indeed vindicates to materialism the entire province of Nature, but at the same time excludes materialism from explaining mind. Mind and Nature stand contrasted as subject and object; the object, as simply presentation to mind, requires mind as the ground of its existence, and so can never explain mind.

But the relativity of our knowledge, continues Lange with especial emphasis, reaches wider than 
Kant suspected, and its contradictions are profounder. The limiting thing-in-itself Kant assumed as a reality, or, at all events, he declined to doubt its existence; but to carry the a priori principle to its proper conclusion, we must now recognise the phenomenal nature of this notion itself. Our all-encompassing distinction between thing and conscious presentation, between noumenon and phenomenon, is itself a judgment a priori; in fact, an illusion of that order. The illusion arises from our constitutional tendency to put the positive pole of the category of relation - Substance, Cause, Agent - as if it were something additional to the system of experience, instead of merely a term within this. It is thus itself a contradiction, one not simply functional but organic, and therefore provokes to endless other contradictions.

And not only, let us steadfastly remember, is it an illusion; it is an illusion which, though we recognise, we can never dispel, - any more than that of the moon's enlargement on the horizon, the bending of the stick when thrust into the water, or the apparition of the rainbow. But, like these, it will mislead only such minds as persist in the stolidity of the peasant; and just as the cited illusions, when comprehended, not only do not disturb our science, but continue to quicken the pleasure of existence by their variety and their beauty, so will this ground- 
dissonance of our nature, with the whole array of its derivative discords, serve when once mastered to enrich the diapason of life and raise it to orchestral fulness and harmony. The metaphysical passion, born of this illusion, is indeed worthless for knowledge, but it is precious for experience. In its immature stages, it burns to transcend the limits of experience, in the vain hope of bringing back knowledge of that mysterious Beyond; and so long as it has continued in this delusion, it has been the bane of the world. But when once freed from the error, it will become, with religion and poetry, the benign solvent of the ills of life. It springs from the same source as poetry and religion, and is, indeed, the strongest and most precious jet of the fountain. For it is the work of the imagination, in fact the highest and noblest work; while imagination comes from the illusion of the noumenon, and without this would not exist.

Although, then, we must hold fast by the actual for knowledge, for all the inspiration of life we must take refuge in the ideal. Phenomenal and noumenal - the actual and the ideal-together; and only together, make up the total of experience, of our vital Whole. In not less than this Whole are we to live, Im Ganzen, Guten, Treuen resolut zu leben,-

and the good and the true are to be sought for in the 
idleal; in the ideal, not only as vaguely rendered in the visions of poetry or the solemnities of religion, but far more as framed into organic epics of the mind, and turned upon action with all the force of systems, by metaphysical invention. Nor let it be supposed that our knowledge of the purely poetic character of speculation will paralyse its power over conduct. Though void of literal truth, its ethical truth is real; the conduct that it means is absolutely right. "A noble man," to borrow Lange's own words, "is not the least disturbed in his zeal for his ideals, though he be and must be told, and tells himself, that his ideal world, with all its settings of a God, immortal hopes, and eternal truths, is a mere imagination and no reality; these are all real for life, just because they are psychic ideals; they exist in the soul of man, and woe to him who casts doubt upon their power!"

Having thus cleared up the "Standpoint of the Ideal," Lange next turns to the view it affords of practical philosophy. He touches first upon the question of the worth of life, where his settlement is this: Neither pessimism nor optimism is an absolute truth; the problem of evil, if we push for its radical solution, belongs to the transcendent world, of which we can know nothing. But applied to the world of experience, the doctrine of the Ideal gives an optimistic or pessimistic result, according as 
we consider life in its whole, with the ideal in it, or only in its part of actual stubborn fact. The mere fact, in itself, must always seem bad; but it must be remembered that this very badness is the shock of contrast with the ever present ideal; and, after all, the optimistic solution has to come from moral energy. Play into fact with aspiration after the ideal and enthusiasm for it, with the firm resolve to transform fact into a semblance of the ideal pattern, and the reward will come in a gentler tolerance of defect and a calmer contentment. "The freer our career in the metaphysical region, the more is our world-view pervaded by sentiment, and the more is it optimistic; but the more ethical, also, is its reaction on our doings and bent. We are not only to reconstruct the actual according to the ideal, but are to console ourselves for the perception of what actually is, by contemplating what ought to be and might be."

The transition hence to ethics is natural and obvious: the highest ethical maxim is, Serve the Whole. But the Whole here intended is the entire complex of experience, with the active ideal in it. "Work upon fact with recognition of its stubborn reality, but in the light of the ideal," is what the maxim means. We cannot know that we are free or immortal, but we cannot help assuming we are the one, and hoping we may be the other. And, 
on the other hand, we do know that in our relation with mechanical Nature, in whose domain, after all, the larger part of our action lies, we are not free; we know that time is exceeding short, and that enjoyment is for the most part hope cleferred. The lesson of life is chicfly fortitude and resignation. Lange, however, has no personal drawings toward egoistic ethics, nor to hecłonism, even in its most public or social form. He announces himself as in ethics the legitimate successor of Kant: he desires to act, and to have men act, from duty solely; to seek the ideal and serve it at all personal hazard, though with due regard to the imperfections of men and the obstinacy of fact.

Lange's sociology follows the lines we should now expect. His doctrine of the Whole leads him to a pronounced socialism, but he would have this socialism a real one, in which organised society is to correct the aberrations of the individual with vigour. He sees, too, like Duhring, the import of political economy in a comprehensive practical philosophy, and some of his earlier writings were devoted to vigorous discussions in it. Free-trade and laissezfaire can find no place, of course, in the practical theory of the moralist of the Whole. Spontaneous "harmony of private interests," like the talk of the Cobden school generally, is to him mere vagary, springing from a fatuous social optimism. In many 
essentials, however, he affiliates with Stuart Mill, while he derides Carey; whereby he fell into many an acrimonious dispute with Duhring, for the vitriol of whose sarcasm, too, he had but little relish.

On the religious question, Lange aims at a purely ethical position: one religion is to him as good as another, provided it does the work of consecrating the ideal and giving it practical influence with men. As for "rationalising" religion, let it be done, if it must be done in the interest of culture and taste, but beware of dreaming that in this way you are getting at truth! The Christian religion, for instance, we may retain in spirit, but in letter, no. Its entire ecclesiastical Symbol, in fact, whether cultus or creed, may freely stand as long as it can, provided it be understood to mean nothing but a mode, strictly symbolic; of enshrining the ideal as such.

It is impossible not to recognise the higher tone, both intellectual and moral, of Lange's general view as contrasted with that of either Hartmann or Dühring. The substitution of fortitude for despair on the one hand, and for mere enjoyment on the other, betokens a sounder moral feeling, while the standpoint of critical agnosticism is at least in so far more intellectual as it gives clear vision of the difficulties that must be radically removed before any doctrinal procedure can be validly begun. The 
adroit preservation, too, of the play of the ideal in the world of fact is evidence of quick susceptibility to imagination, and to its necessity and value in the conduct of life. In this respect, Lange reminds one of Stuart Mill, though with far greater ethical fervour, as Mill appears in his Three Essays on Religion. Like Mill, too, he will prove in the end to have been a man of feeling, even more than of intellect, determined in his judgments by the wants of the heart more than by the lights of the head. We cannot long conceal it from ourselves that his belief in the ethical energy of his "Icleal" is without foundation in his theoretic view; that to talk of duty based on what we know to be pure fiction of the fantasy is a hollow mockery; that the only reason which agnosticism can put forward for acting under the ideal is the anodyne this offers for the otherwise insupportable pain of existence.

Nor are clear indications wanting that Lange forebodes the spectral nature of even this excusethat he divines the foregone failure of a remedy applied in defiance of our knowledge that its essence is illusion. Vaihinger, himself a thinker who pushes the agnostic view to an extreme almost deserving the Scotch epithet of $f c y$, says truly enough : ${ }^{1}$

${ }^{1}$ Dr. Hans Vaihinger : Kartmann, Dïhring und Lange : cin kritischer Essay. Iserlohn, IS76. A book full of interest and of acute criticism, though marked by some agnostic extravagances. I have 
"There breathes through this doctrine of Lange's a strain of tragic resignation. . . A lofty moral pathos speaks out in all that Lange teaches, and in his manner of teaching it." He is like Carlyle, who, gazing upward at the silent stars rolling through the solemn and trackless night, and seeing there the image and type of all existence, could only ejaculate, "Ech, it's a sad sight!" For him, life has reduced itself to the phenomenon of a phenomenon, to contradictions born of one fundamental contradiction, and that an illusion we can never dispel. The professed "new critique of reason" has ended in representing reason as essentially irrational; the self-harmonious turns out to be a thoroughgoing discord, our "organisation" is clisorganisation.

Neither can all the seeming glow of the "ideal" blind us to the reach of this contradiction into Lange's doctrine of action. The ideal is put forward as an end in itself; but in reality it is only viewed, and by the consistent agnostic can only be viewed, as a means to suppress weariness of life. So while Lange proclaims duty, his implicit principle is actually pleasure; he denounces egoism, but cannot surmount hedonism; he declares for the autonomy of

found it of admirable help in preparing this paper. [I ought now (1899) to add that Dr. (now I'rofessor) Vaihinger seems in the course of years to have receded from his extremer negations, and to have become an idealist more after the type of Kant.] 
the will, but his doctrine forces a strict heteronomy. He stands professedly for a stern socialism, the sovereignty of the Whole as the organisation of the ideal, but in his theory there lurks an utter social atomism: so many individual fantasies, so many systems of the ideal; and, for each, the sacred "duty" of meeting the antagonism of the countless other private illusions with becoming fortitude and resignation.

Beyond evasion, so long as conscious existence is, as Lange holds, shut in to mere appearance, its ghostliness cannot but betray itself in all its movements. If with Hartmann the universe becomes a colossal and shadowy Blind Tom, endowed with a clairvoyance whose infallible "intelligence" displays itself in striking through the reach of æons with fatal precision at its own existence, and, with Dühring, a gigantic Automaton Chess-Player, matched against itself, moving with balanced "charm" to the checkmating of its own game, with Lange it fades into a phantom Panorama, in front of which sits man, a forlorn imbecile maundering over a Perhaps behind it, and shaking the flimsy rattle of the "ideal" in the fatuous persuasion that he is stilling the irrepressible sob in his heart. Let it do its best, agnostic philosophy cannot make of life anything but essential delirium, - with the shapes of its phantasmagory distinct enough, no 
doubt, and with a persistency in the recurrence of its wanderings that is even too fatal, but delirium still. In the wan light of "critical" thinking -

We are such stuff

As dreams are made of, and our little life

Is rounded with a sleep.

It is no proper refutation of a theory, however, to show its evil practical results; the very question in our day is, Whether our being is not compact of evil? It is a just retort upon all such ethical reproaches to say, "Yes, our fate is heavy and our prospects are desperate; but what does that do toward disproving the fact?" It is true enough that Lange's ethical structure breaks down, and that the gap between it and his theory is a discredit to his logic, but his "critical" view is not to be displaced except by strictly theoretical means. His procedure must be forced to expose contradictions, or else both the procedure and its results must be accepted. But should it now prove to be self-contradictory, it will annul itself and its assumed principle. That such a contradiction is really involved in it, we may convince ourselves by the considerations which follow.

\section{IV}

Lange's principle is, that the a priori nature of our cognition prohibits us from assuming that we can 
know by means of it things as they are. ${ }^{1}$ This is but another way of saying that we are forbidden to assume it is anything more than a peculiarity of man. It is in effect represented as simply a limitation belonging to humanity. Whether its forms are those of possible other intelligences, of intelligence as such, we are told we can never know; and for the reason that we are shut in by the "limiting notion" of the thing-in-itself. This agnostic principle, now, Lange will carry out with unflinching comprehensiveness: it is extended to include even the fundamental distinction between our phenomenal world of experience and the noumenal Reality.

This aim of Lange comes from a genuine insight into the requirements of system. Not only is it true in general that a principle, to be such, must work in its sphere with unqualified universality, but, in this particular case, omitting from the compass of phenomenalism the contrast between consciousness and things would be fatal to the claims of phenomenalism as a principle. If the notion of the thing-in-itself be more than phenomenal, then there is a thing-in-itself, and in cognising the contrast in

1 It deserves special notice, in passing, that this confusion of Kant's Ding an sich, or thing-in-itself (something existing "on its own hook," underived from other beings, independent of any one ego), with things as they are, is a very prevalent misconception of Kant. It is at the bottom not only of Neo-Kantianism, but of much other misinterpretation of him. 
question, in putting the judgment There are thingsin-thcmselves, we put a judgment of absolute validity, and see by the light of intelligence as such - with the eye common to all possible intelligences. This would force upon the agnostic the further perilous question, By which of our merely subjective categories, then, do we manage this astonishing achievement? The admission of this one noumenal judgment would open the entire agnostic mechanism of the a priori to the inroad of absolute knowing. So, by some means, this judgment must be reduced to a mere conjecture. It will not do to dissipate it wholly, for then another absolute judgment would arise in its place, namely, There are no things-in-themselves. But the validity of this would put an end to phenomenalism conclusively. If there are no things-in-themselves, then our cognition, call it "subjective" as long as we may, is the cognition of all there really is, by all the minds there are; the objects that we represent to ourselves in our normal activity are then the only objects, and our intelligence becomes itself the universal because the only intelligence.

Hence it is with the instinct of self-preservation that Lange draws the mentioned distinction back within the sphere of merely human consciousness. Even this distinction itself he will have us refrain from using as if referring to anything absolute. We 
must treat this also as phenomenal, and hence we cannot be sure if there is, or is not, a thing-in-itself. But he holds we cannot now silence the apprehension that there may be one. So the distinction remains, and the thing-in-itself becomes simply a notion, but a limiting notion. The antithetic formula Me and Not-me becomes the all-encompassing category, ${ }^{1}$ which therefore causes all our cognition to secm merely subjective, whether it be so in reality or not, and thus compels us to limit our certainty to phenomena. The agnostic force of the formula is accordingly rather increased than diminished: we have now not a single cognition remaining that can pretend to belong to intelligence as such. Except unluckily (let us, the readers, add in passing), this very last decision that condemns every other, - the goblin of certainty which haunts the steps of all agnosticism, and which it cannot lay! This Nemesis of phenomenalism will presently appear in a clearer form.

For it cannot longer be concealed, that in setting out upon his chosen path Lange was in fact moving towards a goal he little suspected and still less intended. He has decided that to validate the phenomenal limitation of knowledge he must make the thing-in-itself a mere form a priori. But we have

1 How Schopenhauer the Epistemologist must have blessed Lange for this stroke, so masterfully repeating his own! 
the right to demand that he shall be in earnest with this apriority, and a form a priori means a principle from and in our consciousness organically and solely. To say that a notion is a priori is to say that its being a spontaneous thought of ours exhausts its existence completely; that the entire being of it is in a native energy of our consciousness, and that this elemental discharge from consciousness is the whole meaning of the corresponding name. For instance, our pure thoughts corresponding to the words "space," "time," "cause," are upon the $a$ priori theory exactly and utterly what Space, Time, and Cause respectively are. Anything short of this view would render apriority null. For if there were anything extra mentem to which, even possibly, the a priori elements corresponded, we could never then be certain that they originated in ou consciousness at all - we should remain in a quandary as to whether they did or did not. Yet from our consciousness they must originate if they are to have that absolute universality, and that necessity of application to their objects, with which we incontestably think them. As a consistent Kantian, Lange must assent to this ; and not simply assent to it, but proceed from it wholly and thoroughly. To make the thing-in-itself a genuine form a priori is therefore to exclude its existence in any other sense. But this annuls the desired phenomenalistic conjecture of its 
perhaps absolute existence; we have committed ourselves irretrievably to the judgment There are no things-in-themselics. Therewith, as shown already, an act of absolute cognition enters, and universal phenomenalism falls to the ground. The "critical" procedure has annulled its own principle. The Nemesis of all agnosticism, of which we caught a glimpse above, has for the a priori agnostic formed to itself a companion avenger.

Lange, however, is equal to the emergency; he has that dogged courage which does not realise its own defeat. He rallies on a new base, and this rally is the real explanation of his singular doctrine that the ground-form of consciousness, as he considers it, - this contrast between consciousness and noumenal Reality, - is an "organic contradiction." He would evade the force of the above conclusion by showing that the "critical" thing-initself - the noumenon as pure category - is not the actual contents of that a priori notion which forms the "limiting" term in the relation Phenomenon-Noumenon. On the contrary, that limiting term is an hypostasis by consciousness, an imaginary "enrealising" - a putting as beyond, independent of, or plins consciousness - of its own system of internal categories appertaining to phenomenal objects. In short, it is a putting of the notions Substance, Cause, and Agent, as if they 
transcended conscious cxperience, and existed apart from it as its object and ground. The a priori category of substance and accident (subject and predicate), which, properly, only connects one composite phenomenon (called the "subject" of a judgment) with another phenomenon (called the "predicate") so as to compose a new and fuller unity, lends its term "substance" for this purpose; the category of cause and effect, which, properly, connects one phenomenon with another so as to condition and determine the second's occurrence, lends similarly its term "cause"; and, in like manner, the category of agent and reagent, which, properly, connects phenomena into a system of mutual attraction and repulsion, lends its term "agent."

Thus this trimne hypostasis, by some a priori impulse which Lange does not attempt to cxplain, ${ }^{1}$ is projected beyond the limits of consciousness, and is thought as one term of the relation Phenomenon-Noumenon, while consciousness as a whole is taken as the complemental term, its "organisation" (as Lange calls it) being viewed as the $r$ agent, its sum of phenomena as the cffect of an interaction between it and the thing-in-itself, and as the predicate of this supposititious being. By this spontaneous contradiction of the strict nature of its categorical system, our consciousness, con-

1 Compare pp. 167 and 174 , below, as referred to in their foot-notes. 
founding its own organic notions with the hypostatised notion of a thing-in-itself, sets a bound to its own certainty by an a priori illusion which, just because a priori, it can never dispel; though it learns by "criticism" to interpret the illusion correctly.

The justness of this analysis, so far as it goes, is evident enough. We doubtless have here the correct partial genealogy of the remarkable notion Thing-in-itself - in so far, that is, as this notion forms the basis of the common-sense dualism of mind and matter - and the exact genesis of all "critical" agnosticism. There is missing from the analysis, however, the very important fact, that the coöperation of the other a priori elements - Space and Time - with those actually mentioned, is what imparts to the "material-substance" interpretation of this notion its specific character and its chief plausibility. The infinity of Space and of Time, in contrast to the finitude of every sense-presentation, joined with our tendency to ignore the strictly supersensible elements in consciousness - the categories in their purity, and the pure Ideas - and to take our leisure in the familiar region where Time and Space render all things plain, makes it easy for us to suppose there is "abundant room" for "existence wholly out of consciousness" and, as the saying is, "independent" of it. This blun- 
der of mere inadvertence is no doubt stimulated by the incessant activity of the pure categories, but its primary provocative is that very deepest principle of our conscious life, the consciousness of our relation to other minds; and it is this principle which Lange's analysis persistently overlooks.

This primal consciousness of our relation to others is the real secret of our belief in noumena, and contains their only true meaning; and it supplies the element which carelessly and wrongly united with Space and Time gives rise to a sensuous misinterpretation of things-in-themselves. This primal conscious principle Lange, as just noted, ${ }^{1}$ quite omits to investigate; and this onission is the contral defect of his analysis of the noumenon. The oversight leaves his account of the nature and function of this notion seriously inadequate - a deficiency of which something further presently. ${ }^{2}$ By the misapplication of Space and Time to the thing-initself, we are prompted to think it extended and enduring; and this, even when we view it as the soul or as God. Here is the source of that mechanical psychology and that faultily anthropomorphic theology-we should call it zoomorphic, instead, if we spoke correctly - which have always been the bane of religion, the constant cause of religious scepticism and indifference. With the 1 See p. 165 , above.

${ }^{2}$ See p. 174, below. 
explanation here made, we get a clarifying account of that travesty of the noumenon which we oftenest understand by the thing-in-itself, and may now attend to the real meaning of Lange's result.

The meaning is striking enough. For, in fact, our philosopher has unwittingly completed the proof of the absolute quality of human knowledge, and at the same time demonstrated the falsehood of materialism - not simply the impossibility of cstablishing this (which he had already done, as Kant had before him, merely from his agnostic standpoint), but its final impossibility, even as an hypothesis.

As to our real knowledge, he has now shown (I) that a bare thing-in-itself, a thing out of all relation to minds, does not exist; (2) that, even as notion, it is a self-contradiction, something whose sphere is solely within consciousness putting itself as if it were beyond it; (3) that, in spite of this, we continue, and must continue, to accept this illusion, which compels us to limit our knowledge to experience and to renounce all claims to its being absolute. That is to say, then, the sole cause of our doubting the rigorous validity of our knowledge, and reducing our cognition to the mere idiosyncrasy of one species out of an unknown number of possible orders of conscious beings, is an illusion whose genesis we know, a contradiction that we distinctly detect. Then, beyond dispute, our discrediting limitation of 
our cognitive faculty is an crror, and we ought to correct it by disregarding its cause.

It is idle to say that we cannot do this because the illusion is organic, and will therefore continue to play upon us forever. When it is once detected, it is completely in our power, so far as concerns its affecting our judgment. The presence of organic illusions in our faculty of cognition, especially in its function of sense-perception, is an unquestionable fact, - the multiform phenomena of refraction, for instance, - but from the moment we know them as organic they cannot mislead us; because, to know them so, we must have traced them to an origin in the necessary laws of the function they affect. Thenceforward we learn to interpret them, - as signs, namely, of a complexity in our system of consciousness far richer and more various than we had suspected, signs of a far more intricate harmony of antagonisms than we had dreamed of; and the more wide-embracing their recurrences become, each time detected and corrected, the more do we gradually rise to the conception of the sclf-resource and selfsufficiency of our intelligence. The power of detecting and allowing for them comes just from their being organic, and depends upon that.

Therefore, precisely by the investigation through which Lange has led us, we are now in the position to assure ourselves of the reality, the absoluteness in 
quality, of our human intelligence. From the Kantian doctrine of the a priori carried to its genuine completion, as we have now seen it, we infer that the objects which present themselves in course of the normal and critical action of human conscious. ness are all that objects as objects can be; that beyond or beneath what completed human reason (moral, of course, as well as perceptive and reflective) finds in objects and their relations, or can and will find, there is nothing to $b c$ found; that our universe is the universe, which exists, so far as we know it, precisely as we know it, and incleed in and through our knowing it, though not merely by that. To state the case more technically, the cognition belonging to each mind is the indisponsable condition of the existence of reality, though it is not the completely sufficient condition. If one asks, What then is this sufficient condition, the answer is, The consensus of the whole system of minds, including the Supreme Mind, or God.

The process which has led us to this result, and which might justifiably be called a Critique of all Scepticism, yields also the final impossibility of materialism in a still clearer way than we noticed before. We saw, some distance back, that the actual of sense could by no possibility be the source of consciousness, being, on the contrary, its mere phenomenon - its mere externalised presentation (picture-object) origi- 
nated from within. But the hypothetical potential of sense, the assumed subsensible substance called matter, we have now seen to be precisely that selfcontradiction talked of as the physical thing-in-itself, and it therefore disappears from the real universe along with that illusion. We have, then, a definitive Critique of all Materialism.

By the path into which Lange has led us we therefore ascend from the agnostic-critical standpoint to the higher and invigorating one of a thorough, all-sided, and affirmative idealism. A few words must suffice to outline its general conception. The result is, in brief : Our normal consciousness has the trait of real universality, - it puts judgments which in the same circumstances every intelligence, and every order of intelligence, would put. The objects it perceives, and seen as it sees them when it sees to its full, are the same that from the same outlook all intelligences would perceive. For such objects are themselves but complexes of its judgments, and the mentioned circumstances and outlook are in fact part of the objects as perceived; they are not limitations imposed upon consciousness from without, but are particularisations of its own primordial processes. Or, to state the case inversely, the potential reach of normal human consciousness is the very thing meant by universality : intelligence as such is simply the fulfilment of human intelligence. 
The attempt to take the universe as beyond or apart from or plus consciousness has sublated itself into bringing the universe wholly within consciousness and coincident with it; and the ancient saying, Man the measure of all things, comes round again, but in a new and pregnant sense - a sense which in the last resort gets its meaning from the intrinsic harmony of human with divine cognition. Only, this universe-consciousness must be thought as it is, without omission or exaggeration of any of its contents, and, above all, by mastering the grounds of its existence and the method of its possibility.

What we have arrived at is this: All that is, comes within consciousness and lies open to it, - the literal all, - whether "starry heavens without" or " moral law within," sensible system of Nature, with its bond of mechanical causation, or intelligible system of moral agency, with its bond of free allegiance constituting a "kingdom of Ends." A reorld of spirits, a world of minds each self-active, with the Father of Spirits omnipresent to all-consciousness means that. In being conscious, we are conscious of a universe; wherein each of us, to put the case in a metaphor (inadequate, of course), is a single self-luminous but focal point, upon which the remaining whole of light is poured in rays that are reflected back and then returned again, and so on without end, each added return bringing rays in 
greater fulness from remoter and remoter confines, to be shed forth again, with increase, and farther and farther.

Consciousness and universe are in truth but two names for the same single and inclissoluble Fact, named in the one case as if from within it, and in the other as if from without. Not that in every conl. scious focus all the contents of this universe are at any temporal moment imaged with the same clearness or reflected forth with the same energy as in every other; only that, dim or bright, strong or feeble, confused or distinct, the same Whole is in somewise always there. Nor is it to be overlooked, that, to the fulfilment of each mind's universe-consciousness, it is essential that the consciousness be not simply a private but a social, an historic, and, in fact, an immortal consciousness.

The satisfactory and convincing grounds for this conception, it is not in place to enter upon here with any detail. ${ }^{1}$ Let it for the occasion be enough to say that the interpretation of the facts of ordinary consciousness into their implying this Social Universal might be the business and achievement of a genuine and completed Critique of Reason. Such a critique would proceed to the adequate explanation not only of the a priori categories, of which since

I For a fuller pronf of it, see the essay on "The Harmony of Determination and Freedom," p). 326-359, below. 
Kant's day the world has heard so much, but of that residue of the noumenon which we noticed Lange leave unexamined. ${ }^{1}$ It would find the explanation of the categories, and the nature of the final noumenon, in a single active principle in consciousness, of which the vague notion Noumenon is only our confused native feeling. Our ordinary name for this principle is the moral consciousness, the consciousness in each mind of its own reality, integral and sacred, and of the equal reality of all others; but this is in fact rather the supreme thcorctical principle, the spring of all intelligence, the master-light of all logic and all knowledge. The categories are the intrinsic modes in which this principle puts its activity forth. Though they appear so different to our first or natural view, they turn out on critical investigation to be expressions of one and the same single synthetical energy - simply forms of a nccessary nexus between all possible terms of sense, which reduces these to the serviceable means of our reality as free intelligences. This principle, as blending in one energetic whole above the categories the two activities of absolute subject and absolute cause, is the one intelligible creative unity - the unity of the Person in its whole reality. The universe-consciousness thus passes from apparent mere Fact into a pure conscious Act. And this Act, as always determin1 See pp. I65, I67, above. 
ing itself in view of a system of conscious subjects, embraces in its living process of self-definition for every self the whole world of other selves, and therein the Supreme Self, or God, and is thus strictly and truly personal, - is in the last analysis that order of intelligence which we call a Conscience.

It is plain, of course, that any proof of this depends upon the validity of the doctrine of a priori cognition; only by our proved possession of such cognition can there be any evidence that we are self-active realities. It is in this reference noteworthy, therefore, that Lange, as defender of agnosticism, sees he cannot afford to admit the theory upon which alone cognition strictly a priori can be established. Of course, to determine that its principles are indeed underived from its sensible objects, consciousness must be capable of an act in which it extricates itself from its world of things, and contemplates its cognitive equipment strictly per se, apart from actual application to objects; an act, accordingly, which transcends experience, and was consequently named by Kant "transcendental reflexion"; an act, moreover, which presupposes the power not only of using the apparatus of judgment upon objects that are not sensible at all, but of making judgments absolutely valid, since the decision that anything is organic in us must be a decision upon our real nature - our nature as it appears to the 
whole world of intelligences. This presupposition is radically at variance with Kant's subsequent finis to his theoretical critique, by which he shut in knowledge to the world of sense, and with Lange's acceptance and development of this. It is simply in keeping with this acceptance and development that Lange takes the ground, which otherwise would be quite surprising, that the contents of our a priori endowment can only be determined by induction. This position, however, is clearly a self-contradiction. For an induction, despite its formal generality, is always in its own value a particular judgment, always comes short of full universality; whereas, to establish the apriority of an element, we must show it to be strictly universal, or, in other words, necessary. It is evident, then, that Lange has here finally abandoned the standpoint proper to Kantianism, and, without so intending, has really gone back to the standpoint of Locke. There we may leave him and his followers to the thoroughgoing surgery of Hume.

A sufficient cure, in fact, for all such agnostic and empirical tendencies might be found in a faithful study of Hume, not in the more literary and much mitigated form in which he appears in the Essays, but in his undiluted masterpiece, the Treatise of Human Nature. The very common neglect of the Tratise in behalf of the Essays is no doubt 
in great part owing to Hume's own request, in the preface to the posthumous edition of the short "Pieces," that the public would thenceforth look in these for the proper form of his philosophy. But in the Treatise he had written down and published what his genuine public, the keenest philosophic minds, have credited with a permanent significance of its own, quite apart from its author's afterthought about it. This critical material, philosophic thought can never abandon.

In Part IV of the First Book of the Treatise, too often overlooked, Hume has supplied a key for the destruction of the empirical position and the agnosticism logically involved in it. There his diligent and penetrating reader will see he cannot longer stop with Hume's doctrine, that experience gives only, but gives surely, the sensation of the present moment. He cannot but go on to discover, as Hume himself seems clearly to forebode, that without presupposing the abiding unity of personal identity, even the fleeting impression of the instant is impossible. ${ }^{1}$ This permanence of personal identity, however, Hume has by simply carrying out the rigorous logic of empiricism already done away with: it is nothing but a "deposit" from the "artificial idea"

1 Treatise, p. 187 foll., edition of Selby-Bigge. Oxford: Clarendon Press, 1896. Compare, especially, the passage in the Appenclix, pp. 635,636 . 
Causality; and this, empiricism has condemned as having no basis in fact - as being the creature of "fantasy." Hence all perception - all experience, even to its simplest item - is itself dissipated and reduced to illusion.

The flat contradiction between this and the empirical principle, which derives its whole force from the assumed absoluteness of the single sensation, is obvious. Hume is thus the instrument of bringing about a curious result - that a principle should disappear by merely being taken in full earnest and carried out with unflinching consistency. What he has really done, and quite irrefutably, is to remove in this way the empirical principle finally; or, rather, he has simply let the principle dialectically remove itself. True is it indeed, that without an Abiding and Active in us the transitory and sensible is impossible. As the case has been forcibly put in a saying that deserves to become classic, "Our unconditioned universality is the ground of our existence," - its ground, that is, at once its necessary condition and its sufficient reason. 
THE ART-PRINCIPLE AS REPRESENTED IN POETRY

THE subject which is to engage us this morning, ladies and gentlemen, has been stated in your ${ }^{1}$ programme by a title, just read, which fits in naturally with your whole present Course, on Art in its General Principles and its Particular Phases. The title describes the actual contents of my essay rather more accurately than the one chosen for it when it was first written nine years ago. It was then called The Essential Principle of Poetic Art. ${ }^{2}$ There is still a use in turning your attention to this former title; it will afford us a rather more significant starting-point. To most of you, I dare say, it would secm more natural to speak of the essential principles of poetic art, so many coöperating conditions, of course, must go to the making of poctry. But I purposely leave the main word of the earlier title in the singular. To follow to the end the varied conditions of poetic power, in all their diverging multitude, time would wholly fail us. We must content

1 The essay was read before the Channing Auxiliary Society of San Francisco, October, 1894.

2 Printed in the Overland Monthly, May, r\$85. 
ourselves with an endeavour to find the single determining principle from which they all arise.

But is there any such single principle? We must confess this seems unlikely, when we contemplate the confusing diversity of the actual species of poetry. Not to speak of a common originative principle, it hardly looks probable, at first sight, that there should be common to the varieties of poetry anything important at all, - to the epic, the dramatic, the lyric, the didactic; the tragic, the comic; the heroic, the sentimental; the meditative, the sportive; the elegiac, the satirical; the classic, the romantic. And if we turn from the form and mood of the poetry to its subject and contents, - to love and war, to myriad-visaged Nature and the "marvellous heart of man," to joy and sorrow, glory and shame, to "the loud laugh that speaks the vacant mind," and to "those thoughts that wander through eternity," - the belief in the unity of the poetic spirit becomes still more difficult. How can diversity so wide be reduced to unity? How can a single principle provide for such manifold effects, or preserve its identity through such an infinitude of variations - variations that go to the extreme of embracing opposites?

To satisfy these wonderings, and dispose of them, is doubtless part of our business in the effort to ascertain the essential principle of poctry. But 
this theoretical aim of our inquiry is not its only aim; there is a practical interest to be served by it, too. The theory, to be sure, might if attained yield us the pleasure of a gratified curiosity; but we may rightly demand of such an inquiry that it furnish us with a discipline in culture, and with a permanent canon of taste. If its result is real, this should put us in possession of a touchstone by which not only to sift the pretensions of a production that professes to be poetry, but to discriminate between works undoubtedly poetic, and to assign to each its place according to its merits. Our question, then, is not simply whether there is a single essential principle of poetic art, and what it is ; but, more pertinently, just what the subtle quality is that makes a poem a poem, and determines, by the degree of its presence, the rank of any poem in the great company of poems.

The surest method of settling this question might seem to be to examine those works which the mature judgment of the world has pronounced the best examples of poctry, and by a careful analysis and comparison penetrate at length to their common secret. But the execution of this would require at least an academic term of daily lectures. In no less time 
could we hope to traverse the Iliad and the Odyssey, the Book of Job, the Agamemnon, the Antigone, the Rubaiyat, the Divina Commcdia, the Hamlet, Lear, Othello, and Macbeth, the Death of Wallenstein, and the Faust. Even then, almost the whole of lyric poetry, and the whole of comic, would be left untouched. We are fortunate, however, in having a swifter method within our reach. We can set out from a theory concerning the essential principle of art in general. As poetry is a species of art, its essential principle must be a specific development of the principle essential to all art; and it will merely remain for us to determine what the specific addition is, which the peculiar conditions of the poet's art make to the principle of art in general.

The general principle of art has been lucidly and forcibly presented to you in the lecture by my predecessor, Professor Le Conte. ${ }^{1}$ Starting from the faniliar contrast between the ideal and the real, which people for the most part take so abstractly as to place the two in irreconcilable antagonism, Professor Le Conte has shown us how one-sided are the usual views of art. These, as we all know, come forward in two implacably hostile schools, the school of Realism and the school of Idealism. The one would have art reproduce Nature in all

1 Joseph Le Conte : "The Principle of Art as illustrated in the Novel," in the Overland Monthly, April, I885. 
the coarse reality of its surface appearance; the other would have it ignore fact, and work only in the medium of an ideal nowhere distinctly traceable in Nature. The true view, as Professor Le Conte shows, is neither the one nor the other exclusively, but a higher union of the two, limiting both and fulfilling both. Accordingly, the universal principle of art may be stated, summarily, as real-ideality.

That is, art is not the cancelling of the actual and imperfect, and the putting in its place of a vague and fanciful perfection that is only an illusory abstraction after all; it is the transfiguring of the actual by the ideal that is actually immanent in it. The actual hides in itself an ideal that is its true reality and destination, and this hidden ideal it is the function of art to reveal. The artist is a seer, whose eye pierces to the secret of which the natural fact is the sign and prophecy. $\mathrm{He}$ is a magician, whose hand releases the spirit imprisoned in matter, and transforms the brute token into the breathing and speaking body. And as the ideal in the whole of Nature moves in an infinite process toward an Absolute Perfection, we may say that art is in strict truth the apotheosis of Nature. Art is thus at once the exaltation of the natural toward its destined supernatural perfection, and the investiture of the Absolute Beauty with the reality of natural existence. Its work is consequently not a means to 
some higher end, but is itself a final aim; or, as we may otherwise say, art is its own end. It is not a mere recreation for man, a piece of by-play in human life, but is an essential mode of spiritual activity, the lack of which would be a falling short of the destination of man. It is itself part and parcel of man's eternal vocation.

Now, this self-sustenance, this serious necessity, grounded in the very nature of art as the investiture of the actual with its ideal-reality or real-ideality (call it which you will), is the true criterion of art. If a work comes to us claiming to be a piece of art, its claim must stand or fall according as we can or cannot find a place for it in a scheme of life that is consistent with our permanently respecting and revering human nature. And according to its place in the scale of things compatible with the worth of man, as measured by his rational self-criticism, must be its rank in the scale of art.

Applied to poetry, this theory would teach us that what makes a poem a poem is the embodiment in it of some element of actual experience, set in the light of the genuine ideal - the ideal which by virtue of fitting in with the ideal of human nature forms at once the true reality of the embodied fact, and a permanent factor in the complete reality of man. The theory rests upon the doctrine that the final truth of Nature and of man is one and the 
same; that the ideal law of Nature - the predestined end toward which Nature moves by force of its immanent idea - is identical with that revealed in the human imagination as the ideal of man; that the criterion of imagination, as distinguished from fancy, is this conformity with the profound law of Nature - this holding fast to the sobriety of the actual, and pursuing the lines of its ideal-real, as projected according to rational thought. Such writings as show this healthy and prophetic imagination are genuine poems; such as lack it are not.

These last, no doubt, may afford a transient pleasure to minds dominated by passion and impulse; such minds are always seeking for some intense experience that will satisfy the craving for novelty and change, and so they fall naturally under bondage to the glittering but capricious illusions of fancy. But writings of this order will have no place in the abiding judgment of man: they cannot endure the test of time. It is thoroughly true that it is not only the quality but the test of a real poem, that, like every other work of genuine art, it possesses $a$ perpetually increasing interest; and this, not only for the individual reader, but for historic mankind, as culture advances in successive generations and from age to age. Indeed, we may carry this test even farther than Professor Le Conte has done, and not only say that great works of art, and therefore great 
poems, fail of their full effect on a first view, but that they fail of it just in proportion as they are great. Only the most experienced judges can recognise a work of the highest order at sight; even to them the proper realisation of its true compass and depth comes only through repeated examination and careful study; while the ordinary examiner finds the first impression of the greatest works ineffective or even disappointing. Work of genius demands for its swift recognition an answering genius in the beholder; in lack of it, there must be a patient teachableness, that awaits the slow self-revelation of greatness.

So far, somewhat altered in form of expression, and with its implied grounds partially exhibited, the theory presented by Professor Le Conte. We have from it a fruitful conception of the ground-trait in the essential principle of poetry. Namely : All poetry, in common with all other art, must combine in one whole a fact of sense and the real-ideal of the imagination - the ideal that conforms to the root-idea of the fact. This real-ideal must in poetry, as in Nature, accord with the principle that determines the permanent worth of man; and the whole into which the ideal and the fact are blended, must in order to poetic treatment be presented as a self-justifying end - the poet must regard and treat his poem as completely its own end. 


\section{II}

It should next be our business to trace the steps of specialisation by which this trait of art in general is differentiated into the specific principle of poetry. But before doing this, and in order the better to effect it, I will endeavour to present the theory advanced by Professor Le Conte in a somewhat altered and developed form, and from a different point of view. His theory, seen in the historic relations that show its importance, may be regarded as in the main a fresh outgrowth from the doctrine of Schiller and of Schelling; and in what I now have to add, I shall follow the principles suggested by Hegel, in his development of the hints furnished by his two great predecessors; though I shall also feel at great liberty to depart from Hegel's lines, as those conversant with his Aesthetik will readily discern.

The point of view from which I would now reconstruct our theory of art is this trait of art's being its owe cnd, but put in conjunction with another quite constantly implied by Professor Le Conte, and once or twice mentioned in his lecture, though not developed, nor applied in explanation. I mean the trait of literal creativeness. In virtue of this, every true work of art is not only a union of the 
two contrasted elements, the real and the ideal, but is an individual unit, in which each element lives, indeed, though not in its own restricted and excludent form. Each lives, on the contrary, in a higher realisation in one and the same new reality. The real is, but is idealised, and the ideal has attained a completer realisation than it had in the original fact. And thus the work of art brings into existence a new and unique being - a genuine but higher real objcct. This is the sovereign as well as the essential quality of art; and it is because of it, and only because of it, that we can say that art is its own end. Art is its own end, because its new creations are set into existence in pursuance of the real-ideal constituting the law of Nature, and thus enter the world as units really belonging to Nature - units prophetic, too, of that transfigured Nature which is kindred with rational man and is to form his fitting abode. And it is only for this reason that we can truly assert - or, rather, must not stop short of asserting - that not merely art in its collective sensc, but every separate work of art, is an end in itself.

The doctrine which thus comes to light, that in art man not only shares literally in the creative office of God, but enriches Nature with new members that express its divine Ground in a still higher form, will scem to many overbold - extravagant 
and irreverent. But its advocates are neither few nor inconsiderable; it is supported by the greatest names. We can cite for it, among many, the voice of Emerson, who in his poem called The Problem states it with impressive splendour:-

Earth proudly wears the Parthenon As the best gem upon her zone; And Morning opes with haste her lids To gaze upon the Pyramids; O'er England's abbeys bends the sky As on its friends, with kindred eye ; For out of Thought's interior sphere, These wonders rose to upper air; And Nature gladly gave them place, Adopted them into her race, And granted them an equal date With Andes and with Ararat.

Shakespearc, too, - the same truth, of the blending of the real and the ideal in a new actual, in a more veritable identity, at once more ideal and more real, is the burden of those forever quoted, yet forever fresh lines of his, -

The poet's eye, in a fine frenzy rolling,

Doth glance from heaven to earth, from earth to heaven; 1

And as imagination bodies forth

The forms of things unknown, the poet's pen

Turns the'm to SHAPES, and gives to airy nothing

A local habitation and a name.

Emerson again, in one of the most perfect of lyric poems, To the Rhodora, has joined with a

${ }^{1}$ That is, from the ideal to the real, from the real to the idcal. 
classic expression of the self-sufficingness of beauty, and consequently of art, a sublime utterance of the great secret in which their self-measured excellence subsists :-

In May, when sea-winds pierced our solitudes, I found the fresh Rhodora in the woods, Spreading its leafless blooms in a damp nook, To please the desert and the sluggish brook.

The purple petals, fallen in the pool,

Made the black water with their beauty gay; Here might the red-bird come his plumes to cool,

And court the flower that cheapens his array.

Rhodora! if the sages ask thee why

This charm is wasted on the earth and sky,

Tell them, dear, that if eyes were made for seeing,

Then beanty is its own excuse for being:

Why thou wert there, $\mathrm{O}$ rival of the rose,

I never thought to ask, I never knew :

But, in my simple ignorance, suppose

The selfsame Power that brought me there brought you.

The self-excuse of beauty and the self-warrant of human nature, holds the poet, are alike grounded in the ideal being of the Power who is revealed in both. We cannot hesitate to hold with Emerson. The beautiful and the soul of man are indeed in an eternal correlation. Each, as the expression of the selfsame Ideal Reason that is the Light of both, reflects the other and implies the other. In this inherent union with the other, each is truly self-complete, and, taken in its entire reality, needs for its justification nothing but itself. It must be 
said to be an end in. itself, to be its own end. Now, art is art only as it creates the beautiful, that is, only as it sets the beautiful into actual existence, or, what is the same thing, transforms the actual into the beautiful which is its proper truth and higher reality. To be itself, art must generate that which in its necessary correlation with the ideal of human nature is an end, and not a means; and hence, just to be itself, to be at all, art must be its own end.

We need, however, to keep clearly in mind what this rather magisterial cxpression really signifies. It is liable to great and even gross misunderstanding. It seems to challenge the most sacred convictions of the Puritan spirit, - which, as a genuine historic spirit, has a real authority, - and it does challenge, mortally, the Puritan's one-sided conception of human life. But it might seem also to justify or excuse the sensual spirit, as much as to say, "Quicquid libet licet - art is its own law, it may do as it will. If it please, it may clothe license and sensuality in the enticing garb of colour and fair form and melodious sound and ravishing words; its only condition is that its product shall be beautiful."

Now, this its sole conclition, a sufficing beauty, we may fearlessly accept; but we must also as fearlessly apply it. When applied with rigour, it 
puts an end to the pretensions of the sensual school of professed artists and poets, and allays the righteous rage and honest apprehensions of the Puritan, and may hope, possibly, to win him to a larger apprehension of life. For it is not mere physical or sensuous beauty that constitutes art, but that intellectual beauty whose consummation is the beauty of a completely right character. It must be remembered that the ideal which inspires and guides art, genuine art, is the Supreme Ideal at once of man and of Nature. The true artist worships, and must worship, God; though his rite and symbol must be his art, and, so far as he is artist, must be his art alone. Not that the God whom he adores by his art is other than the God whom we all adore by a common dutiful life, but that to him, in his function of artist, the godhead in all its manifold of perfections is summed up in the Spirit of Beauty.

Nor does the doctrine that art is its own end mean that art is indifferent to science $^{1}$ and religion, that beauty stands in no necessary relation to truth and goodness. On the contrary, to reach the heart of the case, we must go even farther than Tennyson in the striking lines prefixed to his Palace of Art, in which he declares -

1 Throughout the essay I use this word to designate what might perhaps be better called philosophy, except that I wish to include also under it science ordinarily so called, - natural science. 
That Beauty, Good, and Knowledge are three sisters That dote upon each other, friends to man, Living together under the same roof, And never can be sundered without tears.

For we must say, rather, that beauty, truth, and good stand in an eternal mutual necessity; neither of them has any real existence at all, apart from the others. Though each has a quality peculiarly its own, so that they are all real in a distinction that is irreducible, yet this distinction is in the form of their being, and not in its contents; for neither of them can complete its own idea except as it gathers the two others in itself. Beauty that does not embrace truth and goodness is no complete beauty, but only the rudiment of beauty; truth that does not include good and beauty is only the fragment of truth; and goodness that does not compass truth and beauty is only an arrested goodness. There is between them a triune relation which might well be expressed by taking the stanzas of Goethe on Art, as translated by Carlyle, and enlarging their sense:-

As all Nature's myriad changes still one changeless Power proclaim,

So thro' Thought's wide kingdom ranges one vast Meaning, e'er the same:

This is Truth - eternal Reason - that in Beauty takes its dress, And, serene thro' time and season, stands complete in Righteousness. 


\section{III}

It will aid us in further clearing up the conception of beauty and art as ends in themselves, if we now trace to a sufficient precision the nature of the distinction between these three consubstantial Ideas that have their fruition in this hypostatic union.

In attempting to do this, we naturally have our attention arrested by a time-honoured and very striking definition of beauty: Beauty is the reduction of diversity to unity; it is variety in unity, or unity in variety; it is the harmony of divergent parts in a single whole; it is the reconciliation of antagonistic elements; it is the triumph of the one over the many. The definition has not only the note of age, but of genius: it is itself beautiful; we feel that it is fit to have come, as it did, from the lips of Plato and of Augustine. Moreover, it is undeniably true, in the sense that it states a real and universal quality of beauty, and an indispensable condition of its existence. It is certain that everything beautiful must be self-harmonious: that every work of art must have an inward fitness of its component members. But while this is true of art, and of beauty as its principle, the crucial question is whether it is peculiar to art and beauty; or, to state the case otherwise, granting that it is an in- 
dispensable condition of their existence, is it also the sufficient condition?

Now, upon thorough reflection, is it not plain that in this quality of self-harmony, this unity of diverse terms, we are not upon the nerve peculiar to beauty and art, but upon the trunk of their kindred and identity with truth and science, with good and religion? To differentiate this into the specific quality of art and beauty, some further principle is needed; the principle of self-harmony, though indispensable, is by itself insufficient. For science is as unquestionably a self-harmonious whole, a variety in unity, as any work of art can be: truth is a system, of which science is the imaging exposition, and its supreme objective principle is the same as that of religion - the one Creative Idea or Perfect Person; while religion is the imaging practice of the moral system (or harmony) in which good by its own nature subsists. Beauty, truth, and good-art, science, and religion-come thus alike under the formula of unity in variety. But while this corroborates their kindred, and even puts it in a new and striking light, the formula not only fails to give the secret of their distinction, but makes no more than a formal statement of their identity; the essence of their common nature is missing, after all. To say that beauty, truth, and good are all self-harmonies - all unities in variety - tells us as little of their 
common secret as of the specific secret of each; we would know what unity of what variety is present in each.

Well, if we press the matter, we shall discover that nothing affords any key to either secret except the nature of our own human personality; that the trinity we cannot but observe in beauty, truth, and good is counterposed to a trinity in our own being as persons, and that the distinctions in it are dependent on this correlation, get their definition from it, and are in so far founded upon it. We too, as persons (or beings rationally conscious), are existent in a triune synthesis - an individual unity of intellect, emotion, and will; a unity in which the supreme illumination of knowledge blends and subordinates the capacity to feel and the power to act. The power to act and the capacity to feel find their only satisfying object, therefore, in the object that alone can satisfy the sovereign light within us; and so our whole being, in all its three constituents, turns an undivicled aim upon the Eternal Perfection - the one and only Supreme Ideal, who is at once the Supreme Beauty and the Supreme Good, and thence the Supreme Truth, just because he is the satisfaction at once of our sentiment, our will, and our reason. Beauty, truth, and good are therefore nothing more and nothing less than the forms in which the one Supreme Ideal who defines 
all being defines himself, now to our capacity for joy, now to our power to know, and now to our power to act. We cannot define the three without God - without the Ideal of the Reason. And we cannot define them without man - without the indivisible threefold of human life. They have their indissoluble unity in an organic correlation between God and man, and their distinguishing variety in the threefold distinction expressive of the unity in variety characteristic of human nature.

So runs the answer to our question, What unity of what variety do beauty, truth, and good each severally present? The unity is the unity of God, the Sovereign Ideal; or, indifferently, the unity of man, who in his reason images that Ideal; and its changeless identity rests in the organic harmony subsisting between God and man. The variety is the diversity in things; but dissolved in the unity of the Ideal, which is varied into a specific principle of unity, now for beauty, now for truth, now for good, by its permanent correlation to our delight, to our insight, to our devotion. While beauty, truth, and good, then, each and all clerive their distinct quality from their relation to human nature, and not from anything intrinsic in a fancied being of their own, we find the specific trait of beauty in its setting the Supreme Ideal into living relation with our faculty of delight. The Idcal is beanti- 
ful, in so far, and in so far only, as it fills us with joy; and our joy is the sentiment of the beautiful, in so far, and in so far only, as it is joy in the Idcal.

Art, therefore, in order to fulfil its idea, must put the Supreme Ideal before us as a reality. But while the indispensable ground of art thus lies in the ideal, the identity of its ideal with that of truth and good requires that it found on fact, that it follow the law of Nature, and that its works, while genuine facts of Nature, - sensibly-objective unique things, - be higher embodiments of the Creative Idea that grounds the order in Nature and foreordains its course. In art, then, the Universal Ideal descends into sensible particularity - descends in fuller self-realisation than in the merely natural fact. Thus the work of art, to exist, must literally be created; and in art man actually adds new and genuine and higher forms to the system of Nature itself. This is the sublime prerogative of human nature. Man completes Nature, not as himself a mere nature - a round of endowment passively received-standing at the summit of the natural system, but as a free creator, to whom God has accorded the transcendent office of carrying out the prophetic types of Nature into that higher world which is Nature's end and true fulfilment, - a world of new existences fit to be the expressions 
and the companions of man's spiritual life. It was with literal truth that Schiller sang-

But thine, O Man, is art! thine wholly and alone.

Yes, - the entire world of spirit - the world of religion, of laws, and of science, as well as of art, of good and right and truth, as well as of beauty God creates only through the creative freedom of man. And thus every work of art is and must be an embodicd Theodicy - a symbol of the justification of the ways of God to man, of the perfection of the Sum of All Perfections in accepting and directing an imperfect world. It is a monument of that kingdom of Grace, built upon yet above the kingdom of Nature, wherein good is wrought out of evil, and evil transformed into good, by the free coöperation of man and God. It is the visible or audible token that God regards man with the grace of recognising freedom - creative power and coöperation with him in the regeneration of things and in self-regeneration. It avouches the perfection of the world by making palpable the atonement this affords for evil, in being the means of free reasonable life. Every work of art is an incarnation of man's faith in the perfection of things when seen in the whole; in short, it is the visible confession that there really is a God. Art in its unblemished nature, like religion and the search for truth, is thus literally a 
sacrament. The artist's calling and genius are sacred, and the men of old spoke with strict accuracy when they called the poet holy, and directed that he be venerated as a prophet.

Heavy, then, is the sentence on our time of boasted " enlightenment," and on those minds of prostituted power who stand for the ministers of art in it, if belief in this elevating truth has become as good as dead and well-nigh impossible. Art will never get its own, nor do its proper work in the discipline of life, until the sense of its sacred character comes once more into the general judgment, and masses of men look upon it as the few great spirits have looked who have been its true masters and interpreters. But art cannot be kept sacred except by the consistency of its contents with its sacred normal character, and with the Ideal which, as embodied beauty, it shares with truth and good. It is hollow and trivial enough, if its soul of deep thought and reverent imagination is lost, and if men descend to the folly of taking its formal technique for its real quality. The power of art lies in the artist's flashing insight into beauty, truth, and good. It is the power of thoughit; but of thought that swifter than the sage's, and more sure of its symbols, utters itself directly in its proper sensible forms. Nevertheless, its genuine contents are such as the sage and the man of science will surely verify in proportion 
to their degree of wisdom and knowledge. So that, as Ruskin in his Modcrn Painters says, "He is the greatest artist who has embodied, in the sum of his works, the greatest number of the greatest ideas."

\section{IV}

This brings us to a final removal of the mistake made in saying that the principle of art's being its own end implies indifference to truth and good. The principle does not mean that the contents of a work of art - of a poem, for instance - are not necessarily true and moral; much less does it mean that the contents, if the artist choose, may violate truth and morality. Such a meaning would contradict the nature of art, as we have now seen it. The meaning is, that while truth and good, in all their various gradations from the lowest to the highest, form the essential contents of art, its character as art-as distinguished, that is, from science and religion - turns upon its form, and that its whole business, in dealing with whatever contents compatible with its nature, is to put them into its own form, instead of the form proper to religion or to science; to put them into this form upon the form's own merits, and not merely as if the form were subsidiary to the form of science or of religion. The proper form of science is explanation and argument, 
and the proper form of religion and morality is exhortation and command; but that of art is simply the directest embodiment of its theme as the theme itself requires. Assured that the theme is compatible with the ideal nature of art, the artist knows that it will justify itself and work its own work, if it can only find expression in its natural embodiment.

The theme and its right embodiment stand to him as their own end; his sole business is to give them free being. He has faith in his art, faith in the substance of his theme, and faith in the power of its own self-determined form to make its worth and meaning clear. It stands in need of no assistance from the explanation that belongs to science, or the exhortation that belongs to religion. Nor has it any need or intention to instruct for instruction's sake, or to cxhort for the sake of edification. It has what we may dare to call a higher aim. It will render its theme as the theme is, sure that the inward worth which makes the thing of beauty a joy forever will shine by its own light, and that instruction and edification will take care of themselves. So far as the artist entertains any other motive than the exactly fit expression of his fit theme, so far will he surely fall short of his artist's aim; for the presence of the foreign motive, however moral or judicious it may be, will certainly distract his attention from the essential clemands of his theme, and mem- 
bers will appear in his work that do not belong there, while others that do belong will fail of getting rendered. This is the reason why didactic or hortatory versifying offends a healthy taste, why allegorical sculpture and painting and music and poetry are insipid, and why the "novel with a purpose" has become a by-word and reproach.

To return now to our starting-point, and realise upon the long transaction we have been carrying on in the grounds of our view, we may say, with a better comprehension than at first, that art is imaginative creation taking its hint from fact, and setting into existence a thoroughly singularised unit, for the simple purpose of giving the theme which the work represents an embodiment in living accord with its nature; but this nature must be such as agrees with the real-ideality that makes up the cssence of art. In short, art is the literal origination of a beautiful object simply for the sake of its genuine beauty.

To apply this to the poetic art: A poem, to be such, must present some theme, of a completely original unity, wrought out of the materials of real experience by force of the ideal which, while carried in them, points beyond them; and which, though condemning them to imperfection, recognises in them a token, at least, of the Supreme Perfection. This theme must not simply be rehearsed, it must be cmbodicd-set 
forth in an organised and unique whole that gives us the sense of actual life, and the verity as if of a personal identity; and into the treatment of this theme no motive may enter except the aim to set it forth in the form its own nature determines. In fact, the essence of poetic form, in common with that of all other artistic form, lies just in this intimate correspondence between theme and expression; and it is this that is the secret of that impression of living reality which marks the work of art and the genuine poem. Form, in this sense, is the very life of poetry, as of all art. For though rationality of contents is indispensable to art, and the degree of this is a main criterion of the rank of a work, this still belongs to art in common with science and religion, and art only obtains its sufficing differential quality in this trait of appropriate and adequate form.

\section{V}

But all that we have thus far determined leaves us still on the ground of art in general. We have as yet no canon of poetry distinct from a canon of art universally. Our passage to this must be effected by ascertaining the basis of distinction among the different orders of art. Starting with the common distinction of the arts into the useful and the fine, we might do better, for the sake of clearness, to call the 
first the mechanical arts, and the second, after Schelling, the esemplastic - those that form a manifold into unity for the sake of the unity. And let us note distinctly that the real difference between the two classes is this: a mechanical whole (so-called) is nothing but a means to something beyond it, while a whole of imagination is not a means at all, but strictly an end. In short, the mechanical arts do not result in true wholes. Every mechanical art is after all only a contributing part to the real whole that comes into existence in the realm of the esemplastic arts alone-- the realm of the fine arts.

Nor may we omit the important fact, that the dis. tinction between the mechanical and the fine arts is not really a distinction into separate classes, but a distinction of order, or gradation, in the elements of one indivisible system. The products of mechanism are doubtless in most instances separate material objects, but these are never finalities. They are, as was said, only means to some want in our rational nature, and thereby get their justification; or else they receive their condemnation, and eventual dismissal from the world as man will have it, because of their lack of such service to reason. The rational ends, it is the function of fine art, in conjunction with religion and science, to express; and it must be borne in mind that the mechanical enters into every fine art, and is indispensable to its existence and completion. 
But let it be still more carefully kept in knowledge, that this mechanical element is only the servant of the fine art as such, and that the fine art, in its own proper nature, is not even hinted at in the mechanical. The sculptor must be a deft draughtsman and modeller; but draughtsmanship and modelling are not sculpture. The painter must be a draughtsman and colourist; but drawing and colouring are not painting. The composer must be a master of melody and counterpoint; but melody and harmony are not an oratorio or a symphony. The poet must be master of rhythm, metre, and all the resources of rhetoric; but rhythm, metre, and all the arts of rhetoric are infinitely short of the soul of poetry. No, nothing short of the creative principle of imagination gives the fine arts their specific quality - the principle that creates for the sake of creating, for the sake of giving free course to that imagination which is not only an essential but the guiding factor in the supersensible being of man, and which not only founds for him the world of religion and of science, as well as that of art, but is the constructive and developing principle of the universe itself.

So then, to get to a specific canon of poetry, we must settle the grouping of the fine arts, and find how they are really differentiated from each other. There are generally recognised a standard five, architecture, sculpture, painting, music, and poetry. 
Aristotle throws these into two main groups: the mimetic or imitative, embraced in sculpture and painting; and the poetic or creative, which are architecture, music, and poetry. But this Aristotelian division calls for criticism, and to bring its questionable character out, let me first emphasise Professor Le Conte's statement, that the so-called mimetic arts "are more than imitative, otherwise they would not belong to the category of fine art." And I would not only emphasise the statement, but add to it this: that fine art, as such, is not mimetic at all, and that the distinetion between the various fine arts is not founded on their relation or non-relation to the sensible world. In fact, architecture, music, and poetry must as truly derive their materials from the world of sensible experience as sculpture and painting; while sculpture and painting must as really contain imaginative creation as architecture, music, and poetry. That the sense-world which supplies the basis of music and poetry is a world of inner sense, while that which gives a footing to all the others is an external world, is a point of no material import. The vital thing in all the fine arts is their self-motived creative function; and any real distinction among them must refer to a gradation in the perfection with which they give this function free play. If one, but only one, of the arts recognised as fine is so hampered by relations to the mechani- 
cal arts, so circumscribed by certain uses its product has to serve, as to be prevented from entering unreservedly into the ideal of its theme, while it unquestionably still deals with the ideal, then we must place that art at the bottom of a hierarchy in whose higher grades the other arts will follow each other according to their compass of creative freedom. By this principle, it is found that the recognised fine arts form an ascending series in the order in which I have already named them, - architecture, sculpture, painting, music, and poetry.

Architecture, it is very obvious, in its aim of giving the masses and details of a building ideal form is guided and restricted both by the purposes of shelter and room that the building is to serve, and by the laws of constructive engineering. The two unite to prevent the free action of imagination, not only in regard to the proportions of the structure and the mode of combining its component masses, but also, though in a less degree, in regard to the ornamentation of its details. A building cannot be made with an isolated reference to the demands of beauty. Use and stability must be secured at all hazards, and the architect can only make it as beautiful as these conditions will permit. Any other method in building would be ruinous and absurd. Accordingly, it has been well said that architecture is not pure art, but only art struggling to get into 
being - or, as the Germans say, it is only ar "striving to become."

In all of the other four arts in the list, the creative function is quite emancipated from external uses and mechanical conditions. The only question regarding each is, What limits to the perfection of creative freedom remain because of its material or medium of embodiment? - what enlargement of free expression has it, by reason of the greater complex of elements which it merges into unity in its material, or by reason of the more inward and intellectual nature of its medium of embodiment?

Sculpture, by this principle, ranks below painting, not only because its material, as matter in mass, is less kindred with the intellectual nature of imagination than the surface of pigment which painting presents, but because its medium of embodiment, physical form, is less complex than that of painting, which unites both form and colour with perspective. The consequence of all this is, that sculpture is much more restricted than painting in its control over the principles of unity. It is limited to one narrow spot of foreground space, as well as to a present instant of time, while painting is limited in the unity of time alone. Thus the larger manifold that painting has the power of reducing to unity opens to it a vaster range of creative combination.

Painting, in its turn, must yield to music in crea- 
tive scope, partly because music works in a medium - sound, and the scale, and the harmonic and the rhythmic system - not only more ethereal, but incomparably more complex than that of painting, giving rise to an enormous increase in the alternatives for combination; partly because music is almost wholly released from space, having its proper form in time, and even in this is unconstrained by any rigidly defined boundaries; but most of all, because music, in its medium of sound, has an organ of utterance more expressive of the mystery of existence than any other, more immediately answering to the obscure and inarticulate longings with which the soul looks into the clim Unknown from whence the ideal unveils itself. It is in sound that the human heart spontaneously pours itself forth when in communion with those thoughts "that wander through eternity," or when thrilled by those other thoughts "that do often lie too cleep for tears."

Poctry, finally, is the form of art where not only are the unities of time, place, and action freed from the restrictive bounds of the single instant, the single spot, the single simple transaction, but the medium of embodiment is thought itself, with its completely articulate utterance in language. Here the very source of the ideal view of the world, the very origin of the creative artistic impulse, becomes the material and the instrument of its own purpose, 
the executor of its own will. The scope of the creative faculty is therefore the utmost conceivable, and poetry rightfully takes the highest place as the art of the greatest possibilities - the art, indeed, of an all-inclusive compass, as at length completely selfsupplying and self-directing.

\section{VI}

If we now sum up all that our inquiry has gathered concerning the essential principle of poetic art, our result is this: What makes a poem a poem is the fact that there is presented in it, in a rounded whole of rigorous unity, a theme of real-ideality - a theme founded in actual experience, but transfigured in the light of the ideal borne within it which unites it at once with the reality of Nature and with the Supreme Ideal toward which all Nature moves. This real-ideal strikes in with the law of Nature, expresses it, and is in fact its product. The theme this affords the poet must be embodied in exact accordance with its own nature, and simply for its own worth, for its own beauty, for its own sake. The whole that this embodiment gives must be a literal creation, a unit thoroughly new and one; and if it is a complex unit, as in clramas and epics, every one of its members, whether characters or incidents, must be equally unique and created. Finally, this creative embodi- 
ment must be in the genuine medium of thought and language. Hence it must avoid all those meretricious effects, exaggerations, and extravagances, that come of attempting to force thought and speech out of their natural province and make them ape the functions of music or painting or sculpture. It must avoid, in short, the fault of falsely mimicking external Nature by that whose proper function is only to suggest its ideal - the fault of over-melodiousness, over-description, over-delineation, over-initation.

Now, the trait of true poetry mentioned last - that it shall conform to the nature of thought and language - is the specific quality that the poetic art must add to the essential principle of art in general. And yet it might casily seem to be one that will be present of necessity, and consequently of no practical moment as a factor in ascertaining the existence and rank of a poem; we might suppose that we could perfectly well disregard it. But to do so would expose the very substance of poetic art to mutilation, and even to destruction. The tolerance which the disregard would foster of the extravagant externalism just mentioned is of a piece with another common mistake - that of supposing that poetry must be set in metre and rhythm, or that poetry is identical with verse; and that its contrast to prose is simply the contrast between versified and unversified utterance. This brings us to the question of the real clistinc- 
tion between the substance of poetry and that of prose. The settlement of this will decide another question, quite as important, Whether the series of fine arts should be enlarged by the addition of prose writing? We must therefore investigate these two questions briefly.

It is plain that, since poetry is creation, it cannot be limited to composition in the form of verse unless we can show that imaginative creation in the medium of thought and language demands verse as its only normal expression. But to this there are two objections, which together are fatal. In the first place, it is a fact that some of the greatest poems lose nothing essential to their poetic character by being translated into an unversified form: witness the Book of Job, in our English Bible; the translation of the Odyssey, by Butcher and Lang; and John Carlyle's version of Dante's Inferno: something of effect they may and do lose, but they are real poems of the highest order, just as they are translated. In the second place, there are unversified works of genius that are unquestionable poems; for instance, Coleridge's wonderful fragment The IVanderings of Cain, De Quincey's Vision of Sudden Death, with the Dream Fugue that follows it, his Flight of a Tartar Khan, and Jean Paul Richter's Drcam. In fact, verse and poetry are quite distinct. Verse may often be the form of poetry, and is usually its most effective and most 
appropriate form, but verse has no necessary nor absolute relation to the essence of poetry; verse of a high order may be, and frequently is, quite void of true poetry, and poetry is often independent of verse.

Thus we must either add to our list of fine arts three others, namely, novel-writing, play-writing, and writing such as De Quincey's pieces and the other works just mentioned with them, or else we must take poetry as including them. But in its proper character of creative embodiment it surely does include them. It is clear that poetry, in the only sense in which it belongs to our discussion, is not contrasted with prose in the sense of unversified writing, but with prose in the sense of writing that is not creative, and not its own end; with prose as prosaic - writing used only as a means, to the end of instruction, conviction, excitation, or edification. Now, in this sense, the only sense pertinent to our inquiry, it is manifest that prose is not a fine art, simply because it does not pretend to be a selfmotived art of creation. Its aim is not an imaginative whole, produced for imagination's sake.

But this adverse settlement of the pretensions of prose writing to a place among the fine arts has its chief interest in the light it throws upon the real cause of the frequent impression, not only that prose, particularly in the form of oratory, is a fine art, but that, since it is, the doctrine that fine art must be its 
own end is groundless. The impression has its source in a confusion of ideas : first, in a failure to discriminate between a delicate mechanical art (which prose certainly is, and so may justly be called "fine" in that sense) and a fine art in the only sense in which æsthetics recognises the term; and then in a further failure to avoid the double sense in which we constantly employ the words "prose" and "poetry." This is an additional reason for discontinuing the name "fine arts" and substituting for it Schelling's phrase "es. emplastic arts"; and it would be well if we always said "verse" and "unversified writing" when we meant them, and kept the words "poetry" and "prose" to mark the deeper difference regarding art.

Moreover, of this prevalent error there is a further explanation in the overlooking of the whole series of decorative arts. These form between the mechanical and the strictly fine or esemplastic arts an intermediary group - a sort of ascending series of "arts striving to become." Architecture is properly their "upper limit," the point at which they vanish into esemplastic art, so that some recent writers on the theory of architecture have taken the ground that architecture is merely a decorative art; though surely it should be plain that architecture involves creation in a degree amounting to a difference in kind from any mere scheme of decoration. Now, prose in its strict sense, as the antithesis of poetry proper, is an 
art combining the mechanical and decorative in one; and oratory, perhaps the highest form of genuine prose, illustrates this fact with the greatest clearness.

Such confusions and oversights as are involved in the misapprehension which has just been exposed, might be prevented if we grouped the whole series of arts as mechanical and fine, and subdivided fine arts into decorative and esemplastic, recognising that in architecture we have the nodal point of ascending transition from the decorative to the creative.

As I reach the end of this over-prolonged inquiry, in its unavoidable hardness and dryness so little akin to the fair attraction of its theme, there float into my memory, as a poetic pointing of our search's moral, these lines of Emerson's, from his fragment called The Test: -

I hung my verses in the wind, Time and tide their faults should find ! All were winnowed through and through : Five lines lasted sound and true ! Sunshine cannot bleach the snow, Nor time unmake what Poets know. Have you eyes to find the five Which five hundred did survive? 


\section{THE RIGHT RELATION OF REASON TO RELIGION}

On the question, What is the real relation between reason and religion, the range in contrast of views is of course very great. And this is true, whether we consider the views as merely conceivable or as actually presented in the course of history.

It is evident, first, that the view might conceivably be taken, that reason and religion are incompatible. This incompatibility might moreover be construed in behoof of religion as against reason. It might be saicl, that, granting the reality of religion, the recognition of superhuman Power, the active presence of the Power must be accepted as simply an awful Fact - inexplicable, incomprehensible, inscrutable, yet unquestionable - before which, terrible and indeed resistless and overwhelming, reason must prostrate itself, keep silence, and slink away into undiscoverable hiding. And this view is not merely conceivable, but is actual and historical; nay, it is the eldest view; and if hoary antiquity or multitude of adherents were taken as the true measure of value and authority, it would be the weightiest view. 
Then granting, in contrast, the reality and the supremacy of reason, it is conceivable that reason and religion might be declared incompatible in the opposite sense. It might be said that reason necessarily puts an end to religion; that religion is only another name for superstition; that men who heartily accept the authority and guidance of reason must dismiss religion from the field of reputable intelligence and real motive, and must relegate all interest in it to the field of archæology or of mental pathology. Nor is this view any more a mere hypothesis than the former. Rather, it is in a certain sense the youngest actual view; and with the natural vigour, the verve, and the assurance of youth, it braves the world in the confidence that it is the only true view, and alone commands the future. One must no doubt admit, for candour's sake, that it is the view of men in a stage of comparative development, the view of ages comparatively recent and enlightened. Sooner or later it has made its appearance in every civilised community. It came to its head in our eighteenth century, and we should hardly be extravagant in saying that it was then the characteristic view of the minds that made themselves most prominent, especially in France, in England, and in Germany ; in fact, it is the tone of the eighteenth-century Zeitgeist. From the spirit of that age it has been transmitted to our own; it 
survives widespread in much of the temper of our latest days, is heard in the proclamations of most agnostics, and is felt in the spirit of much evolutional philosophy.

Secondly, at quite the other extreme, reason and religion might be viewed as in one sense or another compatible. They might either be regarded as essentially identical, each the same interior life and reality, uttering itself in two different forms; or, if not quite this, as at any rate in a tolerant harmony with each other, occupying their several provinces in reciprocal peace, nay, even supplementing each other in a sort of friendly alliance; or, finally, as at least capable of a modus vivendi, a peaceable compromise of hostilities.

This irenical view, in its general sense, has undoubtedly been the opinion of the vast majority of religious minds in all ages of enlightenment. To speak more accurately, it has been the growing conviction of religious minds as enlightenment has grown, and it has engendered efforts, ever increasing and ever improving, so to understand both reason and religion as to bring their harmony into clearer light and better apprehension. Indeed, the religious history of mankind within the period of enlightened human progress, with the vast religious changes that have marked it, is explicable by the persistent 
impulse to bring religion and reason into harmony, and is not far explicable otherwise. This history of religious changes means that men are advancing, steadfastly if haltingly, on the path of comprehending what reason is and what religion really is. . They are learning better what is truly reasonable, and, at the same time, what is truly religious; and this learning is gradually putting them in mastery of the relation in which reason really stands to religion, and true religion to genuine reason.

But in the course of this development, three very different doctrines as to the basis for harmonising reason and religion have been brought into use and belief. For the sake of distinction, I will call them, respectively, the Old Doctrine, the Middle Doctrine, and the New Doctrine. Let me attempt to state them all exactly and succinctly.

(i) The Old Doctrine. - This runs to the following effect: Reason and religion have an intrinsic antagonism as well as a possible compatibility, and their harmony, if religion is to survive, depends on the submission of reason to religion as to an absolute sovereign; the harmony rests on authority. Reason doubtless has its own proper province in human life, and religion has likewise its province. But the former is minor, subordinate, merely natural, and only temporal; while the latter is paramount, 
spiritual or supernatural, and eternal. Reason is the organ of the natural man; it is altogether of this world, and has no light for the world to come. Its function is merely instrumental, not at all lawgiving. It teaches us how the benefits of the visible world may be won, or how they may be made to serve even the aims set forth by religion; but it is silent as to the invisible world which is the end to be served by the visible. Dicl we listen to reason alone, as it rcally is, we should know of no world but this world, and be led to cleny the world everlasting, to ignore and deny religion altogether.

For - this Doctrine adds, by way of explanation it is the nature of reason, really, to concentrate all its view on the "things that are seen," and yet to assume that its compass embraces all being. Thus extending its judgment into the invisible world, as it is prone to do, it must of necessity contradict the transcendent principles that reign there, and be in its turn contradicted by them. The "evidence of things unseen" is FAITu; and Faith means, that reason has met and accepted its due rebuke from a higher authority; that it has made its submission to Divine Revelation, which is and must be immediate, without means, supernatural, supra-rational, and, indeed, in the highest resort, contra-rational. The first lesson of religion is, that what is impossible with man is possible with God, - "With 
man it is impossible, but with God all things are possible."

(2) The Middle Doctrine. - This says: There is no intrinsic antagonism between religion and reason, but merely a difference of gradation in light. Religion never contradicts reason, but supplements it, and their harmony is the natural accord of the incomplete with its needed complement. The harmony undoubtedly rests at last on authority, but not on authority solely; rather, on authority coming as fulfilment, aud meeting confessed insufficiency. Where according to the Old Doctrine authority was sternly repressive, in the Middle Doctrine it is gracious.

The Middle Doctrine agrees with the Old in assigning to reason and religion separate provinces. But it does not limit reason utterly to the things of sense, nor does it find in the judgments of reason upon things invisible any contradiction of the judgments of religion, but only a shortness of reach and a deficiency of light. Nor does the Middle Doctrine find in the judgments of religion any contradiction of the judgments of reason, so far as these can reach, but only light and fulness of revelation where the light of reason fails. To the Middle Doctrine, as to the Old, the "evidence of things unseen" is unquestionably Faith. But here Faith is not a submission to rebuke and reproof ; it is a humble and grateful 
acceptance of instruction in darkness, and of support where power has failed; of support hoped for and longed for, and of instruction looked for with presentiment. Religion does not, indeed, contradict, affront, and suppress reason, but it confessedly transcends reason, and in its interior doctrines and agencies remains to reason essentially incomprehensible and inscrutable, to be accepted not in knowledge, but on trust.

(3) The New Doctrine. - This declares: Reason and religion have an intrinsic harmony; their harmony is that of cause and effect, of fountain and stream, of enfolder and enfolded. Here reason is viewed as the real source of religion, and real religion as the outcome and self-completion of reason: religion owes its being to reason, has no complete reality except through its reasonableness, and takes all its final laws from reason.

Thus, according to the New Doctrine the harmony rests, not on authority, but on reason itself ; or, let us say, it rests not on authority as authority, - as compulsory decree or nagisterial edict, - but on the authority of reason, on the autonomy of each rational being as a rational being. The harmony is the immutable harmony of reason with itself. In the New Doctrine as compared with the Old, the order of dependence and the source of authority are both 
reversed: reason, instead of paying homage to religion and making its submission to cxternal authority, now legislates for the religion which is its own offspring, and becomes itself the authority from which the credentials of religion must issue.

It is this New Doctrine, known generally, and properly enough, as the doctrine of RATIONALISM, that I am permitted by the courtesy of this Congress ${ }^{1}$ briefly to explain and defend. To the question, What is the right relation between reason and religion, you will now understand me to answer, It is that reason should be the source of which religion is the issue; that reason, when most itself, will unquestionably be religious, but that religion must for just that cause be entirely rational; that reason is the final authority from which religion must derive its warrant, and with which its contents must comply; that all religious doctrines and instrumentalities, all religious practices, all religious institutions, and all records of religion, whether in tradition or in scripture, must alike submit their claims at the bar of general human reason, and that only those approved

1 The essay was read as an address before the Congress of Religion, held in connexion with the International Exposition at San Francisco in April, IS9.4. 
in that tribunal can be regarded as of weight or of obligation; in short, that the only real basis of religion is our human reason, the only seat of its authority our genuine human nature, the only suffcient witness of God the human soul. Reason, I shall endeavour to show, is not confined to the mastery of the sense-world and the goods of this world only, but does cover all the range of being, and found and rule the world eternal; it is not merely natural, it is also spiritual ; it is itself, when come to itself, the true divine revelation.

And now, in attempting to make all these assertions good, I must of necessity depart a little from the precept of this Congress that bids us rather make for unity and peace than stir the fires of controversy. I am confident I shall introduce no odium into the discussion upon which we are about to enter; for, as I feel none, so I have the cheerful hope that I shall arouse none. But the proof of the New Doctrine, I call it new, in spite of its antiquity, because it is so much the youngest of the three, - the proof of the New Doctrine can only be made out by traversing and refuting the Old and the Middle. Controversy, in the sense of criticisn, is therefore unavoidable. But it need have no bitterness, nor awaken any; and unless I greatly mistake my own temper and the temper of this company, it will not.

The doctrines I have named the Old and the Middle 
have a marked feature in common, which is characteristic of their contrast to the doctrine called the New. It is that they both present religion to each soul on the warrant of authority, albeit the one does this severely, with rebuke of reason's pretensions, and the other graciously, with encouragement and support of reason's weakness. Therefore it will be best for the purposes of our discussion to cast them together, and to pit them in their common reliance on authority against the view that proposes to rely entirely on reason. The issue we are to consider and weigh will thus be presented in its simplest terms, as an issue between two methods with religion, - the Method of Authority and the Method of Reason, or the Method of Sheer Declaration and the Method of Conviction. Which, now, is the right method? What are the grounds on which the Method of Reason must rightfully supplant the Method of Authority, the Method of Conviction the Method of Declaration?

\section{II}

In order clearly to define the provinces between which this issue lies as a matter of history, and to avoid misunderstandings as to what historical religious bodies are really involved in our criticism, let us first touch upon a distribution of these doctrines and methods which is natural, if erroneous, and which has 
no doubt already half expressed itself in your thoughts. We are prone to connect the Old Doctrine, the strongest expression of the Method of Authority, with the teaching and practice of the Romanist church. And it is plausible to take the Middle Doctrine, which at bottom is still a Method of Authority, though mingled professedly with a method of reason, as characteristic of the Protestant churches. Then we naturally complete this interpretation by allotting the New Doctrine, with its unmixed Method of Reason, either to minds entirely outside the pale of Christianity, and arrayed in opposition to it (whom it is convenient and comforting to designate as Infidels), or else to those small groups - still partly holding to the name of Christian themselves, but by the great body of the orthodox acknowledged only askance, if at all - which are usually called Liberal Christians, or, perchance, Unitarians or Free Religionists or what not.

But this distribution of views, handy and plausible as it may be, is really quite wrong, quite out of accord with the facts. We cannot afford to carry it into our discussion. The so-called Old Doctrine has been, and is now, held alike by some Romanists and by some Protestants; indeed, it has never been stated with such unqualified emphasis by any Romanist as it has been by the elder Protestants, of the school of high Calvinism. The gracious Middle Doctrine is held alike by many Protestants and by many Romanists, 
nor has it ever had a stronger affirmation or a nobler utterance in the mouth of any Protestant than it received from the great doctor angelicus of Roman theology, St. Thomas Aquinas, or than it continues to receive, and to receive increasingly, from the members of his great school, unquestionably the most influential, and deservedly the most influential, in the Roman church of our day. Nor can we justify the blunder of assuming that the New Doctrine, with its Method of Reason, belongs only to so-called Infidels and the feeble handful of disapproved Liberals in the United States and in dissenting England or elsewhere. The New Doctrine might with far less error, though still not with much accuracy, be said to be dominant among the leading official teachers in the two great established churches of Protestantism, - the German and the Anglican; while in the less important but still intellectually influential Protestant organisations of Holland and Belgium the same is true, and even more true. Later in the essay, I shall give what seems to me the unanswerable proof that the Method of Reason is not only not unchristian, but is really the only method consistent with the principles of Christ; that, with its rise, Christianity, in its full meaning, first became actual in the Christian body, and that with its victorious supremacy the full "mind that was in Christ" will for the first time have come to expression in the mass of his followers. 
No, we shall labour under a really injurious misconception if we pursue our discussion in the persuasion that Rationalism means hostility to genuine and fulfilled Christianity. Much less is it to be supposed that the chief object of assault in attacking the Method of Authority is the great church of Rome. Rome simply shares the attack with that Protestantism, self-styled Catholic or Evangelical, which, like Rome, founds religious life and religious doctrine on authority. Moreover, let it be insistently borne in mind that neither Romanism nor Protestantism is assailed by Rationalism in so far as either is Christian, as both, in the centre of their quickening spirit, indeed are. But both are criticised by the growing rational spirit of mankind, and criticised not in bitterness, but in all tolerant though unyielding sobriety, in so far as they have received into Christianity, and have persisted in maintaining there, the Method of Declarative Authority; a method long antedating Christendom, and really surviving in it from the primeval religions and the great organised religions of the Orient and the pagan West; a method contradictory of the genius of Christianity.

Let us realise clearly, then, that while the most pertinent bearing of our discussion, and its greatest weight of meaning, must doubtless be with reference to the developments of the Method of Authority in the history of Christianity, we shall have a 
conception of the dispute altogether too narrow, indeed seriously wrong, unless we regard the Three Doctrines and the Two Methods as principles pervading religious history in its world-wide scope. The struggle between Reason and Authority dates from eld, and its history within Christendom is only the history of a survival, though a history on the field incleed most significant. For this reason, while we keep in mind the universal reach of the conflict, it is natural and proper that our discussion shall cast its argument in the terms that have come into use through the working out of the Method of Authority in the region and the circumstances of Christendom.

Why, then, is the Method of Authority invalid? - what is its fatal defect, religious or other? Above all, what is its especial condemnation when working in the medium of the Christian religion? - what is there in it that contradicts the "mind that was in Christ"?

\section{III}

To the former of these two chief questions I answer, That the Method of Authority is invalid, and so must be discarded, first of all, because it is logically unreal, - it involves a profound self-contradiction. Understand that we mean by this method either the rebukc of reason for invading the spiritual region where all its carnal judgments must contra- 
dict the mind of God, and so, for righteousness' sake, must be contradicted by God's direct word; or else the discrediting of reason, even though with gracious condescension, by excluding its incapacity from the realm of things sacred, and essential to the welfare of the soul, where again resort must be had to the direct word of God as the only means of supplement. And if reason - and let me here say that in this discussion I shall always mean by reason the human powers of insight in their completest scope, and not merely the faculty of "reasoning," or consistent and consecutive syllogising, or "explaining" and "proving," in this mechanical sense - if reason either necessarily misjudges concerning the things of eternal life, or is incapable of any judgment at all about them, then there is of course nothing for it, in the highest concerns of its being, but simply to hear and obey the direct declaration of God.

"Most true!" - I can imagine the advocate of Authority saying, - " most true! and that is exactly our impregnable doctrine." I cannot agree with him in this confidence, however; the doctrine is anything but impregnable, it really contradicts itself, and this in more than one way.

Certainly it is a doctrine on the surface very plausible, but it will not bear the test of an exact and careful thinking out. For we cannot but go on to ask, How, then, is the direct declaration of God 
to be known and verified? The unevasive answer to this must be, either ( $\mathrm{I}$ ) that our human intelligent power, our deep interior reason, already possesses such a knowledge of divine things, of God's own nature, that when our reason reveals itself, through the depths of experience, we can discern by it in the internal character of given utterances their divine origin and authority; or else (2) that the presence and speech of God can be known directly by the evidence of the senses-that a man may see with his eyes, and hear with his ears, things and sounds that are immediate proofs, not inferential implications, of the presence of God then and there, and of his word then and there spoken. Now, the former alternative, that of Internal Evidence, in order to vindicate the claim of authority has to appeal to the revelation of God in reason, and this is a plain contradiction. The second alternative, that of External Evidence, appeals to the testimony of the senses for the proof of supersensible reality; and this is a balder contradiction.

In the case of the Old Doctrine of the relation between religion and reason, the Method of Authority involves the further inconsistency of having to appeal, in order to verify the presence and word of the Most High, to the very reason rebuked for raising its earthcentred eye to things celestial; for this appeal is made, when belief is demanded upon tokens which the 
hearer is supposed to recognise as divine. In the case of the Middle Doctrine, it commits the inconsistency of calling to the aid of incompetent reason the still more incompetent and still less spiritual powers of sense, but powers human nevertheless.

But, in fact, the entire theory of external evidence for Divine Revelation is shown by comparative studies to be a survival from the religious consciousness of primitive times, when men really believed that God could be clothed in a limited body, and could be present in a specific space at a given time, and be seen and heard quite as a man or any other being with a body is. It is a survival despite the declared abandonment of this sensuous view of God, and can only be explained by supposing negligence - a want of critical attention to the consistencies of the spiritual view of God that we all now profess. For such sense-given evidence is manifestly incompatible with the cloctrine of reason and of Christ, that God is Spirit and is not to be truly worshipped in Mount Gerizim, or even in Jerusalem, but only in the spirit. It is not consistent with the spiritual infinity and true omnipresence reasonably attributed by all Christians to God.

Secondly, I hold the Method of Authority to be invalid because it is impossible to make it intelligibly out: in obedience to its plausible lead, we search from one point to another of the asserted 
prools of God's presence and authoritative voice, but can never come to anything that is conclusively and palpably the Divine being. To show this, I must ask you to review with me, briefly, the history of religious Evidences.

Here it is that the chief point of dispute between Rome and orthodox Protestantism arises. Both teach that the primary source of authority is the sovereign declaration or revelation of God; but on the question of its supreme medium for mankind they profoundly differ. The Romanist lodges this vicegerent authority over human reason in the Holy Catholic Church; the orthodox Protestant lodges it in Holy Scripture. Both appeal to a miraculous communication of the Divine will; but the Romanist teaches that this communication is directly to the Church, the corporate whole quickened by the indwelling of the Holy Ghost, while the orthodox Protestant maintains that it is directly to the single inspired writer, whoever he may be. Preëminently, of course, for both, the Divine Revelation is in the Person and Work of Jesus of Nazareth, taken for God Incarnate; but the witness to the Incarnation must be absolutely competent and intact, and this the orthodox Protestant finds in the supposed infallible inspiration of the writers of the Scriptures, while the Romanist finds it in the supposed infallible inspiration of the Church: 
for him, Holy Scripture is but the gradually devel. oped record of the tradition of the Church, verified at due times by the Church, and given a derivative but still unbending authority by being enrolled in the Canon by solemn act of the infallible body.

But how, for the Romanist, and still more for the unconverted to whom he would go with the credentials of salvation, - how is the infallible witness of the Church to the Incarnation made evident? And for the orthodox Protestant, or for the unconverted whom he would win to heaven, how is the infallible witness of the Scriptures made sure? Is it not plain that in both cases the whole question must come down, at last, to the simple matter of tes. timony, either first-hand or second-hand or, finally, many hands removed? And what is the first-hand testimony? The declaration of a certain man that he was the Living God, and that when he spoke God therefore was speaking, - admitting, for the sake of argument, that he did so declare. What is the second-hand testimony? That of certain persons, present when he made the declaration, who heard and believed it; heard and believed, also, manifold teachings of a morally guiding, morally inspiring, and morally regenerative power, and passed all onward to those with whom they conferred, from whom the teachings passed, and still are passing, onward to multitucles of others. What is the remote testi- 
mony? That these testimonies of presumed and declared ear-witnesses have been securely and inerrantly transmitted from generation to generation for hundreds of years: on the one theory, by the unbroken consensus of tradition in the Church; on the other, by the unbroken preservation of the inspired record in the Scriptures.

But now we come to the crucial point: What alone can all this, in its parts and in the whole of it, even supposing the testimony to be flawless, - what alone can it cstablish? At most, that there was an ever-memorable and indeed stupendous Declaration, that a few believed it, and that many, on their testimony, have believed what those few believed. Whatever else may be true, it must be assumed in all this inquiry that Jesus was a real man, and spoke as a man. Well, then, how is it possible that the simple declaration of any man should establish the truth of it? Above all, how can the declaration of any man that he is the Living God prove him actually and verily to be so? Not even the word of Jesus could, in itself, prove anything more than that he believed he was God, - supposing for the sake of argument, I repeat, that he really said he was God, with the intention that he should be understood literally. Not all the testimony of all the saints that they heard this declaration, could in itself prove anything more than that they did so 
hear, and that he did so declare, and that they believed it, as he eviclently believed it. There can be no evidence in all this that what they believed was really fact. If it be said that it was enough to witness the manifest character of Jesus, to believe his words beyond all doubt; that the witnesses were so transfixed and inspired by the evident worth of Christ as to "know in whom they had believed," as they firmly testify, - this is to abandon the principle of Authority, and to appeal to the latent human knowledge of what constitutes a divine character.

And all this holds, remember, irrespective of the further difficulties which the Method of Authority, with its necessary dependence upon human testimony, must meet when we come to the intricate question how testimony, of whatever original authenticity and sincerity, can be securely and verifiably transmitted; and to the yet closer question, whether the conditions for such secure and verifiable transmission have actually been met in the case either of the Church Tradition or of Holy Scripture. Grave and indeed terrible are these questions; the more so for the soul that has true piety toward God and faithful love for Christ, yet is habituated to rest its faith on an authority supported by testimony, when it comes to realise, as by a sufficiently wide comparative study it must, how rarely testimony is either exact or exactly trans- 
mitted; nay, how almost impossible it is that testimony should be so.

The plain and unavoidable truth seems to be, that there is no way of making out a Divine authority by declaration alone, by ear-witness alone, or by testimony alone, however inerrantly preserved and transmitted. The radical difficulty is with the original Declaration, and with the original ear-witness: neither of these can possibly come at the indubitable presence of the invisible, inaudible, altogether supersensible reality of the divine Eternal Essence. Our mind, following the indications of the evidence offered, searches and reaches for the unmistakable presence of God at the back of the sense-signals, and is met by - vacancy.

A perception of this led the early apologists of Authority to supplement the evidence of declaration and testimony by the evidence of miracle. Thus it was - and from an intelligent motive - that miracles came to constitute an integral factor in the accepted historic system of Apologetics. The miracle was supposed to demonstrate the actually present power of the eternal Creator. The claimant, declaring himself God's authentic messenger, had his declaration verified by the manifest presence of God, - manifest by the clear exercise of that power which made the world, and ordained and sustains its order; manifest by the interruption of that order and the 
sustentation of the world notwithstanding. The argument was: By a Divine Revelation, an authoritative declaration of God, we mean a direct utterance of Him who created and who sustains the world; we know it is He that speaks, because here, in the miracle, is the infallible sign of that complete control over Nature which is the prerogative of its Author.

But this attempt to support testimony by miracle, striking as the argument seems when first presented, will not endure a serious examination. Upon sufficient reflexion, we see clearly that the proof of the reality of a miracle, of the actual occurrence of an event supplanting the ordinary laws of succession in Nature, rests in its turn upon human testimony again, and, still worse, upon human judgment. A supposed miracle called in to validate testimony, the assurance of whose occurrence must yet itself depend upon testimony, nay, upon human judgment, certainly cannot be called a secure support, a proof real, final, and conclusive. The same inferential judgment that collects from certain sensible signals the actual presence of God, that concludes God is speaking then and there, because certain sights and sounds are perceived, must of course come again into play when some amazing event, not to be paralleled in the previous experience of its observers, is construed into a suspension of the order of Nature, the 
doing of something impossible to any being but God. Worst of all, the whole argument rests upon the tacit assumption that the entire connexion of sequences in Nature reposes on nothing but the will of God-a basis of reasoning that has not borne, and will not bear, the light of our maturer and more deliberate thought, grown critical and more exact in the course of human culture.

Thus it becomes plain that in the last resort testimony has nothing but other testimony for its support, human judgment other human judgment; and never by any means or method at our command do we succeed in getting past our human faculties, so as to come directly upon the infallible and immediate fact of God speaking in his own person. Here, for the sake of argument, I purposely reason on the assumption of that comparatively loose and superficial philosophy which treats miracles as real possibilities, capable of proof by testimony, quite as the normal cvents in Nature are. But even granting this, we see by the analysis just presented how futile a circle there inevitably is in the argument from miracle, and how it must perpetually come short of any authority directly Divine. In any proposed cxternal communication from God, the channels of human faculty are never to be got rid of ; so, if they do not in their own native quality constitute divine vouchers, they must operate as barriers to any com- 
munication with God. Of God, who is essentially supersensible, there can be no such thing as a presentation directly to our senses; and all belief that sensible facts mean his real presence must rest at last on inferential judgments of our reason, while these will be nothing but self-continuing circles, worthless for evidence, unless our reason is granted to have in itself the real revelation of what accords with the Divine mind. An absolutely clirect utterance of God in the external world, evident strictly in itself, is thus upon close examination unintelligible and unthinkable. Yet this is what is implied in a consistent doctrine of Authority.

\section{IV}

But now let us pass to the second, and the much more important, of our two main questions : - Why must a religion that would rightfully bear the name of Christ, especially reject the Method of Authority?

What is there in the principle of Authority that contradicts the "mind that was in Christ"? What is there in the central teaching and the spirit of Christ that puts upon such a method with religion the stamp of its condemnation? For I have thus far constantly implied not only that the principle of Rationalism does not carry us away from real Christianity, but that genuine Christianity demands and 
involves this principle, and that in its interior heart the Method of Authority is fatally in conflict with the spirit of Christ.

In making this assertion, I do not mean, of course, that the principle of Authority has not, as a matter of history, been compatible with some of the teachings and something of the spirit of the great Founder. To mean this, would amount to saying that the great bulk of the historical Christian body, whether Greek or Romanist or Protestant, has always been entirely false to the spirit of its Lord; and this no man of impartial or intelligent judgment could affirm. But what I do mean is, that wherever the principle of Authority has entered and operated in historic Christianity, it has interfered with the free expression and development of that teaching and spirit which is most specifically characteristic of Jesus when his mind and work are viewed, as they must be, in the light of the comparative history of religious thought. I mean that so far as the various Christian bodies which adhere to the principle of Authority have succeeded in displaying the spirit of Christ, and unconsciously keeping its inmost secret still alive in the world, they have done so, not because of the doctrine of Authority, but in spite of it, - such inward vitality, so kindred with the interior life of humanity, as this advances along the pathway of civilisation, has that central insight, 
that subtle spiritual sense which Jesus communicated to the world, possessed.

Now, that the very fountain and vitalising heart of this spiritual sense is a new insight into what really constitutes the nature of God, and into the real relation of men and all souls to God, it will be possible here to show, I believe, without too much taxing your time; and when it is shown, we shall have the plain proof that this essential and central doctrine of Christ puts a logical end to the Method of Authority, demands for its proper expression the Method of Conviction, and cannot be satisfied with anything else.

The cultivated world has now for some years been familiar with the phrase "the secret of Jesus," iterated with such adroit rhetoric by the brilliant author of Literature and Dogma. Very likely, in common with most of his many readers, you are little satisfied with Arnold's explanation of what that "secret" was; and I will frankly say that I shall not be sorry if you are: your state of mind will better open the way for a new endeavour to answer the question. For at the point our discussion has now reached, we have really to ask what the "secret of Jesus" was; and we shall agree, I hope, that it lay in a new Doctrine and a new Temper: a new doctrine concerning the nature of God and the nature of the religious relation of men to God and to each 
other; and such an unparalleled temper of complete personal identification with the doctrine as was even more new in the history of the world. Foreshadowings of the doctrine, though only foreshadowings, there indeed had been; they had even been put into written record, generations before Jesus, in the Greek thought of Socrates and of Plato. But any such temper, any equivalent tone of life, we cannot with truth affirm there had really been. For not only did this Hellenic thought fail of consistency with its highest glimpses, and so come far short of full insight into the nature of divine and human personality, but it failed to fill its cliscoverers with that absolute and ever-vivid consciousness of benignant relations between God and the soul, and thence between all souls, as constituting the only real life of the spirit, which is transparently the characteristic personal trait of Jesus. To the great Greek teachers, even to Socrates, as it still is practically to us all, this one and only truth of living religion was more or less but a distant thought, summoned into direct consciousness at intervals by a reflective effort, and brought to bear upon conduct amid the clamours of our animal being. To Jesus, on the contrary, it is an ever-present perception, like light to vision, like space to our movements, like time to our projects in life.

Manifestly, then, we are to say it must be the chief 
aim of any religious method that can justly lay claim to being Christian, to bring about, in all the minds upon which it acts, the possession of this secret of the Founder; the same insight, namely, into the nature of God that he had, the same ever-luminous conviction as to the real relation between God and souls, - from God toward all souls if God is to be truly God and adorable, from souls toward God if the soul is to be genuinely a righteous mind. It seems clear that the transcendent temper of personal devotion which Christ displayed is owing to nothing but his vivid and constant consciousness of this view of God and the spirit; so that any inquiry into what his secret of life was, any inquiry especially that looks to the imparting of the secret to others, resolves itself into asking what, exactly, the peculiar view was, that he held and was the first to proclaim, concerning the divine and the human nature, and the essential relations between them, and between human bcings in consequence.

In a general sense, all Christian people know well enough, and have always known, what this secret of their Founder is, what the doctrine of God and the soul that constitutes his characteristic insight, his new and unsurpassable message to mankind. The intelligent ordinary Christian, if asked to say how he would sum up in a single phrase the new and central doctrine of his Master, would hardly 
fail to answer: Christ tanght, and revealed in his own life, and aboi'c all in his death, the previously unknowen truth, that God is a Being of universal and exhanstless LOVE, who "would not that any should perish, but that all should have etemal life." This statement of Christ's peculiar doctrine is in so far right that one cannot fail to find corroboration of it on nearly every page of the New Testament, nor can one state the real teaching of Jesus without including this. The whole view held by Christ, however cutting in its sharp contrast with the theistic views that went before him we may find it, centres no doubt in this principle of universal love - love of God for every soul alike, love due from all souls to God, love owed by every soul to every other. His single New Commandment only sums this up: "Thou shalt love the Lord thy God with all thy heart, and thy neighbour as thyself." Nevertheless, when we leave the statement simply in this general form, we fail to reach its real implications.

We need to go beyond the broad precept of universal love - benevolence that knows no limits of number, race, sex, or other external conditions and ask searchingly what real love really implies, love that without reserve can be called divine, or suited to the nature of a Being of absolute goodness, of infinite wisclom and power. There might well enough be a universal love that was full of 
reserves, and loaded with discriminations: every being might be included in its scope, but each would receive only the one specific share of regard allotted to each. A love universal might, too, in every case be only a condescending love; or, again, only a pitying love, the love that is commiseration. And when religious thought preceding Jesus had generations earlier passed out of the darkness that hid the love of God altogether, leaving him to appear only as a dreadful Power, and had come to recognise in the Almighty some tokens of love, it was at best only this commiserating love, this grace that condescended, this benignity that reserved and discriminated, which was its theme. But this early conception of the Divine Love falls far short of the meaning of Jesus, just because it falls utterly short of a love that is completely love, and so of a love that is worthy of a Being truly God. Consequently we must seek for Christ's meaning elsewhere than in those phrases of the New Testament that come, perhaps, most readily to our lips.

These most familiar Christian sayings, like those already alluded to, have indeed a great import and pertinence, and may serve to point us on the way to the whole and luminous truth; but, also like them, in their own form they stop short of it. It is true to say, for instance, that it was laze that came by Moses, but grace and truth by Christ; for this pre- 
sents the important and significant fact about the doctrine of Jesus, that the highest religious thought of the older world viewed God as a magisterial Sovereign only, while Jesus revealed God as full of "grace," and his view gives the "truth" about the Divine nature, rather than the view of Moses. But here the phrase is again insufficient. "Grace" is a word of enormous range, just as "truth" also is; and what we need to know is whether we are to understand by it an incomplete and partial graciousness, such as the grace of pity and of condescension, or a grace absolute and complete, that accords to its object the prospect of equality with the sonrec of it, and intends to confer companionship yes, partnership - in every power and gift.

Now the meaning of Jesus, when he spoke of God as a Father, as a Being of love toward all the living, and urged men to love each other as each loved himself, in the light of complete love to God, this meaning is manifestly to the effect that God's love is not only universal, extending to all that live, without exception, but that in its scope and intention it is without reserves, and contemplates for every spirit the same possession of God's own eternal image. The standard Christ presents for the aim of him who would love God is God himself; and the bond by which he suggests the free possibility of pursuing such a standard is just the relation 
called, in the strongest image Oriental life could supply, the relation of the son of the house to the father. This Jesus conceives to be the real tie between God and all other spirits, and between all spirits as morally united through God. The soul, as Jesus conceives it, is the direct heir of all the Divine fulness. It is literally and strictly frec, and has the spirit of inhcritance, not simply of "adoption," as St. Paul names it. This means, if it means anything, that in Christ's view of God and the world of spirits the individual soul stands, in reality, and also in the mind of God himself, in quite the same relation of free self-activity toward God as the heir of the Eastern house stands, when he comes into his own, toward the father who went before him; and that God has the same active interest and purpose toward the intelligent freedom of each soul as the Eastern father has toward the son who is to represent and direct the house when he himself is in the world no more. In the most authentic utterances of Christ, as the storms of the Higher Criticism have left them unharmed, ${ }^{1}$ it is clistinctly taught that God in governing the world employs none at all of the legalism that characterises human administrations, rejects the principle of retaliatory infliction altogether, letting "his sun shine and his rain fall alike on the just and on the unjust," and therefore relies entirely

${ }^{1}$ In the Sermon on the Mount, especially. 
on the resources in the personal conviction of the wrong-doer, gradually brought into action by the discipline of personal experience.

This novel, unprecedented, and astounding doctrine of a universal moral equality as the aim of all spiritual being, an equality which is to embrace all minds in a complete union with the mind of God, and from which all external authority is to be excluded, Jesus by the plainest implication sets forth as the object and goal of all spiritual effort. All souls are to strive after just that form of life with each other in which none will employ toward another any method of constraint, but will rely upon the moral action of the powers in the others' souls, just as God eternally does. I do not understand him to teach that there is no place at all, in the evil part of the spiritual life, for the operation of constraint. Rather, judging by the sayings later recorded as coming from him, he admitted such an office for compulsion. ${ }^{1}$ But it was only by the way: it was to be viewed as only contingent and transient, as belonging only in this world of fleeting shows; it was the "law," which, as St.

1 For instance, "I came, not to bring peace, but a sword"; and, still more to the point, having said, in the Sermon on the Mount, "If any man will . . . take away thy coat, let him have thy cloak also," he says, later, "But now'. . . he that hath no sword, let him sell his garment and buy one." Also, his recognition of the right of external governments, in their sphere: "Render unto Caesar the things which are Caesar's, and unto Gud the things that are God's." 
Paul says, is to lead us to the moral freedom which is "in Christ," that is, is Christian. The aim, the only ultimate aim, the ideal of a society of minds, is this moral reliance on the inherent moral freedom of all spirits, guided by the contemplation of its perfect fulfilment in the Supreme Soul, or God, and inspired by his boundless love beheld and therefore felt by all.

In this conception of God and of the religious relation of souls to God and to each other, Christ had parted company with all the piety that had gone before him, and to such a degree as had never in the older world been paralleled. His theistic step was not simply new, it was absolutely revolutionary. His point of view, of the literal divine-sonship of every lowliest and most sinful and sinning spirit, committed him logically to the assertion of the implicit equality of all spirits with each other, so far as concerns their moral powers and destination, no matter what their actual and contingent state; and also of their potential equality with God. His doctrine may well be summarised in the consecrated phrase, usually applied only to himself, "The son of man is the son of God." To take in the full scope of his teaching, we must translate the icliom "son of," which is the Hebrew way of expressing the generic, ${ }^{1}$ and then the saying reads, "The spiritual powers

1 $\mathrm{S}_{0}$, in the Psalms: "What is man, that thou art mindful of him? and the son of man, that thou visitest him?" Again, in the Book of 
of human nature are in their eternal compass the same as the spiritual powers of God." His Pharisee contemporaries took in the purport of his position correctly, when they said, "He called himself the Son of God, thereby making himself the equal of God." They were inconceivably shocked by an expression which, to their view of men and of God, was simply blasphemy.

For, to take the situation in, we must bear in mind that to every older religion, even the most improved and enlightened, such as that of the Jews, the very essence of the Divine lay in an exaltation above all categories in which man could share-lay in its intrinsic and unapproachable Sovere1Gnty. God, in all these religions, is at best conceived as an awful and ineffable Majesty, before whom even angels and archangels may only veil their faces, prostrate themselves, and cry, "Holy, holy, holy! Lord! God Alnighty! There is none like unto Thee!" How much more, then, must men lie prostrate and keep silent before Him! Even when God was spoken

Ezekiel : "Son of man (i.e. $M(a n)$, can these bones live?" In the Book of Daniel, the king, looking into the "burning fiery furnace," sees besides his three victims a fourth figure, "like the son of God," i.e. resembling a god. Similarly, Lucifer is called "son of the morning," signifying him as the very lind and type of the light - the morn incarnate. So also "sons of Belial," for villainous men; "sons of deceit," for false and crafty men; "sons of thunder," for men of domineering will ; etc., etc. liut the list might be extended indefinitely. 
of as compassionate and long-suffering, with tender mercies upon all his works, the note of condescension which this carries is the proof that the quality of Sovereign Exaltation was still present, and really the dominant idea. In fact, this note pervades even the one utterance by an Old Testament writer that approaches nearcst to escaping from the usual Judaistic moods and entering into the spirit of Christ; for when this noble writer asks, "What is it that God requires of thee?" and answers, "Nothing but to do justice and love mercy, and walk humbly with thy God," we hear again an echo of the same overwhelmed and awe-stricken voice that says, "God is in Heaven and thou upon the earth, therefore let thy words be few;" or, "The Eternal is on his Throne, let all the earth keep silence before Him."

To break away from this magisterial and monarchical conception of God, which left men nothing but the submissive subjects of a Lord, whose sovereign will ordained all things, even the supreme distinction between what is right and what is wrong, ${ }^{1}$ was indecd a great, an unprecedented step. But Jesus took it. Instead of Majesty and a Lord, he presents God as the Friend and moral Father of men, who calls every human being, every spirit, to

1 "Kight," on this view, heing merely what God has commanded, and simply because he has commanded it ; and "wrong," on the other hand, merely what he has forbidden, and because he has forbidden it. 
the equality of sharing in that fulness of spiritual powers which constitutes the Divine glory. $\mathrm{He}$ felt the unspeakable courage, resting on settled conviction, which emboldened him to say, "I and the Father are one"; and he invites all men, as his brethren, to avow for themselves, and to seek, the same unity with God in a divine character. It is in an entirely just appreciation of this as Christ's meaning, that the writer of the Fourth Gospel represents him as praying for those that God has given him, "that they may be one, as Thou and I are one," and declares of the Eternal Worc', that "to as many as believed on His name, He gave the power to become sons of God."

Under this new inspiring and regenerative conception, religion changes from the worship of an exalted and unapproachable Sovereign into a joyful communion in all goodness and nobility with a perfect Guide and Friend. The spirit of awe is replaced by the spirit of confidence and friendship. Religion passes out of the stages, however high they may be, of the religions of Faith or the religions of Hope, - religions that are actuated by nothing higher than fealty and trust, or than longing aspiration with some chance for fulfilment, - and enters into the stage of the religion of Love. Here, not devout fidelity to an accepted authority, merely, and not merely the encouraging hope that service 
faithfully done may bring the soul fulfilment of its aspirations, but adoring love becomes the spring of the religious life - love for him who, we now know, has from eternity first loved $u s$, and is himself essentially Love. The aim of such a religion is not merely to "glorify God"; rather, it is to glorify all souls, as all in the image of God; to glorify them by fulfilling for every one of them its vocation to repeat in a new way the life of universal love that is the life of God, and thus to attain, through the universal greatening, such a real glorification of God as other forms of religion seek after in vain. The God of Christ is incleed one who comes "not to be ministered unto, but to minister," and who illustrates in his own Person the great and characteristic truth spoken by Jesus, "He that findeth his life shall lose it, and he that loseth his life shall find it."

Not exaltation, not isolation, not might, not being merely the centre of devotion rendered by others, not any of these lordly things is truly divine. But to be an active member in a society where all alike strive to recognise the infinite worth, the boundless possibilitics, of all the others; to be the inspiration and the uniting spirit of such a socicty; to give himself eternally and exhaustlessly for it and for every member in it, - this, according to Jesus, is what makes God the God of the living and not the God 
of the dead. This is what God really is - imper. sonated Love, fulfilled, complete; and what a com. plete soul of man is called to be and to do, is to fulfil itself by playing this same divine part; assuming it even in this finite world below, in the place and after the manner that the temporal burdens of each impose, and the terrestrial gifts of each make possible.

Thus the absolute reality of man, the absolute reality of all souls, comes forward as a complemental part of Christ's doctrine of God. Every soul in the great circle of this divine society, in which God is but the central member, has in this conception of God the quickening assurance that he is treated by the Eternal as a being indeed literally and completely free, - free not only in the sense that his own conviction is the sole arbiter of his actions, but in the larger sense that all possibilities of growth in conscious life are open to him, even divine possibilities, since there is but one standard of action in the etcrnal circle of spirits, and that is the spirit of love displayed by God. And this freedom of infinite scope in growth involves the reality, and carrics with it the assurance, of imperishable continuance. Accordingly we may explicate the new doctrine of Jesus into these three truths: (I) That God is the perfect Person, the central member in the universal society actuated by love; (2) that the soul is immortal; (3) that it is free, both in the sense of being the 
responsible author of all its acts, and in the sense that its fund of ultimate resources is equal to fulfilling its duty to love as God loves.

It is this third tenet, the essential freedom of the spirit, as implied in the conception of God as impersonate Love, that in fact forms the touchstone of Christ's new religion. It is in this, and in this only, that the full and real meaning of love as the very principle of the Divine life comes out. For just as perfect love "casteth out fear," so it casts out not only condescension and commiseration and mercy and alms, as but poor substitutes for its riches, poor lowly approaches to its height, but it makes away also with that false benignancy which would smother the spontaneous action of its object under the overwhelming weight of its lavish gifts. The true love wherewith God loves other spirits is not the outpouring upon them of graces which are the unearned gift of his miraculous power; it is the love, on the contrary, which holds the individuality, the personal initiative, of its object sacred. As the true father desires that the son who, after him, is to be the head of the family shall have a method and policy of hic own, by which the honours of the line shall be increased by new contributions, so he who is the Father of Spirits will have his image brought forth in every one of his offspring by the thought and conviction of each soul itself. 
Love that does not thus in the renunciation of all might address itself to the freedom of its object, and find its satisfaction in the spontaneous movement toward it from within the mind beloved, is not the reality of love. The moral government of God, springing from the Divine Love, is a government by moral agencies purely. It relies utterly on the operation of the powers native to the soul itself; and leaving aside all the juridical enginery of reward and punishment, it lets his sun shine and his rain fall alike on the just and on the unjust, that the cause of God may everywhere win simply upon its merits.

Thus God's revelation of himself is in a certain great sense accomplished by his hiding: ${ }^{1}$ invisible, impalpable, his very existence is unknown to other spirits, except as it is avouched by their own inward voice. On this point, such is his love and justice, he will assume for himself no privileges; he only takes the common lot of every soul, the fact of whose being must be gathered by all the rest from the testimony of their own interior thought. And as the very root and beginning of God's relations with men or other souls thus springs out of his recognition and reverence of their thinking freedom, so, according to the idea of Jesus, the entire pro-

1 Christ's new principle gives this new meaning and enlarged fulfilment to the saying of the ancient prophet, "Our God is a God who hideth himself." 
cedure and circuit of these relations is in terms of this freedom, and by means of it.

With such a conception as this, the Method of Authority as a method with religion is profoundly at war. I do not say it may not have its uses in the vast course of the external history of religion, just as we find the principle of police, of the reinforcement of statutes by punishments and rewards, has its uses in the struggling history through which the moral life of man shows itself in the world. But we cannot allot to it any but a minor and very transient office, and its nature must be to check the development of the Christian ideal of religion, as we have now seen this to be. The principle of Authority is not only foreign to the "mind that was in Christ," but is antagonistic to it. If we reject the principle, as we saw we must, on the ground of its self-contradictions and its fatal illusoriness, all the more should we as professed Christians reject it, since it conflicts so directly with the central ideas that our Founder introduced into religion.

At the core, what Jesus did was to reform the conception of God in the interest of the absolute reality and the moral freedom of men. With this what can be more discordant, what more hostile to it, than the attempt to establish by an appeal to declarative authority doctrines that either contradict the human reason or have no witness from it? For let us 
remember that there has never been any appeal to Authority, except for dogmas either contrary to reason or else met by it with entire silence; and this is not a case where "silence means consent." The undertaking, above all, to present Christ himself as the incarnation of this declarative authority is the complete reversal of his character, the direct contradiction of the religious idea which was the soul of his work, and for which he laid down his life. It is not conceivable that he who gave himself utterly for a new conception of God and man which turns entirely upon human mental freedom, should himself adopt the method of arrogance and dictation. I know well the passages in the Gospels that the advocates of Authority, as well as the hostile critics of Jesus, are in the habit of citing in proof that he claimed such authority and spoke accordingly. But I simply say the passages are needlessly and grossly misinterpreted, by adhering to their isolated letter instead of reading them in the light of a large, exact, and whole view of his work and his central idea. Into any detail on this question, however, there is not now time to go; nor do I feel that on this occasion there is any need.

\section{V}

In view of all the foregoing reasons, I cannot but think the case conclusive, that neither form of the 
Doctrine of Authority can be maintained. We should abandon, as consistent thinkers, and still more as consistent Christians, the imperative authority both of Church Tradition and of Scripture. There is nothing left, then, but the Doctrine of Reason - the Method of Conviction as the only real method of determining religious belief and practice, resting on the use of the human rational powers taken in their entire compass.

The form of our proof for the Rationalist method in religion, with a promise of which I set out upon our discussion, is therefore, at least thus far, only indirect: we have found but two alternative methods possible in religion, - Declaration and Conviction, Authority and Reason; we have shown the one to be invalid and unchristian, and therefore the other alone remains. Formally, this indirect proof is conclusive enough, and clears the ground for our general proposition that the only right relation between reason and religion is for reason to be the source and religion the derivative, for reason to legislate in the whole doctrine, and consequently in the whole practice, of religion.

But it may perhaps be said that the material question is still untouched; that our reasoning, thus far, simply assumes that the Method of Reason is a method possible with religion, whereas this possibility needs to be shown real. Those who would raise 
this objection would enforce it, too, by recalling our attention to the fact, that, in the very beginnings of this issue, we confronted the assertion - maintained by one great religious school - that reason is intrinsically incompetent to religion, because its judgments, however conclusive and infallible in its own field, are limited to that field, which is the world of senseexperience only, and not in the least the world of supersensible and spiritual reality. Our vindication of Rationalism will accordingly not be complete till we have grappled with this contention common to the religious dogmatist and the agnostic, and made an end of it by showing not only that the opposite is true, but that its truth is implied in this contention itself.

I am not the least clisposed to evade this indication of a needed completion to our argument. Rather, I willingly grant the point as correctly made, and I cordially take up the task which I accepted at the outset as part of this hour's duty, namely, to show that reason is not confined in its judgments to the things of sense, but extends also to the things invisible, - to all the things of the spirit, the things of religion.

In entering upon this final stage in our discussion, it is only fair to take the preparatory advantage of noticing that the very parties which discredit reason and maintain the cause of author- 
ity tacitly admit the appeal to reason to be finally unavoidable. Throughout the historical development of the Method of Authority, whether at the hands of Romanists or of Protestants, there is after all profoundly implied the power of human reason to judge of spiritual things, - of God, his character, his nature, his will toward men and for men. It is this silent assumption, constantly coming to light even amid the most plain and formal professions to the contrary, that imparts to the method of testimony, and to the theory of miracle as the credential of testimony, whatever of plansible force they may have. The working-power of this whole authoritative scheme is really derived from a reliance, albeit unconscious, on the fact that human reason is all the while deep in the counsels of God; it knows the true signs of God's presence and word, because it knows from of old what God is, and what are the word and the act that become him. This is revealed in the striking fact that none but commands of great moral worth are received as parts of Divine Revelation, whereas the miraculous vindication, taken purely and simply, would not provide for regarding the supreme rational distinction between Right and Wrong. On the contrary, on the ground of pure authority, tested by power alone, whatewer came as edict would have to be regarded right, as the primitive religions held. 
This tacit assumption is displayed, in a way especially noticeable, in the history of that part of Christian theology called Apologetics, or the Evidences of Christianity. The silent but irresistible influence of this discernment of the supremacy of reason is the explanation, and, as it seems to me, the only explanation, of the steadfast change we observe in the methor employed to exhibit these Evidences. At first, in the earlier stages of the Church, the method was to insist almost exclusively on the evidences known as External, to rely upon supposed authoritative declaration, supported by the testimony of present witnesses, with the claim of an unbroken transmission of the testimony from generation to generation. The whole force of the evidential argument was spent in the endeavour to establish this unbroken transmission as a fact, and thence the fact of the original declarations, and the fact of the miracles supporting them. The argument was made to turn upon showing the testimony to be that of eye-witnesses, and upon proving the witnesses to be trustworthy both in faculties and in spirit. When, later, notice began to be taken of Internal Evidence, - of the character of the precepts conveyed in the declarations, - this was at first kept in thorough subordination to the External Evidences, and used merely as a corroboration. It marked an epoch-in fact, a 
crisis - in the history of the Evidences, when a distinguished and accepted Christian thinker first took the step of reversing this order. ${ }^{1}$ The Internal Evidence was then placed first, the weight of proof was made to rest directly upon that, and the evidence of testimony to declaration and to miracle, and of miracle to the primary declaration, was reduced to the rôle of corroboration and secondary support. At length, in our own times, among the Protestants, particularly among those of them called Liberals, - Liberals of all clenominations, - we hear the evidence of personal experience, of inner personal life, of the adaptation of Christianity to rational wants, - in short, the evidence, not of mere reasoning, but of the large and deep rational or spiritual nature as a whole, put forward on all sicles as the real ground of proof; while the free career of what is called Criticism, whether the Lower or the Higher, sets the External Evidences more and more aside, and tends steadily to their final discredit and entire disuse. Meanwhile, in the minds of those who employ these latest methods of Christian Defence,

1 The late 1)r. Nark Hopkins, president of Williams College, in his notable lecturcs on the Evidences of Christianity, at the Lowell Institute, in Boston. He follows the lead set by Coleridge in his Confessions of an Inquiring Spirit, though (it must be confessed) haltingly and at a distance. 
religion not only does not lose it ascendency, but is found to increase in estimation and in power.

The same increasing recognition of the human rational spirit as the measure of religious truth is shown still more significantly in the general historical development of religion, taken on the largest scale. The movement from the Oriental pantheisms, on the one hand, and from polytheisms, especially of the Occident, on the other, into monotheism; the movement from simple monotheism to Christianity; from Greek or Eastern Christianity to the Christianity of the West; from the Latin Christianity of Rome to the Germanic Christianity of Protestantism; from Calvinistic Protestantism to Arminian ; from Evangelicalism to Liberalism, this vast movement has in all its stadia one steadfast trend, diverge as it may, now on this side and now on that, from the straight and shortest path to the manifest goal. It is a persistent movement from the non-recognition of the divine-sonship of man to the fuller and fuller recognition of it; to the consequent acknowledgment that rational human nature is the true witness to the Divine thought and will, the true medium of revelation. Ever stronger and clearer, in the successive stages of man's religious history, - ever stronger and clearer, and ever more and more unreserved, - becomes man's growing conviction of the final authority of 
the light that is within him. More and ever more toward dominance grows the Method of Reason in religion.

Now let us test, then, this instinctive drift of human nature by the standards of our disciplined and critical reflexion. These will show us, I am sure, that the instinctive movement is neither accidental, capricious, nor transient, but represents the profound and lasting judgment of our intelligence. We shall arrive at our clesired proof that human reason is not a circumscribed power, confined to judgments within the world of sensible experience alone, but is as wide in its scope as all possible reality, and in fact has for its supreme and most appropriate object the world of the spirit, the society of all spirits, and God as central therein. In short, we shall obtain the proof that essential reason is directed upon the things of religion.

Religion, in its broadest but shallowest definition, is the recognition and obedience of the supernatural Power supposed the Cause and Controller of all things ; religious life is fed by communion with this Power, and directed into courses corresponding to the conception which the worshipper has of the nature and the character of the Power. This definition will fit any and every religion alike, and is therefore of correspondingly minor significance. But in the present discussion we have no need, any more than we have 
the liberty, to limit ourselves to this very non-committal and little significant definition. We can better accept the profound statement characteristic of the Christian religion, and say that religion is the communion of the soul with God, and the inspiration of conduct by the spirit which animates God, by the spirit of him who is perfect Wisdom because he is perfect Love, who is the perfect Person because his whole being concentrates its powers upon the recognition of every member in the world of persons upon the preservation and promotion of every soul in the integrity of its freedom as a rational nature. It is this highest definition of religion that the Method of Reason must meet, if we are to vindicate for our human powers a commanding religious office; so that what we have to show is, that our rational powers do affirm for us, and make known to us, the reality of this World of Persons, benignly related, and of God in it as its fulfilled and inspiring Type.

This I believe we can show convincingly; especially in the light of the problems and theories most char. acteristic of our times in their concern with the large questions started by the progress of natural science, - an aspect of the case the more natural for us to consider, in view of what my eminent and venerated colleague ${ }^{1}$ has laid before you in his address. Yes,

${ }^{1}$ Professor Joseph Le Conte, - who had just spoken on the bearing of the doctrine of evolution on religious belief, particularly with reference to the conception of an Immanent God. 
our ripest intelligence asserts religion and a God, in that highest sense of both to which I have just referred. Our power of rational insight, when it has free course and comes to its own, does not stop with the paralysing doctrine that Infinite Wisdom and Love is a mere ideal; it declares it to be a fact nay, the only complete fact. We have no time at this hour, of course, to enter into all the paths by which enlightened human minds have endeavoured to find God at the centre of all things; but it will suffice, for our present argument, to consider the existence of God in the light of that phase in the history of human reason which is most characteristic of our times, - I mean in the light of evolutionary doctrines. What, let us ask, is their true bearing on the question whether there is really a God-not some all-pervading, vaguely diffused cosmic Pan, but a distinct Person, the Person supreme among all persons, infinite in wisdom, in justice, and in love.

I am as familiar as any of you with the cries that have on every side risen, and still are rising; from the camps of evolutionary science - cries that call upon us either to bury our divine ideals in the vague obscure of agnosticism, or else to replace Personal Theism by what its advocates are fond of calling Cosmic Theism, which is after all only another name for pantheism. We are even told that science, with its now settled principle of evolution, must hold by 
this cosmic impersonal or super-personal God, or else by no God at all. But I confess that the logic of such cries, whether agnostic or pantheistic, seems very queer to me. For what is the doctrine of evolution, as it has now taken definite form at the hands of its illustrious promoters, but the doctrine of the evergrowing reasonableness of things? Human reason, in short, in the stadium of its history which is characteristic of our day, has arrived at a view of Nature and natural processes that regards two great matters as settled. In definitive opposition to the philosophy sometimes called phenomenalism and sometimes positivism, of which Comte may be taken as the representative, the evolutional view first insists that sound reason presumes an Eternal Ground of things, distinct from all phenomena, an Omnipresent Energy which is their universal cause ; and then it shows, secondly, by evidences the more convincing in proportion as the minds considering them are more familiar with detailed phenomena of every sort, that the manifestations of this Energy exhibit a steadfast march toward the establishment of a world not of mere mechanical and scientific rationality, but of that infinitely higher rationality which we name justice and benevolence.

So far towards our desired goal, then, the settled results of evolutional theory might seem to go. But it is just at this point that the seeker after proofs of God needs to observe a critical caution. The ordi. 
nary reasoner, no doubt, would here say that the nature of the Eternal Cause was now transparently revealed: the First Principle of things, whatever be its nature, must in the end impress that nature upon the things that survive, and the final survivals must therefore be sure indications of the nature; but the things that survive in evolution, through the vast process of natural selection, bear the impress of a reasonable nature, reasonable in the highest sense; whence it seems irresistibly to follow that the nature of the Eternal Cause must be a reasonable nature, and in the highest sense. But the keener logicians of the agnostic or the pantheistic type call our attention to a flaw in this reasoning, apparently so right and so plain; and I account their warning just.

They say one cannot rightly reason from partial or uncompleted effects of a cause, to the unquestionable nature of the cause; and that the final, the absolutely decisive results of evolution are not known to us, nor are they knowable. To reason from the drift of phenomenal development on the surface of the earth, or even in the visible heavens, however plain such drift may be, to the ultimate results of the Eternal Energy is unwarrantable, by reason of ton sweeping an induction. The verifiable trend of evolution does not and cannot reach to the final effects of the First Principle; yet only in the knowledge of these final effects is the real nature of this Principle 
determinable, and as they are not only unknown but unknowable, so also must the Principle be regarded as only the Unknowable.

Or to put the case at its very best for theism, as Mr. Fiske in his Idea of God has put it, the "quasipersonality" of the Eternal Cause must remain the object, not of a satedly convinced reason, or knowledge, but of a supported and comforted faith, - a faith supported by such actual knowledge of the apparent drift of things within the visible universe, especially upon the surface of the earth and amid things human, or preparatory for human history, as to be a reasonable faith; a faith, that is, of which we may say that it accepts nothing contrary to reason as interpretable by the light of experience. In the ascertained absence of signs to the contrary, the flight of Faith from the footing afforded by such actual signs as are favourable, her flight on wings of hope, is but the natural operation of that gift in human nature which supplements its gift of knowledge. Farther than this, the strictest interpreters of the results of evolution forbid us to go. On the evidence of such results alone, we have no assurance that the quality of reasonableness is anything more than phenomenal and transitory, after all. What fatal possibilities are there not in the infinite, when we essay to read it only by the light of finite historical facts!

Now, this warning from thesc logicians, I repeat, 
seems to me soundly given. Their point is correctly made. And yet I hold it is so far from final, that it leaves their own logic, as I said before, open to the epithet of queer. We must indeed avoid the hasty reasoning of the argument first proposed; but their own reasoning, it seems to me, is guilty of an oversight at least as great as that which it condemns; at least as great, if obscurer and more subtile, and therefore more liable to pass unsuspected. For it is not from the results of the doctrine of evolution that the presupposition, the irresistible presupposition, of the being of God arises; not from its results, but from its very grounds-from the logic on which its conclusions are based. And this logic is not peculiar to the doctrine of evolution; it is the logic, rather, of all natural history, of all experimental and observational science; and biological evolution is only the most striking and significant result of it.

The logical method leading to the theory of evolution is what supplies the key to the argumentative situation in the case; and it is my settled conviction, which I hope now to impart to you, that the agnostic and pantheistic interpreters of evolution quite overlook the real implications of this method. These deepest implications are neither agnostic nor pantheistic, but are on the contrary strictly theistic; and as surely as the man of science relies upon his logic, so surely does he commit himself, whether he realises the 
fact or not, to the reference of all phenomena subject to general laws to an Ultimate Principle that is unquestionably conscious, rational, and moral, and therefore personal. Why this is so, and by what series of logical steps, I will now attempt briefly to explain. The pathway is far from direct or obvious, and consists of many stages, which we are prone to overlook.

The logic of science, the logic of which the doctrine of evolution is so impressive a result, is simply the logic of induction - the logic that raises the infinite superstructure of a universal law upon the finite and apparently all-too-narrow foundation of a specific number, comparatively very small, of carefully ascertained particular facts. The facts themselves will not and cannot support the superstructure : what, then, is its real support? Every act of induction, every case of generalisation, - that is to say, of prophetic universalisation from the relatively few single cases that constitute its observed foundation, is a direct appeal from the limitations of observation to the essential and all-pervading rationality of things. However far the finite results of induction may fall short of assuring us of this pervading rationality, the secret of the inductive method is our unreserved committal to its reality. But there can be no ground for such a universal rationality in facts themselves, as they are simply and historically presented; our first strict statement about it must be, that it is 
a pure addition to the facts, made by the spontaneons instinct of our minds. ${ }^{1}$ In that case, what can save it from the discredit of being a bare ideal of ours, worthless for objective truth?

The considerate answer to this qucstion, which alone can at once explain the instinctive character of the act of generalisation and at the same time give it objective value, is that natural facts are not to be thought of as things-in-themselves, things selfsubsistent as compared with us, and impinging upon our waiting sensibility, but are simply parts or items in our perceptive experience, and being organised by the principles of our inner consciousness are therefore subject to these instinctive judgments of ours, as the conditions under which alone they can exist. In short, the answer consists in coming to an idcalistic view of the reality of Nature and of natural things. We are committed by induction, if it is a valid act, to the main propositions of Berkcley, revised and vindicated by Kant, - that cxistence, primarily and at core, is the existence of spirits or minds or conscious centres, and that the existence of matcrial things is simply phenomcnal, simply presentation in the experience of minds. The latent logic of the method of induction thereforc leads us, first of all and directly, not to the cxistence of a personal God, nor even to that of the impersonal

1 For some fuller statement of this, see p. 33 seq., above. 
God, immanent in Nature, to which the evolutional pantheist concludes, but, on the contrary, to a rational nature everywhere present and regulative, and only to a person or persons as these are necessarily presupposed in such a nature. Nor does taking the next step of passing to these persons bring us to God, but only, at nearest hand, to men. ${ }^{1}$

But the inner logic of induction, secret and silent though it be, does presuppose the reality and the solidarity of conscious society, as an association of beings united by a common rational intelligence, and making common part in a common history of sensible experience. Nor can the objective value of inductive generalisation be thought in any other way than as the benign consensus of the whole society of minds, considering the facts of experience in the temper of justice and truth. What we reach, then, as the all but direct implication of induction, is the reality of a miversal rational society. We attain to the reality of the whole society, such that every really possible member of it must be real.

The further question of the being of God is simply the question, then, of the possible range of individuality in minds. Every act of thought is the act of an individual; and all reaiity, as finally coming back to thinking being, is thus intrinsically individual. Since the inductive act presupposes Nature to subsist 1 See p. $3^{1}$ and p. 41 seq., above. 
in and through the existence of the absolutely total and complete society of possible minds, the question of God's reality is exactly the question whether a perfect Person is necessarily included in the total circle of individual differentiation by which the absolutely entire society of minds is constituted. To this, it would seem there is but one answer: It is impossible to exclude from the total circle that Supreme Person whose mark of individual difference is his eternal perfection in the rational nature which, under various conditions of manifestation amid defects, is common to all the others. ${ }^{1}$

Such is the argument to the inherently religious and theistic character of the Method of Reason when applied to religion. It has undertaken to show that reason, by its nature, asserts the existence of God, - of God in the deep Christian sense of the living and loving Recogniser and Saviour of the spiritual and rational nature of every mind; a God who is an ever-active member, with all intelligences, in the benign society where the ultimate aim of all, quite as it is God's eternal will, is the perfection and bliss of all the rest. Such, I repeat, is the argument. I do not offer it as the only possible proof of the truth of Rationalism, but simply as a sufficient one, and one naturally drawn from the leading mental interests of our time, and

1 For a full treatment of this argument, see pp. 351-359, below. 
therefore suitable and pertinent. Let those who would impugn it, assail the value of the method of inductive science, if they will. But those who value that method - and who in these days does not? - must in consistency with its tacit logic conclude that the voice of reason is for God, the God of Christ and of Christianity ; and that as reason is essentially religious, so true religion is essentially rational. 


\section{HUMAN IMMORTALITY: ITS POSITIVE ARGUMENT}

WITH REFERENCE TO THE INGERSOLL LECTURE OF PROFESSOR JAMES

IN offering you to-night some words on the great question of human immortality, I enjoy the advantage of the interest awakened by the essay of my brilliant friend from Harvard, read a few months ago in this room. ${ }^{1}$ "The memory of that noble evening lives with you, I doubt not, still undimmed, and long will live, as it lives and long will live with me. The thoughts then stirred within you, I can count upon as having waked many another of those questions which haunt us concerning the mystery of life; and I may feel assured of your sympathy when I now attempt to renew their current.

I may assume, I judge, that some of you not only felt regarding immortality the difficuities which our guest addressed himself to obviating, but were also

1 The essay was read before the Berkeley Club of Oakland, California, in April, I 899. Professor James had read his Ingersoll Lecture to the same company in September, ISgS. 
conscious of a certain feeling of insufficiency left by the method he took to relieve them. Probably, too, many of you wished, as I did, that we might be supplied in some way with something more positive, something more satisfyingly affirmative, than the mere opening of a chance to pull ourselves together and seize upon immortal life by a tour de force of resolute belief. For this was all that our essayist could achieve by simply replying to objections, though it was no doubt all that he aimed at achieving.

Many others of you, I moreover suspect, wondered in particular if there might not be some course of thought in which that idealistic theory of our existence, suggested by his transmission-view of the functional relation between our conscious experiences and the brain, would be carried up above the region of mere hypothesis into the world of real fact. I mean the theory, that, as Professor James himself expresses it, "the whole universe of material things - the furniture of earth and choir of heaven - should turn out to be a mere surface-veil of phenomena, hiding and keeping back the world of genuine realities; . . . the whole world of natural experience, as we get it, to be but a time-mask, shattering or refracting the one infinite Thought which is the sole reality of those millions of finite streanis of consciousness known to us as 
our private selves." 1 This theory, Professor James in his argument presents as a possible supposition merely, and his logical aim is simply to show that the superficially alarming proclamation of physiological psychology, which cleclares all consciousness to be a function of the brain, cannot exclude the chance for this supposition, nor our rational right to make it if we will. He puts it, indeed, as an imaginative possibility rather than a scientific hypothesis, and gives it great poetic force as well as logical plausibility by his quotation of Shelley's lines, ${ }^{2}-$

Life, like a dome of many-coloured glass,

Stains the white radiance of eternity.

"Suppose," he adds, "that this were really so, and suppose, moreover, that the dome, opaque enough at all times to the full super-solar blaze, could at certain times and places grow less so, and let certain beams pierce through into this sublunary world. . . . Only at particular times and places would it seem that, as a matter of fact, the veil of Nature can grow thin and rupturable enough for such effects to occur. But in those places gleams, however finite and unsatisfying, of the absolute life of the universe, are from time to time vouchsafed.... Admit now

${ }^{1}$ William James: Human Immortality, p. 15 seq. Boston: Houghton, Mifflin, and Co., 1898 .

2Shelley's Adona is, stanza lii. 
that our brains are such thin and half-transparent places in the veil. What will happen? Why, as the white radiance comes through the dome with all sorts of staining and distortion imprinted on it by the glass, . . even so the genuine matter of reality, the life of souls as it is in its fulness, will break through our several brains into this world in all sorts of restricted forms, and with all the imperfections and queernesses that characterise our finite individualities here below." 1

This ideal theory of the true and real being that hides behind phenomena, Professor James, I repeat, puts forward only as a possible hypothesis, to point and emphasise his contention that "when we think of the law that thought is a function of the brain, we are not required to think of productive function only; we are entitled also to consider permissive or transmissive function." 2 For, on this hypothesis, "our soul's life, as we here know it, would none the less in literal strictness be the function of the brain." 3 And his object in this contention is to display the pertinent and pointed moral, that "dependence of this sort on the brain for this natural life would in no wise make immortal life impossible; it might be quite compatible with supernatural life behind the veil hereafter." 4 So that "in strict logic, then,
1 Human Immortality, pp. 16, 17.
2 Ibid., p. I 5.
${ }^{3}$ Ibid., p. 18.
4 Ibid., p. 18. 
the fangs of cerebralistic materialism are drawn;" ... "the fatal consequence is not cocrcive, the conclusion which materialism draws being due solely to its one-sided way of taking the word "function." " 1 $\mathrm{He}$ points out that it assumes the functional relation of brain to consciousness to be always and solely productive, ignoring the fact that it may just as well be either (I) permissive, i.e. releasing, or (2) transmissive. "My words," he closes by saying;, "ought consequently to exert a releasing function on your hopes. You may believe henceforward, whether you care to profit by the permission or not." 2

Upon this merely permissive conclusion of his argument, this bare opening of room for belief, - to take advantage of which we must summon the courage to risk the belief, and so leave it after all a matter of shecr resolution, - I repeat I can hardly doubt that many of you wondered if this were all that philosophic thought can do for our heart's desire after light and foothold beyond the grave. You must have wondered if that region of "super-solar blaze" must always remain this blank Perhaps; if that "white radiance of eternity" always must be visible to the poet's eye alone; or if it might not, rather, by some better philosophic fortune be revealed to clear insight as a reality undeniable, and so our belicf in it become the act of intelligence, solid and sup-

1 Ifuman Immortality, pp. 18, 19.

2 Ibid., p. 19. 
ported, instead of being an act of that desperate courage which risks all, because not to risk is to perish anyhow.

It is in a hope to meet this query - to show, if pos. sible, the way of raising this ideal hypothesis into fact resting upon positive evidence - that I offer you what follows in this essay.

\section{I}

Before entering upon the affirmative argument for the imperishableness of the light that lighteth every man when he cometh into the world, and essaying to prove really his the white radiance of eternity, which by the dome of physical life, however manycoloured, is only stained, let me point out clearly a certain oversight in the otherwise brilliant reasoning by which our guest and essayist would provide a justifiable chance for faith and courage to cast in for immortality - a chance to risk belief without the risk of demonstrable folly. For that, in brief, is what Professor James's general aim in the philosophical field may be said to be, - to vindicate the exercise of moral and religious faith against the charge of ignorance, unreason, and folly; to make it plain that one is not a fool, even though he do believe out of sheer fealty and loyal will, when once a proved uncertainty leaves him an open chance; and to dis- 
play this open chance in face of those "results of modern science" which are so often declared adverse to it.

What, then, is the exact "open chance" that Professor James leaves us, in this urgent question of immortality, by his transmission-theory of the function performed by the brain for consciousness? Does the transmission-theory, in strict logic, indeed draw the fangs of cerebralistic materialism?-does it take away the real sting of death? The answer to this question depends on the answer we shall have to give to another - whether the transmission-theory, as managed by Professor James, establishes any chance for the personal immortality of each of us. For the real sting of death is the apprehension in each of us that he may perish in dying; and no hope of the changeless persistence of any eternal "mother sea" of consciousness, Divine or other, can afford us any consolation if this clread of our personal extinction be not set at rest.

Professor James has himself partly realised this critical issue in the case. "Still you will ask," he says, "in what positive way does this theory help us to realise our immortality in imagination?" $1 \mathrm{He}$ alludes here to his previous statement, that the transmission-theory implics the "mother sea" of eternal consciousness, in accordance with which

${ }^{1}$ Human Immortality, p. 29. 
"the great orthodox philosophic tradition" treats the body as "an essential condition to the soul's life in this world of sense," but conceives that "after death the soul is set free and becomes a purely intellectual and non-appetitive being." I And he quotes corroboratively from Kant the sentiment that "the body would thus be, not the cause of our thinking, but merely a condition restrictive thereof, and, although essential to our sensuous and animal consciousness, . . an impeler of our pure spiritual life." 2 Then, with great pertinence, he adds: "What we all wish to keep is just these individual restrictions, these self-same tendencies and peculiarities that define us to ourselves and others, and constitute our identity, so called. Our finiteness and limitations seem to be our personal essence; and when the finiting organ drops away, and our several spirits revert to their original source and resume their unrestricted condition, will they then be anything like those sweet streams of feeling which we know, and which even now our brains are sifting out from the great reservoir for our enjoyment here below ?" 3

This keen and indeed irrepressible demand for individual perpetuity of consciousness he still more thrillingly emphasises when he comes to attempt

1 Human Immortality, p. 28.

${ }^{2}$ Ibid., pp. 28, 29.

3 Ibid., pp. 29, 30. 
the rebuttal of the second objection to immortal life - the strange objection drawn from the enmui at contemplating the incalculable thronging of the eternal world, involved in immortality. "Life," he rehearses, in behalf of the objector, "is a good thing on a reasonably copious scale; but the very heavens themselves, and the cosmic times and spaces, would stand aghast, we think, at the notion of preserving eternally such an ever-swelling plethora and giut of it." 1 And to the objection his telling reply is in substance this: The inner significance of other lives exceeds all our powers of sympathy and insight. Every one of these aliens, however grotesque or even repulsive to you or to me, is animated by an inner joy of living as hot or hotter than that which we feel beating in our private breasts. . . Not a being of the countless throng is there whose continued life is not called for, and called for intensely, by the consciousness that animates the being's form. . . Spiritual being, whenever it comes, affirms itself, expands, and craves continuance. $^{2}$

The true and real point of this reply, you cannot fail to notice, turns entirely upon the assumption that nothing short of inclividual immortality can be the object of any serious question in this region. So now let us ask, with accuracy, what assurance-

1 IIuman Immortality, p. 36.

2 Ibid., pp. 39-4I. 
what leaving open of a consoling hope, even - of this personal preservation the transmission-theory of brain-function can afford. Professor James declares, and no one will deny, that the productiontheory leaves no room for the hope of $a n y$ kind of immortality, individual or generic: does his transmission-theory, then, really afford any hope of individual immortality? And let us remind ourselves, once more, that this is the only immortality in which we have any interested concern, or are capable of having any. We are not interested in the everlastingness of the eternal "mother sea," call it God or call it what we will, unless we include in it the sum of all our enduring distinct personalities. So the question is, Does even the theory that the brain performs simply a transmissive function in our conscious life, instead of a producing one, really warrant even a hope of personal preservation forever, not to speak of an assurance of it?

Professor James's own management of this theory is singularly disappointing in this reference, and singularly short of his own pungent emphasis of the universal passion for personal continuance. The white racliance of eternity which he hints as shining through the many-coloured dome of natural life, - the pied translucence of the brain, - is prevailingly conceived by him as in itself a continuous and undivided and undifferentiated Whole. Upon 
this our brains operate ${ }^{1}$ as "organs for separating it into parts and giving them finitc form." Again, ${ }^{2}$ he says: "The transmission-theory connects itself very naturally with the whole tendency of thought known as transcendentalism. Emerson, for example, writes: "We lie in the lap of immense intelligence, which makes us receivers of its truth and organs of its activity. When we discern justice, when we discern truth, we do nothing of ourselves, but allow a passage to its beams." " All this is in even keeping with Professor James's other sentence, ${ }^{3}$ that "we need only suppose the continuity of our consciousness with a mother sea, to allow for exceptional waves occasionally pouring over the dam," and with the earlier one, already once quoted, that "as the white radiance comes through the dome, . . . even so the genuine matter of reality, the life of souls as it is in its fulness, will break through our several brains into this world in all sorts of restricted forms."

Once, and but once only, does he approach the greater idealistic doctrine of an eternal Pluralism. Then he says, indeed, "But it is not necessary to identify the consciousness postulated in the lecture, as preëxisting behind the scenes, with the Absolute Mind of transcendental idcalism, although, indeed, the notion of it might lead in that direction. The Absolute Mind of transcendental idealism is one

1 Human Immoriality', note $3, \mathrm{p} .5^{2}$.

2 Ibid., note 5, p. 58 .

3 Ibid., p. 27. 
integral Unit, one single World-mind. For the purposes of my lecture, however, there might be many minds behind the scenes as well as one." 1 This is undoubtedly so: strictly, too, the rebuttal purposes of his lecture would be far better served by this pluralistic hypothesis than by that of a single all-wide mother sea of Mind; rather, in fact, these purposes cannot be properly served by any hypothesis except the pluralistic. But unfortunately he goes on to say, "All that the transmissiontheory absolutely requires is that they [the many minds behind the scenes] should transcend our minds, which thus come from sometiling mental that preëxists, and is larger than themselves." 2

Thus he is confronted - and so are we in following him - with the awkward consequence that our minds, our individual personalities, only get their being by the fact of transmission through the brain. Existing only on condition that the brain allows us to be, as sifted, restricted, or coloured phantoms of the infinite sea of light beyond, all that we in strictness are must fail of being, must go out extinguished, whenever the transmitting medium shall cease to exist. All that is we, all our individual identities, must vanish into nameless nothing when death arrives. That the vast Mind-ocean supposed to be beating over the brain's threshold, or the many

1 Human Immortality, p. 58 .

2 Ibid., p. 58, at bottom. 
minds, not ours, perchance supposable behind the scenes, abides or abide in the immutable eternity which is its home or theirs - this concerns us not, this consoles us not. What we are, on this transmission-theory of our selfhood, is members of the dead. We were only the phantasmal results of a contingent and passing condition to which the Eternal Reality, by some impenetrable mystery, submitted itself or was submitted. In death that condition has vanished, and so we too are gone. $W_{e}$ are not sharers in the imperishableness of the eternal Consciousness, be it One or be it many. It (or perchance they) alone has (or maybe have) life in itself (or in themselves), alone is an End (or are ends). We are not ends, but are only means, and transient means at that. We are only stage supernumeraries - nay, worse, only stage properties - of the eternal drama, and not at all its proper personages. We are only here as appurtenances of the real dramatis persona, - ouly as masks and false shows. We are made mere tools of a counsel in which we do not share; our personality is trod upon and put to shame, in behoof of the invisible and inapproachable Lord or lords of our life, in whose sight we are as nothing. It is just this that makes the sting of our fate, far more than the cessation of the joys belonging to sensuous perception.

For this defect in the argument of our-essayist 
there is but one possible remedy, - I am sure you will agree with me in this, - and that is, to adopt the hypothesis, not simply that there are many minds behind the scenes, but that these minds are our minds - our veritable and genuine selves; and that the summaries of sense-coloured experiences which Professor James, following the empiricist tradition of the English school of philosophy, especially as voiced by Hume and Hartley and Mill, is led to call the only verifiably real meaning of our self, or our mind, are but the more or less dimmed and darkened expressions of those our real spirits, inhabitants of eternity. Short of this identification, short of this close union of the soul and its experiences in a single identity belonging to the eternal world, and enclosing the world of time, there can be no assurance of our continuing in spite of death. Short of showing that upon some admissible interpretation of the functional relation between the brain and phenomenal consciousness a chance remains for this identification, we cannot even keep open the chance that we may be immortal, and so cannot set the objection drawn from cerebralistic materialism finally aside.

\section{II}

But what admissible interpretation is there of the relation between brain-function and conscious experience that will really dispose of the cerebral objection 
to immortality, and enable us to move onward, far beyond, to some positive proof of our individual permanence?

It certainly seems plain, not only that Professor James's method with the transmission-theory is un. equal to this task, but that no form of transmissive relation between brain and experience is equal to it, or can be. For every form of the transmission-theory must regard the brain and its operations as a prior conclition of such consciousness - as a fact not simply concomitant with the consciousness, but prerequisite to its existence. In every such theory the brain is supposed to exist, somehow, whether any consciousness that can be called ours exists or not. So it must either exist (I) as the creation of the assumed one Mind behind the scenes, and be the medium he uses to display himself in his perhaps endlessly shifting transient disguises; or (2) as the creation, similarly, of the many minds behind the scenes, used by each for the same object of transient disguise; or (3) as somehow self-existent, an unintelligible mystery in being, thwarting more or less the assumed eternity and infinity of the Absolute Mind or the absolute minds. In either case, it acts as a limiting and suppressive condition upon $\iota s$, reducing us to mere shadows of something else, converting us into instrumental effects merely, and only giving us being that is destitute of conclusive reality - being that is only deriva- 
tive, dependent, contingent, and so possibly (or, rather, probably) transient.

This easily appears. If the brain, as in the third supposition, is an inexplicable self-existence, then, as transmitter upon which our individual existence is made to depend, it must in ceasing to exist deprive the eternal Mind or minds of the conditio sine qua non of our being, must thus display itself as in its very destruction victorious over intelligence, and no hope of our continuance remains. And even if the brain is, according to the first or the second supposition, the creation of the eternal Mind or the eternal intelligences not ourselves, and still is the means of our being, then our only hope would lie in the chance that God or the superior intelligences may have the power and the good will to create the brain anew, or to replace it by some better medium. But this hope seems quenched at once in our inability to conceive of an idcntity continuing when the continuity of the conditioning medium has been broken. Or if for argument's sake we waive this difficulty, who can assure us that the creative power is equal to renewal, since its creation has once perished? On the other hand, confidence in the good will of our eternal Source or sources has nothing to go upon but the limited allotment of good that the life actually experienced has afforded; and this, as all serious minds too sadly know, is little enough, when we consider 
only the actual good of the actual world here below. Judged by the light of this "vale of tears" alone, there is no evidence that good will toward us is the chief or the permanent aim of the eternal Lord or lords.

The transmissive interpretation of brain-function, then, must unavoidably fail to do the work we need to have done. Is there perlaps some other way? Is there some other mode of conceiving the correlation between brain-changes and psychic experiencesome conception of their persistent correspondence that regards brain-function as neither productive nor releasing nor transmissive? I suppose there is; and that it is gained by taking two important steps characteristic of the exacter philosophy.

The first of these steps is, to read the doctrine of modern psychology with a still stricter interpretation than Professor James has read it with - to construe it rigidly as a case, to borrow his own words, simply of concomitant variation. When we say that the mind is a function of the brain, we are therefore to understand that in exact scientific truth we can mean nothing more than this: That physical and physiological changes go on, seriatim, side by side with changes in psychic experience; or vice i'ersa, that psychic changes run parallel, pari passu, with physiological changes in the brain and the other neural tissues. We do not even mean that the brain is a transmitter 
of power behind it, any more than that psychic experience transmits to the brain some power behind the experience. Concomitance simply means, at last, that both series of changes are connected with some cause, distinct from either, which is the secret of both. To use a common phrase, it means that the two are "joint effects" of some single higher cause, for the time being undiscovered. It points our investigation at once to the problem of searching for and determining this unknown cause, of converting it from being unknown into being known.

The second step is, to connect these two streams of concomitant or joint effects with our own true primordial and actively conscious self as their real cause, though it is at first unrealised and unknown as such. This step is doubtless impossible for a philosophy which halts, as Professor James's does, with a dogmatic disbelief in a priori knowing, or self-active consciousness, and which insists that no knowing is intelligibly real except the contingent and tentative knowing supplied to us "from elscwhere," and as if inch by inch, in sensible experience. But the clear and scientific connecting of the two "parallel" streams of effects, one physical, the other psychic, with the one organising soul or mind, becomes possible enough, and indeed easy, when once we penetrate the too superficial theory of empirical philosophy, and settle upon the a priori or self-active character 
of knowledge as a fundamental fact; when once we pass beyond the external view of experience, which causes it to appear as if it wcre constituted out of scnsation or impressions alone, and were not, as it really is, itself a complex, in which the utterly vague something we call "sensation" or "impression" is always organised and made to take form and descriptive definiteness, and thus clear reality, by a priori or self-active consciousness.

Our real experiences, day by day and moment by moment, are so intrinsically organised and definite, it does not at first occur to us that the principles which organise and define them, rendering them intelligible, and consciously apprehensible, are and must be the spontaneous products of the mind's own action. We do not at first see, as careful reflection later brings us to see, with Kant, that the mental elements without which the apprchensible presence of the items of cxperience would be inconceivable and inexistent cannot possibly be dcrived from these, and thence applied to the mind. But this later penetrating reflection convinces us that what our experienced objects must have in order to be objects - to be percived at all-must be brought by the mind itself to the very act of experience. What must be presupposed, if the objects are to be perceived at all, can by no conceivable means be explained as first coming to the mind from the objects, 
and must therefore, as the only alternative, be acknowledged to be contributions from the mind's pure self-activity.

But when we have reached this conclusive conviction that the roots of our experience and our experimental knowledge are parts of our own spontaneous life, we then readily come to see, further, that the system of our several elements of consciousness $a$ priori is precisely what we must really understand by our unifying or enwholing self, - is exactly what we try to express when we say we have a soul, and that this soul possesses real knowledge; that is, a hold upon eternal things. The realm of the eternal, in short, then becomes for us just the realm of our self-active intelligence; and this it is which, if we can show its reality in cletail, will prove to be the clue to our immortal being. So the critical question is, How can the real existence of such a prioriconsciousness, such genuinely self-active intelligence, be conclusively made out? I have already in a few sentences indicated the general line of this proof, as we inherit it from Kant; but there is now required some fuller account of it, made intelligible and convincing by clear particulars.

Any comprehensive answer to our question would carry us much farther into the ficlds of critical speculation than I could possibly go in the brief time at our disposal, and certainly much farther than I could 
hope to have you willingly follow. But fortmately we can argue here cx excmplo. It will be sufficient for our purpose to establish the reality of a single thread of such a priori or self-active knowing. And this it is simplest to do in the case of such a constituent element in our experience as, for instance, Time or Space. For these elements, as we all know, are the "containing" conditions of the whole of our sense-perceptive life; indeed, of the whole physical world, upon whose decay and clestructibility all our fears of death, and of extinction through death, are founded. It will be most pertinent, moreover, to confine ourselves to the single element of Time alone, as it is in this that we find nearest at hand the medium of union between the physical and the psychic series in our experience, and thence the means for connecting both with the unity of our real self.

We return, then, to the strict concomitance of the two series, as all that can in exact science be meant by the functional relation between the brain and the sense-perceptive consciousness. And we ask, Must one stop with this mere parallelism of the physical and the psychic? - must we rest in it as an obsti. nate and impenetrable fact? That we must, is the ordinary dictum of the proclamatory "new" or "objective" or "physiological" psychology — the two "parallel" series are there, and nobody can get 
beyond the dead fact of their concomitancy! But why not? Surely the concomitance of the two is in Time, and conditioned by Time; that at least is indisputable, is involved in calling the relation concomitance. If it can be shown, now, that Time is no "thing-in-itself," no thing existing of itself independently of minds, but must be explained as a peculiar form of consciousness, in each of us, that cannot be conceived of as derived from any possible communication $a b$ extra, and consequently must be acknowledged as the expression of our mental self-activity, we shall clearly have connected our empirical consciousness, our varying flood of serial experiences, our states of mind, with our active unit-being, and shall have lodged this our active identity in the eternal world, or order, in the only sense in which such an order of existence can be made intelligible.

I must not delay you with prolonged or intricate proofs that the real nature of Time is such as I have described, though such proofs are indeed numerous and prolific. It is enough for our purposes to-night to call attention, first, to the simple fact that we cannot rationally entertain the proposition that there is, or can be, no Time, - which shows that the consciousness of Time is inseparable from our essential being; in other words, is intrinsic in it. Secondly, let us attend to the more significant fact, that we are conscious of Time as a unity at once absolutely com- 
plete and also infinite, and cannot be conscious of it except with thesc characters, - which shows that it cannot have come to us by transfer or communication. For if it did come in this way, then, in the first place, it must have a history, and a limit of history to date, quite as all else that comes so has; and this would mean that it must be thought as finite in quantity, as well as an incomplete unity capable of increase. And, in the second place, its coming in this heroic fashion is itself unstatable and unthinkable, except in terms of Time itself; and this shows that the pretended empirical explanation requires the preëmployment of the thing whose origin it would clear up, - all the light the explanation gives, it borrows from the very thing it pretends to explain.

Time is therefore inevitably brought home to the soul as its real source, and our convinced judgment confesses the consciousness of Time to be a consciousness a priori; that is, an act of the soul, of the individual mind, in the spontaneous unity of its existence. It is seen to be a changeless principle of relation, by which the active-conscious self connects the items of experience into the serial order which we call sequence or succession, and blends the two concomitant series, physical and psychic, into the single whole that expresses the self's own unity.

So a sufficiently strict interpretation of the modern psychological doctrine, instead of mercly making 
materialism give way, and yield place for a chance and hope that we may be immortal, - instead of simply leaving room for the imperishable eternity of the universal mother sea of Mind, - lays sure the foundations for a certainty that we each belong to the eternal world, not simply to the world of shifting and transient experience. It provides for our selves, for each of them individually, a place in the world not merely of consequences and mediated effects, but of primary and unmediated causes. Hence it gives us assurance that death no more than any other event in experience is our end and close, but that we survive it, ourselves the springs that organise experience. It shows us possessed, intrinsically, of the very roots and sources of perception, not merely of its experienced fact, and so presents us as possessed of power to rise beyond the grave - yes, in and through the very act of death - into new worlds of perception.

Accordingly, it matches the Christian improvement upon the older conception of the future existence - the ascent to the doctrine of "resurrection" or á $a^{\prime} \sigma \tau a \sigma \iota$, the supplementing of immortality by the exaltation of the "body," or sense-perceptive life. As ourselves the causal sources of the perceived world and its cosmic order, we are not clestined to any colourless life of bare ideas, to "some spectral woof of impalpable abstractions or uncarthly ballet of bloodless categorics," but arc to go perceptively 
onward in perpetumm, exercising forever our inherent power of framing experience, of begetting worlds of sense-coloured variety and definiteness, in their long career surely of higher and higher subtilty, refinement, beauty, and goodness.

\section{III}

But you may now not unreasonably ask for some clearer exhibit of the steps by which this conviction is reached. So far, our argument must be admitted to have achieved, explicitly, nothing more than this - to connect our experience, our psychic history of sensible states, with the active unity of our own minds, each for itself, in contrast to connecting our consciousness, as Professor James cloes, with the "mother sea," the one and only Mind, or the eternal many minds not ours. As yet, then, we have done no more than shift the mere hope or chance for continuance from that diffused "white radiance of eternity" to these our own eternal centres of light. Two things it is therefore natural to ask:

(I) How do the results we have just established carry us beyond the mere possibility to the positive fact of human immortality?

(2) How does our connecting the two concomitant series of expericnces with the individual being of each soul, lcad to the knowledge that we are not only the 
lords over death, but are essentially imperishable against every other contingency?

I have just said that our argument has not yet answered these questions explicitly. But it is right I should add that it clocs answer both of them by implication. As for the first, lct us now note that our discussion, in proving Time to be an expression of each mind's spontaneous activity, proves the selfactive existence of every mind as such, and so establishes the eternity of the individual spirit in the only ultimate meaning of eternity; since, as the ground and source of Time itself, the being of the soul must transcend Time, though including Time, and consequently, while involving everlastingness, must have its full meaning in just that spontaneous sourcefulness of self-consciousness from which everlastingness arises. In this established certainty of our indiviclual self-activity, supposing our previous reasoning about Time to be valid, we have therefore passed beyond the mere open chance of being the arbiters of the time-world and all its contingent events, and have entered upon a corresponding certainty of all the consequences that logically follow from our selfactive legislation over the whole of possible experience. And as for the second question, these consequences of the ascertained sourceful and directive power of our individuality will now be shown in detail to involve, first, the essential supremacy of the 
soul over death, and then its intrinsic imperishableness from any cause.

Surely, if each soul, so far from being the result of temporal antecedents or being the simple aggregate of its various experiences, gives evidence of a self-activity that conditions not only all actual but also all possible experience, then each of us must possess an existence that subsists independently of any and every contingent event, including the event of death no less than the various events of life. For what, upon the now proved time-giving nature of our real self, is the great event called cleath? It may well be clescribed, to borrow the language of the geometers, as a singular point on the curve of our experimental being, a point where a given stage or mode of our experience, or sensible consciousness, comes to its cessation and close. But not only is it no longer what the same geometers call a point d'arrêt, where the curve comes to a sudden end; it is, rather, from our now established coign of vantage, a point of tronsition, where the curve undergoes a change in the expression of that continuity which has its unchangeable form summed up in the equation stating its essential nature and law of being - the self-definition of the indiviclual.

This result follows, clearly enough, from the single fact that our personality is the source of Time, and that Time is the all-inclusive condition of the occur- 
rence of any event, including therefore even the event of death. But we can carry our legislative and clirective relation to experience much farther if we will, - as far as the complete summary of the conditions prerequisite to the whole process of Nature, and thus discover our personal self to be the regulative source of all the laws under which natural or sensible existence must have its course, and so to be possessed of a being that by its essence transcends all the vicissitudes of the merely natural world, surviving all its possible catastrophes and supplying the ground for its continuance in new modes under new conditions. For, evidently, we can apply the same reasoning to Space and to Causation that we have applied to Time. By the same arguments from unity, infinity, and strict necessity, we must conclude to the a priori or spontaneous character of the forms of consciousness which we call Space and Cause. Thus we conclude to the dependence of Nature upon $u s$, taken in our primary and active being, instead of our derivative dependence upon Nature. In the place, then, of cleath's ending $u s$, - cleath, but one item in the being of the natural world, the whole of which is conditioned upon our central self-consciousness, - we arrive at the settled and logically immovable conception that we are ourselves the changeless ground of that transition in experience into which death thus gets interpreted. 
We are not yet come, however, to the utmost goal of our desire: we are still short of the complete meaning of immortality, for that is the utter imperishableness of the soul. Our argument, so far, only goes expressly to the point that we survive death, - perhaps many deaths. But one can well ask, May we not be subject to substantive destruction, by some other cause, some other power? - to annihilation outright, in our eternal essence, and, if the reasoner please, mysteriously, inexplicably, whether by the power of God or otherwise? Yet to this more searching question too, our argument, once its subtlest implications are brought to light, yields an answer favourable to our most impassioned aspirations. For the ultimate and real meaning of the argument is, that a soul or mind or person, purely as such, is itself the fountain of its percipient experience, and so possesses what has been happily named "life in itself." Proof of the presence in us of a priori or spontaneous cognition, then, is proof of just this self-causative life.

A world of such individual minds is by the final implications of this proof the world of primary causes, and every member of it, secure above the vicissitudes of Time and Space and Force, is possessed of a supertemporal or eternal reality, and is therefore not liable to any lethal influence from any other source. Itself a primary cause, it can 
neither clestroy another primary cause nor be destroyed by any. The objector who would open the eternal permanence of the soul to cloubt, then, must assail the proofs of a priori knowledge; for so long as these remain free from suspicion, there can be no real question as to what they finally imply. The concomitance of our two streams of experience, the timed stream and the spaced stream, raised from a merely historical into a necessary concomitance by the argument that refers it to the active unity of each soul as its ground, becomes the steadfast sign and visible pledge of the imperishable self-resource of the individual spirit.

\section{IV}

We sometimes hear it objected to the foregoing line of proof, that it comes quite short of any immortality which a rational being can value. It can establish nothing, the objectors say, but the indestructible power of staying on, merely in a world of sense-perception.

The objection is pertinent, and would be serious were our a priori consciousness completely summed up in furnishing the conditions sufficient for a world of sense-perception only, and for self-preservative action in such a world. But the objection vanishes as soon as we realise that our argument, properly 
judged, rests upon the spontaneous character of the organising cognition as a source, not upon what happen to be the contents to which, for brevity's sake, we have thus far confined our attention in making out the fact of this spontaneous mental life. The truth is, our a priori cognition is not confined to these conditions of mere perception; it goes, on the contrary, and with still clearer eviclence, to the region of our guicling ideals - to the True, to the Beautiful, to the Good. These all-controlling ideals are not only the goal of the sense-perceptive or experiencing spirit, but are actively constituent in the soul's primary being. The same reasoning that leads us to conclude Time, Space, and Causation, the conditions of sense-perceptive life, to be structural in our active primal being, leads quite as unavoidably, and more directly, to the higher conclusion that the three ideals are also structural in it, and still more profoundly. By their very ideality they conclusively refer themselves to our spontaneous life: nothing ideal can be derived from experience, just as nothing experimental is ever ideal.

The worth-imparting ideals, then, are, by virtue of the active and indivisible unity of our person, in an elemental and inseparable union with the root-principles of our perceptive life. Proof of our indestruetible sourcefulness for such pereipient life is therefore ipso facto proof that these ideals will reign everlast- 
ingly in and over that life. Once let us settle that we are inherently capable of everlasting existence, we are then assured of the highest worth of our existence as measured by the ideals of Truth, of Beauty, and of Good, since these and their effectually directive operation in us are insured by their essen. tial and constitutive place in our being.

'Tis but a surface-view of human nature which gives the impression that the argument to immortality from our a priori powers leads to nothing more than bare continuance. What it really leads to, is the continuance of a being whose most intimate nature is found, not in the capacity of sensory life, but in the power of setting and appreciating values, through its still higher power of determining its ideals. For such a nature to continue, is to continue in the gradual development of all that makes for worth.

Not only does this follow from the general fact that all conscious being - at any rate, all human conscious life - takes hold a priori upon worth of every sort, but it can be made still plainer by considering for a moment just what the a priori cognition of Worth is, when taken in its highest aspect - the aspect of good will, or morality. The consciousness of self is intrinsically personal-the consciousness of a socicty - of being in essential and inseparable relation with other selves. ${ }^{1}$ That a mind is con-

1 See pp. $35^{1}$ seq., below. 
scious of itself as a self, means at the least that it discriminates itself from others, but therefore that it also refers its own defining conception to others, - is in relation with them, as unquestionably as it is in the relation of differing from them. It cannot even think itself, except in this relatedness to them; cannot at all be, except as a member of a reciprocal society. Thus the logical roots of each mind's very being are exactly this recognition of itself through its recognition of others, and the recognition of others in its very act of recognising itself. Hence moral life is not only primordial in the nature of mind, but what we commonly call a moral consciousness, as if we would thereby divide it permanently from the rest of consciousness, and count this remainder mere knowledge or mere esthetic discernment as the case may be, turns out to be in fact and in truth the primary logical spring of all other possible consciousness. So profoundly and so immovably is this deepest Fountain of value and worth inseated in our being.

From this fact it follows, and still more clearly, as was just now said, that the barest proof of our simple continuance must in reality carry the proof of that form of life which we reckon the highest expression of worth. To prove continuance, it suffices to display the self as the spontancous source of perceptions simply. But equally spontaneous is our positing of 
the Good, the spring of all excellence and worth, by our recognition of the society of minds in our primary act of being conscious of ourselies. Strange elemental paradox, self-affirmation by self-denial, selfdenial in self-affirmation! Ego por alteros! - he that findeth his life shall lose it; and he that loseth his life, the same shall find it! And thus the easy argument of exhibiting the least conditions sufficient for experience, so like a simpleton in its seeming clutch at the thin surface of things, carries in its subtle heart the proof of an imperishable persistence in all that gives life meaning and value. 


\section{THE HARMONY OF DETERMINISM AND}

FREEDOM

A STUDY IN THE METAPHYSICS OF DIVINE CAUSATION

You have asked me, Mr. President, and members of the Theological Society, ${ }^{1}$ to give my views upon a question into which I should hardly have made any public venture of my own motion, at least at the present time. But as you have been kind enough to extend the invitation, and also quite urgently, and as the subject has occupied me much for many years, with results that may at length have taken a form definite enough for at least a tentative expression, I have listened to your hospitable request and to my interest in the topic, and have perhaps not let the vastness and the intricacy of the theme give me the pause they ought. For our subject is the deep and hitherto very dark question of human freedom, and its compatibility with the omniscient and therefore omnipotent supremacy of God.

The historic way of dealing with this has usually been either to assert the Divine Supremacy ruthlessly, to

1 The essay was read before the Theological Society of Iacific Seminary, in Oakland, California, April 5, 1898. 
the denial of freedom, or to maintain freedom $a$ onttrance and deny the omnipotence and omniscience of God, or even the existence of God altogether. The times are now, however, full of a consciousness that a religious view of existence demands the justification of both principles, and their reconciliation.

The problem is stated by your president, in your current programme, in these words: Are the ideas of Determinism and Freedom reconcilable, and do they merge in idcntity and lcad to the outcome assumed by Dr. Gordon? In this statement, there is a reference to the belief quite surely implied in the tenth chapter of Dr. Gordon's volume, ${ }^{1}$ that determinism and freedom clo merge in identity, or tend to do so, and that this means the tendency of God's supremacy and man's free action to blend at last in universal salvation.

To the questions so squarely and so candidly put, I think it most becoming, as well as most natural, to answer squarely and with equal openness. It appears to me, then, that the two ideas are reconcilable, and that though they never themselves merge in identity, nor even tend to do so, they yet do lead, by their constant coöperation, to one

${ }^{1}$ G. A. Gordon: Immortality and the New Theodicy. [The Ingersoll Lecture at Harvard University for I 896.] Boston: Houghton, Mifflin and Co., 1897. The book formed the basis of the year's studies in the Theological Society. 
and the same sublime result, the salvation of every soul in every world. By this "salvation" I mean the establishment - in the temporal as well as in the eternal or causative life of every spirit, and from and by that causative life - of the dominant love of righteousness, and the everlasting progress of each soul thenceforth in bearing its rescued "natural being " toward the goal of completely possessing the image of God.

Any interest my thoughts on this subject may have for you must turn upon the way in which the reconciliation of the two contrasted ickas is worked out in them, - if indeed it be worked out. So I must try to show you what I think Determinism and Freedom severally are, when deeply and abidingly defined; how their reality is for each of them made sure and stable; how their harmony follows naturally and easily from their genuine ideas; how, in fact, this harmony is involved in their necessary and complemental relation to each other; and how, finally, out of their incessant joint action in the life of every mind the inspiring result arises of a universe evermore freely moving to a higher and higher harmony with God.

It is a judicious remark of Dr. Gordon, in which he follows the lead of Frederick Denison Maurice, that the key to Jonathan Edwards's genius in theology was his possession by the idea of the Divine 
Supremacy, and that the success of any new theology will depend upon its setting out from the same transcendent base. The problem is, keeping upon this highest theme in accord with Augustine, with Calvin, and with Edwards, and avoiding any compromise of its true exaltation, to find a new way, more genuinely divine and more expressive of the spirit of Christ than theirs, to carry out the sovereign reign of God, to display its reality, and to accord to it commensurate results. In all this, in its wide but unfortunately vague generality, I agree with Dr. Gordon; as, I doubt not, many of you also agree. But from the method-so far as one can gather it from his various writings, especially his Christ of To-day ${ }^{1}$ - by which Dr. Gordon would aim to render more rational the omnipresent supremacy of God, I presume many of you would seriously dissent; and so, too, do I, - though doubtless for extremcly different reasons.

You, I presume, would dissent on the ground that Dr. Gordon's belief in an immanent God savours too much of pantheism and of rationalism. I, too, dissent from the pantheistic trend of his theory; but I dissent from his method much more, because I feel that, however rationalistic, it is still not rationalistic enough. It admits far too much of the mystic

1 G. A. Gordon : The Christ of To-day. Hoston: Houghton, Mifflin and Co., I 894 . 
and occult agency of an omnipresent Deity in our human life to leave room for that freedom for which Dr. Gordon himself partially contends, and upon which, in its unabated completeness, genuine human goodness and a government really divine are, for me, irreversibly conditioned. No genuine, no complete freedom for the human spirit, then no real righteousness, no supremacy of a true God, nothing really Divine in all the universe!

But as in my way of stating the conditions for our freedom, and the corresponding relations between God and other beings, I have to depart so far from Dr. Gordon's that I fear he would dissent from my views because they seemed to him not sufficiently religious, - even to him, - I can hardly hope that they will appear entirely religious to you. For the sake of that freedom which is the soul of righteousness, that righteous justice which is the soul of a Divine sovereignty, and that exhaustless though indeed severe love which is the very soul of God, I am led to state God's crcative and regenerative supremacy in a fashion that can hardly fail to wear in your cyes the look of making away with it altogether. So, at least I fear, the case must appear to you at first; and perhaps for a long time.

Nevertheless I offer you these views in good faith, and not wholly without good hope also; for I am convinced they arc true, and I feel that their truth 
must gradually become commanding. I only ask, but I do ask earnestly, that you will think them out as patiently as I have done these many years; and that you will bear in mind, as you listen and think, that they are put forward with the sincere purpose of rendering clearer, and more convincing, the truth that there really is a Living God who is "love indeed," and therefore God indeed - the ador. able object of the loving devotion of all possible spirits; that he is, and that he reigns with that rule of freedom whereby alone a God can reign; that of his kingdom there can indeed be no end; that his victories and the boundaries of his realm will literally continue increasing forever.

But let us proceed to our proper task.

\section{I}

Of the questions whether Determinism and Freedom are by any method reconcilable, and what the steps in the method are, it seems plain that any settlement must proceed upon recognising as true the points which follow:

(I) The desired harmony is impossible if determinism is taken to imply Predestination. That is, if it nieans a completely defined detail and order of existence fixcd from withont the agcnt, and imposed upon him by edict and constraint. In such a case there could be no freedom. 
(2) On the other hand, no harmony can be reached by merely translating freedom into determinism and yet keeping up the name of freedom. This is usually done by raising the question whether freedom does not simply mean spontaneity in the agent, instead of alternative or choice, and answering it by cancelling choice in favour of spontaneity. But there can be no freedom that omits alternative and choice. It may be true enough that chance for alternative is not the bottom account of freedom, that the existence of alternative needs to be explained, as to both its meaning and its source, by the higher principle of spontaneity, or self-activity; but in no free system can alternative be omitted. In a moral order expressing itself in a time-world of events, it must always be possible to say of any act that it might have been otherwise - it need not have been. Instead, then, of asking whether freedom means choice or spontaneity, we should say that it means both, and explain how the fact of choice arises out of the determinism contained in self-determination, when this acts upon a world of experience which at the time of the choice answers imperfectly to the reason, or ideal-guided consciousness, which self-activity really is.

(3) Nor, again, is the harmony possible if freedom is taken to imply Caprice, or, in the technical sense, Chance. That is, if frecdom means power to act 
without motive, without the influence of plan or purpose, whimsically, incalculably, in disconnexion unforeseen and unpredictable. There is no possible reconciliation, that is to say, if will in the freeagent is conceived as simply self-will or mere arbitrium, a sheer "first cause" as mere power, not only underived, but unreasoning and unreasonable, inexplicable, and in fact meaningless. In such a case there could be nothing definite; things would be reduced to indeterminism and chaos, which would in truth be simply non-existence.

(4) So the conciliability of determinism and freeclom depends on the fact, if this be a fact, that determinism simply means dcfnitcness (instead of constraining foreordination), while frecdom means (instead of unpredictable whim) action spontaneously flowing from the definite gniding intclligence of the agcnt himself. In short, the desired harmony will fail unless the determinism and the freedom are both alike defined in terms of the one and identical definiteness of the rational nature; but it will be secured if they can be so defined, and are.

Let us proceed, then, to settle whether this simple definiteness may not be the sufficing sense of determinism, and whether action really free may not remain when the utter indeterminism of caprice or chance is taken away. 
As for determinism, it is clear that one of its meanings is predestination - prescription from without, inevitable and fatal. This is what we mean by the "uniformity of nature" — the "law of causality," the "iron band of necessity," in the physical world; there the things and the events are bound in a rigid order not originated by them, but coming upon them from some higher source, which they passively obey. Yet even this predestination is but a species of definiteness; and so, as definiteness may be predestined and constrained, it is of course a legitimate question whether there may not be clefiniteness when the factor of constraint and edict is taken away. Indeed, the imperative and constraining definiteness of physical fate implies somewhere an ultimate Defining Source, itself therefore free, from which the constraining edict issues; and this Source, as free and yet defining, must be selfdefined, must be itself perfectly definite though unconstrained by anything else; for the indetcminate could not possibly confor detcminatencss upon anything. Thus there may be - rather, there must besuch a fact as definitencss simply; definiteness that is not predestination, but is the definiteness involved in self-dctermination.

On the other hand, as to freedom, we have just seen that in the last resort definiteness is free. It remains for us to discover, conversely, that freedom 
is definite, and essentially so; that freedom cannot mean indeterminism, and thence caprice or chance. ${ }^{1}$ Our first step toward this is to realise that for freedom's sake we may need to keep, as belonging to the free being when all the factors of its life are considered, both meanings of determinism as these were just now found - the free definiteness and the determinateness that is constrained. For action, to be free, if concerned as our human action is with a world of sensible particulars, must have in that world a calculable order - unchangeably calculable. There antecedent must be followed by consequent with rigour incapable of variation. Otherwise, and just so far as uncertainty of the order exists, there is ignorance what to count upon, there is risk of frustration: the actor is disconcerted, perplexed, all at fault; in so far, enslaved.

On the other hand, in such a necessitated world the actor cannot be free unless he is in conscious

1 In his brilliant and memorable essay on "The Dilemma of Determinism," Professor James chooses to state the doctrine of freedom in terms of the word "chance." To be sure, he warns his readers that he only intends by this to mark with emphasis the fact that the world where the agent acts leaves him a "chance" (i.e. an opportunity) to make himself effective in it, and to render its course different from what it would be without his voluntary acts. But the word seems time and again to ensnare him in its ambiguity, so that he often treats freedom as if it meant caprice or mere Willkür. See The Will to Believe, and Other Essays, pp. 145-183. New York and London: Longmans, Green and Co., 1897. 
possession of the law that rules it; and he cannot consciously possess the law, as a genuine laze, mandatory upon his world, except independently of the world. The possession cannot be imparted to him from without; for then, at most, he could only know it as mere fact true to date, without any assured control over the future. That is, in the phrase which Kant's decisive discussion has made classic, to be free he must know the law a priori; know it by its issuing from the spontaneous activity of his own intelligence in defining himself, and by its legislating thence upon his world of things. $\mathrm{He}$ organises his world of sense-presented experience as a complemental part of his whole self-organised life. Therefore, further, for a being who involves such a finite world, the condition of his freedom in it, the condition inclispensable but at the same time sufficient, is that his world shall indeed be his; shall be of him, not independent of him; shall be embraced under his causal life, not added to it from elsewhere as a constricting condition; shall be, in fine, a world of phenomena, - states of his own conscious being, organised by his spontaneous mental life, - and not a world of "things-in-themselves."

From this result, now, we can pass on to the remaining sense of determinism, its meaning of simple definiteness without predestination, and can reach our goal regarding the nature of freedom. We dis- 
cern, namely, that this free Definer, this legislator of predestination upon his world of mere things, is, in accordance with our initial reasoning, himself full of definiteness; he is not undefined, but is self-defining. This is his essence; and so, just because he is free, he is determined, though of course self-determined. He is not and cannot be capricious, formless, whisking in infuitum, self-shattered to chaotic dust and showered into the bottomless void, but is inherently self-planned, purposeful, continuous, coherent, calculable, and thus knoreable. So the free being, as selfdetermined and taken in his whole contents, is definite in both senses of the word: he defines himself, and thus has the definiteness of unpredestination; he defines his empirically real world of things, and thus adds to himself a field of action having the definiteness of predestination, - in a manner arms himself with it, inasmuch as he transcends and controls it.

Our result thus far is, that determinism and freedom, when justly thought out, are in idea entirely reconcilable. Determinism proves to need no fatalistic meaning; but to be, possibly enough, simply the definite order characteristic of intelligence; while so far from freedom's being indeterminism, chance, or caprice, these are seen to be incompatible with it, and freedom proves to be, like determinism, the spontaneous definiteness of active intelligence. And one thing, of the highest importance, we must not over- 
look - our discovery that no free being can be the product of processes in Nature, that on the other hand none can exert freedom in an unpredestined natural world, and that consequently every free being in relation with such a world must himself predestine it, must impart arrangement (or "form ") to it from the form of his own active intelligence. In fine, a condition of our making freedom possible in a world ordered by the rigour of natural law is that we accept an idealistic philosophy of Nature: the laws of Nature must issue from the free actor himself, and upon a world consisting of states in his own consciousness, a world in so far of his own making.

This principle of cosmic subjection has by theists always been realised with reference to God: the natural world, they are always telling us, however full of laws to which other conscious beings are subject, is completely subject to the mind and will of God, and its laws are imposed upon it from his mind in virtue of his creating it. What we now learn, and need to note, is that this is just as true of any other being who can be reckoned free. If men are free, then, they must be taken as being logically prior to Nature; as being its source rather than its outcome; as determining its order instead of being determined by this. Not God only, but also the entire world of free minds other than God, must condition Nature; and, as we shall learn later in our inquiry, they must condi- 
tion it in a sense that God does not. They, we shall find, must be directly and productively causal of it, while God's conditioning of it can only be indirect and remote; namely, as we shall see, by the constant reference to him, as their ruling Ideal, which these nature-begetting minds spontaneously have. In short, in securing freedom we come to a Pluralistic Idealism, instead of the idealistic monism that has so long dominated philosophical theism.

This exaltation of man over the entire natural world, however, though easily shown to accord with the teaching of Jesus, and to be clearly prefigured in it, is nearly antipodal to ordinary notions, to the current popular "philosophy" assumed to be founded on science, and to much of traditional theology. But by this fact we must not be disturbed, if we mean to be in earnest about human freedom and human capability of life really moral and religious. And the next step in our inquiry will reinforce this "divinising of the human" very decidedly.

For we must now push the question of reconciling determinism and freedom beyond the region of their mere ideas, and face its greater difficulties when determinism means the definite order in the live Divine Mind, and freedom means the self-directing activity of men or other real spirits not divine. It might per- 
tinently be said that determinism and freedom are of course compatible enough when they are merely viewed as the two reciprocal aspects of self-activity in a single mind, but that the real difficulty is to reconcile the self-determinisms in different free minds.

Paramount is this difficulty when one of the minds is the supreme God, creator (as he is held) and ruler of all existence. In this case, it becomes plain that the solution of any antagonism between determinism and freedom must depend on solving the conflict apparently latent in the contrasted freedoms of God and other beings. If the solution is possible, then, it will only be so by the fact that, on the one hand, perfect intelligence or reason is the essence of God, - who therefore determines all things, not by compulsion, but only in his eternal thought, which views all real possibilities whatever; and that, on the other hand, the spirit other than God also has its freedom in selfactive intelligence. This granted, the range of its possibilities is precisely the range of reason again, and so is to God perfectly knowable and known, since it harmonises in its whole with the Eternal Thought that grasps all possibilities, though it is not at all predestined by this. Thus the course of, say, human action, viewed in its totality, since it springs from selfactive reason, must in its result, as in its source, freely harmonise with the Reason who is supreme.

Solution of this knot by any other conceptions of 
freedom and determinism than these, there plainly can be none. But the solution is secure if God and other spirits are alike rational, simply by their inner and self-active nature; in other words, if the solution is by spontaneous harmony from within, and not by productive and exccutive domination from without. If the Sovereign is perfectly rational, if the whole of his being is just perfect intelligence, and if the free subjects are also essentially rational, while this rationality defines the course of their being as a whole, then the perfect definiteness of his realm and the freedom of its members - his perfect possession of it by complete knowledge, and their complete possession of their own lives, rationally self-determined will in the whole coincide, and the harmony is complete. Each spirit other than God, let us suppose, fulfils in its own way and from its own self-direction the one universal Type, or Ideal. Then each in doing its "own will," that is, in defining and guiding its life by its own ideal, does the ultimate or inclusive will of all the rest; and men realise the "will of God," that is, fulfil God's ideal, by fulfilling each his own ideal, while God fulfils the "will of man" by freely fulfilling himself.

This explanation, however, in presenting a universal World of Spirits, every one of whom is free, - that is, independently self-active, self-moved from within, and none operated either directly or in- 
directly from without by any other, - brings us to a fresh and greater difficulty. For it requires us to suppose every spirit, the human, for instance, as well as the Divine, to have "life in itself"; that is, to be in a very profound sense underived, self-subsistent, or, in the technical language of the deeper philosophical schools, eternal. But this coeternity of man with God appears to conflict directly with the two most essential attributes of God - Creation and Regeneration. To be sure, this self-activity of the human soul is prefigured in that highest symbol of the Christian Faith, the Fourth Gospel, where it is declared ${ }^{1}$ that "as the Father hath life in hiniself, even so gave he to the Son also to have life in himself: and gave him authority to execute judgment, because he is a son of man," - though how it can be given to have life in oneself, has hitherto been left aside as "the mystery of grace"; and so long as "giving" is taken to mean transfer or endowment, and so to imply productive action from God toward men, it must continue a perplexity - not to put the case too ruclely - to confront at once Divine causative authorship and human spontaneous action. Yet without this last, let us repeat, there can be for man no divine living, his own, sincere and wholc, coming from the springs of his inmost being and penetrating him

${ }^{1}$ John v, 26, 27, Revised Version. 
throughout; he can have no "righteousness of God," - righteousness, that is, such as God has, but must remain in bondage to the false and external "righteousness of the law."

Before it can be said, then, that human freedom and the absolute definiteness of God as Supreme Reason are really reconciled, we must have found some way of harmonising the eternity of the human spirit with the creative and regenerative offices of God. The sense of their antagonism is nothing new. Confronted with the race-wide fact of human sin, the elder theology proclaimed this antagonism, and solved it by denying to man any but a temporal being; quite as the common-sense of the everyday Philistine, absorbed in the limitations of the sensory life, proclaims the mere finitude of man, and is stolid to the ideal considerations that suggest immortality and moral freedom, rating them as day-dreams beneath sober notice, because the price of their being real is the attributing to man nothing short of infinity. "We are finite! merely finite!" is the steadfast cry of the old theology and of the plodding common realist alike; and, sad to say, of most of historic philosophy too. And the old theology, with more penetrating consistency than the realistic ordinary man or the ordinary philosophy, went on to complete its vindication of the Divine Sovereignty from all human 
encroachment by denying the freedom of man altogether.

Well, if we grant that finitude is the whole or the characteristic truth about man, then the old theology was wholly right. There is no escaping from the reasoning of an Augustine, a Calvin, an Edwards, except by removing its premise. That premise is the utter finitude of the "creature," resting upon the conception that the Divine functions of creation and regeneration, more especially creation, are operations by what is called "efficient" causation, that is, causation by direct productive energy, whose effects are of course as helpless before it as any motion is before the impact that starts it. Creation thus meant calling the creature into existence at a date, prior to which it had $n o$ existence. It was summoned into being by a simple fiat, out of fathomless nothing; and quite so, it was supposed, arose even the human soul, just as all other things arose. In exact keeping with this was the dogma of "irresistible grace": regeneration was the literal re-creation of the divine image, out of the absolute death which it had suffered in the supposed fall of man, - re-creation by just such a miraculous productive efficiency as had originally called the soul out of the void. Human finitude as the summary of human powers, with its consequent complete subjection to 
Divine predestination, is inwrapt in this conception of Divine causation as causation by efficiency; and there can be no way of supplementing this finitude by the infinity (i.e. freedom) required by a moral order, except by dislodging this view of creation and regeneration.

\section{III}

If we are in earnest, then, about human freedom, - if there is to be any real freedom to reconcile with a real Divine definiteness that is unchangeable, - we must face the problem of supplanting the older theological conception of the two Divine offices by a conception compatible with a freedom that is freedom indeed. Especially must we find a substitute for creation by fiat, or efficient causation. For no being that arises out of efficient causation can possibly be free. Let us clarify our minds of all traclitional obfuscation about this, and see the case as it really is.

Not even by the theory, sometimes advanced, that God freely and "of his grace" cndows the creature with an "inner" nature which "works out its own salvation," does a being created by efficient causation become really free. Even then it is only apparently, not really, self-active. It merely obeys a preëstablished order, - like a clock, for example, to 
which the maker's transcendent skill should impart the power to run perpetually, from the original setting and winding of its mechanism. The plan, to be sure, would be free relatively to the componcnt parts, and would control their movements; but the plan would not itself be free. It would be derived from the contriving thought of the maker, would be completely in subjection to that, must simply unfold and follow out the course implanted in it. The maker alone would be the source of its purposive action, the intention would be his alone, and he alone would therefore merit the fame or the shame of its performance.

Either, then, we must carry out our modern moral conception of God's nature and government into a conception of creation that matches it - a conception based on that eternity (or intrinsic supertemporal self-activity) of man which alone can mean moral freedom - or else, in all honesty and good logic, we ought to travel penitently back to a Calvinism, a Scotism, an Augustinianism, of the so-called "highest" type. Then we would view man as a "creature" indeed. We should have to accept him as a being belonging to time only, with a definite date of beginning, though lasting through unceasing ages, if that could indeed then be. We should have to surrender all freedom for him as a delusion. In effect, with this conception of creation, we must 
return to an unmitigated Predestinationısm. Nor may this stop short of foreordination to Reprobation as well as to Election - a foreordination not simply "supralapsarian," but precedent to creation itself. The separation of the Sheep from the Goats must be from "before the foundation of the world," and the Elect must be created "unto life everlasting," while the reprobate are creatcd "unto shame and everlasting contempt."

Thus we see that not even Divine agency can give rise to another self-active intelligence by any productive act. Such creation, by whomsoever it might be, could only apply to the existence of mere things, things lifeless and inorganic, and never to that which has "life in itself." Much less could regeneration, the bringing-on of voluntary repentance and genuine reformation in the soul, be by any sort of efficient causality, - a truth to which modern theology has evidently for some time been alive, as its forward movement is keyed upon the increasing recognition of the metaphor in the name. These thoughts, however incontrovertible they may be, are no doubt staggering thoughts, so much are we of old habituated to calling regeneration the "work" of the Holy Spirit, and to naming man the "creature" of God, and God his "maker." Still, staggering though they be, they must be true if human freedom is to be a fact; and that human freedom is to be a fact, the modern con- 
science, quickened by the very experience of the Christian spirit itself, firmly declares, having now apprehended that otherwise there is no justice in human responsibility, and then no moral government, but only government edictive and compulsory; and then - no personal God, no true God, at all!

But if under the moral view of universal being creation by efficient causation is untenable, by what mode of causation can it come about? Or, if by no mode, then does not creation cease to be an attribute of Deity? Have we indeed, then, in the course of our religious consciousness, come to that point of complete reversion which shows us that henceforth God is to be worshipped as Redeemer alone, and no more as Creator? Was the Gnostic heresy, which brought to Christianity its first great inward schism, - was Gnosticism right, then, after all ?

Well, if so, if the "great category of Cause" is not to hold of Divine relations, how are we to gain any evidence that there is a God? Is not the creation the one witness to God? - and if God be left without a witness, what becomes of his reality as Reckeemer, as Regenerator? Must we not, somchowe, still affirm the judgment of the early churches against the Gnostic, and in the name of our faith once more declare the identity of the good God with the God of might, of the Redecmer with the Creator? But -again how? When efficient causation is excluded, 
has not causation, as a principle of inference, lost all its efficacy? Nay, when that effectuating Power is gone, is not the vital meaning gone out of causation altogether? All these difficulties we must somehow dispose of. Nor are these the worst; for if freedom requires the seating of man in eternity, companioning there a so-called God, what office has God as Regenerator? - must not the new conception of moral being place regeneration also within the scope of man's self-active freedom? Has not God, then, become superfluous and supernumerary every way, in this society of eternal free-agents?

We shall gain nothing by trying to evade the difficulties in such questions, which are real difficulties. We can easily imagine an Edwards rising from his grave to put these questions as with the voice of God himself, - questions which beyond doubt still wake a large echo in the hearts of his softened successors even; so softened - so demoralised, he would say - that he must disown them unless they speedily returned to the high and stern doctrine of a Sovereign God who forms every creature to such destiny as He pleases. No, let us make no evasion; let us rather, at first, make the difficulty greater, by reiterating the insuppressible demand for justice and love, for justice and love universal, which generations of further communion with the spirit of Christ have at length awakened in us, and which 
reveals to us the truth that moral freedom is the soul of our soul, and the soul of Divine government, if Divine government indeed there is. Let the two apparently contradictory voices confront each other for a while - the voice that calls for proofs, for infercntial justification, and the voice, still deeper, that calls for righteous warrant, for moral justification.

In the end our decision will be, that, while neither voice can be stilled, the moral voice has primacy, and the voice for inference must seek satisfaction more subtly than by searching in the harsh paths of merely natural or temporal power. Perchance the "great category of Cause" has resources that give to creation and to regeneration, both, a greater reality of meaning than efficient causality can provide. Perchance, when this deeper and richer interpretation of cause comes to knowledge, the real witness of God will appear - the witness to the Spirit, to the Eternal Love, who thinks only in terms of spirit, has only free minds for his realm, and, himself frec with perfect moral freedom, reigns there through the free processes of the living souls themselves.

Let us reiterate, therefore, that the demand for a moral world is a demand for a world of freedom a world of genuine persons, beings who think their own thoughts, originate their own decisions, yet really do think, not ruminate merely, and so decide 
rationally, - with judgment at once private and yet public; their own, yet all-embracing and benign. Potency for such judgment, whether yet actualised in time or not, - power to make it real under whatever conditions, be they of time or of space, be the victorious realisation never so delayed or so gradual, - this is what moral freedom in reality means; as Edwards maintained, power to do, not alone to choose. For moral freedom, the spontaneous activity of reason, chooses its own ideal, not in time, but in eternity. Its own ideal nature is its only absolute or eternal choice; and its eternal choice is its nature. If it has a task in time, - as indeed it has, - it is there not to choose its aim again, but to make its eternal purpose, its chosen ideal, effectual; to make it so in the face of that opposing Check which, as we shall presently sec, ${ }^{1}$ it introduces into its being by its primal act of self-clefinition.

We are not to evade, then, the eternity of free beings that is implied in any serious demand for freedom. If the souls of men are really free, they coexist with God in the eternity which God inhabits, and in the governing total of their self-active being they are of the same nature as he,- they too are self-put rational wholes of self-conscious life. As complete reason is his esscnce, so is reason thcir essence-their nature in the large - whatever may

1 Compare pp. 362-364, below. 
be the varying conditions under which their selfhood, the required peculiarity of each, may bring it to appear. Each of them has its own ideal of its own being, namely, its own way of fulfilling the character of God; and its self-determining life is just the free pursuit of this ideal, despite all the opposing conditions by which it in part defines its life. Moreover, since this ideal, seen eternally in God, is the chosen goal of every consciousness, it is the final - not the efficient - cause of the whole existing self. All the being of each self has thus the form of a self-supplying, self-operating life; or, in the phraseology of the Schoolmen and Spinoza, each is causa sui. This is what its "eternity" exactly means.

But at this point the counter-side of our religious difficulty presses the strongest. The religious life must indeed be free and individual, yet it must also be self-subordinating and universal; whereas the free system now appears to be an uncompromising Pluralism - an absolute democracy, which, read it as levelling down or as levelling up, as all man or as all god, comes ever to the same dead level, where any such superiority as real Deity is jealously excluded. Nay, the older theists of Lordship and Producing Cause will here surely tell us that this moral idealism has overreached itself, and become its own destruction. "This dead level of spiritual 
democracy," they will say, "crushes the very spirit of freedom itself, for its exaggerated individualism erases individuality. It is one endless round of dull repetition, a lethal monotone. Universal exaltation to eternity, in clestroying God and his differentiating supremacy, has destroyed the interest of existence, has cast a banal blight upon all originality, and so upon all the verve of life. Restore difference, by subordinating man!-or else confess that in a godless exaltation of freedom you have made freedom the deadliest bondage, the bondage to the tame and the stale." Nor is it sufficient to reply to this, as no doubt one may, with a tu quoque; for though the old-fashioned subordination to the will of the sovereign God also comes to a monotone of death in life, this does not obviate the charge laid at the door of individualism. It simply shows that, to present appearance, neither view contains a solution of the moral-religious problem, and that our search must be pushed farther.

This possible self-contradiction - I do not say it is real; on the contrary, I hope presently to show it is illusory - is not the only difficulty with our moral idealism. In another aspect, the scheme may be charged with polytheism; or again, on other grounds, with atheism. All the members of this required moral system, men or other spirits as well as the supposed God, are unreservedly self-active; 
it would seem, then, that they are all alike underived and self-subsistent. So that, even in the best case, there is no monotheism, there is polytheism, or "every man his own god"; while, in the worst case, we pitch into the pit of atheism, since one may reasonably ask, Why call one of this circle of gods preëminently God? How strangely our religious consciousness seems here to contradict itself! Feeling itself threatened with the loss of God as eternal Justice and Love, because justice and love cannot subsist unless the agents held responsible are the free causes of their own conduct, it courageously sets up its spirits in eternity; but no sooner are these in their heaven than God seems lost again, vanishing in the universal dispersion of the divine essence.

\section{IV}

Were this the authentic account of moral idealism and its religious resources, our case as religious beings would be bad indeed. For so fast as we supplied our spiritual needs at one pole of our nature, we should destroy the power of supplying them at the other; and they must be satisfied at both. But it is certain that our moral-religious demands must be and ought to be satisfied: better the atheism of a lost First Cause, and a lost Sov- 
ereign Lord, than the atheism of deified Injustice, with its election and reprobation by sheer sovereign prerogative. And while it is certain, too, that the free-agency exacted by moral government can only be fulfilled by allotting self-activity to the spirit, and consequently seating it in eternity, companion there of God, yet in truth this has neither the polytheistic nor the atheistic implications that have been suggested. Least of all, when its true implications are understood, does this free eternity of each mind destroy the distinction between God and souls, between every soul and every other, and thus ruin the logical variety and the æsthetic interest of the universe. On the contrary, the system of free spirits, as already above depicted in its essential traits, far from being a deadly world of dull identity, is kindled throughout by an intense variety which is the very principle of its existence. It provides in its idea just the resources we need for solving the contradiction we are now so aware of provides them as no possible scheme of monarchic and efficient-causative Divine agency can.

The fact is, the real difficulty in the case comes from retaining this old efficient-causal notion of Divine being and function, after we have silently but really parted company with it in accepting a moral order as the touchstone for the character of souls and the nature of God. The tragic situation 
of the modern liberalised Christian mind is just that. Having accepted with fervour the moral ideal as the Divine ideal, it still remains in bondage to the old mechanical conception of the great Divine operations called Regeneration and Creation. These it still thinks, at bottom, under the category of efficient causality. It takes their names literally, in accordance with the etymology, and thus the names themselves help the evil cause of prolonging conceptions that are hostile to the dearest insights of the moral spirit quickened in the school of Christ. Eminently is this true in the case of creation, into the current conception of which, so far as I can see, there as yet enters no gleam of the change that must be made if our relations to God in the basis of existence are to be stated consistently with the independence we must have of him in the moral world. This lack of a moral apprehension of creation is as characteristic, too, of historic philosophy as it is of historic theology, or even of ordinary opinion.

The moral postulate of human self-activity standing, then, and so the coexistence of all souls in eternity with God, - if we may speak here of God, before his being has been made clear, - our question is, How is the reality of God to be established, and how is his so-called creative office to be stated, now that 
it has become plain that a moral governor cannot create his free subjects by efficiency, nor, accordingly, his being be proved by reasoning from produced effect to producing cause?

In coming to grapple with this question, let us understand that the principle of efficient causality, as an expression of Divine relations, once it is settled that all Divine relations are moral, must be discarded in every form. Long ago the rising Christian consciousness abandoned the elder Oriental forms of it, as also the crude forms of Western paganism, accepting instead the doctrine of "creation out of nothing" by the fiat or "word" of God. For that consciousness, accordingly, the pantheistic interpretations of efficiency, such as production by emanation or by extrusion from the Eternal Substance, gave way to a conception certainly higher, in the sense that creation by fat disenthralled the creature from entanglement with the Creator, and gave him an existence in some sort distinct. A similar gain was made over the polytheistic notions of creation, under which neither gods, nor men their work, were delivered from the thraldom of eternal matter and omnipresent Fate.

Still, despite the gains, in abandoning pantheism and polytheism historic Christian thought did not clear itself of the category of efficiency. Its dualism between the Creator and the creation still held fast 
to the older doctrine of a unity by efficient causation and compulsive control. Instead of a unitunity of self-operating Substance or all-dominating Fate, it merely substituted the harmonic-unity resulting from the action of a single intelligent agent upon all his works: the works recorded the plan; the result, up to the "last things," - $\epsilon i s$ $\tau \grave{a}$ "ै $\sigma \chi \alpha \tau a$, - registered the impress of "the counsels held in eternity" from "before the world was."

Philosophy in Christendom, as distinguished from dogmatic theology, so far as it has kept in sight of the main Christian theme of a personal God has steadily tended to abandon this dualism and thus avoid the unintelligible dogma of fiat, and has of late replaced it by various forms of monism, of an idealistic type, aiming to give a philosophic vindication at once to Divine and human personality and to human immortality, by explaining all existence as the acts and inner modes of a single eternal Self-Consciousness.

These more or less thoroughgoing monisms, sometimes called Christian Pantheism, or the Higher Pantheism, have been set strongly in contrast with the monism of materialism or of agnosticism. But, on the main theme, they all really signalise a return to the elder views of the Orient. And they all still employ the category of causal efficiency to express the relation of the Creator to the creature, representing this as the relation of the actively deter- 
mining Whole to the receptively determined parts. Their advantage over the older dualism is the advantage of logical consistency: their application of efficient causation is universally continuous, and not interrupted by a break as the doctrine of fiat is a break merely feigned to be closed by the conception of miracle. This advantage, however, they only gain by sacrificing the distinct freedom of the creature from the Creator, a price which the moral consciousness declares should not be paid.

So far, then, the choice seems to lie between an unphilosophised and somewhat irrational dualism, which nevertheless maintains the distinctness of God from his creation (though, by its way of doing this, it renders the proofs for him inconclusive), and a philosophised monism, continuously coherent, rendering clear proofs of its pantheistic Cause, but really incapable of providing any genuine freedom for the souls that are his parts. The failure of both for the wants of the moral consciousness makes a choice between them unavailing. With neither of them can the conscience rest. Their failure is owing, at bottom, to one and the same defect: they both interpret the causal relation of God to souls in terms of efficiency, of agent and recipient.

I have made this digression to enforce the position, before taken, that the solution of our perplexity requires the abandoning of this efficient notion 
of creation in every form, and to show you, further, that the present marked tendency of the new philosophic theology to take refuge in some species or other of monism, can only end in disappointment and the wreck of that great moral interest from which the new movement takes its rise. Out of the digression let us return now to the main question: Since every form of applying efficient causality to state the causal relations of God to minds is inconsistent with moral reality, is there any mode of causation consistent with this, and capable of distinguishing, in the moral world of eternal minds, between God and souls, between every soul and every other, and of stating, in a way suitable to the essential freedom of spirits, that great Divine function which we try dimly to symbolise by the word "creation"?

\section{V}

The required mode of causation, if any such there be, must be one that operates in and through the spontaneous life of the free being himself. Is there a causality that does so operate?

Yes, unquestionably there is. Its nature was directly suggested in what I said when describing, some minutes ago, the active self-consciousness of any member of an eternal moral world. We then found every soul to be causa sui - at once its own 
cause and its own effect - in virtue of its acting from the contemplation of its own self-recognised Ideal. The action of such a causa sui is purposive, but its own self-consciousness provides the aim, and the aim is just its own complete being, as this really is; namely, as self-defined in the light of the Divine Perfection. Such purposive causation through an ideal is inherently free causation: the being that acts from it is always self-prompted and self-fulfilled, and so is free. No other conceivable mode of causation is free. Since the time of Aristotle this operation of an ideal has gone by the name of "final" cause - the causality in a consciously put "end," or aim. Sometimes it is called by the more sounding title of "teleological" cause - the cause whose logic, or explanation, is in a $\tau$ étos, the Greek name for a goal; that is, again, an aim, an ideal, the highest term of a thinking agent's self-expression. To sum up its nature in a single phrase, let us call it simply the free attraction of an intelligence by its own ideals, preëminently by its Ideal of ideals.

Final Cause, then, or the Ideality at the logical heart of conscious life, - to that we are to look for release from the perplexity about the determinism in Divine supremacy and the self-determinism in human or other non-divine freedom. And in finding the 
release we must show that our means preserves in God the two great offices which our religious consciousness demands - demands with much vagueness of meaning, no doubt, but which it strives at least somehow to name in the words "regeneration" and "creation." We are in sincerity bound, too, to show that our explanation by Final Cause, for the sake of saving undiminished freedom, is not at the expense of Christian monotheism. We must make it ingenuously clear that the world of free persons, subsistent in eternity, is not open to the charge of polytheism, and, still more, not to that of atheism.

These charges, it is worth while to observe, are not new. They have, to be sure, been recently pressed with much emphasis by Professor Royce in his "Supplementary Essay" in The Conception of God, ${ }^{1}$ but they have been brought against pluralism, against the system of manifold free-agency, ever since the day when the great Leibnitz first sketched its outlines in his midsummer-night's drcam of monads and the Monad of monads. He too was accused of rendering God superfluous; and the innuendo was not omitted, that he had annexed God to his system for diplomatic reasons - from motives of "cconomy." Even his admiring American translator, the late honoured Dr. Frederic Henry Hedge, pilloried the Monadologie in most dubious company, in his volume

${ }^{1}$ See The Conception of God, pp. 275, 321. 
bearing the ominous title Atheism in Philosophy. ${ }^{1}$ To be sure, monism was in a way Dr. Hedge's religion, and so pluralism was for him the unpardonable sin. But for every type of the genuinely religious mind, the omission of God must be unpardonable; and what we need in these perplexing discussions is some settlement of what is the central attribute of God, that shall impart to all the others legitimate meaning, and put an end to unmerited charges of atheism.

So that I am now called upon to show that the elevation of the human spirit to genuine freedom, with the consequent placing of the soul in the order of eternal being, so far from transforming men into gods or rendering God superfluous and non-existent, carries us, on the contrary, to just such a central attribute of genuine godhead. I am to show you, too, that in the world of eternal free-agents, the Divine offices called creation and regeneration not only survive, but are transfigured; that in this transfiguration they are merged in one, so that regeneration is implicit in creation, and becomes the logical spring and aim of creation, while creation itself thus insures both generation and regeneration-the existence of the natural order within the spiritual or rational, and subject to this, and the consequent gradual transformation of the natural into the image of the spiritual:

${ }^{1}$ F. H. Hedge : Atheism in Philosophy, and Other Essay's. Boston: Roberts Brothers, I 884 . 
a process never to be interrupted, however devious, dark, or often retrograde, its course may be. I am to show you all this by the light of Final Cause, which is to take the place of the less rational category of Efficient Causation, since - let it be repeated - this last cannot operate to sustain moral relationship, and since moral values, measured in real freedom, are for the conscience and the new theology the measure of all reality.

\section{VI}

Now, after our long making ready, the sufficient exhibition of these conclusive truths may, fortunately, be comparatively brief. Let us begin by showing that our uncompromising Pluralism, our system of self-active or eternal persons, is not atheistic, but demands God; yes, reposes on God, and alone presents him as adorably divine.

Bear in mind, then, that by the terms of our problem we set out upon our present quest from a granted world of beings really free, and that this freedom means their subsistence by their self-active thinking. They are thus all eternal, in the highest and therefore sole entirely true meaning of the word; namely, they are all subsistent self-actively, by their own self-defining consciousness. But this does not merely mean that they are everlasting, - existing, as the 
ancient and venerable saying is, "to all eternity." This everlastingness, or indestructible pervadence of infinite futurity, as we shall in a moment see, is a real aspect in the being of one of the two great orders of free self-consciousness, but it is only an aspect, and only in that one order; while eternity, or free reality, means something quite transcending this. It means that each thoroughly real being is just self-defining, self-operative, is existent in a sense that excludes the alternative of its non-existence - in its central unifying essence is quite out of and independent of time, or is necessary (i.e. unavoidable and necessitating) instead of necessitated; and that, in fact, time itself takes its rise entively from this self-thinking which constitutes the free being as eternal and whole. ${ }^{1}$

But now note - and this is the point of foremost importance - this eternal existence of the spirit is essentially self-definition, the putting of existence that is unambiguously definite, incapable of confusion with any other. The spirit is intrinsically individual:

1 For Time, it would seem, is nothing but the mind's consciousness of its own controlling unity, - living on, notwithstanding the throng of differences from its defining Standard that are introduced into its life by its act of self-definition (see pp. 362-369, below), and holding these differences all in its one embrace. It is, however, only the immediate or lowest form of this consciousness, and so gathers this miscellany of items into no more than the loose union which we call sequence. It is supplemented by more significant and increasingly stricter expressions of the mind's unity, such as Space, Force, Syllogism, and so on, up to Truth, Beauty, and, finally, Good, i.e. benignant love. 
it is itself, and not any other; and it puts itself so, incontestably. But such a getting to exact identity can only be by means of difference; and difference, again, implies contrast, and so reference to others. Thus, in thinking itself as eternally real, each spirit inherently thinks the reality of all other spirits. In fine, its self-definition is at the same stroke in terms of its own peculiarity, its own inerasible and unrepeatable particularity, and of the supplemental individualities of a whole world of others, - like it in this possession of indestructible difference, but also like it in selfsupplementation by all the rest ; and thus it intrinsically has universality.

In this fact we have reached the essential form of every spirit or person - the organic union of the particular with the universal, of its private self-activity in the recognition of itself with its public activity in the recognition of all others. That is, self-consciousness is in the last resort a conscience, or the union of each spirit's self-recognition with recognition of all. Its self-definition is therefore definite, in both senses of the word: it is at once integral in its thorough and inconfusible difference from every other, and yet it is integral in terms of the entire whole that includes it with all the rest. Thus in both of its aspects and both are essential to it - in a commanding sense it excludes alternative, and there is universal determinism, that is, universal and stable definite- 
ness, just because there is universal self-determination, or genuine freedom. But this universal self-defining implies and proclaims the universal reality, the living presence in all, of one unchangeable type of being - the self-conscious intelligence; and this, prescnted in all really possible forms, or instances, of its one abiding nature.

Well, then, how many are there of these possible forms, these possible instances? Plainly, as many as answer in full to the free self-defining in which all have their being. The number must be vast enough to provide for all individual differences compatible with the mutual reality of all. The world of spirits is thus "ten thousand times ten thousand, a great multitude which no man can number." Yet it is not vaguely boundless; it is not "infinite" in the sense in which the imagination and the mathematicians take infinity. On the contrary, from the nature of the case, its number must be definite as well as vast, though we do not actually know it now. Still we do know certain things about the world of minds, which in the present context are of determining significance. Little as we may be able to tell its number, the series certainly must run through every real difference, from the lowest increment over non-existence to the absolute realisation of the ideal Type. 
Hence the world of minds must embrace, first, the Supreme Instance, in which the self-definer defines himself from every other by the peculiarity of perfect self-fulfilment in eternity, so that all ideal possibilities, all rational perfections, are in him eternally actualised, and there is an absolutely perfect mind, or God, whose very perfection lies in his giving complete recognition to all other spirits, as the complement in terms of which alone his own self-definition is to himself completely thinkable. But, secondly, the world of minds must embrace this complemental world, and every member of this complement, though indeed defining himself against each of his fellows, must define himself primarily against the Supreme Instance, and so in terms of God. Thus each of them, in the very act of defining his own reality, defines and posits God as real - as the one Unchangeable Ideal who is the indispensable standard upon which the reality of each is measured. The price at which alone his reality as self-defining can be had is the self-defining reality of God. If the is real, then God is real; if God is not real, then neither can he be real.

In the system then, as it really is, God not only eternally defines himself, and so is self-existent eternally, but he is likewise freely defined as selfexistent by every other self-defining being. $\mathrm{He}$ is 
thus, as the universally implicated Ideal, the rational Ground of all other possible self-definition, and " eternal creation" is a fact: all is real through Final Cause. The created, as well as the Creator, creates. Self-activity that recognises and affirms self-activity in others, freedom that freely recognises freedom, is universal: every part of this eternally real world is instinct with life in itself. Each lives in and by free ideality, the active contemplation of its own ideal; and this ideal embraces, as its essential, prime, and final factor, the one Supreme Ideal.

Here it is worth while to digress once more, to take an exact account of the nature of this proof for the existence of God. Those of you at home in the history of philosophy will hardly fail to notice that it is simply what the ontological argument of Plato, Augustine, Anselm, and Descartes becomes when taken in the light of the system of coexistent free minds - the argument so seriously impugned by Kant, and so vainly striving after rehabilitation in the monism of Hegel and his school. For it is the proof of God directly from the idea of God as the freely posited implicate without which no self-active or individual mind can define itself and posit itself as real. But this logically necessary connexion (i.e. connexion put 
by the pure spontaneity of each intelligence) between the idea of each mind and the idea of God, while leading to nothing if it stands by itself, leads inevitably to the reality of God as soon as the reality of any single mind is assured.

Now, the reality of each individual mind it is impossible to question, as Descartes has sufficiently shown; for every effort to question it presupposes its truth. Though I were to keep on saying forever that I doubted my own existence, yet every time I said it I must be a thinking life to make the statement possible. Underneath every doubt of thinking there lies, as a positive fact, the thinking that floats the doubt: so the more persistent the doubting, the stronger the proof of a real selfconsciousness. The inevitable connexion between the $i d e a$ of any single consciousness and the idea of God being given, this dialectically demonstrable existence of the self brings with it the actual existence of God. Here we have the real analogue of Descartes's famous illustration of his form of the argument by the necessary connexion between the idea of a mountain and the idea of a valley: if the mountain is shown actually to exist, it follows resistlessly that the valley exists too. Descartes, however, instead of connecting the idea of God with the idea of the self, made the slip of connecting the idea of perfection with the idea 
of existence, so that his argument runs down into the vapid truism: If perfection exists, then it exists; or (since perfection means God), if God exists, then he exists.

It is certainly the more curious - in fact, it is astonishing - that the great Frenchman should have tripped just here, as he was so securely in possession of the dialectic proof of his own reality, and as, more than once in his Meditations, he also comes squarely upon the implication of the idea of God by the idea of the self. It was criticism exactly pertinent, when he pointed out that the defect in Anselm's form of the argument was its connecting only the idea of existence with the idea of perfection, without attaining to any actual existence at all, and that the argument needed supplementing in the light of the Cartesian "criterion," - the principle, namely, that a necessary connexion between ideas carries with it a like connexion of the corresponding things, so that when the existence of one is established, the existence of the other inevitably follows. But in selecting perfection and existence as the connected ideas, he overlooked the awkward fact, that, in the case in hand, the existence of the perfect was the very point to be proved.

The argument which we have succeeded in working out, on the contrary clearly avoids this 
fallacy. It runs: The idea of every self and the idea of God are inseparably connected, so that if any self exists, then God also must exist; but any and every self demonstrably exists, for (as apud Cartesium) the very doubt of its existence implies its existence; and therefore God really exists. In parting with it, let us not omit to notice that the argument is nothing but the common one upon which we always proceed when we conclude there is any real mind other than our own - that we have fellow-spirits, like ourselves distinct from God. The validity of the process, which in the case of our fellow-men we all so instinctively perform, and with such unhesitating conviction, rests in every case alike upon the same universal implication of each mind with a world of others. Our self-thought being is intrinsically a social being; the existence of each is reciprocal with the existence of the rest, and is not thinkable in any other way. We all put the fact so, each in the freedom of his own self-defining consciousness. The circle of self-thinking spirits indecd has God for its central Light, the Cynosure of all their eyes: he is if they are, they are if he is; but the relation is freely mutual, and he only exists as primus inter pares, in a circle eternal and indissoluble. 
To resume now the main thread of our discussion : We have reached a proof of God from his very nature as central member in the world of freedom, and let us realise how genuinely divine his being is. $\mathrm{He}$ is verily a God unchangeably adorable, because he subsists in and through his free recognition of his complemental world of free associates, and only so subsists. In this free eternity, he is therefore in literal truth -

That God who ever lives and loves,

One God, one law, one element, And one far-off divine Event,

To which the whole creation moves.

For he alone loves, who, by his spontaneous ideal, has for his objects beings possessing the freedom which is his own bliss. He alone loves divinely, who accordingly subsists as the purely ideal Goal, the final cause or "divine Event" of their being; divine, because the Goal is left to be freely recognised, and put as ideal, by the self-defining act of each soul itself, and is not produced nor enacted upon it by any causation that constrains. God is in his proper Heaven, is no mere Maker, no player of the poor rôle of Omnipresent Meddler; and so each soul has all its life, at source and in settled destination, from love and in love - love that "casteth out fear," even the solemnising fear which awe is, and that thrills only to the beauty and the joy in God's 
perfection of love. ${ }^{1}$ Love, too, now has its adequate definition: it is the all-directing intelligence which includes in its recognition a world of beings accorded free and seen as sacred, - the primary and supreme act of intelligence, which is the source of all other intelligence, and whose object is that universal circle of spirits which, since the time of the Stoics, has so pertinently been called the City of God. Its contemplation of this sole object proper to it was fitly named by Dante and the great scholastics the Vision Beatific.

But now to our next point. You will here be prone to say, If this is theism, it is surely - is it not?a universal theism, not monotheism. Why isn't it simply polytheism on an infinite scale? - an infinitotheism, an "apeirotheism"?"2 And I shall have

1 "The abasement of the individual before the Divine Being is really a sort of pantheism, so far that in the moral world God is everything and man nothing. But man thus abased before God is no proper or rational worshipper of him. There is a want of proportion in this sort of religion. God who is everything is not really so much as if he allowed the most exalted free agencies to exist side by side with him." - Professor Jowetr, commenting on the De Imitatione Christi, in his Life by Abbott and Camplell, vol. ii, p. 151. London: Murray, I 897 .

2 So the lamented Davidson called it, coining a name out of \& $\pi \epsilon \iota p \circ \nu$, the Greek word for the numerical infinite, - Dr. Thomas Davidson, of New York, a Scot by birth and training, but an American by choice and adoption, who passed untimely away in the autumn of 1900 , leaving unfinished so much of needed work in classical and medixval philosophy. 
to reply: No, you are quite as wrong this time as you were when you called the free system atheism. The system of freedom is genuine monotheism, and the only genuine. All the members of the eternal world except God freely posit themselves as not God, in freely positing God; and God, in positing himself, likewise posits them as not himself. Moreover, this difference from Deity is thought by each spirit's purely thought-put - and therefore freeexclusion of any alternative, as a difference that is defect, the active maintenance or the passive acceptance of which would be $\sin$.

For inasmuch as its characteristic difference is by each spirit thought against the Ideal who is absolute Perfection, the Unity of all possible perfections, all difference from this must include some degree of imperfection, self-posited in the very being of each self-definer. The active consciousness of each is therefore really answerable for the presence of this in his being, but also answerable, by the terms of its being and his, for the rational control of it: answerable, just because the free self-definer is himself the source of it, and yet by his total nature, which eternally contemplates and mirrors God, transcends it. On this ground, the absolutely singular and unrepeatable personality of each soul lies in the exactly identical manner, one and only, in which his thinking differentiates him (I) from 
the absolutely perfect self-thinking God, and (2) from every other soul, which, like himself, is differenced from God by a deficiency absolutely peculiar. ${ }^{1}$

In fact, the personality of every soul lies precisely in the relation - or ratio, if we please so to call it between that genuine infinity (self-activity) which marks its organising essence, and the finitude, the exactly singular degree of limitation and passivity, to which the infinity subjects itself in defining itself from God. Thus every soul, though indeed, in the unifying whole of its nature, of the divine kind, and of inextinguishable free-infinity, nevertheless carries in its being an aspect of negation to its divine nature, and simply by the operation of its self-thought idea must realise its eternal freedom in a way that differs from God's way in kind.

For the consequence of this individualising selfdefinition by defect or negation is this: Embraced within the total being of the soul there must be a derivative life, which we call its experience, or sensory being, arising from the reaction of the primal freedom upon the negating limit, or Check. $^{2}$ Accordingly the soul's existence, in this sensory

1 Here we come again upon the vast and unknown number of souls not God: there must be a soul for every really possible degree of divergence from the Perfect Ideal, and there is no present knowledge of the number of these degrees.

2 Compare p. 338 , above. 
aspect of it, has the form of an irrepressible conflict between the free reason, moving in response to its Ideal, and this actual antagonising Check. In other words, within the rational (or spiritual) whole man, lives the natural and partial, which is the product of his formal and efficient causation as a self-active life, operating in the light of his Ideal upon the object-matter, or material cause, supplied in the Check. But this union of two antagonistic natures in one individual whole is absolutely foreign to God, the eternal Sum of all Perfections. It belongs, on the contrary, to that non-divine order of existence which, for lack of a better conception and name, our historical theologies have called the "creature," and it therefore forms an inerasible distinction between the one member of the World of Spirits who realises its Ideal etcrnally, and all the other possible members.

We may render this matter clearer by a brief reference to a most important step in the history of philosophic thought. It is a notable remark of Aristotle's when beginning the criticism of previous Greek philosophy, that, while all philosophy must be a research of causes, and preceding philosophy had answered in a general way to this requirement, the schools had yet not been aware of the whole system of causes. This system, he adds, ought to include (I) the material cause, the "raw stuff," so to speak, or "contents," out of which reality is formed; (2) the 
formal cause, the principle of discrimination and arrangement, by which the material is kept from being chaotic, and instead is rendered intelligible; (3) the kinetic, or changing, or efficient cause, by which form is applied to matter, and one form is changed into another; and (4), most important of all, the final cause, the cause "wherefore," - the intelligible and recognised aim under which all the first three operate. Some schools, he continues, had used one, some another of the first three causes, some had used more than one, Plato had used all; but none had used all the four, none had hitherto employed the final cause.

True. But the great Stagirite might himself have gone a step farther: he might have stated the truth, for it is a truth, that the final cause is the originating and organising member of the system, and that all the other three causes arise from it, as well as act by virtue of it. That is, instead of being simply the most important kind of cause, it is the Cause of causes, and the only kind of cause that applies to the existence of primary realities such as minds.

Now, what we were really sceing, a moment ago, was how all this is true in the case of the mind that is non-divine. The operation of final causation, as involved in each spirit's idleal of itself as a thoroughly individuated contrast to God, introduces into the spirit's native infinity the non-divine defining Check: 
here is the beginning, the terminus a quo, of efficiency; here also is the germ of the material cause, the "matter" upon which the further display of effciency is to act. But by the final causation in the spirit's native contemplation of the Divine Ideal, the infinity or freedom reacts upon the Check: this reactive relation and its product constitute a matter or contents more or less formed, bearing always in some degree the impress of the original freedom that moves toward its ideal. Here, then, and in the henceforth endless recurrence of the action and the reaction, we have flowing from final cause - from the free attraction of the free ideal-(I) material, or object for the reaction of freedom; (2) the reactive efficiency, shown (3) in the appearance of form in the material, the form exhibited by the interaction of the spiritual and the natural. And we now recover, in this new light, the doctrine set forth earlier in this essay, that the whole natural world, or world of sense, is embraced uncler the world of the self-active intelligence - the world, as Kant has taught us to call it, of the pure reason, or intelligence a priori. This natural world, by the account of it we now get, must, as noticed already, ${ }^{1}$ be a scene of ceaseless conflict between its immediate or present form and the eternal or ideal form of the spirit. ${ }^{2}$

1 See p. 364 , above.

2 The foregoing account of what and whence Nature is, will of 
Nature is not, indeed, in itself sin; there is no guilt in its mere existence. It is simply part and parcel of the self-definition of the soul, and it has an affirmative as well as a negative aspect, a possible movement upward, toward the free spirit's Ideal, as well as its primary tendency downward and away from this. But it carries with it the risk of $\sin$; for in admitting the negative principle of defect into its being, the free consciousness opens the possibility that in the antagonism between the two tendencies in its nature it may side with the negative, and not keep alert to the affirmative and its ideal Spring. It may lose, for the time being, its response to the Divine Ideal, and, as Plato says, become ensnared in the natural. Hence, so far as concerned with its merely natural life, it is liable to become slothful, an ignava ratio in a real sense, to repose inert in the form that belongs to it at any given date, and to say, as Mephisto craftily hopes that Faust may be tempted to say of some passing temporal moment, and so be lost, Verweile doch, du bist so schön!-

$$
\text { Oh stay! thou art so fair. }
$$

course suggest manifold difficulties to the critical mind, difficulties that particularly concern the usually assumed single-unit character of Nature, the possibility of a communal natural life for souls, and especially the possibility and the meaning of wedlock, birth, heredity, and social liability, or "imitation." To go here into these would lead us too far afield. I will merely say that they are no greater than those involved in any system of idealism, and that I hope to deal with them in another place. 
Or passing to deeper decline, it may out of this sluggard self-love advance into aggressive struggle to maintain it, falling with hate upon the activities of others whom it finds, or assumes, to interfere with its ease.

This empirical volition seduced by the vision of the sense-world, be this sensual or malicious, or be it ever so much raised above the brutal, - this willingness to stay where one temporally is, to accept the actual of experience for the ideal, the mere particular of sense for the universal of the spirit, the dead finite for the ever-living infinite, the world for God, - this is exactly what $\sin$ is. ${ }^{1}$ It may take either of two forms, according as the sinking into sense directly involves only the violation of the spirit's own selfreverence or the graver assault upon the sacredness of others. In either case it is dishonour of God. The risk of it lies in the nature of our being, goes back to the conditions of our existence, of our selfdefinition in freedom; is constituent in our freedom as this is defined against the freedom of God. This

1 Some readers may feel that this account of $\sin$ is defective because it seems to them to omit the characteristic factor of selfishness. But it does not in fact do so. The statement that sin is the choice of the actual instead of the ideal, the world instead of God, is more comprehensive, but is, as directly made, merely formal. In the light of what has preceded, however, it is plain that the real meaning, contained indirectly' in this formal contrast between God and the world, is that the ideal is universal love, and its neglect a violation of this. 
risk is therefore "original" in a sense even deeper than that in which traditional theology makes sin to be original, - though we too have to say that $\sin$ is original, in the sense that it is a fact which comes about by reason of this trait in our self-origination. It is a fact, that is to say, directly connected with our self-differencing reality; it concerns the explanation of our very existence, roots in the origin of the natural man, and follows from that as surely as that is implied in the very nature of our free being.

Here at length we find what is meant by the union of freedom with determinism in the life of every spirit. The union consists in the fact that both determinism and freedom mean the self-determination of the conscious being in the light of his twofold ideal,- his eternal apprehension of the Supreme Ideal in God, and his ideal of himself as a thoroughly individuated being, inherently selfdifferenced from the Divine Ideal, yet essentially self-related to it, - in the great total of his existence moving in response to his contemplation of it, and therefore freely moving.

In our union of the actual and the ideal, we find, too, the explanation of that consciousness of altcmative which prompts us to say of every event in our moral experience, especially of any event of wrongdoing, that it might have been otherwise-we 
might have done right instead of wrong. The question of our effectual freedom in the world of experience is simply the question whether we have not a living source of right within us, our own eternal choice, of fuller flood than the countercurrent tending to arrest it. But, on the other hand, the presence in us of this essential counterstream brings the constant risk that the movement in response to the absolute Ideal may in the timeworld actually suffer arrest. Nevertheless, this arrest cannot annihilate the potential for goodness that lies in our eternal vision of the Supreme Ideal. That lives on; and our sin is, that we fail in our time-world to avail ourselves of it, because we temporarily lose experimental realisation of it, and consequently become absorbed in that side of our life which arises directly from our principle of difference - our difference from God.

Our sense of alternative is the sense that the transcending view which connects us with our Divine Ideal, and which moves us evermore toward harmony with that, is really ever-living, and so affords resources to reduce our defective difference and carry us beyond all temporal actualities. So that when we halt in any stage of these, and act as if our aim and object ended there, and we were there fulfilled, we know that this is false. We know that we have belied our real being, that in our true 
nature is a fountain out-measuring every possible actuality, that therefore we might have done differently, and that consequently we have contracted guilt-guilt, not simply before some external tribunal, be it even God's, but guilt before the more inexorable bar of our own soul.

Assuredly, then, we may dismiss the charge that the free system is a polytheism. Not a single member of it except God is identical with God, either in existence or in character. All but God provide in their own being the liability to $\sin$, and when once, owing to their sins already, they present in their natural circumstances a character sufficiently defective, then the natural law of cause and effect operates, and they are certain then to sin yet more; though not even this certainty in the connexion of their evil experiences is predestined upon them by any "decree" of God, or by any other efficient act of God, for God has no efficient relation to their being, nor they to his. The certainty issues from their own freedom, which is responsible not only for the causal connexion between their antecedent and consequent states, but directly for the existence of the antecedent. It is therefore a certainty for which neither God nor any vague "nature of things" is responsible at all. The presence of it in their life, and still more the presence of the liability from 
which it springs, and of the primal self-defining Check upon perfection, out of which this liability arises, discriminates every soul from God, indelibly and forever. God is God alone, there is but one God, and the souls are at best but his prophets.

\section{VII}

But now we come upon another objection, which I judge will be the last you can raise. You will say, I suspect, that this world of freedom, self-equipped for $\sin$, is indeed a world which "lieth in wickedness," that in truth there is no real hope of good in it: it is a world of inherent and inexpugnable wrong, and not only damnable, but in fact already damned. Yet stay a little: you at least, like your classic spokesman Professor James, - to whose essay on the "Dilemma of Determinism" we have been referred, in your list of reading for this year's studies, as the authority upon freedom, - you at least are souls that have no complicity with the accursed thing - you have renounced it and its evil ways altogether! Still, you and he are certainly of it; and so are all men who have attained in their temporal consciousness to this mighty "judgment of regret," as he poetically calls the sweeping condemnation of the world. You and he and they are of its process, quite as surely as his Brockton murderer, quite as surely as all 
other sinners; quite as surely as those profound and indeed awfully tragic examples of $\sin$ in whom as yet, looking at their temporal life merely, no one can discover any signs of their higher spiritual self. The world, then, with your renouncing and penitential histories in it, cannot be so altogether lost and worthless.

As you have all supplemented the choices of $\sin$ with your purifying "judgments of regret," do not, I beg you, stop there, but add to them the judgment of consolation. See to it that you do not forget, as Professor James at times seems to have forgotten, how the judgment of regret, which arises out of the spiritual freedom of the soul, is in due course of that freedom attended or followed by the judgment of remorse, by the judgment of repentance, by the judgment of reform. These are all in the fountain of the spirit, and flow from the great deeps of the freedom whose shallower expanses make possible the sin. In their sum, they make up for the sinful world a judgment of atonement. The infinite of the soul is mightier than the finite in it. The freeinfinite of the intelligence will go on in the conflict of transforming the finitude of the natural life; will go on to victory ever more and more. It may be, as was said before, by paths never so dark and devious, or now and again even retrograde; it may be by descent with the natural into the nether pit of $\sin$ and its self-operating punishment; but onward 
still the undying free spirit goes, and will go, secure in its own indestructible vision of its eternal Ideal, secure in the changeless light shed on it by the changeless God.

For it is assured of immortality - an immortality that some day, be the time here or be it in the hereafter, must attain to life eternal, to the established dominance of the spiritual over the natural. Nevertheless, the perfection of the "creature" lies just in this never-ending process of victory. Always it must preserve its own identity; must be everlastingly, as it is eternally, divided from identity with God by its own defining negative principle. Thus its life shows its peculiar perfection by the mode in which or, if you will, the rate at which - it surely, though slowly and with heavy toil, heals its own inherent wound. Two forms of self-active being there are, two only: that which is eternally without defect and invulnerable; and that which holds defect in its very nature, but moves toward making itself whole by its etcrnal power of "life in itself." The one is God's infinity; the other is the infinity of manthe infinity of the "creature," the infinity that embosoms finitude and evermore raises this toward likeness with the eternal.

Here our inquiry comes in sight of its close. While I hope that I have now answered your whole 
question, and have shown how freedom and determinism, reconciled in the universal presence of rational activity, do surely lead toward universal recovery from moral evil, it would be no more than natural were you to ask, In just what does the reconciliation after all consist? In answer, I may sum up the whole matter in the following way.

Freedom and determinism are only the obverse and the reverse of the two-faced fact of rational selfactivity. Freedom is the thought-action of the self, defining its specific identity, and determinism means nothing but the definite character which the rational nature of the action involves. Thus freedom, far from disjoining and isolating each self from other selves, especially the Supreme Self, or God, in fact defines the inner life of each, in its determining whole, in harmony with theirs, and so, instead of concealing, opens it to their knowledge - to God, with absolute completeness eternally, in virtue of his perfect vision into all possible emergencies, all possible alternatives; to the others, with an increasing fulness, more or less retarded, but advancing toward completeness as the Rational Ideal guiding each advances in its work of bringing the phenomenal or natural life into accord with it. For our freedom, in its most significant aspect, means just our secure possession, each in virtue of his self-defining act, of this common Ideal, whose intimate nature it is to 
unite us, not to divide us; to unite us while it preserves us each in his own identity, harmonising each with all by harmonising all with God, but quenching none in any extinguishing Unit. Freedom, in short, means first our self-direction by this eternal Ideal and toward it, and then our power, from this eternal choice, to bring our temporal life into conformity with it, step by step, more and more.

And though in this real freedom which is inherently rational there is that determinism, that definiteness, which issues from guidance by the universal rational aim, this very determinism nevertheless, matched as it is against the counter-definiteness in the defective phenomenal side of our life, gives rise to that ever-recurring Alternative, that chance for the experience of choice, which is so often mistaken for the whole of freedom, but is only a derivative part of it. A greater part, even in this region of experience, is the power in our consciousness of the Ideal, the power of our eternal freedom, to decide the temporal choice in its own direction. Thus every $\sin$ is in its central nature a self-dishonour of our freedom, a self-degradation and self-enslavement. And still this freedom, as originative and whole, is immortal, is imperishable, and has abiding might to prevail and to rescue.

So much for a summary of the solution. You must not omit to notice, in parting, that it has not been 
effected by means of any sort of "soft" cleterminism, -as, with a transfer of Professor James's stinging nickname, we may call the sentimental optimism that ignores the world's wickedness and misery. On the contrary, the result has been reached by means of a determinism whose way is the rugged and even tragic path of bitter discipline, through sin and punishment and remorse, through repentance and victorious good works. Beyond sin and the possibility of sin, there lies in the system of free spirits, as the very key to their freedom, this eternal Atonement. It works by the ceaseless chastisement which is freedom's school for its own actualisation in the world.

Let Professor James supplement his Judgment of Regret by this Judgment of Atonement. For there is no "dilemma of determinism," such as he has so forcibly depicted, if the determinism in the world of sense is itself a partial effect of the self-determination of the free beings acting in and on that world, and is subject to continual transformation and correction by the undying source of freedom in eternity. He would have us believe that determinism hangs in a fatal balance between pessimism on the one hand and what he rightly calls by the stigmatising name of "subjectivism" on the other - the revolting theory that the aim of life is, not doing good and avoiding wrong, but getting the deepest knowledge of the greatest sum of the most varied "experience," of 
base and of high alike and indifferently; is eating insatiably of "the tree of knowledge of good and evil," simply for the eating's sake. We must either maintain our judgments of regret, he says, and so pronounce the determinist world accursed to its core, or else quash our regrets and end in a fatuous optimism which confounds good and evil by reckoning evil really good - "whatever is, is right." The latter horn of the dilemma, he holds, can only be taken in earnest if "subjectivism" is true; and this, what unharmed conscience can endure?

But if determinism is but one phase of the free life of each spirit, laying down law upon the world which is the field of its possible higher activity, then the dilemma is dissolved. The pair of alternatives do not then exhaust the possibilities : there is at least one other supposition open. Not mere knowledge of good and evil, for its own shameless sake, but knowledge for the sake of action, and resulting now in penitent and now in benignant reform, is then the genuine alternative to pessimism; and this moral use of the evil that freedom causes is the atonement, the justifying atonement, with which the profounder freedom that wells from the eternal fountain of the spirit expiates the surface-freedom's sin. The atonement is in eternity and from eternity, quite as really as the provision of an apparatus for the sin. It passes thence upon the ceaseless process of the natural life. Thus 
in the course of ages here and hereafter it is sure to be effectual. But the way is hard, the road of discipline and penitence is long, is across deep and appalling abysses, with many a frightful fall to their bottom, and of this tragic side of our being it is strictly true that -

The moving Finger writes, and having writ

Moves on : nor all your piety nor wit

Shall lure it back to cancel half a line,

Nor all your tears wash out a word of it.

Here speaks the fact of Fate-the changeless bond among experiences, the "irrevocable fixity of the past" embosomed within our very freedom: we "sow in Atê's fields" and reap the fitting crop. Remorse, remorse! But Fate is the indispensable means to freedom in a shifting world of experience, is therefore a consistent product of freedom, and the passing over of the "judgment of regret" into this judgment of remorse, stirred in us by the sense of Fate, is exactly what makes in our time-world the signal of our eternal freedom, and points to the coming better judgment of repentance and reform. We cannot, indeed, recall the past that is behind any specific present; but it is only a past thus arbitrarily isolated that is fixed. The real past is a flowing wholc, and we are forever pouring the future into the flood, through the gate of the present. Our past is really always changing, and it is we who initiate the 
change; and so the past, though no part of it can be recalled, is perpetually being re-created and transformed, now for the worse, now for the better, as its whole goes on unfolding. But the whole, it is within the compass of our freedom to bring into fuller and fuller harmony with our active vision of our Ideal, in which at source the freedom consists.

This is the life of the responsible universe, the World of Souls : its freedom is only existent in terms of GoD, who, despite the Inexorable Finger, hears in eternity the sigh of the penitent, and accords to him eternally an indwelling fountain of salvation, from "before the foundation of the world." Thus does $\mathrm{He}$ "still the cry of the afflicted"; thus age by age, to ages everlasting, "wipe away all tears," and grant to each sinning and sorrowing spirit the bliss of repentance consciously free, a redemption that arises out of the soul itself, the merit of virtue that is its own, and a peace that is indeed within. 
APPENDICES EXPLANATORY AND DEFENSIVE 



\section{APPENDIX A}

\section{THE ESSAYS IN THEIR SYSTEMATIC CONNEXION ${ }^{1}$}

I PURPOSE here to supply what many readers appear to have been at fault over - the clue to the parts played, severally, by the essays of this volume, in setting forth the system they illustrate. And I may well enough begin by reiterating the statement with which I first preceded them - that, disconnected as their topics seem, they are still all united by a single metaphysical aim. This is the establishment, chiefly upon Kant's foundations, of a new idealistic philosophy, in extension and fulfilment of Kant's own, though also taking impulse from the views of Aristotle and of Leibnitz. This new idealism seeks to rehabilitate the moral individual in his proper autonomy by seating him in the eternal world; that is, in the self-active, and therefore absolutely real, or noumenal, order of being. It thus stands opposed (I) to the current Monism, whether of Naturalism (Spencer, Haeckel, etc.) or of Absolute Idealism (Hegel and the Neo-Hegelians), and (2) to the older Monotheism, with its dualism (the eternal Creator, the temporal creation) of literal production out of nothing, by miracle. In confronting these older systems, the new idealism seeks to revindicate the Personal God, the Moral Immortality, and, above all, the Moral Freedom, which together formed the chief object of Kant's philosophical concern. But while Kant

1 Reprinted, with slight changes and some additions, from Kantstudien, Band viii, Heft 2-3. 
sought to give these common objects of religion and philosophy a lasting foundation upon the practical as contrasted with the theoretical reason, these essays aim at restoring them to a theoretical basis. The purpose is, to exhibit the theoretical nature and functions of the moral consciousness itself, thus closing the chasm left by Kant between his noumenal world of morality and his phenomenal world of science. And whereas the idealistic systems that succeeded Kant all took refuge in an immanential and consequently monistic view of God's relation to man and Nature, thus wrecking all autonomy and thence personality itself, the essays seek to restore the ruin by a return, on important points, to Kant's view ; namely, that God, relatively to all other minds, is transcendent - is a distinct centre of consciousness, not included in any of theirs, and not including them ; that every mind, relatively to any other, is transcendent; and that the principle of moral autonomy thus involves a strict Pluralism, as the right account of the world of absolute reality, which is the world of minds. Hence (at this juncture passing beyond Kant) they conclude that the only causal principle operative in this noumenal world, linking God with the other minds, and all minds with each other, in an organic Real Logic of being and of purpose, must be Final Cause; which, consequently, henceforth reduces Efficient Cause to a place of derivation and subordination, making it hold only from minds to phenomena, and, in a secondary sense, from one phenomenon to another, or from one group of phenomena to another. Thus an immanential relation still obtains between the system of minds and the system of Nature, quite as in the transcendental idealism of Kant. But Subjective Idealism is hereby overcome, and Social Idealism, which finds objectivity in an a priori consensus of all minds, takes its place.

In Essay I, this result, so far as concerns man and Nature, is worked out by a critique ( $\mathrm{I}$ ) of Empirical Evolutionism 
(school of Spencer) and (2) of Pantheistic Idealism (Hegel and his later followers, English and American). The basis for this critique is secured by reaffirming Kant's doctrine of a priori knowledge, and proving it afresh in face of the modern attempt to explain it away by acquired association, natural selection, and heredity. It results that the individual mind, being thus a system of the very conditions prerequisite to an evolving process, cannot be the product of such process, whether this be regarded as the effect of the omnipresent "energy" of an "Unknowable" or as the expression of the omnipresent "meaning" of an "Inclusive Self-consciousness." On the contrary, it is now seen to be itself at the basis and origin of things, a member of the world of self-causes.

In the course of Essay II, this critique of Monistic Idealism is carried out with greater fulness, especially in exposing the fallacy of the frequent claim that modern science trends resistlessly to this type of monism.

In Essay III, idealism of the thoroughly plural and individual type - Personal Idealism - is reached, as the result of the dialectical self-dissolution of pessimism (Schopenhaver, Hartmann), materialism (Dühring), and agnosticism (Lange). In this self-supplanting of Lange's view, the Kantian restriction of knowledge to the field of phenomena gets at length dissolved. The basis for moral autonomy is definitively established by this self-sublation of scepticism passing to its extreme; the freedom of the rational individual is assured in this settlement of the noumenal reality of his knowledge. The transcendent metaphysics of the essays, in opposition to the merely transcendental prevalent since Kant, is thus rested upon critical foundations, and Critical Idealism attains its proper fulfilment.

In Essay IV, we discover the essentially creative character of Art, the field par excellence of the triumphs of non-divine intelligences, and thus come, as if by a new and unexpected $2 \mathrm{C}$ 
path, once more upon the intrinsic autonomy of the rational individual.

Essay $V$ then deals with this autonomy in its profoundest form, as presented in the problem of religious belief. The issue between Authority and Conviction is argued out to its purest terms, and individual autonomy is established, first indirectly, by refuting the theory of Authority, on the ground (I) of its self-contradictions, (2) of its inability to produce its Divine Authentication, (3) of its antagonism to the essential drift in the historical development of religion, as this shows at full flood in the Christian Consciousness, measured by the teaching, not of Scripture or of Church, but of Jesus himself. Direct proof then follows, by showing that the tacit logic of science, though not indeed its results, - science, the field of the individual's greatest triumphs as knower, - surely presupposes (I) the reality of a society of minds in rational consensus, and (2) the reality of a Perfect Mind, or God. Free intelligence thus means conscience and dutiful self-control; and vice versa.

In Essay VI, the unconditional reality of the individual and the essentially social (i.e. moral) nature of his primordial consciousness are proved by a still closer and fuller vindication of Kant's arguments for the reality of our $a$ priori knowledge. This, as rendering each mind causa sui, thus placing it in the world of absolute causes, is then applied to the proof of individual immortality. In the course of the argument a solution is offered, on the basis of the Kantian theory of Time, of the puzzle presented in the modern doctrine of "psychological parallelism."

Finally, in Essay VII, the metaphysical significance of moral autonomy is still more clearly exhibited, and is carried out in its full bearing upon the nature of Divine causation. Determinism as extraneous predestination, Freedom as inner caprice, are alike set aside, and a new idealistic 
conception of both Freedom and Determinism is set forth, as the aspects, obverse and reverse, respectively, of the complex conception Self-determination, when this is seen to be simply the self-definition inseparable from self-consciousness. It is then shown that moral autonomy, as such selfdefinition by each mind, not only involves a contrast to others, and therefore a recognition of them (in fine, the essentially federal nature of a self, the presence of a public and universal phase in every conscious life), but also the distinction between the noumenal and the phenomenal, the eternal and the temporal, aspects of being; hence, the seating of every moral agent in the eternal world. The consistency of this eternalising of the individual (I) with Theism, and (2) with a purified Monotheism, - in fact, rather, its necessity for both, - is then shown, by means of $(a)$ a new argument for the reality of God, akin to the historic Ontologic Proof, but freed from its defects, and (b) a new and rational interpretation of "creation," as a metaphor symbolising the eternal office of God as Final Cause (i.e. at once Conditioning Standard and Goal) in the entire world of minds. By the operation of this Final Causality, each mind other than God involves in its self-definition a contrast to God as well as an attraction toward him. Each nondivine mind thus gives contributory rise to the phenomenal world of changeful consciousness - the world of defect, of natural evil, of possible moral misdeed. Here Freedom, which in its eternal basis is simply spontaneity, the native response to the eternal vision of God and the other intelligences, takes on the added traits of (I) empirical alternative, and (2) powver to decide this in favour of the eternal Good, by a resort to the changeless fountain of reason which every spirit is at core.

Thus the theme of Personal Idealism - of an eternal world of many rational beings, all self-active, all arbiters of their own destiny and so alike morally responsible, yet, in 
the vast round of their combinative being, all harmonised by their coexistence with God and their native attracting apprehension of God's nature - grows from one to another of the ascending evidences for it, as the book advances from the first essay to the last. 


\section{APPENDIX B}

\section{THE SYSTEM IN ITS ETHICAL NECESSITY AND ITS PRACTICAL BEARINGS ${ }^{1}$}

I HAVE called the system set forth in this book Personal Idealism because, as I undertake to show, it is alone consistent with the existence of a world of genuine persons, including a personal God. My object here is to give a brief summary of it, and then to point out whatever importance it may have for the aims of the higher ethical life.

The system is closely affiliated with another, advocated by the late Thomas Davidson, and called by him Apeirotheism; that is, the doctrine of a divine nature, or ideal rationality, distributed in an indefinite number of individual minds. I mention this affiliation, because, although it is unmistakable, it came about from studies entirely independent, and without collusion or even conference. The agreement, so far as it exists (and it by no means exists throughout), must be explained as an encouraging coincidence, resting on a common connexion with the same foundations in the history of previous thought: two investigators, working quite apart upon a common problem, without any knowledge by either of what the other was doing, have come olt upon a result in the main the same. And it is of great interest to note that a third thinker, remote from both of us, Mr. McTaggart, of the University of Cambridge,

1 Reprinted, with omissions and minor alterations, from the International Journal of Ethics, July, 1903. 
has reached a kindred view, closer to Mr. Davidson's, in fact, than my own.

This common result is the doctrine that the world of absolute reality is a world of minds, each eternal in the sense of being immutably real, self-active, and self-determining; none of them is a derivative, or mere result, of the efficient causality of any other being whatever, though all coexist in a mutual recognition intrinsic to the nature of each. Thus, by their essential freedom, they constitute a moral order, in the profoundest and only proper meaning of that phrase.

But beyond this base-line of agreement, the system as it has developed in my own mind diverges in important ways from that reached by Mr. Davidson. In the first place, I have to dissent from the view recorded in his title of Apeirotheism: I am unable to regard as divine any of the individual minds that he took account of ; they are, to me, all of a type which I should describe as human, in contrast to divine. In the second place, I find it necessary, in order to complete the logical circuit of the whole world of minds, to recognise in it a member to whom the name of God, as designating the absolutely realised perfection of Personality, is alone adequate. This supremely personal Being, this one and only God, my honored friend did not recognise, because, like so many of the members of the Ethical Societies who sympathised with his view or were directly influenced by his reasonings, he found neither necessity nor warrant for it: he could see no propriety in calling by the name of God any one of the eternal society of minds rather than another.

I must not burden the present pages with any argument upon the point of difference between myself and my lamented friend. Here I merely wish to set the difference forth, and to call attention to it as vital to the view I name Personal Iclealism. Readers who care to follow up the 
subject, I must refer to the full discussion of the matter in my fifth and seventh essays.

In accordance with this difference, I aim to show that the eternal world is a world of minds falling under the two heads of (I) God, and (2) non-divine consciousnesses who yet in their eternal aspect constitute with God and with each other an indivisibly harmonious whole. The characteristic difference between God and all the other minds, I find to lie in the possession by the latter, and by them only, of a sensuous consciousness, rising everlastingly, through a serial being in time and in space, toward a complete harmony with the eternal ideal that is the changeless central essence of each mind, and whose proper and only real object is God. In short, the new system refers the entire being and linkage of Nature to the minds other than God, so far as concerns its efficient causation. God is not the creator, in the sense of the literal producer, or First Cause, of any mind as such, nor even of that aspect in the conscious life of other minds which we know as their merely natural being, whether of psychic states or of physical processes. It is here that the system parts company with such an idealism as Berkeley's, and takes part with that of Kant, or, still more closely in some regards, with the earlier theory of Aristotle.

As Final Cause, however, or attracting Ideal, God has, according to this view, absolute and immutable living relations to the being of all other minds (as these also, reciprocally, have to God's own being), and likewise to the being even of Nature; so that Nature takes its supreme law, the law of Evolution, from God's existence as the eternallyrealised Ideal of every mind. Hence, as Final Cause, God is at once (r) the Logical Ground apart from which, as Defining Standard, no consciousness can define itself as $I$, nor, consequently, can exist at all; and (2) the Ideal Goal toward which each consciousness in its eternal freedom 
moves its merely natural and shifting being, in its effort after complete accord between the two phases of its nature, the eternal and the temporal, the rational and the sensuous.

Thus the system teaches that the two supreme Divine Offices celebrated in historic theology, Creation and Regreneration, have alike a most real meaning, though indeed not a literal but only a metaphorical one. It invites theology to realise the pressing need of now revising and correcting the conception of Creation, in a similar metaphorical sense to that in which the conception of Regeneration has now for some time heen reformed: as the latter is now by leading theologians interpreted as the influence of a consciously apprehended ideal truth, the purely final causation by which the Holy Spirit gains its ends, so let the former be for the future read in the corresponding sense of a final causation alone. Between mind and mind, between God and all other minds, there is no causation but Final Cause; the sole realm of Efficient Cause is the realm of Nature, whether physical or psychic, objective or subjective; efficient causation operates from the non-clivine minds to their natural (or phenomenal) and sensuous contents, or else, in a secondary manner, between the serial terms of these. Hence God is in no wise responsible for the evil, either natural or moral, that we find in the world of experience, but only for the good that gradually arises in it; and even for this good, only in chief, and not solely; for to every mind that promotes the good and helps to check the evil belongs indefeasibly the credit of his part in the increase of good and the decrease of evil. The evil in the world is the product of the non-divine minds themselves: the natural evil, of their very nature; the moral, the only real evil, of their failure to answer to their reason with their will.

This brief sketch of the view must suffice as preparation for the main task which I here have in hand; namely, to 
exhibit, with some convincing detail, any advantages the system affords to the aims of moral life. To do this I must proceed from the foregoing outline in two directions: (I) I must clearly show the moral need for the system, by exposing the moral inadequacy of all the other current philosophical schemes, even of the many current idealisms, thus bringing out more exactly, on the way, the precise and pertinent points in which the system is new; and (2) I must then collect the several items in which the system displays its worth for those who care supremely for moral endeavour.

\section{I}

That the historic systems of philosophy, not only those which have been directly influenced by the historic systems of religion and theology, but also those which have originated more or less in opposition to these, or in correction of them, are unequal to meeting the conditions essential to the existence of a moral order and to the possibility of a moral life in individuals, will appear plainly upon a brief analysis of their leading conceptions.

They are every one of them (with the single exception named below) coloured through and through with creationism, - at least tacit, and generally conscious and deliberate, - a term by which, taken literally, I conveniently designate the reference of all realities to a single First Cause, conceived as explaining existence by being their efficient, or originating, or producing Source. In other words, from the fourfold system of causes set forth by Aristotle - Naterial, Formal, Efficient, and Final - they all select Efficient Cause as the category which is to be primordial in their scheme of explanation; then they have this Efficient Cause produce the Material, and mould and change it by the Formal, in answer to the Final as its purpose. In proceeding so, they no doubt follow a universal historic impulse of the human mind, unpurified by sufficient self-criticism ; for this impulse 
displays itself in all the varions systems of religion and their accordant theologies.

This theme of literal creation is so inwrought into the structure of historic thinking, that it will recuire a long struggle on the part of criticism to get rid of it. Through the influence of the Church and the philosophical schools, it may be said to have become in fact institutional, so that combating it is like fighting organised civilisation itself. Yet one can make the truth clear, that only by the dislodgment of it is the success of the leeper principle possible which is the real soul of civilisation, - I mean the principle of moral life, the life of duty freely followed.

If we examine the great historic systems, we see that with reference to this creationism they may be thrown into the following four main groups:

First, those that are either (I) the direct theological expressions of the post-exilic Hebraism which, taking occasion from the Eternal Dualism of the Parsees, and correcting it by a modified recognition of the Supreme Being of the older Orientalisms, taught a dualism of a monarchotheistic sort - of a Creator, and a creation summoned into existence at a certain date by his sheer fiat $\left(\epsilon . \sigma_{0}\right.$., the systems of Augustine, Aquinas, and Scotus), or else are (2) philosophical enterprises, undertaken in all rational good-faith, but silently engendered by the influence of this Hebraic doctrine even when they greatly modify it ( $c . g$., the systcms of Descartes, Leibnitz, Locke, Berkeley, the Deists, and, with all his protests, at the last pinch even Kant).

Second, those that for this dualistic and miraculous exercise of efficient causation, for creation ex nihilo, substitute the older but more rationally: continuous vicw of the immanence of the creation in a monistic Creator or Eternal Source, and thus carry us back into the current of pantheistic emanationism dating from primeval times. E.g., the systems of Erigena, Nicolas Cusanus, Malebranche, Spinoza, Fichte, 
Schelling, Hegel; with such later offshoots as in Spencer, Fiske, T. H. Green, the two Cairds, Bradley, and Royce, all tracing back, in the last resort, to the great Oriental philosophies of which the Vedanta is the type. Here, upon the whole, critical interpretation must place the general views of Plato and of Aristotle, the great fountain-heads of the manifold idealisms of the West. In this group belong, too, unless I quite misunderstand them, the systems of Dr. W. T. Harris, Professor Kedney, and Professor Macbride Sterrett.

Third, those that abandon every sort of consciousness as a First Principle, drop Final Cause from the list of causes, and so make Matter the producing source of every one of its forms, through the force supposed to be inherent in it or commanent with it. These are the manifold materialisns, atomic or other, from Democritus to Büchner, Vogt, or Dühring.

Fourth, those that repudiate the search into causes as baseless and futile. They demand that philosophy, to be sound, shall drop metaphysics as well as theology, and confine itself rigidly to observational and experimental science, merely describing with precision, though as comprehensively as possible, the facts of history and experience. This view is known as positivism, and bears but one noted name, that of Comte, though all the strictly sceptical systems have contributed to it, from the Later Academy down to Hume. In its own way, it frees itself from creationism utterly. But this way is the way of confessed and open atheism.

Considering these four groups with reference to their bearing on the possibility of moral action, we at once throw out the third and the fourth, as systems of confessed necessarianism, which do not even pretend to furnish any basis for individual freedom or for the pursuit of a rational aim (such as fulness of life in the whole spirit) from conviction and choice. On the ground either of positivism or of 
materialism, ethics can never, properly speaking, be morals. If it escapes fatalism of the hardest sort, with all the consequent hopelessness for most, it cannot avoid hedonism, nor, in the logical end, an egoistic and utterly transient and trivial hedonism.

We have to confine ourselves, then, in any hope of finding conditions adequate for morality - conditions adequate, that is, for the life of serious duty - to the first and second of our groups. But from the second, - the systems of efficient causation construed in terms of monism and immanence, - the self-determining individual is necessarily cancelled. All the particular beings involved in the being of the monistic Whole are but modes or expressions of the sole self-activity of the Whole; they have no activity really their own, but only a derivative operation, determined by the One. This is either openly confessed by the supporters of these systems, or, if they attempt to evade it, they are compelled to end in more or less concealed confessions of it, despite all their efforts. If anybody doubts this, let him attentively read Hegel on this question, or T. H. Green, the brothers Caird, and Professor Royce. ${ }^{1}$

The first group of systems, the dualistic (or literal) creationisms, have, to first impression, a certain appearance of providing for the possibility of freedom, and therefore of a genuine morality. For it seems nominally possible that a Creator by fiat might yet say: "Be, thou! - a nature with power to perceive and to judge, and with will to choose, unpredestined; I create thee rational, and leave thee untrammelled." But not to mention the complete contradiction of this which the usual theologies and other schemes of predestination introduce, from the need of organising the

1 Let the interested reader consult, particularly, Professor Royce's "Supplementary Essay" in the volume entitled The Conception of God (New York: The Macmillan Co., 1S97), in the chapter where he undertakes to deal with the question of the freedom of the individual. 
world-plan consistently with their monarchotheistic First Principle, it soon appears that creationism itself, even in this dualistic form (which does to some degree extricate, or appear to extricate, the creature from the embrace of the Creator), must logically exclude the possibility of freedom. For the Creator camnot, of course, create except by exactly and precisely conceiving; otherwise his product would not differ from nonentity. The created nature must therefore inevitably register the will and the plan of the Creator; and there is really no more escaping this under the dualistic scheme than under the monistic, where the consequence has been fearlessly drawn for us all, for all time, in the classic illustration of Spinoza concerning the moving stone, flung from the sling and coming to consciousness after the impulse. Aware only of its unimpeded movement, and not at all of the impelling start, this would of course imagine itself self-moving and free. But those who see whence that unhindered movement really comes, know better. They know how utterly predetermined are both its direction and its rate, by the One who gave it to be.

So much for the problem of Freedom. There is another, the solution of which is also essential to the working fulfilment of a moral life, - I mean the problem of Evil. T'his, our third and fourth groups are clearly unequal to coping with. They indeed have alike no conscious World-Author to blame for evil, but they alike reduce all evil to natural evil, since their necessarian systems provide no room for blamable wrong in men. Thus they furnish no field for the compensation of even natural evil (to say nothing of moral) by voluntary good, and therefore they both force the unreserved acceptance of "things as they are."

Nor is this result escaped by a resort to the second group of our systems. Neither Spencerian Agnosticism nor the higher forms of evolutional philosophy known as Cosmic Theism or Idealistic Monism can avoid making the One 
Cround of Things, whether conceived of as conscious or as unknowable, responsible for all that is in life, the evil as well as the good. And the utterly intimate intermingling of the First Cause with all of its effects soever, which these monistic systems all imply, and which some of them frankly maintain, renders this responsibility so direct and complete as to shock all our ideal sensibilities and make reverence for such a Being, vast and mighty as the Being may be, quite impossible, - even reverence, not to speak of adoring devotion. How can we revere that which consciously produces or permits uncontrolled evil, even on the pretence that it is done for eventual gool? How worship that which sins in and with us, even if this sinning be for ultimate universal penitence and amendment? Or how can we commit our guidance, devoutly, to that of which we cannot say whether it is conscious or unconscious, and into whose counsels, or whose drift, if perchance it have any, we cannot possibly penetrate? It is condemnation, not recommendation of these systems, to any moral mind, when their advocates declare, as sometimes they do, that "the God of things as they are is the God of things as they ought to be." A mind heartily moral knows better, when the poet, however plausibly, declares that "whatever is is right." As moral beings, we know that much which is is wrong, and is in no way palliable, or even to be tolerated, by a good being; yes, that our whole business with it is simply to get rid of it, and to bring on a state of the world in which it shall no longer have room to exist.

This same responsibility for evil, even for sin, is also carried back upon God by the systems in our first group. The predestinating Sovereign, the universal Maker, cannot escape the contagion of the evil and the wickedness that pervades the world which he creates and from moment to moment sustains. Even the natural evil in the world, however regarded as a means of greater good, is so extensively administered with a reckless hand, absolutely regardless of the 
suffering of conscious beings, as to revolt minds even as little developed in goodness as ours. How dare we say that such things are wrought even by the consent of divine Justice and Love? Still less, surely, dare we say that they are wrought by a God's predestinating edict.

Under such lights as these, which are shed from what the vast majority of thinking men agree is the profoundest and best that is in us, all such systems as we have described display their final moral incompetency. Let us turn now to the new view, the view that abandons both monism and monarchotheism, that abandons creationism in both its forms, takes resort to Final Cause as the primary and only explanatory principle, and holds to an Eternal Pluralism of causal minds, each self-active, though all recognisant of all others, and thus all in their central essence possessed of moral autonomy, the very soul of all really moral being. How will this view adjust itself to the primary conditions of moral life? In answering this, I must avoid all practical detail, and confine myself to the universal conditions of moral activity.

( $\mathrm{r}$ ) The first of these conditions is the reality of moral frcedom. Upon this the new system is clear, absolutely clear, and alone is so. It alone founds the real and the phenomenal world in the unqualified reality of a world of individual minds, each of them individual in the only sufficing sense - the sense of self-active intelligence as well as of complete particular identity. It establishes this as a fact in the only way in which such establishment is possible; that is, by proving for each mind a system of a priori cognition, here following and at the same time clarifying the argumentation of Kant, and taking care to note, and to refute, the counter-argumentation founded on the theory of natural evolution. It provides, too, for freedom in looth 
senses: that of spontaneous decision and action, eternally and unchangeably adhering to the cause of Right alone ; and that of choice in alternatives, as these continually present themselves in time, - the ever recurring alternative between the one eternal choice of Right and the manifold and ever varying forms of temporal defect and wrong.

Not a single one of these causally real individuals is determined to his acts by any extraneous efficient causation, not even God's, but each is led wholly by ideal infuerces, by final causation purely, as these ideal influences are by each apprehended and interpreted. The responsibility of each goes back, in the last resort, to his responsibility for right knowledge and right judgment, the sources of which he possesses in his essence, as knowing a priori.

The complete reality of freedom is found, however, in the possibility of realising a moral order in the world of experience. By this I do not mean the mere maybe-so of such an order, but the real power of bringing it about; and the new system provides for this, and alone provides for it, first, by the objective aspect of its theory of Freedom, and secondly, by its supplying a thorough proof for the doctrine of Immortality. But these two matters carry us into further conditions of the moral life, and require separate treatment.

(2) The objective nature of the self-active conscionsness, -objective by virtue of its intrinsically social and federal character. Without this, the moral ideal would be nothing but an empty egoism, incapable of transcending solipsism, and leading only to a self-centred culture. Justice and benevolence would have no place in such a life, but only resthetic self-refinement and self-poise - what the Greeks called $\sigma \omega \phi \rho o \sigma \dot{v} v$, which we try quite in vain to translate by temperance, moderation, self-control, sobriety, modesty, and what not. But the new theory puts altruism into the very being of each spontaneous sclf, and lo:lges his 
necessary recognition of others in the very primal intelligent act whereby he defines himself and gives intelligible meaning to his saying $I$. The spontaneous logical form of this first certainty for each, is thus primordially social. By this the system reveals the fact that Kant's "categorical imperative," in its final and fully significant form, So act as to regard humanity, whether thine owen or that of another, as an End withal, and never merely as a means, is in reality the very first principle of knowledge. Hence the moral principle gets the desired warrant from intelligence which past systems have all failed to give it. The interrupting Kantian gap between morality and intelligence is closed; morality itself becomes intellectual - at once itself objective, inclusive of others equally real with the self, and conferring objectivity, that is, universally intelligible value, upon the individual intelligence. The sources of objective moral judgment in the world of time and circumstance are also thus laid open to the experience of each mind, in the power to consult the public judgment and to verify or correct the private judgment by it.

(3) Fulfilled freedom, however, as the experimental realisation of a moral life, founded in autonomous judgment, depends upon the Immortality of the Individual, in the sense of the everlastingness of his process of experience. On no other terms, as Kant has well shown, can the moral person fulfil his task to win the realisation of his divine ideal, the reduction of his transitional life under the dominance of his eternal choice of the image of God - the image of perfect Holiness, Justice, and Love. Now the new idealism, the organic Rational Pluralism, furnishes the only clear proofs of individual immortality, in the sense of an everlasting personal continuance in a world of perceptions organised by the presence of eternal ideals, supplying power for their eventual victory. But lack of space forlids me from here rehcissing these proofs. I mist refer the 
interested reader to the form of them presented in my sixth essay.

(4) The hope of the real and lasting improvement of this present world by our moral endeavour. With lack of this, there would be moral discouragement, and the chief use of this life would be merely to find the means of departing out of it ; righteousness could only be "in heaven," - in "the hereafter." This added essential to moral effort Personal Idealism supplies, with assurance of hope, in its indivisible union of the eternal and the temporal worlds; a union in which the eternal is the unitary and governing whole, and the temporal the potentially governed part. More than this, indeed much more, and of higher interest, might be said; but more I must here for lack of room forbear to say, and must again refer readers to the fuller exposition in my first and seventh essays.

(5) The validity of the belief in the solvability of the enigma of Evil. We can have no hope in moral endeavour in a world whose Source and Controller we cannot clear of the suspicion of intending or causing evil, or of being in collusion with it, or even of conniving at it. We have seen, above, how all the systems that work from a single Efficient Cause hopelessly fail to attain this clearance of the Cause. I have already hinted at the contrasted success of the new Pluralism. Its God has no part whatever in the causation of evil, but the whole of evil, both natural and moral, falls into the causation, either natural or moral, that belongs to the minds other than God. They alone carry in their being the world of sense, wherein alone evil occurs or wrong-doing can be made real. This evil pertaining to the non-divine is moreover capable of cure, through the immanence of each being's eternal principle of good and the presence to it of the divine Friend and Saviour. So we pass to the concluding condition.

(6) The r'alidity of the belief in Goul. That is, the belief 
in a real absolutely perfect Person, transcendent of every other, immanent in none, except by the presence eternally of his Image, or Ideal, before each mind; a real Being, not an Ideal simply; complete in Holiness, Justice, and Love, changelessly attentive to every other mind, rationally sympathetic with all its experiences, and bent on its spiritual success; its inexorable Judge, but also its eternal Inspirer, by his omnipresent reality and his ever-present Image in the conscience.

The absence of objective reality from such an ideal Being, its reduction to a subjective ideal simply, as some modern philosophers caught in an agnostic snare have proposed, would strip moral life of the main support for its struggle against wrong. Amid the manifold disappointments and discouragements of the long battle with defect and wrong, the merely subjective ideal would tend to fade out, to decline both in vividness and in character, and so cease to attract and adequately guide effort. The only adequate support and it is adequate - is the reality of God, the heavenly Judge, the unfailing Beholder and Sympathiser. To him, the one Absolute Conscience, in every moral disaster our conscience turns for assured refuge and certain renewal of moral courage and strength. That is the real act and infallible function of Prayer.

I think it may justly be said that the new Harmonic Pluralism furnishes the only valid proofs for the reality of such a Being. What these proofs are, I must again spare space by avoiding here to recite. For one form they take, let me again refer to the preceding volume, in its concluding essay, and also, in a somewhat simpler expression, in its fifth. I would point out the fact, however, that all other systems professedly theistic either draw their intenderl proofs for the being of God from naturalistic consiclerations that must fall short of all attributes properly divine, while at the same time unavoidably staining the image of the Most High with direct 
or indirect responsibility for all evil ; or they rest their case on that fallacious form of the Ontologic Proof which fails to carry us beyond subjective ideality ; or else, as in the moral method of Kant, they lose all hold on known reality, and leave God's being, for its sole support, to our fealty towards our moral calling. 


\section{APPENDIX C}

THE SYSTEM $v s$. THE VIEW OF THE OXFORD ESSAYISTS ${ }^{1}$

THE present writing takes its occasion from the publication, in the autumn of 1902 , of the volume entitled Personal Idealism, by eight members of the University of Oxford. By this noticeable event I am moved to express what I must frankly admit are "very mingled feelings" indeed.

One whose fortune it had been to put before the public, some fifteen months earlier, a theory bearing the same title of Personal Iclealism, might naturally be expected to greet with lively interest the announcement of a second book under that rubric, especially a book issuing from the English seat of philosophy justly most venerated. This lively interest 1 have certainly felt; and I have accordingly turned upon the contents of the new volume, not merely with curiosity, but rather with the earnest hope of finding weighty auxiliaries for views which I count to be so inwrought with our greatest human concerns. I come back from the reading, in part fortified and encouraged, but in part also-I fear in greater part-surprised and disappointed. I had supposed, of course, that the cardinal features of the system of Personal Idealism would be agreed about and accepted, if the title was accepted which had been chosen for it by its author. It is the adoption of the title in spite of rejecting

1 Extracted, with some clianges not material, from an article in IFind, April, 1903, with the heading, "In the Viatter of Persunal Idealism." 
essentials in the system, that surprises and in some measure discomposes me; and all the more when one finds his own lines of division for the discussion, and even his own topical titles, running through the book. It is because I hope to prevent misunderstandings on the part of the public, and to forestall a confusion of ideas in presence of an identical name used to cover very different conceptions, - dealt with, above all, by very different methods, - that I am prompted to comment on the Oxford volume, and to point out some of the more important divergences between its metaphysical view and that which I would call Personal Idealism.

That the book has great worth of matter, and will have much weight in the doctrinal controversy that is now upon us, follows of course from the known training and culture of its writers. In many regards, those who are in earnest about a polemic against the current anti-personal philosophies, monisms of one sort or another, may unquestionably rejoice in its uncompromising pluralism, and in its courageous, outspoken, and resourceful assault upon Naturalism and Absolutism alike. And if one were to decide upon the philosophical meaning of a movement solely by the general aim of it, in disregard of its method, there would be little or nothing in the programme set forth by the Oxford Eight to which any idealist could demur. "The reality of human freedom, the limitations of the evolutionary hypothesis, the validity of the moral valuation, and the justification of that working enthusiasm for ideals which Naturalism . . must deride as a generous illusion" - this unquestionably sums up well a cause for which every idealist works; nor could anything much better express one object with which my own volume was prepared. But one doesn't become an idealist simply by attachment to ideals, or by opposition to those aspects of Naturalism which assail the credit of ideals ; otherwise, many an empiricist, many a positivist even, might be called an idealist, and such a persistent railer at idealism 
and all its ways as Professor James might still rank as an idealist of idealists. Idealism is constituted by the metaphysical value it sets upon ideals, not by the æsthetic or the ethical, and rather by its method of putting them on the throne of things than by the mere intent to have them there. It is always distinct from mysticism (which at the core is simply emotionalism), and still more so from voluntarism. Its method is, at bottom, to vindicate the human ideals by showing them to be not merely ideals but realities, and to effect this by exhibiting conscious being as the only absolıte reality; this, again, it aims to accomplish by setting the reality of conscious being in the only trans-subjective aspect thereof, namely, intelligence.

So the fact comes about that idealism gets its essential character from its discovery that intelligent certainty depends on such an interpretation of reality as makes the knowledge of reality by the spontaneous light of intelligence conceivable; in short, that idealism is necessarily rationalism, that is, implies an apriorist theory of knowlerge. No sort of experientialism, so far as it is consistent, can rightly be called idealisn. Voluntarism or emotive mysticism it readily may be, but then it is simply subjectivism; and if it be taken in cognitive terms, it cannot get beyond sensationism, unable as it is to provide for any changeless and universal icleas with which to organise experiences into objects that are inalterably the same for all subjects and therefore abidingly real. Not even such a theory as Berkeley's (to which one of the eight essayists appears to hold, with some added helps from Kant) can be consistently called idealism; for though it teaches that there is an immutable principle at the basis of our experiences, namely, the operation of the eternal ideas in the Divine intelligence, controlling God's communication of sensations to us, yet the assumption of this Divine Mind is unwarranted by the strict experientialism from which the theory takes its departure. 
One might have supposed that all this was settled beforehand, from the time of Locke. But in spite of its title, we find in the Oxford volume experientialism running at large and everywhere; we find, in fact, (I) empiristic epistemology, (2) an organised new assault upon a priori cognitions, (3) a voluntarism of the most pronounced order, (4) an ethical mysticism combating the mysticism of the intellect, and finally (5) a quasi-personalism resting upon the wholly experiential and purely temporal existence of conscious "individuals" added as a society to his own eternal being by the creative fiat of God. In short, not a single trait of systematic idealism is present ; the heart of real individuality, of real personality, is not reached - nay, even the serious attempt to reach it is foregone; yet the whole is brought under the name of Personal Idealism. The force of misnomer could hardly farther go.

One good, however, we shall in all probability reap out of the issuance from Oxford of a coöperative book with this title and with the contents embraced: the attention of all the thoughtful in the English-speaking world, and even far beyond it, will now surely be drawn to the vital questions involved. Thence it may be hoped that the genuinely idealistic implications of freedom, of evolutional limits, of valid moral valuation, and of justified enthusiasm for the ideal, will more and more clearly come into view. Not until this occurs, certainly, shall we get finally rid of those plausible makeshifts in the way of philosophy that leave our chief ideal interests still at risk, and so only serve to prolong the weary procession of philosophic disputes. 


\section{APPENDIX D}

REPLY TO A REVIEW IN THE NEW YORK TRIBUNE ${ }^{1}$

To the Editor of the Tribune: I am of course much gratified at funding in your issue of February $\mathrm{r} 3$ so full and careful a notice of the philosophical views presented in my recent volume. The reviewer shows great candour, sufficient learning, and an unusual hospitality to new ideas in serious regions. I am indeed glad to have any work of mine the object of a criticism marked by so many qualities of the true and enlightening judge. But the one duty of a reviewer that precedes all others is to apprehend his author correctly; and as, with the best intentions, your contributor has somehow managed to misapprehend me in several essential matters, I must beg enough space in your columns to put myself right.

THE SYSTEM INDEED PLURALISM, BUT NOT CHAOTIC INDIVIDUALISM

First of all, though I cannot imagine why, the reviewer sets out with the statement, to me simply astounding so far as it concerns myself, that "both Dr. Royce and Dr. Howison are monists and idealists." ('The italics are mine.) I should have supposed that if any one thing blazed out more than another in my book, it would be the

1 Reprinted, with omissions and immaterial changes, from the Daily Tribune, March 5, 1902. 
fact that it assails all monism, of every sort and fashion, and takes for its task the supplanting of it by a system of pluralism. Idealist, indeed, I am; monist, not at allnot in any sense, until one comes to the very subordinate question, Are there two kinds of substantive reality, mind and matter? - is there a dualism of worlds, physical and mental, each existing independently of the other, or is all reality translatable on the contrary into the existence of conscious selves and the derivative existence of their "contained" experiences? In answer to this question, I do indeed say there is but one kind of substantive being, and that mental. But this is one of the characteristic tenets common to all systems of idealism; in the historic nomenclature of philosophy it has never borne the name of monism. 'The contrast between monism and pluralism is concerned with the theory of ultimate (or primary) reality. A pluralist does not in the least believe (as the reviewer apparently does) that "the ultimate interest of philosophy is to find the One Reality that lies behind the innumerable diverse phenomena of the world." Pluralism is precisely the stubborn denial that the ultimate reality is any such One and Sole Being, in which every other being is but a component and fragmentary factor, with none but a derivative reality. The pluralist maintains, on the contrary, that this pretender, "The Absolute," this asserted "One and All," is an illusion of false speculation, arising from confounding the Real with the empty and meaningless result of persistent higher and higher abstraction. The fundamental issue in philosophy is just this: Is that which is ultimately real One, or is it Many? - or, still less ambiguously, Are there many primary and underived real beings, or is there only one? Here it is that the pluralist divides from the monist; and he divides implacably. The issue is at core the issue between a moral order (which cannot be unless there are many independent agents, the 
true and spontaneous causes of their own acts) and an order simply natural, dominated by the determinism issuing from an all-encompassing Sole Efficiency.

Of course, pluralism, simply as such, might mean universal chaos, disorder, and unreason. It has not infrequently been so interpreted by its advocates. But it has no necessary character of this unruly sort. Idealistic pluralism is distinguished from this pluralism of mere caprice, of pure self-will, by the doctrine that the many Primary Realities, when we discover them in their undermost foundations, are all rational intelligences, and that they therefore spontaneously constitute, not indeed any Unit, in which their freedom would be swamped and crushed, but a rational Union, or Harmony, which is therefore as indestructible as they are. This is the conception at the basis of our American ideal of the state as a Federal Nation, and it might well be represented by our national motto, not plures ab uno, but e pluribus unum. It is just here that I part from Dr. Royce and from the large and justly famous historic company of thinkers from whose lines he sets forth his theoretic array - from Plato, from Aristotle, from Aquinas, from Spinoza, and, above all, from Hegel. Monists of one degree or another all these celebrated minds have been; monist with them is Dr. Royce. They are a proud and weighty company, in fact of a resistless weight if you grant them their fundamental assumption - that the highest and controlling category of true thought is the category of Cause construed as Efficient Causation.

But how the reviewer should have lodged me in their camp - even in any quarter of it - is a mystery I must leave him to explain, if he can. I had supposed that my Preface had put my opposition to every sort of monism beyond the chance of mistake, and that I had rendered my position as a rational (or harmonic) pluralist as clear 
as language could make it. Your readers will surely see that I have done so, if they will take the trouble to read my pages viii-xii, where they can hardly be so inattentive as to miss the words, "Instead of any monism, these essays put forward a Pluralism: they advocate an eternal or metaphysical world of many minds, all alike possessing personal initiative, real self-direction, instead of an allpredestinating single Mind that alone has real frec-agency."

THE SYSTEM NOT THE TIIEORY OF PREZ̈XISTENCE

In the second place, the reviewer, in spite of his evidently wide reading in philosophy, has quite misapprehended the meaning of the phrase "the eternal reality of the individual." His mistake in this connexion I can readily understand, for it is one common even among readers whose philosophical training ought to make it impossible. Unluckily, popular language employs "eternal " to denote the total compass of time, meaning by it "everlasting, both backward and forward." We are fond of hitting this off in the phrase "from all eternity," that is, "from a past date infinitely remote." In this sense people, however wrongly, are in the habit of fancying even the being of God as essentially a temporal existence, only differenced from our transient life of the senses, hemmed in betwixt birth and death, by lasting from forever in the past to forever in the future. But not so does the philosopher understand "eternal." To him the word must either mean something that "temporal" does not and cannot, or else it must be discarded from his vocabulary as superfluous. And inasmuch as the temporal and the eternal are even by common usage contrasted, he justly says that the word "eternal" must by him be taken to stand for what "temporal" does not and cannot stand for ; namely, 
the unchangeable Ground presupposed by the changing temporal; the necessary as against the contingent; the independent as against the dependent; the primary as against the derivative; the self-existent as against that which exists in and through it; the genuine cause, the causa sui, as against that which is after all nothing but effect, however it may be tied, by the causa sui, in an unrupturable chain of antecedent and consequent. Or we may say it means the noumenon as against the phenomenon; or, in fine, the thing in itself as against the thing in other. 'That is, the relation between the eternal and the temporal is not, and cannot be, only another case of the temporal relation. The relation is just one of pure reason, and is, in fact, sui generis: the eternal does not precede the temporal by date, but only in logic; it is the sine qu $\hat{a}$ non without which the temporal cannot exist, nor is even conceivable. In brief, throughout my book I mean by the "eternal" simply the Real as contrasted with the apparent; the world of self-active causes as contrasted with the world of derivative effects, in so far passive.

I have surely taken every pains to make this plain, even to the inexpert reader; one would hardly have supposed my accomplished critic could fail to take it in. Yet he has failed: he expressly construes the "eternal reality of the individual" as meaning an cverlasting preëxistence of each soul. He considers the organising relation which I show the soul has toward Nature to be good ground, to be sure, for a hope of its everlasting continuance beyond the grave, but he says, "One finds it hard to take the jump from the inference of an existence that may be endless to that of an eternal preëxistence [italics mine] of such persons as distinct individuals; or, . . " the coexistence of all souls in cternity with ('od.'" Again, in expressing his acceptance of "such a coexistence of some souls," on the ground that "the conception of a lonely God may well be discarded for 
that of social Deity," he gives even this a purely temporal colouring by speaking of this social God as "never [italics mine again] without filial spirits reflecting the glory of the Eternal Reason." But, I repeat, I have taken every precaution to prevent the reader from supposing me to mean by "eternal" this popular error; I have expressly warned everybody that I do not intend by the "eternal reality" of the individual his everlasting preëxistence, nor any mere preëxistence at all. Let me ask readers to consult what I have printed on my pp. $35 \mathrm{I}, 35^{2}$ seq., and to compare with this the statements on pp. 338,339 .

\section{III}

REAL PROOFS OF THE SYSTEM, AND TRUE RÔLE IN IT OF FINAL CAUSE

Misled no doubt, at least in part, by the preceding misconception, the reviewer next asks what "ladder we are offered for a climb to this position" of individual eternity, to affirm which "of all souls, of every individual member of the human race," he says, "seems stupendously audacious." This "audacity," like the other "audacity" of making out all minds to be co-creators with God, he appears to infer from his sense of the insignificance of most human lives, as exhibited in their temporal history; a sense that, of late, it seems a good deal the fashion to feel, and in regard to which, and its real baselessness, I think it sufficient here to refer readers to the telling exposure of it, though in another connexion, that Professor James has made on pp. 36-4I of his Ingersoll lecture, Human Immortality.

When the reviewer attempts to answer this question about the ladder I offer for climbing to this audacious height, he goes astray again. He thinks the ladder is my substitution of Final Cause for the time-honored Efficient Cause, as the true mode of the causal relationship between 
soul and soul, and between God and all other spirits; and he therefore declares it is too short to reach the object. Doubtless in this last point he is right: to say that the true and only causal relation between spirits is that of Final Cause, is of course but another way of saying that all spirits are caisce sui, or eternal, and hence is, instead of the proof, the proposition to be proved. But the proposal of this view of Final Cause as the ladder is no proposal of mine. I was quite amazed to read the reviewer's words. It never occurred to me, in thinking out the system, nor in writing the essays, that this very important step of putting Final Causation at the root of the causal system was any part of the positive argument for the belonging of the individual to the eternal order. Doubtless it is an indispensable precursor of the proof, in the way of showing just what is to be proved; for if the relation of God to souls is that of their Efficient Cause, or literal Maker, they cannot be possessed of a real freedom, cannot be the genuine causes of their own acts and character; cannot belong, that is, to the eternal order at all. But to be an indispensable condition of a thing is far from being the sufficient ground for it.

What, then, is the proof offered for this "stupendously audacious" proposition? Have I really offered none? The reviewer declares, that, despite the sundry improvements upon the monadology of Leibnitz which he is so kind as to say I have made, I have still "not cleared the essential objection to Leibnitz's scheme" - the objection that it is "an indemonstrable ${ }^{1}$ speculation, motived, indeed, by a noble interest, but a cathedral in the clouds." Is this in fact the case?

It certainly is not. It would be strange indeed, if, com-

1 Undemonstrated, I suppose is meant; to call the speculation indemonstrable, is of cuurse to beg the question. 
ing before the public with a theory somewhat startling in its departure from the ruling opinion, I had indulged the mere desire to stir up a sensation, and had omitted even an attempt to prove my main proposition. I have not been guilty of this negligence. On the contrary, I have argued the proposition of the eternity of each individual mindthat is, its genuinely self-active reality - in the most careful way, and in the only way that I can conceive of its being proved in. This I have done, in some sense, in every essay in the volume, but chiefly, of course, in the first, in the third, in the latter part of the fifth, and especially in the sixth. The argument, in brief, is simply that of taking up the problem of the reality and the source of knowledge, and, in face of the supposed evolutionary explaining of all $a$ priori knowledge away by the cumulative force of hereditary habit massed through ages, proving with exact care that every human mind, and therefore by analogy every individual mind as such, does have and exercise this a priori knowledge. Supposing this to have been done (and I must refer readers to the book to test my proofs), the unavoidable meaning of the fact is that every mind possesses a spontaneous objective cognition, and is therefore a case of what, quoting the ever memorable expression used by the writer of the Fourth Gospel, I have called the possession of "life in itself." This, I maintain, is the only intelligible meaning which anybody can attach to self-existence, inclependent being, and real freedom; as also it is the only intelligible meaning of knowing a priori.

My readers, I fear, have like my reviewer been somewhat misled by looking into my concluding essay for the most important proofs of my main position. But there I am dealing with a problem, or with problems, important and intricate, indeed, but still subordinate to this main one, and only auxiliary to my principal aim. I am there chiefly concerned with showing that if we are to have a moral 
order in the world of ultimate reality - an order necessarily based upon the autonomy of the individual mind - we must abandon what may be called "creationism"; must abandon it in all its forms, and preëminently in the two forms which have come into such serious conflict since the middle of the nineteenth century - I mean, of course, (I) the old dualistic (or transcendent) creationism of Hebraic theology, and (2) the later monistic (or immanential) creationism of Hegelianism and the evolutionary philosophy. If freedom is to be saved, I show it must be saved through such an idealism as replaces this "efficient" view of causation by a view purely final, or ideal, as the principle by which God sustains and rules the world. But, supposing this established, how do we know that a free world is a fact? If freedom requires that the soul shall be coexistent with God in eternity, - that is, in the world of spontaneous first causes, - how are we to prove that freedom and such a world of coexistent self-active beings are both realities?

I answer here as I have answered in the book: By proving the reality of a priori knowledge in the individual. And for the detail of this proof I again refer readers to the first, to the third, and to the sixth essay.

IV

THF, SYSTEM NOT A SUBJECTIVE BUT AN OBJECTIVE IDEALISM

The reviewer's own habitual way of philosophising has led him, finally, into misconceiving my form of idealism as one-sided and merely subjective. "It remains to note," he says, "what seems a confusion of ideas, reappearing from point to point of the argument, in a failurc to recognise the distinction between a subjective and an objective view of the universe. It is human thought which organises the motley phenomena presented to the senses into the majestic order called Nature. And this is reasonable $2 \mathrm{E}$ 
ground for viewing Nature objectively as the manifestation of a creative Divine mind, akin to the human mind that re-creates it in thought. But this our logical construction of Nature is transformed by the author into the real object of which it is but the shadow. Souls are affirmed not only to be coexistent with God, but also cocreators with him."

Now it is just this last point, however, that shows the universally social (that is, the public and objective) aspect of my idealistic interpretation of Nature. I no more teach a merely subjective basis for Nature than my reviewer does. The difference is, that he is in the habit, whether consciously so or not, of finding the objective aspect of the world in the efficient causality of God alone, while I find it in the harmonious coöperation of all the eternal minds, including God as the Final Cause, or Supreme Ideal, to which all are rationally attracted. But let readers consult my pages $\mathrm{xx}-\mathrm{xxii}$, and compare them with my pages 36r-369. I no more explain Nature without the moral world of all spirits, nor without God, than my reviewer does, nor than traditional theology and past philosophy have done. The difference is that I introduce these by the new principle of Final Causation instead of by the old one of Efficient, and thus at once secure a consistent and pure idealism, avoid the impasse of Natural Dualism, and clear the problem of the anti-moral burdens involved in monism on the one hand and in dualistic monotheism monarchotheism - on the other.

In fine, the reviewer's closing criticism arises from his failure to take in my total view. Perhaps it is too much to expect, that, with its many unaccustomed elements, this view should at once be grasped. I ought to say, too, that the objective aspect of my form of idealism, shown in its principle of social recognition and harmony, is the aspect least worked out in the book: the entire doctrine of the 
system concerning Space, as a principle expressive of this public or objective side of being, in contrast with Time, the principle of subjective privacy, though alluded to in passing, ${ }^{1}$ in fact still stands in need of its full and proper treatment.

1 See pp. xiii and xxii, and cf. p. $35^{2}$, note, and p. 353 . 


\section{APPENDIX E}

REPLY TO CRITICISMS IBY MR. J. M. E. MCTAGGART ${ }^{1}$

I AM much indebted to my reviewer for the care and the penetration with which he has considered my theory; and yet I notice some important respects in which he has failed to take my meaning. These I must set forth with all possible clearness, in the hope of preventing further misunderstanding; and then I shall have to reply to the objections which he raises (or, perhaps rather, the diffculties which he suggests) in connexion with my view.

\section{I}

FREEDOM, PERFECTION, GOD, AND THE PROOF OF GOD, IN THE SYSTEM

Judging by his other published writings, as well as by his review, I may fairly assume that Mr. McTaggart is in agreement with me in holding to an idealistic pluralism, the theory of an Eternal Society of many minds, each absolutely real. It is well to note, in setting out to comment on his criticisms, that there is a head under which his views and mine might correctly be brought into collocation with the views of our Oxford colleagues, with those of Professor James, with those of the late Thomas Davidson, and even with those of more pronounced individualists, I mean the head of pluralism : in one way or another, we all hold out for manifold realities that are all alike indis-

1 Reprinted, with some trifling changes, from Mind, April, 1903. Mr. McTaggart's rerizw may be found in Mind, July, I902. 
putable. But only some of us set this pluralism forth by an idealistic method, and hence arrive at what we call the "eternity" of the many minds. By this we mean simply their absolute reality, or the self-based, self-active nature of their being, - nothing else at all, except as something else may be implied by this absoluteness; least of all, do we mean merely their everlastingness, their existence "from all eternity," as the common saying is. Our doctrine has nothing whatever to do with the superstition, born of fancy, about preëxistence. In this matter I suppose Mr. McTaggart to be in entire accord with me, and I am therefore somewhat surprised to note in his review certain misapprehensions of my position. These I will now specify.

(1) He speaks of my doctrine that only an eternal being can really be free, as a "remark." This language is seriously misleading; the reader must surely get from it the impression that my statement of this view is merely incidental and by the way. On the contrary, it is in fact basic and central to the whole theory of my book, is developed with emphatic prominence, and is argued out with much detail. (See my pp. 326-343.)

(2) A more important misapprehension is this: "It [the system of Personal Idealism] offers a God of whom personality, morality, and affection can reasonably be predicated, since, though perfect, he is finite. (I am not sure if the author would accept the word 'finite,' but in effect, it seems to me, he holds God to be finite, since he makes him one of a community of spirits, each of whom has 'a reality as inexpugnable as his own.')"

Indeed I do not accept the word, nor can. I am surprised that my real view in this matter should have escaped Mr. Mc'Taggart. So far from holding God to be finite, I hold, and in the book clearly teach, that all minds are infinite (in the true qualitative sense of the word), and God 
preëminently so. (See my pp. $33^{\circ}$ seq., $3^{6} 3$, and 373 ). Eternity, self-existence, self-activity, freedom, and infinity are to me all interchangeable terms, and are so treated wherever they turn up in the course of the book. My reviewer falls into a non sequitur when he concludes that I make God finite because I make him one of a community of spirits, each absolutely real; not God's finitude, but his definiteness, is what follows from that. This confusion of the definite with the finite is very common, and is the explanation of two tendencies in sceptical thinking - the tendency to deny the personality of God, whose infinity is supposed to mean his utter indefiniteness, and the tendency, in recoil from the former, to assert God's finitude in order to save his personality, which of course must be definite. But the true infinite, as distinguished from the pseudo-infinite, the infinite of quality in contrast to the infinite of quantity, is entirely definite; more definite, indeed, than any finite can be.

(3) Mr. McTaggart misconstrues my various statements about the imperfection in all spirits other than God. $\mathrm{He}$ supposes me to hold this imperfection to be incompatible with their being perfect in any sense whatever, and he mildly blames me for overlooking the classic distinction between the view sub specie aterni and the view sub specie temporis, whereby the seeming contradiction involved in an imperfect-perfect might be reconciled. But my actual doctrine about the spirits other than God is exactly his own. "Sub specic eternitatis, every self is perfect; sub specie temporis, it is progressing towards a perfection as yet unattained," he says. And the very quotation from me on which he bases his criticism (see my p. $3^{6} 3$ ) expresses this, almost in open words: "The personality of every soul lies precisely in the relation . . . between that genuine infinity (self-activity) which marks its organising essence, and the finitude ... to which the infinity [only 
another name for perfection] subjects itself in defining itself from God." So, too, though more explicitly, when (p. 374) I say: "'The perfection of the 'creature' lies just in this never ending process of victory. . . . Thus its life shows its peculiar perfection by the mode in which... it surely, though slowly and with heavy toil, heals its own inherent wound." And, yet again: "The infinity of the 'creature,' the infinity that embosoms finitude and evermore raises this toward likeness with the eternal."

There are sundry other passages in my concluding essay that affirm the distinction drawn by Mr. Mc'Taggart between the complete self-adequacy of the spirit as a whole in eternity and the inadequacy of it as broken up in a time-process and engaged in a perpetual struggle to attain conformity with that eternal wholeness. In fact, this distinction furnishes the whole basis for my reply in that essay to Professor James's "Dilemma of Determinism." I am really quite at one with Mr. McTaggart in what he says about the perfection of all eternal beings, in so far as they are eternal. I have usually avoided the explicit use of the word, because it is in many contexts misleading, and also because the too free use of it would engender prejudice in most readers, thus preventing the proper appreciation of the arguments offered for the world of real freedom. That world as I intend it, and habitually think it, answers to the principles of unity and harmony quite as Mr. Mc'laggart suggests.

Accordingly, my argument for the existence of Crod is not reached by those of his suggested objections which are founded on his assumption that I hold all minds but God to be utterly and totally imperfect, without any aspect of perfection at all. On the contrary, I hold, with him, that all eternal beings are perfect, each in its own way. But the way of God, I maintain, is the way of absolute perfection. which eternally excludes rlefect; whereas the way of every other mind is the way that includes defect, comes (oi 
may come) to include sin, and only exhibits its perfection in its power to return to wholeness through the process of time.

That I have chiefly dwelt on perfection and imperfection as respectively the attributes of God and of the non-divine minds, without entering into the subtle distinction between kinds of perfection, is indeed a fact, but it should be regarded as a rhetorical rather than a philosophical procedure. That is to say, my book was aimed at readers of general cultivation rather than at metaphysical experts, and so I thought I should carry my new argument for the reality of God more surely home if I kept out of the region of the supersubtile, and relied upon those aspects of the difference between God and other minds which are the most obvious. The point of my argument, in this connexion, is that in God there is a perfection in which there is no imperfection at all, while in every other mind imperfection is present, though undergoing an endless process of cancellation. Of course, subtly analysed, this last means a species of perfection. But again my point is, that the sole possible basis for species in perfection is, primarily, the contrast between absolute perfection (excludent of imperfection) and perfection that embraces and proceeds to reduce imperfection; and, next, the manifold modes of which this second species is susceptible, resting on what I have called (see my pp. $3^{6} 3,374$ ) the "rate" of adjustment between the infinite (or perfect) and the finite (or defective) aspects of the mental being.

(4) In connexion with my argument for the existence of God, Mr. Mc'Taggart makes this statement: "Among the different grades [of intelligent beings] which . . . are really possible ... the author assumes that the highest grade of all - that of the ideal Type - is one, and consequently that a being exists who realises the Type. So far as I can see, he does not attempt to prove this." Just what Mr. Mc'Taggart means by his word "this," I am in some doubt - whether 
he is referring to my "assuming" that the ideal Type is one of the different grades of being that are really possible, or to my taking as a direct consequence of this the actual existence of the ideal Type.

As for the first of these matters, it is not true that I assume the ideal Type to be one of the really possible intelligences; on the contrary, I show (see my pp. 353-355) that this Supreme Instance of the intelligent nature present in all possible minds is the one salient certainty in our conception of the whole series, when we view the series as conceivable simply: whatever we can not tell about the series, or the numbers in it, what we do see, and see clearly, is that it must contain, as a possibility, this Type ; this I treat as the implication in the entire process of definition by which other members in the series are determined.

And as for the second point, I do not conclude to the actual existence of the divine Type directly from its ascertained possibility; that would be merely repeating the thrice-buried Ontologic Proof over again, and the futility of that I have dwelt upon in my pp. 357-358. The identification of the divine Type as a necessary member of the conceivable series proves only this: that there is a necessary connexion between the idea of every mind and the idea of God, - no mind can define itself except in terms of God. The argument to the actual reality of God is then completed by resorting to each mind's certainty of its own actual existence through dialectic verification: the attempt to posit the contrary, only ends in positing the self again. From this the actual existence of ( God follows, because the actual existence of the self must carry the existence of whatever the idea of the self synthetically involves. I can hardly imagine how my reviewer can have read my pp. 356-359 and still say that I make no attempt to prove the actual existence of Corl as the ideal 'Type of all the really possible spirits; nor how he can still set it down that I assume the ideal 
Type in be ma of the series of really possible beings, "and consequently that a being exists who realises the Type."

\section{II}

RELATIONS TO KANT, CATEGORIES $v S$. SENSE-FORMS, MONOTHEISM, MISUSE OF THE NAME GOD

But enough of these misapprehensions. I must now turn to sundry difficulties that Mr. Mc Taggart finds with some of the cardinal conceptions in my theory, or else with my method of advocating them.

(I) He complains that after going closely with Kant to a certain point, I then suddenly separate myself, - "abruptly," as he says. By this he appears to mean my rejection of Kant's restriction of all our cognition to phenomena and denial of our power to know noumena. He implies that I nowhere give any reasons for rejecting Kant's criticisms on the Paralogism of Pure Reason, but go on to maintain that pure reason can know that the self exists, and exists eternally, - simply ignoring these celebrated criticisms. It is a fact, of course, that I have not felt it needful to reply in detail to the various branches of Kant's agnostic doctrine, and especially not to his assault upon the possibility of proving theoretically the freedom and the immortality of the self. I have chosen to rely, rather, on a general refutation of the agnostic motif, which I have supplied in my first essay; and I have relied more especially on the self-refutation of Kantian agnosticism by its own inner dialectical dissolution, which I have traced out in the fourth part of my third essay. These very essential parts of my gencral argumentation, my reviewer appears to have quite overlooked. No reader who omits them will properly understand the argumentative procedure on which I rest my case in the seven essays taken together. 
Besides, I have throughout assumed readers will see that Kant's agnostic restrictions are anticipated, provided for, and rendered inapplicable, by the plain implications of the fact of a priori cognition itself, when that is once clearly established and clearly understood; and this fact I have explicitly argued out, in two different places in the volume - in the first essay, and again in the sixth. Then, too, I have relied on the plain power of the essentially social nature of the self-defining consciousness to lead my readers to see how irrelevant Kant's agnostic tenets are. (See, particularly, my pp. 351-353, and cf. pp. I73-175.) That is to say, the Kantian agnosticism is annulled, so far at least as concerns the certainty of the existence, even the noumenal or eternal existence, of the self. In fact, however, my reviewer is a trifle out in saying I depart from Kant on this point, for Kant himself never supposed that this was unknown or unknowable: what was unknowable was not the existcnce, but the nature of the noumenon. If nowhere else, then at all events in the Prolegomena, Kant declares unmistakably that the existence of selves as Dinge an sich is a known certainty. "That there are no Dinge an sich," he says in substance, "is absurd." (Cf. the Prolegomena, passim, but especially in $\S 57$. . $^{\prime}$

(2) A more serious complaint is that which Mr. McTaggart makes that my reasons for treating the Categories as applicable to the self, when I refuse to describe it in terms of the Sense-Forms, are "not brought out anywhere in the book." This fault, if it is a fault, I shall have to admit. Within the limits of the brief volume I could not compress everything pertaining to a complete vinclication of my general view. In particular, Mr. Mc'Taggart's centrally pertinent question - Why are not the Categories in exactly the same position as Time, as to bcing necessarily transcended by the noumenal self? - could only be answered after a complete reëxamination, going to the foundations of the 
whole problem of epistemology. This would need to be taken up along Kant's own lines, and followed to the point where (at the end of the Transcendental Analytic) one gets into the position to show that Kant has failed to establish the objective character of even natural science, and just why he has failed. It would then appear that in order to give really objective value to a priori syntheses in Space and Time, we must combine a pure use of the Categories - a use unmixed with the Sense-Forms - with their use as "schematised" with the help of these Forms. Thus we should learn that there is no possible escape from the transcenclent use of the Categories, even when we attempt to employ them only transcendentally.

But not only did I feel that this epistemological inquiry was at once too long and too subtle for the public to which I chiefly addressed my book; I was also, in the case of more expert readers, relying upon a previous warning as to the general path the inquiry must follow, which I had given in my contribution to the volume entitled The Conception of God, at pp. 124-127. Still, Mr. Mc'Taggart is quite right in pointing out that all this needs to be done in full detail before one can claim to have made a proof of Personal Idealism clear of all queries. And this I hope some day yet to accomplish.

(3) My reviewer finds a "weakness" in that part of my argument concerning the existence of God which aims at showing God's soleness (monotheism), in opposition to the charge of "polytheism" or "apeirotheism" urged against my proposition that all selves coexist with God in eternity. He thinks the argument assumes "that beings who were equally perfect could not be different from one another." But it does not assume this, as I have already shown above, when clearing up the misapprehension about perfection and imperfection as applicable to the selves other than God. It does assume, however, that no beings who are absolutely 
perfect can be different, that is, none that are perfect without immixture of imperfection, and that are wholly supratemporal in their being. The conjunction of this unmixed perfection with eternity is what constitutes the proof for the soleness of God. Mr. McTaggart fails to get the force of it, I think, because he silently omits this divine differentia before the word "perfect" as I use it of God. And thus, contrasting God and other selves as the Perfect and the unrelieved imperfect, he draws the unwarrantable conclusion about "superiority" and "inferiority" which he seems so much to dislike. But I intend no relation of this sort between God and the souls. They are different, and $u n$ changeably different; they are even different in species, God being perfection eternally fulfilled, the other selves having a time-world of unfulfilment and having to carry it on toward the goal of fulfilment evermore. Thus the difference between them, in this reference, is permanent, - to answer my reviewer's question on this point. But I do not teach that it is a difference of "inferior" and "superior"; quite the contrary is the fact, as any one who rightly reads my pp. $243^{-256}$ will know beyond question.

(4) Finally, Mr. McTaggart objects to my calling this sole mind possessing absolute and eternal perfection, God. He insists that the traditional usage shall be absolutely venerated, which makes God the name of the one only selfexistent Being, who brings all other beings into existence by creation ex nithilo. Here I am quite unable to agree with him. I not only do not think that this solitude of selfexistence, conjoined with this universal efficient causality, is the central and essential thing in the traditional religious thought of Christendom, but I am sure that the most spiritually-minded Christians would at once declare that it is not such; they would say, on the contrary, that the essential thing in the being of God is his holiness, justice, and infinite love. Now, what I point out is, not only that the 
function of creation, taken literally, is unessential to this moral perfection of God, but that it is in hopeless contradiction with it; and that the obscurely felt fact of this contradiction, a feeling growing ever more clear as the Christian consciousness grows more sure of itself, is at the bottom of all that restlessness in the region of Christian theology which we all know so well, and which is the characteristic fact in the later Christian world.

To remove the name of God from the clarified and purified conception of the eternal Ideal Type would be to do violence, inexcusable affront, to the deepest and truest element in the historic religious consciousness. I feel the strongest assurance that my new interpretation of the name of God is the genuine fulfilment of the highest and profoundest prescience in the historic religious life. What offends us in the Spinozistic or other monistic appropriations of the name "God" is the evident absence from their Absolute of all the essential moral qualities. In these it is that true Deity lies, and all God's metaphysical attributes must be keyed up to them; not one of these "natural" attributes dare be construed in any way that conflicts with the eternal moral essence. If they have been so construed historically (as indeed they have), gennine theology requires that the conception of Cod shall be relieved of these errors, in order that God's nature may stand revealed as it is in its own reality. 
I N D E X 



\section{IN DEX}

Abasement, of individual before God, a sort of pantheism, $36 \mathrm{I}$, note' $\mathrm{r}$.

Abbot, Dr.F. E., his Scientific Theism, in Concord "symposium," 56 note. Absolute, the, as total World of Spirits, or "City of God," xii seq. ; as the Unknowable, 2, 15, 272; as, proximately, the rational nature, 30, 4I, 70 note, 276; identified, by empirical method, with the Sum of Things, 83 seq.; as IVill, I07; as the Unconscious, IIo seq. ; reduced by Hartmann to relativity, I2O; as the Actual, or real matter, I23 seq. : rendered relative by Diiluring also, I39; as Inclusive Unit, a case of false pretences, of meaningless abstraction, 4IO.

Agnosticism, Spencerian evolutionism a form of, $2,15,29$; an unwarrantable arrest of philosophic movement, I5; evolutional, involves petitio, I6 seq., and also self-contradiction, 22 seq.; claims existence of the Unknowable by " inconceivability of opposite," 23 ; breaks down by this assertion of knowledge, 24 seq.; " critical," reduces conscious life to essential delirium, I58; a haunting certainty the Nemesis of, I62, 168 ; genesis of "critical," I66; self-dissolution of, I68 seq. ; drastic eure for", supplied in Hume, I76 seq.

Alternative, involved in all freedom, $3 \mathbf{I}$, but not the whole account of it, 319,369 ; needs explanation itself by higher principle, 319, 375; explanation of, in noumenal power to transcend sensory Check, 365 seq.; a derivative product of real freedom, 376. [See under Livil.]
Anselm, employs Ontological Proof of God, 356; justly criticised by Descartes, $35^{8}$.

A Priori Cognition, system of, the essential being and true person of a mind, xiii, 4I, 301, 305, 308 seq. ; gives "form" to experience, xiii, 18, 325; not explained away by Spencer, I8 seq.; presupposed in association of ideas, 19; also, in all experience, 30 ; presupposed by logic of induction, 35 ; principle of evolution a case of, 40 ; an act of each conscious being, + seq., cf. 36,302 , but not admitted as such by any evolutional philosoploy, 44; proofs of, 46,296 seq.; faet of. proves immortality, 305 seq.; includes our guiding deals, 309, and so provides for worth of immortality, 3IO; nature and reality of, of worth, 3Io seq. ; proof of, constitutes proof of freedom, and of the whole system of Personal ldealism, xli-xliv, 415 seq.

A Priori Law in Nature, evolution a case of, 40 ; essential to free-agency, 323.

Aquinas, St. Thomas, represents Middle Doctrine of relation between reason and religion, 228.

Aristotle, his definition of God, $\mathrm{xv}$; profound ambiguity of his philosoplyy, xxv; relation of Personal Idealism to his system, xxv, xxvi; his relation to pantheism, xxv, 63 note: his division of the fine arts, 207; his criticism of previous Greck philosophy, 364; his System of Causes, 364, 365; his failure to reach pure finalism, 365 . cf. xxv. 
Arnold, Matthew, on the "secret of Jesus," $2+3$.

Art, its universal principle the RealIdeal, I83 seq.; its own end, as creating for the salie of creating, 187 seq. ; creates the Beautiful, but as involving the True and the Good, IgI seq.; must present the Supreme Ideal as reality, 198; every work of, an embodied Theodicy, I99; a token of man's freedom, I99; unblemished, literally a sacrament, 200; power of, the power of thought, 200; its own end, in exactly what sense, $20 \mathrm{I}$ seq.; definition of, 203; distinction between mechanical and esemplastic, 205; division and gradation of esemplastic, 206 seq.; specific characteristic of poetic, 2II seq.; decorative, intermediate between mechanical and esemplastic, 215; improved division of, 216 ; the essay on, not detached, but organically connected with whole of present work, $3^{85}$ seq. [See Beauty, and Poctry.]

Association of Ideas, Spencer's attempt to explain "necessary" truth by, I8; a priori factor presupposed in, 19, 47; agnostic evolutionism would explain origin of time, space, etc., by, 46 , but fails to refute the arguments of Kant, 47, cf. I8 seq.

Atheism, system of eternal free persons charged with, 340,349 ; charge of, refuted, 35 I seq.

Atonement, afforded by world, by being means of rational freedom, I99; as regeneration, implicit in true creation, 350; structural in the eternal being of minds, 377 ; judgment of, supplements "judgment of regret," 377,378 ; is moral use of evil involved in freedom, 378 .

Augustine, St., on definition of beauty, I94; on Divine Sovertignty, 3I6; on Predestination, 333; employs Ontological Proof,
Authority, as method with religion, not characteristic of Romanism vs. Protestantisin, 227 seq.; fails (I) because self-contradictory, 230 seq., (2) because unable to make out direct presence of God, 233 seq. (3) because at war with the spirit of Christianity, 24 I seq., cf. 229.

Autonomy, the essence of Freedom, xxxvii; rests on adequate cognition of the self as intrinsically altruistic, and hence is first principle of knowledge, xxxvii, 4 or.

Bacon, rejects exaggerated claims of scientific method, 95 .

Balfour, A. J., rightly criticises both forms of evolutional philosophy, 4 .

Beauty, its necessary correlation with the True and the Good, I92 seq. : insufficient definition of, as unity in variety or variety in unity, 194 seq. ; adequate definition of, finds liey in triune nature of man as correlative to triune nature of God, 196 seq. ; is the Ideal as object of our capacity for joy, 198. [See Art, and Poetry.]

Berkeley, his system and the theory of Personal Idealism, xviii; his main proposition, only, accepted by latter, xviii; his idealism rests on empiricism, and so on God as an assumption merely, xix; his main propositions, as revised by Kant, presupposed by valid inductioll, 275 .

Bruno, Giordano, among indubitable pantheists, 63 .

Büchner, among materialists, I22.

Caird, Prof. E., master of Balliol, hope of his services in re Hegel, xxvii.

Calvin, on Divine Sovereignty, 316 ; on "high" predestinationism, 333 . Carlyle, his melancholy over life, 157 ; translates Goethe's stanzas on Art, I93.

Categori"s, the, as universal modes of indivitual self-activity, 174 . 
Causa sui, every self a, xiv, 75,339, 347 seq.

Causation, Final. [See Final Cause.]

Causation, Natural, Physical, or Efficient, highest category in all past philosophy, xvii; in Personal Idealism, subordinated to Final, xvii; made explanation of nind by all evolutional philosophy, 6; an essential clement in evolution, 33; generalised to, tacitly, in scientific induction, 34, though generalisation not warranted by the facts, but added in by mind, 35,275 ; in purest and truest terms, is logical unity, $3^{6}$ seq.; within Nature, only transmissive, 39; must conform to Ideal, 39; the "natural" man a product of, 47,364 seq. ; cannot hold from God to the soul, 73, nor from mind to mind, 74; cannot originate free beings, 329 ; incapable of expressing Divine (i.e. real) creation, 33I seq. ; still holds Cliristian consciousness in bondage, $3+3$; inconsistent with moral reality, 347. [See Final Cause.]

Causation, Supernatural, or Metaphysical, its meaning, 38 ; its function in the constitution of evolution, 39 seq.

Christianity, relation of evolution to, 7,50 seq. ; conflicts with any doctrine of evolution representing whole of man as evolved, $5 \mathbf{I}$ seq. ; requires genuine freedom, and thercfore eternity, of the person, 75. cf. 329, 342; opposed, in its central principle, to the Method of Authority, 241 seq. ; its essence, as contained in New Doctrine of Jesus, 2.45-260.

Conscience, the mutual recognition c? minds, as all absolutely real, xiii ; fundamental in the being of each mind and the system of minds, xiii ; the essence of the Divine selfconsciousness, xvi; not explicable by cosmic process, 49 , cf. note 2 ; lays immovable foundation of human interest in freedom and immortality, 76; forms ultimate explanation of intelligence as pure Act, 173 seq.; gives the type of Cluristian religious life, 250,251 ; forms intrinsic root of all self-consciousness, 3 Io seq. ; the elemental paradox, 312; in essential union with freedom, 329 seq., 334 seq.; is ultimate meaning of self-consciousness, 353 ; is, as love, essentially intelligence, and source of all other intelligence, $36 \mathrm{I}$.

Consciousness, normal, has real universality, I7I; universe comes within, and lies open to, I72; world of, means world of self-active minds, 172; every individual, is social, historic, immortal, I73; selfactive principle of, explains categories, and real nature of noumenon, I74; as involving world in the unity of the Person, is pure Act, 174, I75; moral, is really theoretic, and the logical spring of all other, 174,310 seq., $36 \mathrm{I}$.

Conservation of Energy, its philosophical statement, 87, 88, cf. note ; its apparent tendency toward pantheism, 87, 89, 9I-93; its realıy neutral religious meaning, as part of strict science, 96-97.

Continuity, in universal Nature, not explicable by physiological genesis, 26, nor by "spontaneous generation," 27, but mentally demanded, nevertlieless, 28, hence must be sought in supersensible mode of mind, 28; cannot be supplied by the Unknowable, 29 seq., but inust be interpreted as logical, 30 seq.. esp. 37; issues from the inner harmony of mind as rational, 37 , $3^{8}$; depends, finally, on the teleologic or ideal-governed nature of minds, $3^{8} \mathrm{seq}$.

Continuons Copula, the, required in cosinic evolution, 28 ; its nature determinable by an unarrested philosophy, 30 ; not forthwith the Ulti- 
mate Being, though its kind may be ultimate, 30 ; its proximate seat the human mind, 3 I.

Cosmic Consciousness, not equivalent to Personal God, 7.

Cosmic Theism, evolutional theory of, 3 ; rightly requires a self-conscious Noumenon, 43 ; inconclusive as to immortality, 43 ; hostile to freedom, 43 ; only another name for pantheism, 269.

Creation, Divine, not by efficient causation, xvi, 33i seq.; real meaning of, xvii, $65,75,354$ seq.; as human attribute toward Nature, 48 seq., and in art, 188, 199; by fat, contradicts freedom, 332 seq., 344; monistic theories of, have same defect, 345 seq.; only compatible with freedom, if symbolising final causation, $3+7$ seq.

Criticism, Kantian principle of, relation of Personal Idealism to, 426 scq.; thoroughly "critical" character of theory propounded in present book, 426-427, cf. 385 and I60-I70.

Czolbe, his naturalistic philosophy, and relation to Lotze, I22 note.

Darwin, relation of $\mathrm{Neo-Hegelianism}$ to, 4 ; Dühring on, 132.

Davidson, Dr. Thomas, his " apeirotheism," 36I, note 2.

Defect, involved in self-definition against the Perfect, 362 ; factor in all free beings other than God, 363 ; basis conditional for phenomenal consciousness, and for Nature, 365 seq. ; involves risk of sin, or moral evil, 367 ; capable of reformation and cure by freedom, 369 seq.

Deism, defined, 58,69; its limitations and its merit, $70,7 \mathrm{I}$.

Descartes, overlooks primordial altruism of self-consciousness, xxxiii; disapproves extravagant claims of natural science, 95; employs Ontological Proof of God, 356; demonstrates reality of individual self, 357; illustrates Ontological Proof as case of necessary connexion, 357; pertinently criticises Anselm, 358; his own Ontological Proof criticised, 358, and supplemented, 359.

Determinism, as predestination, incompatible with freedom, 318 ; as simple definiteness, wholly compatible with freedom, 320; "The Dilemma of," Prof. James on, 322 note, 372 seq. [See next article, and also Freedom.]

Determinism and Freedom, logical analysis of the essay on, xl-xliii, 386-387; problem of their harmonisation, 3I3, 3I8; reconcilable, though neither identical nor tending to merge in one, $3^{I} 4$; but irreconcilable, (I) if determinism means predestination, $318,(2)$ if it cancels choice or alternative, 3 I9, (3) if freedom means caprice, 3I9, 320 ; harmonise, if (I) determinism means simple definiteness, and (2) freedom means the definiteness of spontaneous intelligence, or Reason, 320 ; shown to mean these, respectively, 321 seq.; their harmony possible only by an idealistic philosophy of Nature, 325, means not merely a harmony of their ideas, but of their operation in real persons, 326 seq., hence, reaches maximum of difficulty in case of God's determinism and man's freedom, 327 ; their reconciliation impossible, if Divine creation means efficient causation, 332 seq. ; their harmonisation forces search after substitute for efficient causation, 335 seq., takes human freedom to involve eternity (i.e. self-activity) of man, $33^{8}$, hence, resulting pluralism seems (I) to erase individuality, 340 (2) to conclude either in polytheism or in atheism, 340, but solution of Divine-human antinomy is found in Final Causation, as truth of the metaphor in 
"creation," 348-356, and neither atheism, 35I seq., nor polytheism, 36 I seq., is real; harmony of, found in universal self-determination, $356-361$, and union of both in every spirit, 369 ; their harmony a harmony of opposed aspects of rational self-activity, 375 , and not a harmony by any "soft" determinism, 377 .

Diihring, life-sketch of, IO3, IO4 ; materialist and optimist, I2I; why leading materialist, I 22 ; maintains The Actual, or world of sense, to be the Absolute, I23; conceives Actual as under polar union between Permanence and Change, I23, I24; reflects Hegel in this, or early Greek philosophy, I23 note; identifies method and organon of philosophy with those of science, 125 ; makes consciousness not copy of things, but their real outgrowtl, reproducing world-process, I26; seems reminiscent of Leibnitz, I27 note; his Natural Dialectic, I27; his attack on Kant's antinomies, I29; his universal logic, as mechanics of Nature, 130; his Three Laws, as the key to all philosophy, I30; his Critical History of Mechanics, I30 note; rejects the principle of persistence of force, I I I, and the Darwinian "pseudo-law" of struggle for life, 132 ; his Worth of Life, $\mathrm{I}_{32}$; his optimistic results, 133; his principle of "cosmic emotion," 134; his ethical principle, I35; his sociology, I35 seq.; his philosophy of history, $\mathbf{1}_{37}$; his philosophy of religion, 138 ; his system fails by construing the Absolute with relative categories, 139, I.70; his attack on Kant no better than a petitio, I.4O, I4I; self-contradiction of his ethics, I4I, I42; his results really egoistic and pessimistic, $\mathrm{I}^{2} 2$.

Edwards, Jonathan, key to his theological genius, 315 ; on consistent predestinationism, 336; on freedon as power to $d o, 33^{8}$.

Emerson, on the omnipresent Power, not to be eluded, 8 ; on the literally creative power of art, 189 ; on the unity between the Beautiful and human nature, I90; on Time as touchstone of poetic power, 216.

Empiricism, its method traced to its real presuppositions, 34 seq., 273 seq.; its method as employed and construed by its experts, 83 seq. : its self-dissolution, as seen through Hume, 178.

Energy, Conservation of. [See Conservation of Energy.]

Eternity, not merely everlastingness, 35I seq.; philosophic meaning of, $35^{2}$, cf. $33^{8}-339,412$ seq. and $42 \mathrm{I}$; proofs of, in the individual, $4 \mathrm{I}_{4}$ 416; identical, in last analysis, with cognition a priori, $4 \mathrm{I} 6$, and hence with Freedom, 4I7; not to be confounded with Preëxistence, 4 I 3 seq., $42 I$.

Evil, natural, originates in the pure logic of self-definition, $3^{62}$ seq., 367 ; moral, consists in passive or active acceptance of natural, 368 ; junction of both with ideality, source of sense of Alternative, 369 seq.; referable, not to God, but to the minds other than God, 392.

Evolution, World of Spirits (or idealistic pluralism) the ground of, $x v$ : limited to phenomena, I3 seq.; scientific, interrupted between Inorganic and Organic, 26, 27; also between physiological and logical genesis, 28; cannot cross gulf between Unknowable and explanation, 29, 30; conception of, analysed to its mental presuppositions, $3 \mathbf{I}$ seq. ; fact of, has proximate ground in human nature, 31,42 ; cannot attain to noumenal reality of mind, $43 \mathrm{seq}$. ; has direct ground in each indizidual mind, 45; camnot explain, on contrary presupposes, conscionsness of Time, 46 , cf. 18 
seg. ; grounded, indirectly, in total worlel of minds, $48,276,35^{2}$ seq.; cannot explain genuine conscience, 49; grounded, ultimately, in a Supreme Mind, or God, 49, 277. 355 ; seconding conservation of energy, suggests pantheism, 89 seq., but does not in fact require this, 94 seq. ; implicate of, seems ever-growing reasonableness of things, 270 seq., but direct conclusion from, as result, to rationality of. Eternal Cause invalid, 27 I seq.; method prcsupposed by, however, makes indirect conclusion possible, and demands it, 273 seq.

Evolutional Philosophy, discriminated from materialism, 2; a mode of idealism, 2 ; takes two main forms, 2; agnostic form of, characterised, 2 ; idealistic monism, as form of, 3 ; claims to supplant traditional religion, 4 ; relation of, to Christianity, $4,7,50$ seq.; destroys reality of the person, 6 ; annuls freedom, and moral value in immortality, 7 ; reduces minds to mere effects (or else modes) of Absolute, 8; agnostic, makes human person merely phenomenal, I4; same, rightly declares for Eternal Ground of things, 25, 29, 270 seq., and, with reserves, for a development in rationality, 270 , 27 I seq.

Existence (or reality) of God, exact nature of argument for, in present book, $424-426$, cf. $35^{6}$ sc $7 ., 3^{8} 7$, and 403; rebuttal of objections to the argument, $425 \mathrm{seq}$.

Experience, organised by a priori consciousness of individual minds, xiii, 3 o seq., 297 seq. ; direct objects of, distinguished from noumcnal reality, 13 ; restriction of knowledge to, makes noumenal reality unknowable, I6 seq.; a priori factor in, indicated, 17 , and proved, 20 seq., 299 seq. ; factor of limitation in, 49,338 ; explanation of, as con- stituent in every mind but God, 363 seq., 374 .

Faith, basis of religion, in the Method of Authority, 22I, 222; religions of, as distinguished from religions of Hope, and the religion of Love, 254 ; only basis for theism attainablc by agnostic evolutionism, 272; exercise of, as "will to believe," defended by Prof. James, 284.

Fichte, the elder, takes monistic alternative in view of dilemma brought on by Kant, $x x x v$, and so falls into deeper one, xxxvi; question of his pantheism, 63 note.

Final Cause, God reigns by, xiii; supremacy of, key to Personal Idealism, xvii ; factor in explanation of Nature, xxi ; not consistently treated by Aristotle, xxv; conditions conception of evolution, 38 ; sole complete causality, because alone free, $3^{8}$; vital cord in notion of evolution, 39 seq. ; basis of genuine omniscience and omnipotence, 65; sole causal relation between minds, 74; definition of, 348 ; only clue to harmonising Divine supremacy and hıman freedom, 348 seq.; as sole mode of Divine causation, key to God's adorable nature, 360 ; notably dealt with by Aristotle, but not completely, 364 seq. ; the fundamental Cause of causes, 365 ; the essence of freedom, 380; supreme place of, in Personal ldealism, 348; twofold meaning of, 39 I ; error about rôle of, corrected, $4 \mathrm{I}_{5} \mathrm{seq}$.

Finite, no spirit is, in its defining whole, 329 seq., 42I; God, does not follow from his individual distinctness, or his membership in VIorld of Spirits, 422; not to be mistaken for the definite, 422.

Finite and Infinite, their qualitative meaning, 330 seq. $363,373,421$ seq. Fiske, J., his Idea of God, in Concuril "symposium," $5^{6}$ note; his cal:- 
tious and correct statement of evolutional argunent for theism, 272.

FitzGerald, the translator of Omar Khayyan, on pantheistic "suijectivism" of existence, 3 ; on the Unalterable Record, 379.

Freedom, all proof of, comes finally to proof of a priori cognition, xliii seq.; fundanental postulate of Christianity, 7, 52, 74, 75, 257, 331, 335; annulled by all evolutional philosophy, 7, 8; impossible, if man is product of natural processes, 5I, 325; apparently discredited by conservation of energy and by evolution, 92 , but not really so, 96; essential to human goodness, and to government truly divine, 3 I7 ; not simply spontaneity, to exclusion of choice, but inclusive of both, 319; agents possessing, logically prior to Nature, 325 ; reality of, means pluralistic idealism, 326; defined as eternity, in sense of self-activity transcending time, 329, 333, $33^{8}$ seq., 35 I seq., 380 ; impossille, if Divine causation is "efficient," 33 I seq., 334, 339, 343; demand for moral world is demand for, 337 ; involves power to $d o$, as well as to choose, $33^{8}$; defined as self-determination, in the sense of self-definition, 35I seq., hence, as power to transcend sensory Check, 366, 369, further, as self-direction according to Ideal, 376 ; a principle of renewal and reform, and so of Atonement, 377i contributed to by Fate, when latter is kept to its proper realm, 379 . [See Determinism and Freedom.]

God, existence of, necessary in order to other minds, xiii-xv, 49, 355: immanence of, according to $\mathrm{rvolu}$ tional philosophy, 2, 3; as imminnent, is efficient or prorlucing causc, even of other minds, 6 seq. ; pcrsonality of, disappears in all evolitional philosophy, 7 ; not personal, unless in relation with other real (i.e. free) persons, 7, 52; genuine omnipotence of, only realised by his causation being purely final, 65: relation of, to souls, must be in terms (I) of pure thought, and (2) of final causality, 73 seq. ; implicitly dispensed with by Scliopenhauer, 107, and by Hartmann, I09, II9; expressly so, by Dühring, I23, 138 ; dissipated in the "Ideal " by Lange, I45, I55; transcends possibility of presentation to the senses, 24I; early conception of, as Sovereign Polver, 252; Cliristian conception of, as Father, or Impersonated Love, 253, cf. 245 seq.; central member of the society of spirits, 256; governs by moral agencies only, 258; recognises freedom of other minds, 259, 268; not a bare ideal, 269; reality of, implied by tacit logic of scientific method, 273 seq.; supremacy of, whether compatible, under any view, with human freedom, 3I4 seq.; not the direct, much less the sole, source of natural world, 325,326 ; the ruling Ideal, 326 seq., cf. xiii seq.; demanded by eternal system of free persons, $35 \mathrm{I}$; proof of, by idealistic pluralism, 352-356, and this proof compared with Ontological Proof, 356-359; exists only as primus inter pares, 359; attributes of, in light of eternal free system, 360 , $36 \mathrm{I}$; exact nature of the argument for, in present book, $424-426$, cf. $_{3} 5^{6}$ seq., 387 , and 403 ; rebuttal of objections to this argument, $425 \mathrm{seq}$. [See Religion.]

Goethe, his stanzas on Art, modified, I93.

Good, the, the first principle of intellisence, 40 note, I73 seq., $36 \mathbf{1}$; correlation between, and the True and the Beautiful, I93; distinction of, from these, I9t seq.

Gordon, Dr. G. A., his views on harmony of determinism and frce- 
dom, 314; his Ingersoll Lecture, 3I+ note; his estimate of Edwards, 3I5 seq.

Haeckel, not to be reckoned a materialist, I22 seq.

Harris, Dr. W. T., U. S. Commissioner of Education, his connexion with Hegel's Logic, xxvii; his part in Concord "symposium" on pantheism, 56 note; place of his system in the Four Groups of Philosophies, 395.

Hartmann, life-sketch of, IO3; his Philosophy of the Unconscious, 105 ; mental heir of Schopenhauer, 105; gives empirical method predominance, 105, 109; pessimism apparently his chief motive, I09; his basis of proof for Unconscious, IIO; his tracing of its historical recognition, IIO; attempts refutation of Kantian limitation of knowledge, I I ; reminiscent of Spinoza, III note; makes Unconscious the source of duplicate phenomenal worlds, II I seq.; holds Mystic and Induction the two organs for knowledge of Unconscious, I12; makes Unconscious a transcending union of Will and Idea, II3 seq.; asserts preponderance of suffering over happiness, II5; his Three Stages of lllusion, I15, I16; maintains being of world worse than its not being, II6; implies highest ethical precept is Make an end of it! II6; commends universal self-annihilation as means for this, II7; his philosophy of history, of politics, of religion, II8-II9; his theory criticised, I20; his services, in common with Schopenhauer, I2I.

Hedge, Dr. F. H., puts Leibnitz in dubious company, 349 ; his monism in religion, 350 .

Hegel, monism of, and of his school, ix; permanent debt of pluilosopliy to, xxvii ; in dilemma brought on by Kant, takes monistic alternative, with Spinoza, as against agnostic, whether Humian or Kantian, xxxv; falls into deeper dilemma between saving knowledge at cost of autonomy or saving autonomy at cost of knowledge, xxxv-xxxvi; pantheism of, questioned but finally admitted, 63 note, and confirmed, 67 note; degeneration of later German idealism from, $\mathrm{IO}_{3}$; indirect debt to, on part of Hartmann, I06; misinterpreted by Hartmann, II4 note; one-sided reminiscence of, in Dühring, I23 note; Aesthetik of, followed in part, 187.

Heraclitus, among undoubted pantheists, 63 .

Heredity, attempt to explain consciousness of Time by, fails, Ig seq., 46 seq.

Hopkins, Dr. Mark, his signal innovation in treatment of Christian evidences, 265 note.

Hume, detects subjective character of necessity, when self-consciousness is taken non-socially, xxxiv, and so discounts in advance Kant's "critical" vindication of its objectivity, xxxv; failure of, to recognise evolution, exposes Kant's rejoinder to him to evolutional objections, 19, but rejoinder holds, evolution notwithstanding, I9, 20; supplies drastic cure for agnosticism, through his dissolution of empiricism, I76 seq.

Huxley, implies non-evolutional origin of conscience, 49, cf, note 2.

Ideal, origin of, according to evolutional philosophy, I; spontaneous, essential to the notion of evolution, 38 seq. ; as manifested in the three Pure Ideals, fo; with Lange, not a philosophy, but a standpoint, I45; substituted by Lange for Absolute, I $46 \mathrm{seq} . ;$ made the meaning of religion, 155 ; the, immanent in the actual, 183 seq.; function of, in 
art, 184 seq. ; the supreme, of man and Nature, inspirer and guide of genuine art, 192; as object of joy, defincs the Beautiful, 198 ; free attraction of intelligence by its, 338 ; action under self-recognised, constitutes mind causa sui, 347 seq.; supplics key for proof of God's reality, 354 seq.; correlation of, with defining Check, makes basis of proof for monotheism, 363 seq.; same, explains origin of Nature and possibility of $\sin , 366$ seq. ; union of, with actual, explains consciousness of Alternative, 370; indwelling influence of, the essence of freedom and of Atonement, 378, 380.

Idealism, pluralistic, or Personal, explained, viii seq., and outlined, xii seq., 389 seq. ; historic, generally impersonal, viii, and at one with materialism and evolutionism in monistic tendency, ix ; monistic, irreconcilable with personality, divine or human, $\mathrm{x}$; pluralistic, or Personal, rests on spontaneity of all minds, $x-x i$, asserts, for all, potential knowledge, universal and complete, xii, provides for moral order, xiii, God, xiv, freedom, xiv-xv, and evolution, $\mathrm{xv}-\mathrm{xvi}$, and means "eternal reality of individual,"xxvii; all evolutional philosopliy a mode of, 2 ; negative, or agnostic, sketched, 2 ; affirmative and evolutional, outlined, 3 ; complete and pluralistic, outlined, I7 I seq. ; one-sided, as theory of art, 182; pluralistic, or Personal, proved thoroughly theistic, 35I-359, and monotheistic, $362-372$; essential nature of, , 06 seq. ; makes intelligence, not feeling or will, the organic principle, 407 ; necessarily rationalistic, i.e. apriorist, 407 ; cannot be any sort of empiricism, 407-408.

Ideas, association of, see Association of Ideas; origin of, according to Spencer, 18 seq., and as decisively treated by Kant, 19 seq., 297 seq., 300 seq., 309 seq.
Imagination, source, according to Lange, of metaphysics, of poetry, of religion, I5I, and comes from transcendental illusion, I5I ; distinguished from Fancy, 185 ; strictly creative nature of, 189 ; organic function of, in art, 203, 205; essential and guiding factor in supersensible man, 206; constructive and developing principle in universe, 206.

Immortality, no genuine reached by evolutional philosophy, $7,43,52$; chance left open for, in Cosmic Theism, 43, 5I ; no worth in, without moral freedom, 52 ; an essential condition of fulfilled righteousness, 78-8I ; apparently discredited by conservation of energy and by evolution, 87 seq., 92 ; denied, consistently, by Schopenhauer, I08 ; also by Hartmann, II5, II6 ; dispensed with by Dithring, 138 ; made vague hope by Lange, 152 , I53 ; essential to fulfilment of individuality as universe-consciousness, I73; one of the Three Truths constituting New Doctrine of Jesus, 256 ; individual, alone can satisfy us, $285-287$; but not reached by transmission-theory of brain-function, 289-295; yet is possible on theory of simple concomitance between brain and conscious states, 295 seq. ; is involved in the self as organiser of its own experience, 297 seq. ; proved actual, by $a$ priori consciousness of Time, 303 seq. ; and, more fully, by all-conditioning relation of self to Nature, 306 ; proved not simply superiority to death, but utter imperishableness, 307 seq. ; shown not mere continuance, but of absolute rationial worth, 309-312; provicles for established dominance of the spiritual over the natural, $374 \mathrm{seq}$. Induction, philosophy of, as really presupposing idealism, $3+$ seq. 98 ; empirical theory of, is unclerstood 
by its practitioners, 83 seq., 85 note; theistic implications in logic of its method, 273 seq. ; valid, only on idealistic view of reality, 275; logic in method of, only leads, directly, to universal rational nature, 276; but, indirectly, to society of rational persons, 276; and, finally, to God, 277.

Infinite, in last resort, qualitative and not quantitative, 422 ; always definite, never indefinite, 422; essentially individual, 422 .

Infinite and Finite. [See Finite and Infinite.]

Intelligence, primarily moral cognition, xxxvii, 38, 46, 73, 75, I74, I93, 276, 312, 353, 36I, 40I; selfactive, other than God's, embraces a natural world, 325,363 seq., 365 seq.

James, Prof. W., his doctrine of pluralism distinguished from Personal Idealism, xi, xii ; hypothetic character (intentional) of his argument upon immortality, 280, 28I; his general philosophic aim characterised, 284; his transmissiontheory fails to provide for individual immortality, 285 seq.; makes individual consciousness still depend upon the brain, 290 seq.; remedy for this defect in his procedure proposed, 295 seq., and explained in detail, 299-312; his ambiguous use of "chance," 322 note; real presupposition in his "judgment of regret," 372 seq., 377 ; his " dilemma of determinism" not exhaustive of the alternatives, 378 . [See Immortality, and Determinism.]

Jesus, in question between Reason and Authority, must be assumed real man, and to speals as man, 236 ; his word simply, capable of proving what, 236,237 ; conflict of Method of Authority with spirit of, 24I-260; central insight of, a new view upon nature of God and God's relation to all souls, 243; his "secret" a new Doctrine and new Temper, 243, 24+; his new Doctrine rightly stated as presentation of God as exhaustless Love, but not adequately, $2+6$; his forward theistic step not simply new, but revolutionary, 25I; replaces conception of God as Sovereign Power, and Awful Majesty, by conception as Love Impersonated, without condescension, without reserves, 253 seq., cf. 248 seq.; the God of, Guide and Friend instead of Lord, 254; his doctrine of man, and all souls, their absolute reality, in sense of their complete freedom to seek equality with God, 256; his Three 'Truths - God the Perfect Person, Souls immortal, Souls indeed free, 256, 257; key to his Doctrine and his Temper alike, this new view of men as free, 257 seq. ; his words, cited to the contrary, uncritically misinterpreted, 260.

Jowett, Prof., on the De Imitatione, and its excessive type of religion, $36 \mathrm{I}$, note $\mathrm{I}$.

Kant, relations to, of Personal Idealism, xviii-xxii, xxxvi, 383 seq.; notes primordial sociality of selfconsciousness, but holds it not objective, and hence extralogical, xxxiv; distinctly rejects monistic way of escape from dilemma between Spinoza and Hume, xxxiv; hence relies on pure fealty to World of Spirits, and so fails of objective necessity, xxxv; shows experience not simple, but complex, getting "form " through a priori factor, I7, 297 i his "a priori" cognition not outflanked by Spencer's "happy thought," I8 seq.; his reply to Hume not invalidated by evolution, I9; first to expound cosmic crolution in grand detail, 20 note; 
his implication true, that evolution cannot produce our consciousness of Time, 20 seq. ; his " causality with freedom " identified with Final Cause, $3^{8}$; rightly makes sensation point to noumena, 49 ; rejects extravagant claims of scientific method, 95; shows reason legislative over Nature, 98 note; distorted by Neo-Kantianism into supporting empiricism, IO2; his Thing-in-itself identified with Will by Schopenhauer, 107; and with Unconscious by Haltmann, IIO; his empirical limits of knowledge attacked by latter, IIo, III; his "antinomies" assailed by Dühring, 125-129; Fall back on, the rallying-cry of Lange, I 4 , but his "primacy of practical rexson" is denied, 146, and his a priori settiement of "elements" is shifted to induction, 147 ; his Thing-in-itself reduced to mere "limiting notion," I 49 ; same, erroneously confounded with " things as they are," I60 note; cited by Prof. James, on senseworld as restrictive of our thinking, 286; impugns Ontological Proof, 356; his world of "pure reason," as embracing Nature under it, 306, 366; his Iestriction of knowledge to phenomena dissolved by the tacit self-criticism of Lange, and his doctrine of autonomy thus given theoretical basis, 385.

Knowledge, centres in conscience as cognition of World of Spirits, xiii, xxxvii, 174-I75, 310, 312, 353, 36I ; problem of its pussibility tive fundamental issue in philosophy, 17; petitio regarding, made by agnostic cvolutionism, I7-2I ; contradictions regarding, in same, 22-25; $a$ priori, proofs of, 46-47, $297 \mathrm{seq}$. $300-301,306,309,310,311-312$; reality of a priori, proves personal immortality, 298, 302, 304 seq., 307, 308,310 , and alsu worth of same,
309 seq., and constitutes essence of real freedom, 322-323, 325, 329, 333 , 362 seq. , 369-37I, 373, 375, 380; coristitutes also, fundamental proof of Personal Idealism, xlviiseq.,4I 4 seq.

Lange, life-sketch of, $\mathrm{IO}_{4}$; his History of Materialism, 10.5, I43; his general aim and its ethical motive, I43: his return to Kant, 147 ; his recognition of the truth in materialism and in idealism, I44, I45; makes the Ideal not a philosophy, but a standpoint, I45, I46; states negative and positive functions of philosophy, I46 ; criticises Kant, I46 seq.; attacks Kant's " primacy of practical reason," and his a priori settlement of a priori elements, I47; makes cognition and will wholly phenomenal, I47; holds a priori elements must be discovered by induction, I47; adds motion to the list of these, I47; counts senseworld explicable on mechanical principles, 148 ; declares Thing-initself merely "limiting notion," I49; makes "limits of knowledge of Nature" limits of all knowledge, 149; considers our hypostasis of "limiting notion" an organic illusion, I50; hence makes metaphysics, religion, poetry, sprung from this illusion, all work of imagination, an effect of the "Ideal," I5I; holds balance between optimism and pessimism, 152, 153; his ethics chiefly fortitude and resignation, I54; Jis sociology a stern socialism, I54; his philosophy of religion a reduction to the bare Ideal, 155; merits and defects of his "standpoint of the Ideal," 155-159; self-dissolution of his agnosticism, 159-169; his movement in fact establishes absolute quality in our knowledge, 170, supplies a Critique of all Scepticism, I70, and a definitive Critique of all Materialism, I7I, cf. I48 note; in effect, opens 
way to affirmative idealism, I7I seq.; avoids this, by rejecting Kant's " transcendental reflection," and substituting induction, as clue to a priori, I75 seq.; abandons, thereby, Kant's standpoint, and returns to Locke's, 176; provicles, in fact, by dissolving Kant's restrictions, a genuinely critical basis for a new transcendent metaphysics, 385.

Le Conte, Prof. Joseph, his idealistic philosophising of evolution, 7 ; his treatment of evolution in interest of immortality, 52; his theory of the art-principle, I82-I86; his relation, in this, to Schiller and Schelling, 187 ; his view of the "mimetic" arts, 207 ; his address at San Francisco Congress of Religion, 268 note.

Leibnitz, the only great modern mind to break witl monis m, ix; his troublesome use of metaphor, xxiii ; relations of Personal Idealism to his system, xxiii-xxv; notes, with Spinoza, though inadequately, the altruistic character of self-consciousness, xxxiv; his statement of the principle of conservation, 88, cf, note; rejects extravagant claims of scientific method, 95; reminiscence of, in Dïhring, 127 note; accused of rendering God superfluous, $349 ;$ in a clubious context, in Hedge's Atheism in Philosophy, 350 .

Lotze, why not included in account of later German pliilosophy, Izz note.

Love, divine as conceived by older religions, only pity and condescension, 2.47 i as conceived by Christianity, the unreserved offer of complete sharing in divine life, 248 seq.; governs by inner conviction alone, $249 \mathrm{seq}$, yet admits of transient place for compulsion, 250 ; implies recognition of individual freedom, 256; God's, holds individuality and its mental initiative sacred, 257 ; adequately defined, is essential intelligence, source of all other, 36r.

Lowell, quoted as authority for " unbeknown," II3 note.

Lutoslawski, Prof. W., as extreme individualist, xi.

Martineau, Dr. James, on mystic species of pantheism, quoting Rothe, 65 note.

Material Existence, defined as experience organised by a priori mind, xii-xiii; is under a priori law of evolution, $x v, 40,366,375$; its origin in the constitution and action of non-divine self-consciousness, $33^{8}, 3^{6} 3$ seq. 365 seq.

Materialism, its relations to pantheism, 63 seq.; its subtle defense by Dühring, 123-132; its services and its shortcomings, according to Lange, I4t seq.; its incapability of proof, shown by agnosticism, I48, I68; its final impossibility, shown by Lange, I7o seq.

Maurice, F. D., his view of key to Edwards's genius, 3 I5.

Mc Taggart, J. M. E., his penetrating criticisms of present book, xlviii; his coincidence with Davidson, and, in part, with author, 389 ; reply to his criticisms, 420 seq.

Mill, J. S., on the "final inexplicability," 29; Lange compared witl, $1_{5} 6$.

Mind, cocxistence of, with others, means mutual logical implication, xiii ; equality of, with others, rests on having common 1 deal, xiii; has no literal origin, no time-begin ning, no efficient cause, xiv; intrinsically free, $x i v, x v$; origin of, in efficient causation, according to evolutional pliilosophy, $I, 6,8,44$; but not so originable, 40-41, 54. [See Person, and Spirit.]

Miracle, apologetic misuse of, 70 ; profound truth implied in doctrine of, 70 note; popular misinterpretation of, 70 note; logical motive of 
introducing into Apologetics, $23^{8}$; weakness of, as resting at last on human testimony and judgment, 239 seq., and as presupposing $\mathrm{Na}$ ture to depend on will of God, 240.

Moleschott, among materialists, 122.

Monism, true meaning of, 410 ; not the theory that but one kind of Substance exists, 4 Io; fundamental issue between, and pluralism, 4 II.

Monotheism, pluralistic idealism proved the only genuine, $362-372$.

Monotheistic character of Personal Idealism vindicated against $\mathrm{Mr}$. McTaggart's objections, 428 seq.; its right in using name God, 429430.

Montgomery, Dr. E., in Concord "symposium" on pantheism, $5^{6}$ note.

Morality, in strict sense, impossible without real freedom, xxxvii, 329 , 333. 35I ; hence involves coeternity ot souls with God, 35 I seq., cf. 338 , 342,343 i its first principle an act of knowledge, as well as first principle thereof, xxxvii, 400 seq.

Natural Selection. [See Selection, Natural.]

Nature, in essence, sum of organised experiences of minds, xii-xiii ; joint explanation of, by Efficient and by Final Causation, $\mathrm{xx}-\mathrm{xxi}$; not properly a cause, but only a transmissive effect or aggregate of such effects, 39 ; its origin in the complete self-dcfinition of the individual, 306 seq., 362 seq.; factor in every mind other than God, 362365 ; scene of ceaseless conflict between actual and ideal, 364, 366; not in itself guilt, but carries risk of $\sin , 3^{6} 7 \mathrm{sec}$.

Necessity, as nexus of phenomena, issues from individual minds, $4 \mathrm{I}-45$.

Neo-Hegelianism, its dubious relation to Darwinian theory, 4.

Neo-Kantiani $\div m$, its singular reversal of apriorism, 102; German school of, prominent members in, IO3 note.

Noumenon, distinguished from phenomenon, I3 seq. ; the human person not a, if evolutional philosophy holds, 14, 43, 52; possibility of knowing the, I5, I7, 24 seq., I68 seq. ; if knowable, must be Reason, I5, I70, I74 seq. ; reality of, necessary to evolution, 22,29 ; every real mind must be a, xvi, $4 \mathrm{I}, 4+4,45,333$, $33^{8}$ seq.; interpreted as mere notion, and limiting notion, by Lange, $149,160,162$; belief in, as real, held organic illusion by same, $150,163-$ 166 , but in fact has source in each mind's primal consciousness of others, I74 seq. ; final explanation of, $\mathbf{1} 75$.

Objectivity, problem of its nature and basis, xxxiii; new theory of, characterising Personal Idealism, xxxiii seq., I73-I75, 310-3I 2, 35 I-354, 359 , 384,400 seq., 4I7 seq.; dilemmas over, in course of modern thought, xxxiii-xxxy, and their solution by Personal Idealism, xxxvi.

Oken, among undoubted pantheists, 63.

Omar Khayyam. [See FitzGerald.]

Ontological Proof of God, historic employers of, 356; impugned by Kant, 356; not rehabilitated by Hegel, 356; formalised by Anselm, 358; improved by Descartes, $35^{8}$; how related to proof by Personal Idealism, 359, cf. 356 seq.

Pantheism, common confusion as to its meaning, 58 ; distinguished from theism and deism, 58,69, 76 ; definition of, 62,76 ; two forms of, Atheistic and Acosmic, 62 , both at bottom atheisms, 64; relations of chief philosophic systems to, 63 , cf. note; relation of, to materialism and to subjective idealism, 65-68; theistic gains in, 68, 69; merit of, in comparison witl 1 deism, 69, and 
with sensuous theism, 7I; contribution of, toward genuine theism, 72, 73; fatal shortcoming of, compared with demands of religion, 75,76 ; contradicts real freedom, and immortality with worth, 77 ; truth or falsity of, not settled by this, but its human significance is, $77^{-81}$; suggested by modern science, (x) through empirical method, 8386 , (2) through this resulting in conservation and dissipation of energy, and in evolution, 87-93: not really warranted by science, 94-97; entire neutrality toward, on part of strict science, 97,98 ; 11ecessary, as stage of thought preparatory to genuine theism, 99 ; needs to be transcended, 100 .

Parallelism, Psychologica], not strictly construed by Prof. James, 295; exactly interpreted, is not obstacle, but key, to personal immortality, 296 seq.; concomitancy of its two streams explained by unity of 'Time as pure act of soll1, 300 seq., $3^{86 .}$

Parmenides, among undoubted pantheists, 63 .

Peabody, Dr. A. P., in Concord "symposium" on pantheism, $5^{6}$ note.

Person, sign and test of true, $\mathrm{x}$; real, disappears in all evolutional philosophy, 6,7 ; human, in same, merely phenomenal, or else modal, 8, 43; defined, by its essence, 52 ; the, sovereign over Nature, 54, 306, 325 ; each, focal point in universe of minds, $\mathrm{I}^{2}$ seq. ; to each, worldwhole somewise present, I73; each, a transcending unity of subject and cause, 174; each, in art, a literal creator, 198 seq.; divine functions of each, in religion of Jesus, 255 seq.; each, in same, recognised by God as free, 256 ; self-active nature of, proverl, 299-302; every, essentially social in root of self-consciousness, xiii, 310-312, 359; how numerated, in world of persons,
$354,3^{6} 3$, note 1 ; the Supreme, defined as God by eternal self-fulfilment, 355 ; every, unrepeatable, 362 seq.; each, other than God, selfdefined against God, 363, cf. 355; every, except God, joins two antagonistic natures in its unity, 364 ; each, from this inner conflict, liable to $\sin , 367$; yet holds in its idealising freedom a recovering Atonement, 376 seq.

Personal Idealism, why so called, viii-x, 389; outlined, xii-xviii, 390392 ; relations of, to Berkeley, xviiixix, to Kant, xix-xxii, xxxiv-xxxviii, 426 , to Leibnitz, xxiii-xxv, to Aristotle, $x x v-x x v i$, to the Oxford Essayists, $\mathrm{xxx} x-\mathrm{xxxij}, 405-408$, and to views of Davidson and of Mc'Taggart, $3^{89} \mathrm{scq}$.; two theories, quite diverse, going by the name of, xxxi; not to be confounded with Subjective Idealism, xxxii seq., 38., 400 seq., 417 seq.; how contrasted (I) with monism, and (2) with elder monotheism, 383 ; put on critical b.tsis by self-criticism of Lange, 385 ; the proofs of, their real nature and their actual presence, xl-xliv, xlvi-xlviii, fI4 seq.: interprets God by final cause, how, 391 , and how, the Divine Offices of Creation and Regeneration, 392, cf. 329 seq. and 342 seq.; jts moral necessity and practical bearings, 389 seq.; alone really solves problem of Freedom, 399, of Immortality, 40I, of Evil, 402, and of the reality of God, 403; not atheism, $351-361$, cf. $268-278$; not polytheism, 36I-372; not chaotic individualism, 409 seq. ; not the theory of preëxistence, 4I2 seq. ; omissions of, in present exposition, relative to Kant, 426.

Personal ldealism, the Oxford volume called, xxx; views in, contrasted with those in present book, $x x x i$ s*q.. 405 seq. ; prior right of latter to title, xxxi seq., fo5 seq.; points 
of agreement with, 406; views in, not in fact idealism, 407 ; violations of iclealism by, summarised, 403.

Phenomena, evolution limited to, I3; distinguished from noumena, I3 seq.; minds not merely, proved by analysis of notion Evolution, 44 seq., and by establishing a priori cognition, 300 seq.

Philosophy, historic systems of, their moral insufficiency, 393-398; their classification, quoad creationisin, into Four Groups, 394-395; inability of any of the Four to provide for Freedom, 395-396, or to solve problem of Evil, 397-398, or to prove existence of God, 403404.

Plato, whether a pantheist, 63 note; rejects extravagant claims of scientific method, 95; defines beauty as unity in variety, 194; foreshadows New Doctrine of Jesus, 24. ; criticised by Aristotle, 365; his "ensnared in the natural," 367 .

Pluralism, as implied in Personal Idealism, xi-xvii; not to be confouncled with utter individualism, xi ; nor with disjunct world of empirical agnosticism, xi, xii; nor with theory of universal finitute, xii; involves moral order, xiii; implied in genuine theism, 73 seq.; sketched, as result of selfdissolved agnosticism, I7 I sec.; illustrated in theory of art, I88 seq., 199; presupposed in religion of Jesus, 256 scq., 326 ; implied in tacit logic of induction, $27^{6}$; basis of proof for immortality, 304, 305, 367 ; required by the moral order, 333. 337 seq.; not atheistic, 35I359; not polytheistic nor "apeirotheistic," $362-372$; solves the "dilemma of determinism," 377 seq. ; may be chaotic, but need not be, 4II; rational, is harmonic, federal, expressed in $e$ pluribus unum in contrast to plures ex uno, 4 II; prcëxistence not involved in,
$412-413$; in what sense common to several phases of recent thought, 420 ; essential principle of idealistic, "eternity" of individual, $42 \mathrm{I}$. Poetry, its essential principle the Real-ldeal, 183 ; its own end, I86, IgI seq., 201 seq.; eșence of, 203 seq., 2II; highest of esemplastic arts, 210; creates new real unit, $2 I I$; differential trait of, in contrast with other arts, 212; not identical with verse, 213-216. [See Art.]

Polytheism, system of eternal pluralism charged with, $340,349,36 \mathrm{r}$; but proved not to involve, 362-372. Pope, poet, on the pantheistic nature of existence, 3 .

Predestinationism, efficient theory of Divine causation leads to, $333 \mathrm{seq}$. Preëxistence, not the meaning of a rational pluralism, nor of Personal Idealism, 4I3, 42I.

Psychological Parallelism. [See Parallelism.]

Realism, as one-sided theory of art, I83, I9I, 200.

Reality, primary, the existence of minds, xii; derivative, the existence of their experiences, xiii; as first reached by metaphysical cognition, is human mind, 3 I seq.; necessary and sufficient condition of, consensus of all minds, I70; of other selves, involved in all selfdefinition, $3^{\text {IO }}, 3^{\text {I } 2}, 353$.

Reason, as knowable Noumenon, I5; the true divine revelation, $225,268-$ 277 ; as method with religion, not peculiar to Protestantism, nor confined to unbelievers, 226-230, but alone fulfils the meaning of Jesus, 242-260; not confined to judgments of scnse, 225, 262; this proved in detail, 267-277. [See Religion.]

Religion, possible views of relation of reason to, 2I7 seq.; two opposed theories of reason's antagonism to, 217-218; three doctrines, Old, Mictdle, New, of reason's possible 
harmony with, 219-22.4; two methods with, - Method of Authority, Method of Reason, 226; this divergence about, not to be confouncled with Romanism vs. Protestantism, nor with Christianity us. Infidelity, etc., 226-230; Method of Authority fails in, (I) because self-contradictory, 230 seq., (2) because unable to verify directly present God, 233 seq., (3) because at war with essential spirit of Christianity, 2.4 I seq., 259 seq.; essence of Christian, or "secret of Jesus," 243-258; doctrine of Christian, foreshadowed in Hellenic thought, but its tone and temper not reached, 244; Christian insight in, failed of also by Judaism, 252 seq.; contents of, inust be determined by reason, $26 \mathrm{I}$, as $\mathrm{Method}$ of Authority itself tacitly implies, 263 , and ever-increasing reliance on Internal Evidence shows, $26_{4}$ seq.; historical development of, shows manifest and constant growth in using Method of Reason, 266; broadest and deepest definitions of, 267 . 268; common fullacy in arguments for, on basis of evolution, 270-272; highest form of, presupposed in tacit logic of scientific method, 273-277. [See K'eason, and Love.]

Responsibility, individual, disappears by logic of evolutional philosophy, $7,5 \mathrm{I}$; requires an eternal Pluralism, 328 seq., 337 seq., $3+2$ seq., 399.

Reviewers, errors and oversights of, in dealing with Personal Idealism, xxxii-xlviii, 409-430; owing, in part, to absence from present book of sufficient discussion of Space, xxxviii-xl, 4 I8.

Rothe, on pantheistic mysticism, 65 note.

Royce, Prof. J., on uncertainty of immortality, 43, note I; admits, in effect, opposition of Cosmic Theism to strict freedom of individual, 43 , note 2 ; charges pluralistic ideal- ism with atheism or else polytheism, 349 .

Ruskin, on criterion of "greatest artist," 20 .

Salvation, real meaning of, 3I5; ultimately universal, 315,373 seq., 375377 ; indwelling source of, 379,380 . Schelling, takes, with Fichte, monistic alternative in the dilenma brought on by Kant, xxxv, and gets into deeper one, xxxvi ; among undoubted pantheists, 63 ; his "Neutrum," as bearing on Hartmann's "Unconscious," II3; his theory of art, germ of Le Conte's, 187; his title "esemplastic," for fine arts, $205,215$.

Schiller, poet, on art theory, influences Le Conte, 187 ; on art as man's prerogative, 199 .

Schiller, F. C. S., his special form of pluralism, universal finitude, xii.

Schopenhauer, his wide spluere in later Germany, 105; his influence upon Hartmann, I05, 106; his doctrine of Thing-in-itself as IVill, I07; his pessimism, 107, 108; sum of his ethics, 108; his atheistic religion, I08; his service to philosophy, I2I.

Science, Natural, and its world, matter of sheer belief, when World of Minds becomes so, xxxv; cannot settle question of limits in evolution, 9-I2; evidence of, comes short of widest universals, 9, II ; method of, as viewed by philosophy, 34, 35; cannot explain human nature, 49,54 ; within its own limits, completely compatible with religion, 54; method of, as naturally construed by its practitioners, $83^{-}$ 85; seeming pantheistic drift of, (I) through its method, 85 seq., (2) through its chief results, 8793; " modern," restricted to experiential science of Nature, 94; cannot solve problem of limits of knowledge, 96; outside its own limits, entirely neutral, 97 ; its real 
presupposition the primacy of mind over Nature, 98; its function in religion, only corroborative, 99 ; tacit logic of, presupposes theism, 273277.

Scotus, Duns, his system of arbitrary predestinationism, 333 .

Selection, Natural, only metaphorical, 9o; eventually, only to death, gr.

Self-consciousness, primordial logic of, xxxiii; its essentially social character, xxxiii-xxxviii, I73-I75, $35 \mathrm{I}-35+4,359,3^{8} 4,400$ seq., 417 seq. : at bottom a conscience, 175, 310 seq., 353. [See Self-definition.]

Self-definition, involves reference to other real selves, 353 ; number of the minds determined by, $35+363$ note. [See Self-consciolasness.]

Shakespeare, on life as illusion and dream, 159; on poesy as s'rict creation, 189.

Shelley, on life as staining the eternal light, $28 \mathrm{I}$.

Sin, origin of, 367 ; is passive or active acceptance of defect, 368 , cf. note; fuller definitions of, $370,37 \mathrm{~T}$, 376 ; is grounded in freedom, $37 \mathrm{I}$, $373 ;$ is freedom's self-dishonour, 376 ; profounder freedom the eternal Atonement for, 377,378 .

Socrates, in doctrine, precursor of Jesus, 244; in spirit, comes short of lim, 2.4.

Space, omission of its adequate discussion, xxxix; this probably cause, in part, of confounding Personal Idealism with Subjective, xxxix; actually founded in the a priori sociality of self-consciousness, xxxix; contrasted with Time, as public principle vs. private, xxxix, fr8. [See Space and Time.]

Space and Time, their contrast as the public and private, objective and subjective, principles of continuity, or synthesis, xxxix, \&I8, cf. 352 note and 353 ; why both necessary Sense-forms, and why no others, xxxix, cf. $43^{8}$. [See, also, Time and Space.]

Spencer, his philosophy an expression of new consensus of the times, 4; limits evolution to phenomena, $\Upsilon_{3}$; holcls to empirical origin and limits of all ideas, I7; would explain necessary ideas away by evolution, I8; his "happy thought" fails to dispose of Kant, rg-2I; falls into contradiction by use of his "criterion of truth," 23 seq.; rightly makes Noumenal Energy essential to evolution, 25, 29; his "criterion" proves necessity and infinity of Time, 47.

Spinoza, notes, with Leibnitz, the other-referent character of selfconsciousness, xxxiv; whether a pantheist, $6_{3}$ note; rejects extravagant claims of scientific method, 95; reminiscence of, in Hartmann, III; his infinitum imaginationis, 127; on causa sui and the eternal, 339.

Spirit, or intelligent being, essentially infinite, 422 seq.; true meaning of finitude in the "finite" spirit, 423 ; contrast, in this regard between God and other spirits, 423-42.t.

Spirits, World of, the true Unmoved Mover, $x v$; the true meaning of consciousness, 172 ; involved in self-definition, 353 ; object of the Vision Beatific, 36r. [See Mind, and 'Prerson.]

Stewart, Balfoirr, on "waste-heap" of cosmic energy, 89 .

Stoics, among undoubted pantheists, 63 i their " city of Gorl," $36 \mathbf{r}$.

Struggle for Lxistence, the metaphor in, 90; discredit of, by Dühring, 132.

Survival of Fittest, like "natural selection" an extravagant metaphor, 90; in end, only true of Whole, 9 I seems thus to mean pantheism, 91 .

Systematic exposition, absence of, from present essays does not incan 
absence of adequate exposition, i prerequisite to evolution, 32, cf. I8; xlv. again proved to be a priori, 46 seq., 300 seq., 306 seq.

Tennyson, on limitation of knowledge, 16 ; on futility of life without immortality, $80,8 \mathrm{I}$; on mystic union of Beauty, Good, and Knowledge, 193; on nature of God, 360 .

Theism, pure, definition of, 58, cf. 6r ; Christian, epitomised, 73 ; pluralistic in its interpretation of Divine immanence, 73,74 ; distinction of, from pantheism, 76; Christian, requires method of Conviction, instead of Authority, 2.4I -260; presupposed in tacit logic of scientific method, 273-277; proved, by logical implications of eternal pluraiism, 35I-359.

'Theism, Cosmic. [See Cosmic Theism.]

Time and Space, due to essential coexistence of minds, xiii; consciousness of, proved to be $a$ prior $i$ by Kant, 19-2I; why not generalisations, 19; not capable of production by evolution, 20; shown

Universal, the, scientific method comes short of, 9, II $85,176,274$.

Unknowable, The, evolution philosophy of, 2 ; represented as producing cause of all minds, 6 ; self-contradictory, 23, 25; not explanatory, 29 seq.

Vaihinger, Prof. H., as Neo-Kantian, IO3 note; as extreme agnostic, later modified, 156, cf. note; on Lange's ethical melanelioly, 157 .

Vanini, among undoubted pantheists, 63.

Vogt, Carl, among materialists, 122.

Worth, judgment of, untenable if not also judgment of reality, xxxv ; cognised a priori, in form of the three Pure Ideais, 308; hence, provides for ideal character of immortal life, 3 ro seq.

Wundt, Prof. WV., on Hartmann's philosophy inter alia, I2I note. 

60708 


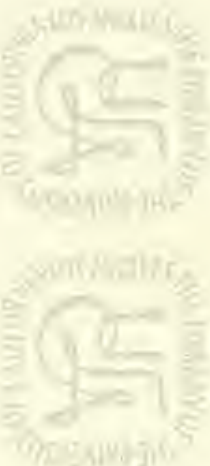

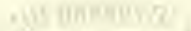

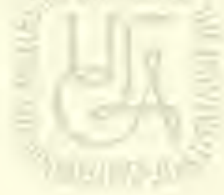

3. 1 4 1175.

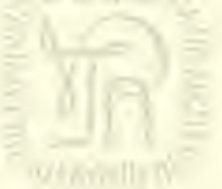

al intille,

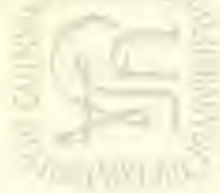

dontanty

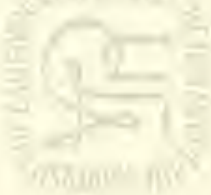

wi gagres

$=1+10$

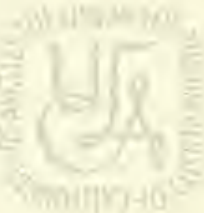

seth H HOAYY
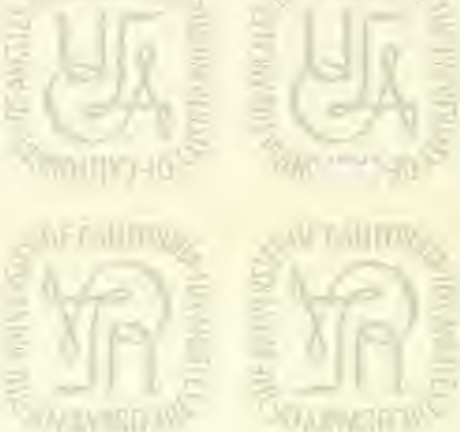

ill whe ins
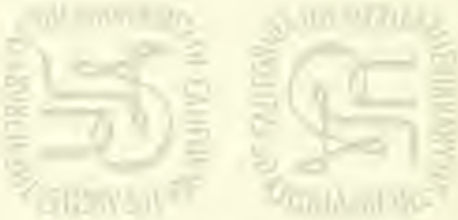

WI ningin.
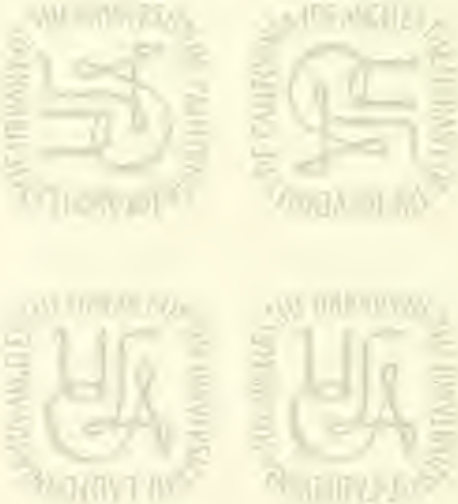

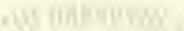

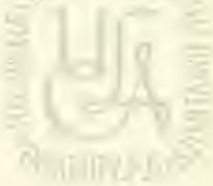

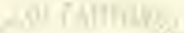

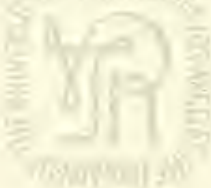

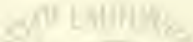

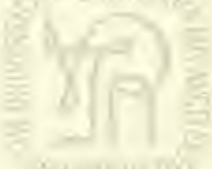

nit an in now
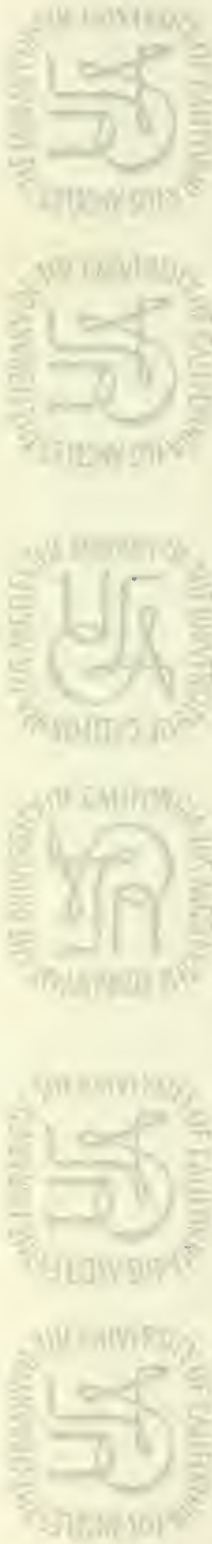

why nowho 

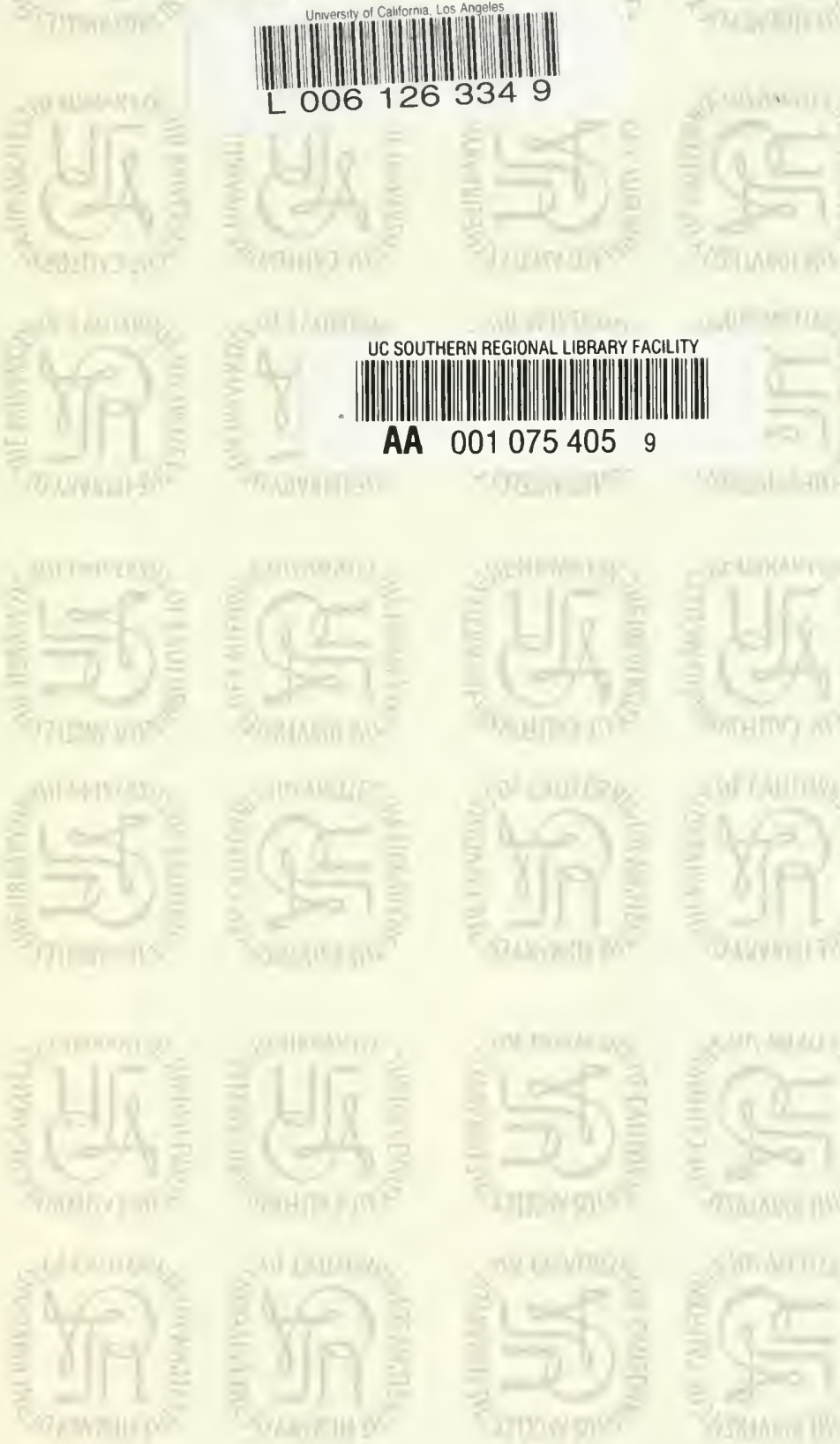
